\title{
The Music of Organisations: An Aesthetic Ethnography
}

\author{
By
}

\section{Ralph James Bathurst}

\author{
A thesis \\ submitted to the Victoria University of Wellington \\ in fulfilment of the requirements for the degree of \\ Doctor of Philosophy \\ in Management
}

Victoria University of Wellington

2006 


\section{CONTENTS}

Abstract $\quad$ ii

Acknowledgements $\quad$ iv

Tables and Figures vi vi v v v

Chapter 1 Aesthetics: A New Theory of Organisational Analysis 1

Chapter 2 The Genesis of Organisational Aesthetics 34

Chapter 3 Towards a Contemporary Theory of Aesthetics 59

Chapter 4 Aesthetic Inquiry and Organisational Identity 93

Chapter 5 Overcoming Muteness: Making The Hidden Knowable 138

Chapter 6 Concretisation: Exploring Perception 173

Chapter 7 First Movement: Emotional Attachment 203

Chapter 8 Second Movement: Cognitive Detachment 258

Chapter 9 Third Movement: Integrated Synthesis 310

Chapter 10 Management and the Artistic Enterprise 346

$\begin{array}{lll}\text { Chapter } 11 & \text { The Music of Organisations } & 371\end{array}$

$\begin{array}{ll}\text { Appendices } & 394\end{array}$

$\begin{array}{ll}\text { References } & 404\end{array}$ 


\section{Abstract}

Arts-based expressions are becoming an increasingly important for understanding and improving business practice. More specifically, drama, painting and music are all artistic tools being used as ways of helping leaders gain insights into organisational life. However, there is a gap between art as a consulting practice, and its theoretical underpinning.

Organisational aesthetics is a relatively new theory of organisations that endeavours to close the gap between the theoretical underpinnings of art and its application as a consulting practice. This thesis contributes to the theory-building efforts of this rapidly expanding field by exploring and developing a novel research methodology: Aesthetic Ethnography. This method is a means whereby researchers work at the arts-business nexus to investigate the ever-changing landscape of organisational life.

In order to show how this occurs, the Auckland Philharmonia is offered as an exemplar. Its developments are observed during a time of governance restructure. As an aesthetic ethnography, the case study positions the orchestra as a work of art and describes how it is intentionally presenced as an artistic piece. Its concretisation is described as a construct by both the researcher and the stakeholders within the enterprise, occurring in 
three ethnographic movements: Emotional Attachment, Cognitive Detachment and Integrated Synthesis.

The thesis concludes that the aesthetic lens can be turned on other artistic enterprises, and indeed beyond these, to the wider organisational world. To do this, further research is proposed into the music of organisations. Specifically, it is suggested that the nature of ensemble be explored and that the artistry of composition be used as a way of further teasing out the musicality of organisational life. Furthermore, music's temporality and its reliance on both fixed structure and sensitivity to the moment make it an apt tool to reflect on management practice. 


\section{ACKNOWLEDGEMENTS}

I have enjoyed writing this thesis but it has been far from a solitary assignment. Thank you to all who have journeyed with me through the process; and in particular to my supervisors Professors David Barry and Brad Jackson. David, I would not have even embarked on this research without your encouragement and friendship. Brad, your enthusiasm and insights have helped immeasurably in keeping the finishing line clearly in view.

My colleagues in the Department of Management and International Business at Massey University (Auckland) have been sounding boards for developing ideas; and, in particular, Associate Professor John Monin and Drs Nanette Monin, Janet Sayers, and Marco van Gelderen have given me much needed and timely feedback. Thank you for your support and for being interruptible when I asked for advice and critique.

Thank you to the others who have also contributed. Linda, my wife, who has provided an outsider's appraisal of some of my ideas; Lloyd Williams, my fellow musician and collaborator, thank you for helping me to understand the deeper complexities of orchestral life; Peter Schischka for your assistance with designing the graphics in Chapters 4 (The Symbolic 
Interplay between the Real and the Ideal) and 8 (Backward Reflexivity) and Dina Cloete for proofreading my work.

Finally, thank you to the subject of this study, the musicians and managers of the Auckland Philharmonia. I have the utmost respect for your commitment to the orchestral music repertoire and your desire to perform with excellence. 


\section{TABLES AND FIGURES}

Table 2.1: Vico, Baumgarten and Kant in Summary

Table 6.1: Research Movements, Focus and Questions

185

Table 7.1: $\quad$ Sources of Auckland Philharmonia's Funding (1998)

Table 9.1: Comparison of Auckland Philharmonia's Funding 344 1998 and 2006

Table 10.1: Governance and Funding: A Model of Integration 369

Table 11.1: The Music of Organisations

392

Figure 4.1: The Continuous Interplay between the Real and the 105 Ideal

Figure 4.2: A Synthesised Plan of Sonata Form

128

Figure 4.3: The Symbolic Interface between the Real and the Ideal

137

Figure 6.1: An Example of Figured Bass

181

Figure 7.1: AP Society Structural Relationships (2001)

Figure 7.2: $\quad$ AP Board Relation and Structure (2001) 
Figure 7.3: $\quad$ AP Lines of Accountability (2001)

Figure 7.4: AP Management Team Structure (2001)

Figure 7.5: $\quad$ AP Budgetary Control (2001)

Figure 8.1: A Divided Orchestra

Figure 8.2: Backward Reflexivity: A Backward Summary of Key Events

Figure 8.3: The Amoeba Structure of the Orchestra

Figure 8.4: The Lawyer's Proposed New Structure as a Human Skeleton

Figure 9.1: The Theatre of Dionysus in Hellenistic Athens 


\section{ChAPTER 1 AEsthetics: A NeW THEORY OF ORGANISATIONAL ANALYSIS}

- Beginnings

- Questioning the Scientific Paradigm

- The Aesthetic Approach: What Does it Offer?

1. Gestalt: Form and Content

2. Empathy: Self and Other

3. Process: Thinking Forwards and Backwards

- Aesthetic Research 


\section{Beginnings}

A study of aesthetics within the business environment involves a strange juxtaposition. Perceptions of beauty and the appreciation of art seem at odds with the instrumental goals of efficiency and profit making. And yet aesthetics is becoming an increasingly important means of organisational analysis. In this regard, Pierre Guillet de Monthoux makes the assertion that, 'If the German artist Joseph Beuys ... was right in claiming that art is tomorrow's capital, it seems reasonable to consider aesthetics its new organization theory' (Guillet de Monthoux, 2000, p. 35).

This rise of aesthetic awareness in organisational studies is rooted in the existential question posed by Michel Foucault, who asked: 'Couldn't everyone's life become a work of art?' (Foucault, 1991, p. 350, emphasis added). Therefore, if life itself is to be lived artfully, could this notion be extended beyond the individual to the corporate? Could we ask along with Paul Willis: 'What happens if we understand the raw materials of everyday lived cultures as if they were living art forms?' (Willis, 2000, p. ix, emphasis added). These questions form the assumptions of this investigation: that organisations are cultural products which can be 
approached and interacted with in the same ways as works of art. And further, that aesthetic ideals provide the tools for social action leading to the revitalisation of organisational life.

Aesthetics has been a life-long interest providing the backdrop for my work as a musician, pastor and, now, organisational theorist. I have had an abiding interest in the way people organise, whether as performers in musical events, or worshipers within a liturgical context. Part of this fascination has been with the question of how to understand the contradictions inherent in these activities.

Both music and worship are similar in their repetitive nature. In music, the word rehearsal implies reiteration where a work, or passages within a piece, are continually revisited to refine performance. As a young symphony orchestra musician, I became familiar with much of the standard repertoire, simply through repeated performances. Similarly, liturgies are cyclical with weekly and annual repetitions of the same acts. For instance, festivals such as Christmas and Easter are well-known commemorations in which I have regularly participated almost by rote. 
And yet in spite of their continual replication, both music performance and liturgical participation create a vehicle through which to experience the sublime. In both there is nothing that is hidden; the musical canon is well established and Christian festivals do not change. But in spite of this, there is mystery, with each iteration offering a unique and sometimes transcendent experience. My curiosity centres on this paradox, and I consider that aesthetics offers ways of understanding why these seemingly monotonous acts can become beautiful and engaging.

My agenda here is to present a work that seeks to develop aesthetic ways of knowing, and to propose how these may inform organisational practice. This builds on my Masters thesis (Bathurst, 2001) in which I take Bakhtin's notion of dialogue and apply it to an organisational context. Bakhtin's discussions on the relationship between art (the novel) and sociological inquiry (Soviet Russia) formed the basis for that study. This served to increase my fascination with the aesthetics of organisational behaviour.

Therefore, as an organisational theorist, I ask a similar question of business enterprises to the one that I have asked of music performance and liturgical worship: how do people experience organisational life? 
Further, what lies beyond the regularity of daily activity that offers organisational actors a sense of meaning and purpose in what they do?

Hence, this study is grounded in personal interest. It is this search for an aesthetic view of organising; a way of understanding the complexities of contemporary organisational life, that gave me the initial impetus to undertake this journey. Beyond this, as Guillet de Monthoux signals, aesthetic inquiry is an important dimension which has only recently become part of the repertoire of organisational research methodologies, and my aim is to make a contribution to this newly evolving field by studying the relationship between music and organisational life.

Still, defining aesthetics adequately is a slippery project. While it can be found in common parlance, it has far from an agreed meaning. In spite of the growth of aesthetic awareness, summarised by Wolfgang Welsch as 'an aesthetics boom' (Welsch, 1997, p. 1), and its use both in communitybuilding and in business practice (Postrel, 2003; Rudman, 2004), it eludes definition (Edström, 2003).

One possible way of finding a definition of the term aesthetic can be by looking at its opposite - anaesthetic. The purpose of an anaesthetic is to 
dull pain and to render a medical patient insensitive to the surgeon's knife. If anaesthetic is concerned with the absence of sensation, its antonym, aesthetic, seeks to understand sensation and our perceptions of those sensations - sometimes understood in the concepts of beauty and ugliness.

Contemporary usage of the word aesthetic is embedded in Greek antiquity where it sprung from the tragic drama. Notwithstanding Plato's reserve about art-making, (he deemed it to be 'dangerous') (Welsch, 1997, p. 60), Aristotle held that art mimics life in that it 'represents human affairs by simulating human events' (Carroll, 2000, p. 20). Through these 'imitations', audiences could not only be educated, they could also experience 'catharsis', and by responding emotionally to the story, the psyche would be 'purified' (Gottlieb, 2001, p. 277). Art for the Greeks was a way of projecting the difficulties of daily existence onto the dramatic form, thereby 'transforming even the ugliest disasters into themes for a high delight' (Bowra, 1957, p. 139). Therefore, for the Ancients, art performed a social function and 'was ubiquitous in all social and religious events' (Osborne, 1970, p. 31). 
As claimed above, the centrality of the dramatic theatre to Greek life enabled a 'reflexive cathartic experience' (Lancaster, 1997, p. 76; Meisiek, 2004), and it is this belief that an immediate sensate response could enable the audience to interpolate their life experience, that lies behind the root word aesthesis which can be translated as 'sense perception' (Sorbom, 1994; Williams, 1983, p. 31). Therefore, within the Greek context, aesthetics involved both an emotional, sensate reaction to the drama, and perceptual associations with daily existence.

However, the widespread usage of the term aesthetics in the Englishspeaking world is relatively recent, since it only found its way into common idiom around the 19th century. Philosophical inquiry into senseknowledge saw the growth of two separate branches, each with its own advocates and literary canon.

One area of inquiry involves discussions regarding the nature of art and the way in which perceivers interpret and attribute meaning to specific works. Here the literature focuses on the philosophy of art - why humans make art and the meanings of that art (Osborne, 1970) - and seeks to link these understandings with the wider human journey (Read, 1967). Within 
the organisational studies sphere, for instance, aesthetic inquiry has looked at the function of art and architecture in engendering more desirable workplaces (Hancock, 2005; Postrel, 2003).

The other trajectory is broader and centres on the affective domain. This second element assumes that all people have perceptions of beauty and ugliness and that these aesthetic opinions inform relationships within their work-life (Gadamer, 1986; Starkey \& Hatchuel, 2002). Following this route in the organisational arena, aesthetic research focuses on sensate responses and tries to draw conclusions from them (Barry, 1996; Boje, 1999). To this end, Dean, Ottensmeyer, and Ramirez succinctly state:

Because aesthetics is considered to be universal, all experiencers are taken to have the potential, at least, to experience beauty and ugliness. This universality extends to individuals in organizations, and individuals experiencing organizational phenomena.

(Dean, Ottensmeyer, \& Ramirez, 1997, p. 420)

An aesthetic perspective, then, is concerned with 'a logic of sensation' (Malpas, 2001, p. 174) and is a way of understanding day-to-day experiences within our work-life. 
In this thesis, I propose a meeting of these two strands and argue for an aesthetic that attends to both artistic reception and recognition of the sensate. Notwithstanding the rejection of the 'univocality' between art appreciation and life experience (McFee, 2005, p. 368), precedents for the convergence of the artistic and aesthetic are seen, for instance, in Anthony Savile's claim that it is possible to observe 'a smooth transition from art to nature' (Savile, 1982, p. 181).

Such an assertion is rooted in early Enlightenment aesthetic thinking. Writing of Kant's notions of beauty, Howard Caygill argues that concepts of time and space are perceived through aesthetic perception. Indeed, Caygill goes so far as to contend that 'the aesthetic is a crucial element in any account of knowledge' (Caygill, 1995, p. 54, emphasis added). Holzhey and Mudroch concur, claiming that an early Enlightenment project was to 'integrate the beautiful and art into the system of philosophy' (Holzhey \& Mudroch, 2005, p. 35). In this thesis I pick up this claim and focus specifically on musical aesthetics. I maintain that, because music can be engaged with on both intellectual and emotional levels, it sits on the cusp between the artistic and aesthetic. 
Recent studies have used the aesthetic frame to understand and critique organisational problems such as the need for flexible leadership over fixed hierarchical systems in the aero-space industry (Feldman, 2000) and the ways in which attention to beauty has shaped the way the law is practised (Schlag, 2002). It is not surprising, then, that accompanying Guillet de Monthoux's prognostication that aesthetics could be the 'new organization theory' (Guillet de Monthoux, 2000, p. 35) is a growing coterie of champions working towards developing the field of organisational aesthetics.

Among the progenitors are Europeans Pasquale Gagliardi (Gagliardi, 1996), Antonio Strati (Strati, 1999b), Stephen Linstead (Linstead \& Höpfl, 1999) and Pierre Guillet de Monthoux himself (Guillet de Monthoux, 2004) who each provide insights into how to analyse organisations through the aesthetic lens. Steven Taylor (Taylor, 2003) and David Boje (Boje \& Rosile, 2003) are representatives of developments in North America and their focus is dramaturgical. New Zealand, too, is making a contribution to these beginnings with the work of David Barry (Barry, 1994) whose emphasis is on the visual arts as a means of exploring the conundrums of organisational behaviour. 
Signs of this quiet revolution go back to 1985 when Henry Mintzberg and Frances Westley wrote a short but provocative paper entitled 'Spinning on symbolism: Imagining strategy'. Here these authors take the notion of strategy beyond its scientific roots and postulate an artistic perspective strategy as an experience. Profundity, they suggest, is not found in the rigorous application of concepts and principles, but rather through imagination. In making this claim they ask: 'Can we say that organizations rich in tangible imagery are more inclined to pursue more profound, creative, individualistic strategies, while those poor in such imagery will pursue superficial banal strategies?' (Mintzberg \& Westley, 1985, p. 63). Underpinning Mintzberg's disquiet is that the instrumental focus has its weaknesses and that strategy is as much an art as a science (Mintzberg, 1987). He argues that traditional approaches of producing socalled hard data, distorts strategic thinking by removing 'random noise, gossip, inference, impression, and fact' (Mintzberg, 1994, p. 258) from the frame.

Almost two decades after their symbolism article, Mintzberg and Westley produced another piece in like vein that advocates an artistic approach to planning (Mintzberg \& Westley, 2001). This kind of intuitive approach to 
organisational leadership is finding an audience in the academy that now values intuition as an important compliment to rationality (Sadler-Smith \& Shefy, 2004), making Mintzberg's aesthetic forays part of a larger critique of technical rationality that provides intellectual support for this developing field. These developments represent a significant change in perspective after almost a century where the scientific world-view dominated organisational studies resulting, in large part, from the work of F. W. Taylor.

\section{Questioning the Scientific Paradigm}

Frederick Taylor's seminal work focusing on the science of management and the subsequent development of Fordism greatly influenced the growth of a scientific paradigm that has reigned supreme in the organisational world for much of the last 100 years. Taylor's belief that efficiency and prosperity are comfortable bedfellows and that the vicissitudes of managing complex situations can be minimised by assiduously applying scientific principles which rest on 'clearly defined laws, rules, and principles' (Taylor, 1911/1998, p. ix) made his ideas appealing. 
This 20th century scientific turn was also reflected in the arts. Music saw the rise of the 12-tone serialism - an atonal system that relied on 'fixed permutations [of] the 12 notes of the equal-tempered scale' (Griffiths, 2005) - which engaged the intellect more than the emotions. The eschewing of traditional harmonic and rhythmic structures was mirrored in the plastic arts with the decline of the vanishing point and perspective (Jones, 2004; Small, 1996), and the emergence of abstract figuration.

Arts organisations, too, were transformed, with the ballet, theatre and symphony orchestra being managed as strict hierarchies (Van Delinder, 2005). These large enterprises, similar in scale to the corporate firm, vested power in directors who ensured strict compliance on the part of the performers. In the symphony orchestra, the musical score became the final arbiter, placing the 'focus on the objective, the measurable, the traditional and the ordered, at the expense of that which appears subjective, qualitative, emotive, and disordered' (Montuori, 2003, p. 248), resulting in the conductor being the focal point, who provides interpretation of the score in performance (Kamerman, 1983). Consequently, a new style of arts administrator emerged who could, as a background figure, attend to the bureaucratic demands of these large 
enterprises (Peterson, 1986), with the tendency for economic returns to take precedence over artistic integrity (Chong, 2002).

However, the triumph of instrumental rationality has not been without cost. E. F. Schumacher (1977), argues that the scientific view, founded on Descartes' belief that humanity's goal to become 'masters and possessors of nature' (Descartes, cited in Schumacher, 1977, p. 19), has left us bereft of imagination. In support of this view, Schumacher offers insights from French philosopher and Cartesian critic Jacques Maritain, who claimed that, whilst reducing human life to geometric data could be useful at a technological level, it leaves unexamined the existential essence and meaning of that data. 
Thus Cartesian evidence goes straight to mechanism. It mechanises nature; it does violence to it; it annihilates everything which causes things to symbolise with the spirit, to partake of the genius of the Creator, to speak to us. The universe becomes dumb.

(Maritain, cited in Schumacher, 1977, p. 19)

Critics of the modern organisation concur, arguing that unbridled rationality has resulted in a workforce of 'working wounded' (La Bier, 1986, p. 76), that has lost spontaneity (Schwartz, 1990). The resulting totalitarian organisational cultures often debase their members, crippling them emotionally and spiritually (Hirschhorn, 1988).

It is not surprising, then, that the 'careering juggernaut' (Giddens, 1990, p. 53) of modern life, has for some, resulted in disillusionment with the dream of progress and development. Instead, 'repression and totalitarianism [have become] the social products of modern industrial technocratic rationality that deadened the emancipatory hopes and visions of modernity's espoused project' (Casey, 1995, p. 7).

The symphony orchestra, as a peculiarly modern phenomenon, echoes this state. Although championed as a creative endeavour, the orchestra is more a 'bureaucratic hierarchy' (Montuori, 2003, p. 248) that has a 
workforce with demonstrably low job satisfaction, behind even that of process workers (Wichterman, 1999).

In summary, despite its advances, modernity has left a trail of disaffection in its wake, both in the business world and in the arts. It is not surprising that a new aesthetic has been called for where management is seen as being more of an art than a science (Barry, Brearley, Guillet de Monthoux, Hatch, \& Whiteman, 2004; Onsman, 2003), and where the ephemeral, unpredictable and sensate become parameters for a revitalised workplace. How, though, does the new aesthetics lens signalled by Guillet de Monthoux address these issues?

\section{The Aesthetic Approach: What Does It Offer?}

If Guillet de Monthoux is correct in claiming that aesthetics is the next organisational theory, what are the epistemological fundamentals of such a theory? This section explores some of the foundational elements that a theory of organisational aesthetics would consider. These elements, rooted in engagement with art, translate into organisational research and form a conceptual cyclorama from which aesthetic research proceeds. In 
this section, I introduce and summarise these concepts; themes that recur in different guises in subsequent chapters.

Aesthetic engagement revolves around three motifs of gestalt, empathy and process. Undergirding these is an inclusive both-and view that embraces the complexities of form and content, self and other, and forward and backward thinking. Ronald Hepburn, in his summary of aesthetic ideals, maintains that the appeal of this both-and approach is that it goes beyond the limitations of binary thinking, noting that the 'familiar either-ors of human finitude are replaced by something closer to the both-ands of metaphysical ideals' (Hepburn, 2002, p. 27). This inclusivity is important because it makes it possible for an enriched view of organisational life to emerge.

\section{Gestalt: Form and Content}

Adopted from German, the term gestalt literally means 'form or shape' (The Concise Oxford English Dictionary, 2002, p. 595) and entails the ability to see particular phenomena as a coherent whole, and to observe the continual interactions between form and content. A gestalt approach holds that human beings have the 'innate tendency to constellate or to see as belonging together elements that look alike' (Behrens, 1998, p. 300). 
Further, it is the interrelation of parts to the whole that enables the perceiver to determine the shape or form of phenomena. This view is informed by Gestalt psychology, a therapeutic tool that grew out of aesthetic reception, and most notably the way in which we listen to music.

In exploring the essence of thinking holistically, one of the progenitors of Gestalt therapy, Christian von Ehrenfels (1859-1932), considered that because a melody retains its identity in terms of shape, regardless of the key, it communicates a totality rather than individual notes. His pupil Max Wertheimer (1880-1943) extended the gestalt approach also through music. He considered that when listening to a melody 'the effect of apparent movement is generated not so much by its individual elements as by their dynamic interrelation' (Wertheimer, cited in Behrens, 1998, p. 299). Wertheimer explored his claim that 'the whole is more than the sum of the parts' by adding that 'the properties of any parts are determined by the intrinsic structural laws of the whole' (Wertheimer, cited in Brosnan, Scott, Fox, \& Pye, 2004, p. 460). Therefore, the parts and the whole work together, so that perceptions of form and content interrelate. 
Translating this into research methodology, the researcher, by attending to specific elements within an organisation, is able to make assertions as to the relationships among the elements by observing how they cohere. Confirming this, Antonio Strati (1999b) claims that all human processes revolve around form. The very acts of problem-framing and problemsolving are formative in that ideas are represented in an identifiable shape.

Strati reaches back to the work of Friedrich Schleiermacher (1768-1834) to support his thinking. Central to Schleiermacher's view is that life consists of 'hermeneutically freighted texts' (Margolis, 1987, p. 363) where, paradoxically, the part and the whole work in concert together, in that 'the meaning of the part presupposes and entails the meaning of the whole' (Margolis, 1987, p. 364). Therefore, according to Strati's reading of Schleiermacher, the researcher examines specific phenomena and moulds them into a gestalt, creating a form around particular content (Strati, 1999b).

The value of the aesthetic lens, then, is that it focuses on a holistic rather than just an atomised view. Aesthetic symbols 'are grasped in a single act of perception and understood simultaneously by virtue of their reciprocal 
relations and of their relation with the global structure of the object' (Gagliardi, 1996, p. 574).

The interrelation between the parts and the whole highlights a research problem; namely, how much does the researcher impose a structure on data? The next theme addresses this problem by positing that an empathic Self-Other awareness guards against whimsical formations.

\section{Empathy: Self and Other}

Earlier in this chapter I offered a critique of instrumental rationality through the work of E. F. Schumacher. As an economist, Schumacher's primary concern is that unbridled growth is detrimental to sustainable human existence (Schumacher, 1973/1999) and that Cartesian thinking is the root cause of modernity's flaws. As an antidote, Schumacher offers an alternative epistemology based on lived experience. He claims that we interact with our world both internally and externally. Thus there is a continuous reference to the Self and Other which can be summarised with the questions: 
What do I feel like?

What do you feel like?

What do I look like?

What do you look like?

(Schumacher, 1977, p. 74)

These questions form the basis of aesthetic research in that they engage both with sensation (what do I/you feel?) and perception (what do I/you see and hear?). So within the arts milieu, the idea of empathy examines the interplay of the work of art, the artist, and the perceiver. Taken over into aesthetic research, this element seeks to investigate the relationship between the researcher and researched, and the organisation within which they are participating.

Rather than seeing this as fixed and lineal with the researcher deriving objective data from the research subject, an empathic connection is fluid and active. To explain this dynamism, Guillet de Monthoux deploys the Schillerian concept of play (schwung). For Schiller, schwung is more than a swing from one state to another; instead, it is a continual oscillation between two states (Guillet de Monthoux, 2004, p. 20). This is an important aesthetic concept because it enables meaning to be continually negotiated between the research subject and the researcher by not presuming a unitary lineal shift from the subject to an objective view. 
Rather, the two are in a co-equal fluid relationship with each informing the other.

Further, aesthetic research acknowledges that there is an 'empathic space' (Tamisari, 2000, p. 274) that is explored as the researcher becomes part of the world of the researched. A potent metaphor that explains this is to think of 'a musical conversation between performing jazz musicians ... in which the identity of the self as well as the other is jointly explored' (Humphreys, Brown, \& Hatch, 2003, pp. 6 \& 10, emphasis added).

Similarly, Strati favours this notion by arguing that empathy allows for

the researcher's self-immersion in the role of the Other and the activation of his/her sensory and aesthetic faculties in order to gather qualitatively rich data from self-observation, intuition, analogy, relived experience and, often, description.

(Strati, 1999b, p. 73)

For Strati it is this empathic relationship between the researcher and researched that allows for the continual self-reflection and negotiation of meaning that eventually leads to theory development. Reflection and continual renegotiation, though, necessitate a change in thinking to a polytemporal orientation which is sensitive to process. 


\section{Process: Thinking Forwards and Backwards}

The third element of aesthetic engagement is process. Here the perceiver develops a view of the work of art as being organised in time. This is especially the case with performing arts such as dance, drama and music, which can only be understood as they unfold through time.

In its wider context, the notion of temporality holds that there is a difference between 'physical time and social time' (Elias, 1992, p. 44) with social time being heterogeneous. Hence thinking about the 'cyclical and qualitative nature of social time' (Hassard, 1996, p. 586) necessitates not only thinking in anticipation of what is to come, but also by retrospectively allowing the past to inform the present. The ability to think backwards (Moore, 1996) can be illustrated in musical perception where listening skills require a 'backward reflex' (Ingarden, 1986, p. 72) with the listener continually referring within a piece to the past melodic and harmonic ideas as a reference point for present sound. To explain this aesthetic, Hepburn uses the phrase 'paradoxical co-presence' (Hepburn, 2002, p. 27) where the present, past, and indeed future, are considered simultaneously in the both-and view that underpins aesthetic research. 
In organisational research, Karl Weick coined the aphorism 'stamp in verbs' (Weick, 1995, p. 187) to signal a shift from seeing organisations as fixed, static entities to acknowledging their temporality. Changing the emphasis from nouns to verbs, according to Weick, forces a shift to a sensemaking mentality which is unfolding rather than determinate. He argues:

Sensemaking itself is ongoing and the sense it makes, transient. Verbs force us to face that. Nouns do not.

(Weick, 1995, p. 188)

For Weick, to be alert to process means being 'attuned to sequences, unfolding, generative settings, amplifications and small events with large consequences' (Weick, 2004, p. 664). Therefore, he considers elements such as evolution, ambivalence, and complexity to be necessary prerequisites for appreciating process (Weick, 2004). Further, Weick and his colleagues propose that sport is an apt forum to observe process at work, because it 'thrives on verbs and images' and questions like "“what are people doing?" and "what is going on?"' (Wolfe et al., 2005, p. 205) to tease out these elements. Music performance also offers this perspective in that it relies on the individual musician continually adjusting his or her sound to fit what is occurring at each moment. 
Hence the three motifs of gestalt, empathy and process are the basis of the aesthetic lens. How, though, do they relate to the development of a new theory of organisation?

\section{Aesthetic Research}

In a series of letters published in 1795, Schiller explores the nature of aesthetic response, the foundations of which he considers as being a dynamic state, termed in English translation as the 'play impulse'.

The object of the play impulse, conceived in a general notion, can therefore be called living shape, a concept which serves to denote all aesthetic qualities of phenomena and - in a word what we call Beauty in the widest sense of the term.

(Schiller, 1795/1965, p. 75, emphasis in the original)

Because it is living, this impulse allows for meanings to be continually renegotiated as new ideas and sensations occur. In this way, rather than reaching a fixed position, the aesthetician is able to become 'detach[ed from] ... assumptions' thereby avoiding becoming 'ossified through too rigid applications of schemes of thought' (Savile, 1982, p. 97).

Over 200 years later, Richard Rorty writes of a 'poeticized culture' (Rorty, 1989, p. 53) that continually questions the need for finalised, definitive 
solutions. To explain, he uses as a metaphor from the dramatic stage, the painted backdrop. He maintains that a poetic approach continually searches for the backdrop behind the backdrop. On first investigation there may appear to be a wall at the back of the stage. However, Rorty argues for an aesthetic that perseveres, and through the use of irony, discover what lies behind the wall.

The wall then turns out to be a painted backdrop, one more work of man, one more bit of cultural stage-setting. A poeticized culture would be one which would not insist we find the real wall behind the painted ones, the real touchstones of truth as opposed to touchstones which are merely cultural artifacts.

$$
\text { (Rorty, 1989, p. 53) }
$$

Living artfully, organising artfully, and researching artfully are indeed lofty ideals; but can they be shaped into the kind of new theory of organisation that Guillet de Monthoux suggests? The play impulse, irony, fluidity, and schwung, are all terms that grasp at the essence of the aesthetic move towards a contemporary theory of organisation; and although a comprehensive investigation into the existential questions implied in the notion of an artful life are beyond this thesis, it is my intention to offer a research methodology that contributes to our growing understanding of aesthetic awareness in organisations. 
In what follows I aim to provide a framework for aesthetic research. This is a much needed step which addresses the problem that Steve Taylor highlights, namely that organisational actors are aesthetically mute, lacking a language with which they can talk about their experience (Taylor, 2002). It is important that an aesthetic language is evolved to enable people to speak about the ephemeral and sensate, as it is this that may contribute to the organisational revitalisation project. For, as Strati claims: 'Meaningful social action is therefore a fundamental concept for the aesthetic interpretation of organizations' (Strati, 1999b, p. 49).

Consequently, the focus of this work is on artful research, with the aim to outline an aesthetic theory of organisation that is aware of sensation and perception. I will propose an aesthetic ethnographic method that attends to the three motifs of gestalt, empathy and process introduced in this chapter. Hence the method will describe how the researcher interacts with the parts and the whole - the organisation's gestalt. The empathic Self-Other relationship between the researcher and researched will be investigated through the dual notions of presencing and concretisation presencing being the way the organisation manifests itself and concretisation the means whereby the researcher makes sense of what is 
presenced. Finally, the method will explore the notion of process through three ethnographic movements of emotional attachment, cognitive detachment and integrated synthesis.

Just as Wolfe et al. (2005) claim that sport provides a context for research not yet realised, I ask: 'What do the aesthetics of music and musical artistry offer organisational research?' To answer this question, I investigate the nexus of organisational practice and music as a performance art. In particular, I ask this question about members of a symphony orchestra the Auckland Philharmonia - with the view of observing the translation of aesthetic ideals from the concert platform to the manager's desk.

The Auckland Philharmonia in 2005 celebrated its Silver Jubilee and from its inception has functioned as a cooperative. This has meant that the players are their own employer, and responsible for all elements of the business - artistic, financial, managerial and governmental. So, in what follows I set the stage for an investigation into this orchestra. My agenda is to turn back on the orchestra the aesthetic values that have seen it become a successful artistic enterprise, and discover how the members of the ensemble express themselves within this frame. 
To set the stage, in Chapter 2 I offer an examination of the aesthetics of three early Enlightenment philosophers: Vico, Baumgarten and Kant. By exploring the heritage that begins with these contemporaries of Descartes, I focus on alternative discourses to technical rationality. Where Descartes' search for 'certainty' through what he termed the 'self evidence [of] mathematics' (Descartes, 1637/1985, p. 31), reduced human existence to that which can be measured, the works of Vico, Baumgarten and Kant are expansionist. They offer alternatives to Cartesian rationality through explorations of myth, sensate experience and the concept of beauty, all of which are the genesis of contemporary aesthetics.

In Chapter 3 I take the implications of these three philosophers and consider a contemporary theory of aesthetics. In doing so, I call into question the nature of appearance by asking: is what we see and hear an unqualified expression of reality, or is there something beyond that appearance that is knowable? This chapter begins with an explanation of phenomenology and then inquires into what lies behind that which is immediately accessible to the senses by discussing the tensions between the physical and metaphysical. 
Chapter 4 sharpens the focus by taking the notion of organisation and postulating it as a temporal phenomenon. I argue that to understand the volatility of this temporality it is necessary to consider the oscillation between the parts and whole, time and space, things evident and things hidden.

Having established the temporality of organisational existence, in Chapter 5 I introduce aesthetic ethnography and discuss how organisations are intentionally presenced as living symbols. I explore the relationship between art making and perception in order to address the difficulty organisational actors have in expressing sensate experience. Works of art begin in the artist's imagination and then take shape through the creative process. This first step in aesthetic ethnography begins with this same assumption: that organisations have their origins in the imagination, discourse, and behaviours of the actors, and that as this intentionality is discovered, muteness can be overcome.

Chapter 6 goes beyond intentionality to discuss how organisational actors and researchers constitute the enterprise through concretisation. In this chapter, I introduce three ethnographic movements as a way of exploring 
how organisations are presenced and concretised. These movements chart the changing relationship of the ethnographer with the organisation, and the developing awareness of how the enterprise is constituted. These movements are Emotional Attachment, Cognitive Detachment and Integrated Synthesis.

Chapters 7 to 9 are explanations of an empirical study into the Auckland Philharmonia using the three movements explained in Chapter 6. In these chapters I describe the changes that occurred in this symphony orchestra over a two-year period 2003-2005. During this time, the Auckland Philharmonia went through a sustained period of self-examination resulting in changes in its governance structure. I explore some of the paradoxes inherent in these changes, showing how the aesthetic lens offers insights into the developments within the orchestra.

In conclusion, Chapters 10 and 11 summarise the key areas of the study. I comment on the ways in which organisational leaders could use the aesthetic lens as an analytical too and then conclude the thesis by offering a future research agenda that further explores aesthetic ethnography and the music of organisations. 
My hope is that you, the reader, will enjoy the journey as much as I have.

Notwithstanding the need to produce an academic work that meets the requirements of a rigorous exploration and explanation of the field of study, in this piece I have aimed to write in a way that I hope both informs and entertains. My objective is to write a thesis that attends to the search for artistic beauty. Further, because the aesthetic approach is multifaceted, I try to consider the harmony of the narrative while at the same time being true to the variety of the cross-rhythms and contrasting motifs that emerged throughout my research. In order to attend both to particular ideas as they develop and to the over-arching structure of the work, each chapter is a stand-alone piece but builds cumulatively on preceding chapters. My hope is that, like a symphony with its different moods and tempi, the music of this thesis will be true to the diverse nature of aesthetic engagement.

Where possible I have taken a story-telling approach and have tried to simplify complex ideas without following a simplistic path. In doing so I have taken my lead from John Van Maanen (1995) in his advocacy for an imaginative approach to academic writing. To this end I have made myself present to the text, and by implication, have tried to gradually 
draw the veil away from that which at times seems opaque (Weick, 1996, p. 253). In what follows, I invite you, the reader, to participate with me in this journey of discovery into the aesthetics of organisational life. 


\section{ChAPTER 2 The Genesis OF Organisational AESTHETICS}

- The Philosophical Heritage

- Vico: The Present Informed by the Past

- Baumgarten: Sensation as the Ground of Knowledge

- Kant: Form and Content

- The Beginnings of Aesthetic Research 


\section{The Philosophical Heritage}

The discussions of the previous chapter built on Guillet de Monthoux's assertion that aesthetics could represent a new organisational theory. In it I made a case for a both-and approach that considers three motifs of gestalt, empathy and process. In this chapter I propose that, by examining its antecedents, aesthetics offers the research community a way forward in theory development. In particular I concentrate on the beginning of the modern era, and specifically three early Enlightenment scholars, each of whom made a significant contribution to aesthetic thinking: Vico, called by some the father of aesthetics; Baumgarten, whose two-volume treatise Aesthetica was the first in-depth study of aesthetics; and Kant, who has become a touchstone for inquiry into the nature of beauty.

Contemporary aesthetics has its genesis in 17th and 18th century epistemological debates. By examining these historical discussions, it is possible to discern the beginnings of a tradition that is now mushrooming in the organisational studies arena. In particular, Vico, Baumgarten and Kant present ideas that question Cartesian rationality, thereby providing the roots of a contemporary organisational aesthetic. 
Over time the Enlightenment has come to be associated with the 'rationalist belief in a single coherent body of logically deduced conclusions, arrived at by universally valid principles of thought and founded upon carefully sifted data of observation or experiment' (Berlin, 2003, n.p.). However, the transformation was not sudden, with ideas being contested in the form of a 'confused mêlée, [with] each protagonist lashing out at his particular opponent' (Hampson, 1968/1990, p. 31), rather than as a unified and reasoned shift.

Further, Richard Rorty (1989) claims that the work of the Romantic artists, and poets in particular, contested the scientific positivism that Enlightenment thinking privileged. He argues that Schiller and later, Nietzsche, explored notions of truth that eschewed a unitary and rational view of the world. Central to this contestation are questions surrounding the nature of knowledge: is it out there waiting to be discovered and described through the astute application of scientific method, or is it continually being constructed and reconstructed from an enlivened imagination? Rorty argues that as a result of the flowering of 18th- and 19th-century Romanticism, the initial Enlightenment struggle between 'science and religion, reason and unreason' has now evolved into 'a 
struggle between reason and all the forces within culture which think of truth as made rather than found' (Rorty, 1989, p. 3, emphasis added).

For Rorty this philosophical split circumscribes a crucial distinction. Scientific positivism sees the truth as an external reality waiting to be discovered, with the purpose of language being to simply describe that reality (and by implication, this is a language which is parsimonious and sparse). The alternative, however, is to locate the truth internally and subjectively; that the search for knowledge is a quest for new forms of description, and that this quest 'gradually bring[s] Spirit to selfconsciousness' (Rorty, 1989, p. 19). Here the purpose of language is to find ways of continually re-describing what is seen. In this latter case, language becomes 'expansionist', relying on the author's imagination to conjure metaphors that are 'strange, mystic and wonderful' (Rorty, 1989, p. 19). It is not surprising, then, that Rorty sees the arts and aesthetics as the means through which truth can be explored and 're-contextualized' (Rorty, 1991, p. 110). Through aesthetic engagement, our awareness of the world in which we live and work is continually enlarged. 
Underpinning Rorty's view is the idea that a person's existence is poetic rather than an objective list of achievements and accomplishments; and he contends that "culture as a whole can be "poeticized" rather than, as the Enlightenment hope[d], that it can be "rationalized" or "scientized"" (Rorty, 1989, p. 53). Therefore, the roots of contemporary aesthetic inquiry are found in the philosophical traditions that sought for alternative ways of knowing, that sit alongside the scientific and universalising modes of thought ultimately privileged by the Enlightenment (Pappe, 2003).

Hence, returning to the 17 th and 18 th centuries is predicated by 20 thcentury critiques of the Enlightenment, which acknowledge the benefits to humanity of the scientific turn, but question the resulting hubris. In this regard, E. F. Schumacher writes of the failure of the 300-year 'modern experiment', because with one hand it gave scientific and technological advancement but with the other took an alert imagination that affirmed the metaphysical. Schumacher argues that these latter qualities define what it means to be human:

More and more people are beginning to realise that 'the modern experiment' has failed. It received its early impetus by what I have called the Cartesian revolution, which, with 
implacable logic, separated man from those Higher Levels that alone can maintain his humanity.

(Schumacher, 1977, p. 153)

Contemporary Enlightenment critics, though, do not advocate the repudiation of scientific method, but rather argue for the rediscovery of a 'creative imagination' (Berlin, 2000, p. 19) and with it the ability to speak of the ephemeral and sensate. They claim that art offers a language with which to address these issues and it is aesthetics, according to Berlin, that provides the tools for thinking beyond the rational. He notes that

... such attributes as 'profound' and 'shallow', 'plausible' and 'implausible', 'living' and 'lifeless', 'authentic' and 'unreal', 'rounded' and 'flat' and the like are not often ascribed to the achievements of logic or epistemology or scientific method but are more often used to characterise the arts and works of scholarship, which require a capacity for insight, responsiveness, understanding of what men are and can be, of their inner lives, perception of the meaning and implications, and not only of the appearances, of their observable gestures.

(Berlin, 2000, p. 19)

Here Berlin's list includes a number of features requiring an aesthetically attuned approach that seeks to look behind observable phenomena. For instance, to extend one of Berlin's metaphors, the sensation of flatness relies on our experiences of roundness and sharpness for comparison, and our ability to describe these sensations poetically. It is, then, this 
underlying belief that life experiences can be informed by the ways we engage with the symbolic - art in particular - and that art conveys existential meaning beyond the rarefied atmosphere of the gallery or concert chamber, that lies at the heart of organisational aesthetics.

Hence it is this second line of inquiry, of finding ways of re-describing truth imaginatively and provocatively, that is the focus of aesthetic research. The issues discussed by Vico, Baumgarten and Kant are discourses that belong to this quest and represent a genesis of thought that informs the current evolving field of organisational aesthetics. These philosophers and their rich aesthetic language form the basis for this study. They showed that although 'scientific knowledge deals ... with the external appearance of things' (Hampson, 1968/1990, p. 235) it fails to examine the meanings behind that appearance. Their insights provide for an examination of existential meaning-making by discussing the nature of aesthetic experience.

So by returning to the early Enlightenment, we can observe the development of aesthetic thinking. In particular, discussions on the relationship between works of art and the human journey; the ability of 
the past, especially the mythological, to inform the present; questions of the meaning attributable to sensate response, framed in notions of taste; and the relationship between form and content are the bases of this thinking.

Discussions on these ideas were not limited to these three philosophers, however. For example, in the English speaking world the Scottish lawyer, minister and academic, Archibald Alison (1792-1867) maintained that works of art trigger ideas and images beyond the work itself and that enjoyment of art means indulging in the stream of these perceptions. According to Alison, art provides the stimulus for connections to be made between a specific artwork and the reflexive examination of life. So for Alison, aesthetic engagement 'almost involuntarily extend $[\mathrm{s}] \ldots$ to analogies with the life of man, and bring before us those images of hope or fear, which, according to our particular situations, have dominion of our hearts!' (Alison, 1790/1968, p. 10). It is this translation of aesthetic perception into lived experience that underpins the following discussion of Vico, Baumgarten and Kant. 


\section{Vico: The Present Informed by the Past}

Giambattista Vico (1668-1744) has been called the 'real "father of modern aesthetics"' (Dorfles, 1969, p. 577), even though he did not use the term. His 1744 work Scienzia Nuova (The New Science) focuses primarily on the notion that, unlike the natural world which is 'incommensurable' (Janik, 1983, p. 40), we humans have created our own cultures which can be known through the analysis of the myths and fables of bygone eras.

Vico went back to what he called 'pagan' history - Egyptian history in particular - and saw what he thought were three ages. According to Vico, Herodotus' division of Egyptian history into the age of gods, followed by the age of heroes and finally the age of men, corresponded to three kinds of language spoken by the Egyptians during these ages. These languages in sequence were '(1) a hieroglyphic language using sacred characters; (2) a symbolic language, using heroic characters; and (3) an epistolary language, using characters agreed on by the people' (Vico, 1744/1999, p. 44, emphases in the original). Again, these three divisions further correspond to Varro's historical divisions of a dark age, a mythical age and the historical age. Thus Vico considered past ages to be loaded with 
significance and felt that they could not be discounted simply on the basis of their supposed irrationality. As Hampson summarises, Vico's philology was a quest for 'the story of the past, [that] instead of being an educative manual, in which reason struggled with ignorance and superstition ... was an account whose meaning lay within itself, in which any period was as significant as any other' (Hampson, 1968/1990, p. 236).

For Vico, to reject or even discount the past is to fail to see the wealth of ideas and values that shed light on the human story. Therefore, the age of heroes, symbolic language and myth, represent the ground for aesthetic theory, for it is these artefacts that reveal the essence of human identity. Hence mythical awareness, as a counterpoint to the Cartesian epistemology of causality, relies on a creative imagination that pauses to tease out meanings inherent in the story. Consequently:

In the myth, the traditional enemy of intelligible science, is the original power of the image upon which the capabilities of humanistic fantasia rest. Any theory of knowledge, and any theory of the humanities, must be founded on a theory of mythical consciousness.

(Verene, 1976, p. 34 emphasis in the original)

So then, for Vico, aesthetics embraces more than an appreciation of fine art; rather, it includes the whole of human endeavour. Aesthetic language 
engages primarily with the affective domain, and 'postulates a cleavage between emotional and referential meaning' (Dorfles, 1969, p. 579). This privileging of emotional language over the linearity of mathematical logic set him at odds with Cartesian thought that reduced human experience to universal theorems. He held that knowledge derived from mathematics was 'not a knowledge of reality but only of unreal and arbitrary constructions' (Manson, 1969, p. 12).

Instead, Vico proffers that theorising on human behaviour can be accomplished with immaginazione, an ability to think backwards 'even across long periods of time' (Janik, 1983, p. 41), in the belief that 'human action belongs to the sphere of the variable, of becoming rather than being' (Janik, 1983, p. 42, emphasis added). Therefore, aesthetic inquiry through the exploration of myth, heroic poetry and language offers a process of discovery that sees human existence as fluid and continually unfolding.

In summary, Vico claims that ideas spring from the senses, stating 'there is nothing in the intellect which is not first in a sense' (Vico, cited in Vaughan, 1972, p. 7) and it is this ability to think imaginatively, poetically 
and metaphorically (Nerlich \& Clarke, 2001) that forms the basis for reasoning.

Before man can perform universals, says Vico, he forms imaginary ideas. Before he reflects with a clear mind (i.e. before he reached the ability to philosophize) he apprehends with confused and disturbed faculties. Before he articulates, he sings; before he speaks in prose, he speaks in poetry; before using technical terms, he uses metaphors.

(Vaughan, 1972, p. 7)

It is this ability to consider the past as providing valuable insights into the present, and to think flexibly and imaginatively, that captures Vico's contribution to contemporary organisational aesthetics. The aesthetic researcher takes cognisance that the use of rituals, cultural artefacts, rites of passage and heroic stories access mythological thought. Furthermore, Strati (1998), relying on Vico's work, agues that a metaphysical transformation occurs with myth-making in that 'people use myth and mythical thinking to identify themselves with the things that they do, transforming or translating themselves into these things' (Strati, 1998, p. 1389). Myth-making can enable people to deal with contradiction and anxiety within their lives. For, as Strati provocatively maintains:

The mythical thought described by Vico, therefore, is fantasy, metaphor and image. It is a way of seeing and knowing the world that has nothing to do with analysis, 
explanation or reason. Instead, it involves the construction of civil society through the 'translation' of people into it, and through its adequate understanding 'from within'.

(Strati, 1999b, p. 153)

This latter claim provides the key to Vico's philology, namely, that as we engage with the past by examining myths, fables and symbols, we derive the tools of knowing and becoming. Further, the resulting personal and social transformation, achieved through aesthetic perception, is firstly internal, leading to the external and systemic.

However, what is missing from this schema is a more precise analysis of the nature of aesthetic knowledge. Baumgarten's writings, exploring sensation as an aesthetic response, enhance Vico's philology.

\section{Baumgarten: Sensation as the Ground of Knowledge}

Alexander Gottlieb Baumgarten (1714-1762) was the first post-

Renaissance philosopher to use the term aesthetic (Williams, 1988) and his contribution to the literature is his focus on sensation as the ground of knowledge. In two volumes entitled Aesthetica published between 1750 and 1758, Baumgarten 'defined beauty as phenomenal perfection ... 
plac[ing] a predominant stress on apprehension through the senses' (Williams, 1988, p. 31, emphasis in the original). In the absence of an English translation of his work, I rely on summaries provided by commentators to explore Baumgarten's perspective, which can be summed up in the words:

Aestheticis finis est perfectio cognitionis sensitivae, qua talis. [The aim of aesthetics as a discipline is the development and improvement of the sensitive knowledge.]

(Baumgarten, cited in Gross, 2002, p. 410)

The implication here is that knowledge gained through the senses augments 'cognition meditated by the intellect' (Osborne, 1970, p. 175). Thus Baumgarten applied the term gnoseologia inferior (Cassirer, 1944, p. 137) or 'inferior cognition' to this acquisition. 'Inferior' here is not to be considered as something lesser; rather it is knowledge that is discovered beneath or below that which is immediately available to the intellect through logical reasoning - gnoseologia superior. For Baumgarten, it is art that links the visible with the ineffable thereby allowing for existential meaning to be made by the perceiver. According to Ernst Cassirer, Baumgarten conceived of art 
as an allegory, a figurative expression which under its sensuous form concealed an ethical sense ... a subordinate and subservient means pointing to some higher end.

(Cassirer, 1944, p. 137)

The challenge, therefore, is for the perceiver to work with immediate sensation (an inferior cognition) and to reflexively connect that with wider human values and behaviour (superior cognition).

Although his focus was primarily on literature, Baumgarten conceived that aesthetic inquiry was relevant to 'all the liberal arts and the practical activities of daily life' (Makkreel, 1994, p. 66). He, therefore, rejected the idea that the search for knowledge is reducible to either a rational or a sensual quest. For Baumgarten, human beings are primarily aesthetic beings - or, as summarised in the words of Gross, felix aestheticus (Gross, 2002, p. 404) - who are comfortable with complexity, able to accommodate 'a great number of sometimes conflicting or contradictory faculties, forces, and poietic powers, a great number of different aims, some of them incommensurable with each other' (Gross, 2002, p. 404).

This ability to savour complexity is observed in works of art which are replete with ubertas (richness) - a multiplicity of ideas infused into a single 
creation. Baumgarten's intention was not to think in terms of generalisations but to allow complexity to speak to individual situations. Rather than being anarchic or confusing, form is established around the fecundity of content, and as 'more characteristics are compressed into a single representation it becomes more suggestive of order' (Makkreel, 1994, p. 66).

Therefore, to become a sensitive thinker, alert to both the noble and the mundane, Baumgarten claims that a perceiver must become responsive to the object and all its attendant elements and contributing parts. Hence the perceiver is 'in a continual process of developing all his powers and senses, and exploring them in all possible directions' (Gross, 2002, p. 412), constantly trying to find new angles from which to view an object. In response, the aesthetician too is in a constant process of development and change in an evolving Self-Other relationship.

Paradoxically, even though Baumgarten's ideas explore non-rationality, they also resonate with Enlightenment empiricism. He held that aesthetic reception (sensation) is grounded in the material world and 'postulates that the more sensate determination there is in the artistic form, the more 
actualizable is the aesthetic realm as a site of human activity' (Singer, 2003, p. 14, emphasis in the original).

Therefore, aesthetic research involves becoming sensitive to richness and complexity, with the view to transformation at individual and societal levels. This sensitivity may include putting aside already firmly held beliefs about the way the world operates. The aesthetic researcher's task is to become comfortable with the chaotic and disorderly and not necessarily attempt to resolve these into currently accepted theory. In this way, beauty and order are embraced along with the ugly and confused.

Further, this comfort with disorder and changeability presents the nub of the Enlightenment question, namely, are we dealing only with what we can see and measure or are there elements beyond the visible? In this regard Strati, writing about Baumgarten, notes: 'As such, as art is analogue to reason, it raises a metaphysical-baroque challenge against the analytical rationality that seeks after the truth' (Strati, 1999a, p. 15). It is this relationship between the determinate and the indescribable, changeable and chaotic, which contextualises Kant's discussion on form and content. 


\section{Kant: Form and Content}

Immanuel Kant (1724-1804) in his Critique of Judgment (1790) examines the phenomena of beauty and taste and claims that aesthetic knowledge links phenomena with the noumenal, an idea first explored in his Critique of Pure Reason (1781). Robert Solomon (2001) writes of Kant's perspective by noting that aesthetic experience involves a continual movement between cognition and imagination with each 'enlivening one another' (Solomon, 2001, p. 668). Therefore, imagination and understanding interact together in free play to give meaning to phenomena.

Kant illustrates this with the problem of measurement, which is both a mathematical and an imaginary act (Kant, 1790/2000, § 26) ${ }^{1}$. For instance, the estimated height of a tree is compared to the height of a man, which in turn becomes the standard against which a mountain's height can be ascertained. Here there is an interplay between imagination and reason with imagination being able to conceive of limitless possibilities, while reason provides the tools of conceptualisation.

\footnotetext{
${ }^{1}$ In line with convention I use the $\S$ nomenclature to indicate sections of Kant's text.
} 
It is through this interaction between imagination and reason that a form emerges, thus achieving harmonisation between the two. Kant writes that 'the aesthetical Judgment in judging the Beautiful refers to the Imagination in its free play to the Understanding, in order to harmonise it with the concepts of the latter in general' (Kant, 1790/2000, § 26, italics in the original). The issue Kant grapples with here is how to systematise imagination, which, by its nature, is continually changing, into formal and universal concepts. He solves this by posing a fluid relationship between perception and our ability to create formal concepts based on those perceptions. Lucas concludes: 'Therefore, unlike judgments of agreeableness and goodness, an aesthetic response arises neither from cognition nor sense, but from an ineffable combination of the two, what Kant calls "a universal rule incapable of formation"' (Lucas, 2001, para. 5).

In essence, ineffability is mitigated through concepts of structure and form. When we perceive beauty in something, we are examining its form or shape, a process Kant termed 'Form der Zweckmässigkeit' or, the 'Form of Finality'. According to McCloskey's reading of Kant, it is this capacity to perceive form that lies at the heart of aesthetic engagement (McCloskey, 1987). 
Thus Kant's contribution to the development of aesthetic understanding is to perceive form in the chaotic, thereby deriving meaning from sensate information. His schema entails a development from idiosyncratic, disinterested intuitions, to symbol-formation, and then to establishing universal criteria with which to judge those symbols (Kant, 1790/2000, § 59). Hence there is a continual move from intuition to symbolisation, an interplay between content and form. For Kant, individual taste operates at the intuitive level, but symbolisation involves creating 'concepts and laws' around intuitions and then holding them up for critique (Rueger \& Evren, 2005, p. 233).

Therefore, 'the satisfaction in an object, on account of which we call it beautiful, cannot rest on the representation of its utility' (Kant, 1790/2000, $\S 15)$ but rather on our subjective appreciation of it. However, subjective appreciation alone does not suffice. Instead, this is accompanied and 'mediated' by an objective judgment (Adorno, 1997, p. 163) based on our formal perceptions.

What matters for Kant is not the object itself but our contemplation of it. Underpinning this thoughtful act is the detection of generic forms. In this 
regard, Cassirer comments on this element of Kant's philosophy as follows:

If the work of art were nothing but the freak and frenzy of an individual artist it would not possess ... universal communicability. The imagination of the artist does not arbitrarily invent the forms of things. It shows us these forms in their true shape, making them visible and recognizable.

(Cassirer, 1944, p. 145)

It is, then, the form that individual intuitions assume that resonates with perceivers.

Here the beginnings of a rationale for organisational aesthetics is extended by our ability as humans to make sense of symbols and other media that are ever-present in our work-life. As organisational actors we construct our perceptions around structures that go beyond the personal and idiosyncratic, thereby making sense to a wider community of participants. In this way, particular sensations give way to generic forms which 'impose an interpersonal and public pattern upon sensation' (McCloskey, 1987, p. 61). 


\section{The Beginnings of Aesthetic Research}

In summary, all three philosophers, Vico, Baumgarten and Kant, sought to articulate epistemologies about both the here and now and the beyond.

Their agendas were to find ways of describing present experience, to make meaning of that experience, and to provide frameworks to articulate the ineffable and ephemeral.

Vico integrated the past with the present seeing meaning behind ancient myths and practices. This ability to think symbolically not only enables us to examine the artefacts of the past, it also facilitates a transformation of identity through an enlivened imagination by allowing the past to inform the present. This transformation grows firstly from internal change and then beyond, to the external world.

Baumgarten's search was for a way of understanding what lies beneath the surface; insights that are not immediately accessible through cognition.

He thought in terms of richness and multiple readings of phenomena.

Sensation is the door through which rational thinking can proceed, requiring a flexible aesthetician who is able to respond intuitively and to be open to new directions that unfolding phenomena may imply. 
Kant sought for ways of universalising notions of taste, holding that through the propensity to create forms and structures around the chaotic, we are able to engage in meaning-making activities that identify the essence of the thing-in-itself as well as its appearance. Once form is established around sensation, then we are able to make judgements and develop generic concepts on those sensations.

Aesthetic research, then, concerns the nature of sensation and perception and how these open up our awareness of world in which we live and work. Vico, Baumgarten and Kant offer different but related solutions to this by elevating rather than suppressing the imagination. It is this ability of human beings to think imaginatively that enables interactions at a symbolic and mythological level thereby assisting the research process. Therefore, aesthetic research seeks to make sense of complex and ambiguous environments - where divergence and disunity are the bases of shared experience - rather than 'striving for the end goal of unity' (Cairns, 2002, p. 817).

The three motifs of gestalt, empathy and process introduced in the previous chapter derive from this search. The beginnings of the gestalt motif are 
found in Vico's analysis of symbol and myth, along with the propensity to formalise sensation. Empathy is introduced in Baumgarten's elevation of sensation and the opening of the perceiver to multiple readings of phenomena. Finally process is presented in the free play between Kant's notions of form and content. Each motif relies on the interplay between imagination and understanding, where the past informs the present.

These ideas are summarised in Table 2.1: Vico, Baumgarten and Kant in Summary, and the three categories of Epistemology, Interplay, and Motifs synthesise their key ideas.

Table 2.1: Vico, Baumgarten and Kant in Summary

\begin{tabular}{rlll}
\hline & VICO & BAUMGARTEN & KANT \\
\hline EPISTEMOLOGY & $\begin{array}{l}\text { Past informs the } \\
\text { present }\end{array}$ & $\begin{array}{l}\text { Order is derived } \\
\text { from complexity } \\
\text { and multiplicity }\end{array}$ & $\begin{array}{l}\text { Content and form } \\
\text { contextualise } \\
\text { beauty }\end{array}$ \\
INTERPLAY & Symbol and myth & $\begin{array}{l}\text { Sensation and } \\
\text { action }\end{array}$ & $\begin{array}{l}\text { Subjectivity and } \\
\text { objectivity }\end{array}$ \\
MOTIFS & Gestalt & Empathy & Process \\
\hline
\end{tabular}

In the next chapter I will show how these ideas have been refined and extended beyond their early beginnings. I will investigate how sensation 
and the perception of those sensations lead to symbol-creation and mythmaking. Although I examine these elements as a lineal progression, underpinning the discussion is a more fundamental issue regarding the nature of phenomena. The question that the next chapter ultimately confronts concerns the nature of appearance: is what we see an unqualified expression of reality, or is there something beyond that appearance that is knowable? The chapter concludes with an exploration of the tensions between the physical and the metaphysical, considerations that draw on the philosophical heritage established by Vico, Baumgarten and Kant. 


\section{CHAPTER 3 \\ TOWARDS A CONTEMPORARY THEORY OF Aesthetics}

- Introducing the Aesthetic Problem

- Phenomenology and the Appearance of Things

- Sensation and Perception

- Symbolisation and Aesthetic Theory

- Myth-making

- Tensions between the Physical and Metaphysical

- Aesthetic Organisational Research 


\section{Introducing the Aesthetic Problem}

The ideas canvassed by the early Enlightenment aestheticians set the scene for the search for a contemporary organisational aesthetic research methodology. Considerations of the relationship between the parts to the whole, the present with the past, sensation and perception, background the works of Vico, Baumgarten and Kant. Underpinning their inquiries was the belief that humans have a unique capacity to think multidimensionally, and, as felix aestheticus the human personality is a fertile ground in which this multiplicity can be nurtured.

However, this ability of humans to think multi-dimensionally poses a methodological problem, namely, how do aestheticians research the complexities of social groupings like organisations while at the same time developing theoretical positions that are parsimonious and generalisable? Furthermore, how does the aesthetician avoid the charge of dealing in conjecture and irrationality (Singer, 2003)?

The agenda of this chapter is to respond to these challenges by providing a theoretical framework from which aesthetic research can proceed. The 
overarching issue that I address concerns the heart of aesthetic inquiry by proposing an epistemology that interrogates appearance.

For the contemporary organisational aesthetician, the overarching concern is the nature of appearance - that is, elements that are immediately accessible through our five senses of sight, sound, smell, touch and taste. Does aesthetic inquiry deal only with these elements or are there other considerations beyond appearance that we use to attribute meaning to that appearance? Although this question has occupied the attention of generations of aestheticians, it is important to re-address it here because a methodology that is cogent and replicable rests on the assumptions we make concerning appearance.

In proposing a theory of organisational aesthetic engagement I maintain that aesthetic inquiry is more than sense perception. For, while the definition of the word aesthetic offered in Chapter 1 as 'sense perception' is an adequate beginning point, it is too reductive to properly support a contemporary aesthetic research methodology. For instance, what are the elements that comprise sensation and perception? Furthermore, are we to assume that sense and perception are synonymous, or is there an implied 
dynamic relationship between the two? If there is, what is the nature of that relationship?

This question is important when examining organisations. For instance, in Chapter 1 I claimed that underlying Mintzberg and Westley's (1985) paper on symbolism is an aesthetic view. Evidence of this turn can also be seen in Mintzberg's seminal 1979 work on organisational structure. In his analysis of a number of enterprises, he presents a view of organisations that examines appearance while at the same time attributes meaning to that appearance.

Mintzberg takes multiple manifestations of organisational structures and synthesises them into a generic model of five zones. He achieves this by shuttling between the real (scientific view) and the ideal (abstract view); beginning with the real and then creating an ideal paradigm from those examples. But then, paradoxically, he adroitly reverses the process by turning the ideal back onto the real and uses the ideal as a means of analysis. Therefore, Mintzberg's process of synthesising involves continually shifting from the idiosyncratic structures of particular organisations (the real) to a model with 'five basic parts' (the ideal) 
(Mintzberg, 1979, p. 20). Performing these acts of analysis and synthesis which oscillate between the real and ideal is a peculiarly aesthetic undertaking. How does this occur and how does the researcher deal with paradoxes inherent in the process?

A solution to this conundrum is found in my claim that aesthetic engagement involves a both-and approach that rejects the polarities of either-or binary positions. However, the problem with this approach is that it deals in contradictions. For instance, how can something be both real and ideal? Aesthetic theory seeks to address this problem by examining the character of phenomena.

The works of Vico, Baumgarten and Kant contain the seeds of a resolution. In the work of each is an inherent oscillation between what is immediately evident and what is imagination. Schiller called this the 'play impulse' (Schiller, 1795/1965, p. 74), which is a quality of perception that moves back and forth between the two poles of form and content, an impulse that is in a continual state of schwung (Guillet de Monthoux, 2000). Hence the 'paradoxical co-presence' (Hepburn, 2002, p. 27) of elements like the real and the ideal are not seen as binary opposites. Rather they are viewed as 
being in a dynamic relationship. This then poses a foundational problem that the organisational aesthetician is confronted with; namely, is what is seen in an organisation a microcosm of social reality or is it an idealised view of that reality? Or is it both?

In order to address these questions I begin with a description of appearance by discussing the nature of phenomena. In this discussion I first summarise phenomenological thought, and then argue for a position that validates a search beyond phenomena.

\section{Phenomenology and the Appearance of Things}

In Chapter 1 I maintained that organisational aesthetic inquiry draws on engagement with works of art and life responses (Alison, 1790/1968). In what follows I explore this notion by examining the fulcrum between art and daily life: phenomenological inquiry. Further, I propose that aesthetic research points both to appearance and to ideas below surface phenomena; that beneath phenomena are certain behaviours 'embedded in practices of interaction' that are 'trans-situational' (Cohen, 1987, pp. 303 \& 298). 
Before exploring these ideas, I will first discuss the phenomenological approach, for it is from phenomena that underlying elements emerge.

The works of the progenitor of phenomenology, Edmund Husserl (1859-1938), are a search for an epistemology that attends to both objective and subjective ways of knowing. At its core, Husserl considered his phenomenological quest as a truly scientific view of existence that was grounded in the essence of human life. For him, phenomenology focuses on observable experiences and derives meaning from them. In this way, 'we know to the extent that we grasp essences' (Lauer, 1965, p. 66, emphasis added). Therefore pure phenomenology concentrates solely on that which is immediately present and does not seek to locate meaning outside those phenomena. In support of this view, Husserl writes:

To begin with, we put the proposition: pure phenomenology is the science of pure consciousness. This means that pure phenomenology draws upon pure reflection exclusively, and pure reflection excludes, as such, every type of external experience and therefore precludes any copositing of objects alien to consciousness.

(Husserl, 1917, para. 26)

According to Husserl, we discover the essence of a thing through our subjective experience which occurs within a given time and space - the 
here and now. Only once our senses are fully active can conclusions be drawn and 'scientifically grasped and comprehended with a view to their solution' (Husserl, 1910/1965, p. 115)

Husserl's understanding of phenomenology is a way of viewing the world stripped of any preconceptions. It involves attending purely to conscious knowledge - that which is intentional. As we interact with the world, we describe both the experience of that interaction as well as the object being interacted with. Thus, 'the phenomenological description will comprise two parts, description of the noetic (noesis) or experiencing, and description of the noematic (noema) of the experienced' (Husserl, 1927, p. 4, emphasis in the original). Hence the subject and object are in a state of continual interaction.

However, phenomenology does not look for anything beyond the immediate subject-object relationship; so Husserl's notion of bracketing off anything that is not immediately apparent means initial intuition is of vital importance to the acquisition of knowledge. It is this intuition that provides the starting point for an investigation of phenomena and, by 
attending to a phenomenon as it immediately appears, allows for a reduction to its very essence - its eidos (Husserl, 1927, p. 5).

Therefore, we gain an understanding of the world through 'eidetic' and 'phenomenological reduction' (Kockelmans, 1967, p. 30), a process by which the individual moves beyond 'empirical generalities' to 'pure generalities' (Kockelmans 1967, pp. 30-31). Pure generalities are gained as the individual removes all imagined contingencies until what remains is the unadorned phenomenon. This 'absolutely immutable and unique eidos' (Kockelmans, 1967, p. 31, emphasis in the original) is intuitively grasped and then acts as a guide for 'all individuals of this species' (Kockelmans, 1967, p. 31).

Kockelmans' claim, though, is problematic. If all contingencies are removed so that a phenomenon is reduced to its essence, how does that eidetic view lead to the generalities that the subject engenders? Furthermore, the question still remains as to how meaning is negotiated so that wider societal conclusions can be drawn from that particularity, and this problem cannot be addressed by relying solely on the phenomenological lens. 
By claiming this I am arguing for a position that reaches beyond phenomenology, a position that returns to Kant's distinction between what we immediately see - appearance - and what we attribute to what we see - the thing-in-itself. How, though, can the two be reconciled without reverting to the Cartesian dualism that Husserl was determined to avoid (Lauer, 1965, p. 45)?

Contemporary organisational aesthetician Antonio Strati offers a solution. In his 1999 text on organisational aesthetics he poses a riddle requiring an aesthetically attuned response, that toys with an object being both real and ideal (Strati, 1999b, p. 18). To paraphrase, he asks: 'When is a chair more than a just piece of furniture?' For Strati, the chair, a four-legged piece of furniture to be seated on, is also a tool for exploring meaning beyond the artefact such as the distributions of power within an organisation. The chair, though, is more than a metaphoric prompt. Rather, it represents an ontological exploration of organisational life where the phenomenon, or appearance of the chair, also implies meanings beyond that appearance. Following this line, I argue that pure phenomenology will not yield these deeper meanings. Yes, the essence of the chair can be determined, but not the varieties of meanings ascribed by society to that same chair. 
Methodologically then, if the researcher asks, 'What do you see and hear?', do respondents talk about what they see in terms of the colours, shapes, and sounds they are confronted with - its real appearance - or the meanings attributable to that appearance - the ideal thing-in-itself? The artefact in Strati's riddle, the chair, is both a tool and a symbol. But to think symbolically necessitates looking beyond the essence of a phenomenon to determine how artefacts attract meanings beyond their appearance.

In order to probe this problem, in the next part of the discussion I explore issues that help chart a course beginning with phenomena. The focus is first on the aesthetic essence of the relationship between sensation and perception. In order to explain how perceptions take on meanings beyond their immediate attributions, I then move to a discussion about symbolisation and show how that leads to myth-making. This results in an analysis of the underlying tensions between the physical and metaphysical. These ideas underpin contemporary aesthetic inquiry and reveal a progression that leads from appearance to elements beyond appearance. 


\section{Sensation and Perception}

I began this thesis by looking back to the classical Greek understanding of the word aesthetic and noted that Raymond Williams defined aisthesis as 'sense perception' (Williams, 1983, p. 31). It is to the relationship between these two elements that I now turn.

To gain an understanding of perception and sensation, I will concentrate on aspects of the existentialist and phenomenological traditions focusing particularly on Henri Bergson and Gilles Deleuze. Both have made significant contributions to the aesthetic philosophical canon by examining perceptions of time and space, present and past.

For Henri Bergson (1859-1941), perception involves the process of observing concrete objects, filtering the rich array of information made available by the objects, and then linking these with recollections of previous encounters of those objects. These encounters are 'alloyed' (Bergson, 1911, p. 60) with emotional responses within the individual, allowing him or her to make instinctual leaps beyond the object itself. 
Bergson holds that perception begins outside the body and is pulled centripetally into our consciousness by our subjective responses.

Therefore, the acquisition of knowledge is essentially 'a refraction through the forms of our faculty of perception' (Bergson, 1911/1998, p. 204). Against this inward flow is an outward centrifugal push from our memory: past recollections of experiences that continue to inform our knowledge of the object. Thus 'memory, inseparable in practice from perception, imports the past into the present, [and] contracts into a single intuition many moments of duration' (Bergson, 1911, p. 80).

Perception occurs at the interface between these external and internal forces. In the act of perception, there is a toggling backwards and forwards between the encounter with the object and recollections of previous encounters. Recollections and perceptions 'interpenetrate each other' (Bergson, 1911, p. 72) working to reshape our current experience with the object. 'Memory thus creates anew the perception by reflecting upon it either its own image or some other memory-image of the same kind' (Bergson, 1911, p. 123). For Bergson, an object 'is an aggregate of images ... an existence placed half-way between the thing and the representation' (Bergson, 1911, p. vii, emphasis in the original). Here our 
perceptions help form a construct derived from both an homogenisation of the past and sensations of the immediate present.

Several issues spring from Bergson's work. His turn to the biological sciences as a philosophical tool firmly grounds him in existing phenomena. The body is the site for perception, 'a hyphen, a connecting link between the things which act upon me and the thing upon which I act' (Bergson, 1911, p. 196). However, in spite of this, he also writes of 'zones of indeterminacy' (Bergson, 1911, p. 37) and of an organism's nervous system as 'a veritable reservoir of indetermination' (Bergson, 1911/1998, p. 126, emphasis in the original). Thus there is in his schema a relationship between the actual and virtual worlds even though he considers the virtual dimension to be passive. If there is a zone of indeterminacy between the actual and virtual, between the real and ideal, what is the nature of that space?

An explanation may be located in his notion of intuition. In this regard he holds that memory contracts perceived moments into 'a single intuition' (Bergson, 1911, p. 292). He considers that this 'learnt recognition passes out of time' (Bergson, 1911, p. 95) and as a result is distanced from the 
actual object. In perception there is a coalescence of 'consciousness and matter, body and soul' (Bergson, 1911, p. 292). However, Bergson is tantalisingly silent on the nature of the 'soul', a term he uses synonymously with 'spirit'. These terms, though, may hold the key as to how to progress beyond phenomena.

Both the zones of indeterminacy and contracted recollections represent a shift away from actual phenomena that enlarges our perceptions of the object. The existentialist, Jean-Paul-Sartre (1905-1980) concurs, claiming that 'the emotional subject and the object of the emotion are united in an indissoluble synthesis' (Sartre, 1971, p. 57). By focusing on the object of perception, the perceiver's emotions paradoxically continue to be captivated by, and even perpetuate that perception.

Gilles Deleuze (1925-1995) goes further and proposes a way of exploring the actual and indeterminate. He grapples with the nature of intuition using the term instinct to link the moment of perception with sensation. He notes that 'sensation is what determines instinct at a particular moment, just as instinct is the passage from one sensation to another' 
(Deleuze, 2002, p. 35). He claims there is logic to sensation that surpasses the rational and intellectual.

However, this logic is not without its difficulties. To explore these puzzles, Deleuze considers the aesthetics of Lewis Carroll (Deleuze, 1990/2001), whose works on the surface appear to be infantile nonsense poetry, and yet are inherently reasonable. He offers an extended commentary of Carroll's writings and suggests a way of proceeding from pre-rational sensate experience to objectifying perception.

In his analysis of Carroll's Alice's Adventures in Wonderland, Deleuze shows the logic and sense behind what at face value seems non-sense by posing the conundrum of Alice's size. Alice reduces in size to begin her tumble down the rabbit hole but on arrival finds she's nine feet tall with her head striking the roof of the hall where she stands. Therefore, she at once shrinks and grows. How, though, does the reader resolve this paradox?

Rather than forcing dualities, Deleuze argues that the logic of sense allows for the kind of sense-making that leaves paradox intact (Deleuze, 1990/2001, p. 28). For Deleuze, sensation goes beyond the moment of 
perception and makes intuitive leaps through what he terms diastolic and systolic rhythm (Smith, 2002, p. xiii). This metaphor with its reference to the beating heart demonstrates how sensation contracts around a perception but paradoxically opens up the possibility of new directions beyond perception. Therefore, this rhythmic pulse 'is diastole-systole: the world that seizes me by closing in around me, the self that opens to the world and opens the world itself' (Deleuze, 2002, p. 37) and perpetuates the oscillation between sensation and perception.

Here Deleuze provides a clue for what might lie beyond the interface between perception and sensation. He considers that sensation resulting from perception produces an effect. This effect does not result from a cause but is rather a simulation of the perceived object. Thus the systole that results from the initial sensation opens to a new symbol, a sign which encapsulates the sensation. Deleuze notes that this sign issues 'from a process of signalization; it is in the sense of a costume, or rather a mask, expressing a process of disguising, where, behind each mask, there is yet another' (Deleuze, 1990/2001, p. 263, emphasis in the original). 
As perceivers of Alice's dilemma, we know she must reduce in size in order to travel down the rabbit hole. Therefore, our sensate faculties diastolically open up to the possibility of size reduction. But that carries the difficulties of a change in identity from Alice the growing child, to Alice the midget. In response, our perceptual abilities systolically enable us to maintain her essence but within a new context. But that poses a further size problem. If she remains essentially the same, she will of necessity be taller than her animal associates. Following Bergson, in order to allow the diastolic-systolic rhythm to continue its pulsations, we make references to the past by recognising Alice's size before her rabbit-hole encounter, by holding that perception alongside her new environment within the rabbit hole. Therefore, perceptions of time and space interact with each new sensation as the narrative unfolds, allowing the continuation of the diastole-systole rhythmic pulse. Hence with each new sensation, there is a perception that closes around it to give it meaning and shape.

Alice's paradoxical story highlights the symbolic problem. Our ability to perceive her as both large and small requires us to see her simultaneously as being multi-dimensional. This can be achieved by thinking 
symbolically rather than literally and it is to this capability to symbolise that I now turn.

\section{Symbolisation and Aesthetic Theory}

The propensity for humans to symbolise sensation as a way of discovering what lies behind phenomena is explored by Ernst Cassirer (1874-1945). According to Cassirer, the creation of artistic symbols is a way of objectifying and representing experience through the 'condensation and concentration' (Cassirer, 1944, p. 143) of artistic media. Through the symbolic, reality is discovered rather than merely reproduced. He writes that:

Like all the other symbolic forms art is not the mere reproduction of a ready-made, given reality. It is one of the ways leading to an objective view of things and of human life. It is not an imitation but a discovery of reality.

(Cassirer, 1944, p. 143)

For Cassirer, aesthetics differs from science in that it intensifies and concentrates multiple experiences into a single whole (Cassirer, 1944, p. 148). He considers that aesthetics forms a dialectic between lived experience and the symbolisation of those experiences and writes that sensation leads to the creation of symbols that exist beyond the sensate, 
with the symbol splitting off from the sensation. Symbols allow for conscious thought to go beyond finite expressions to the infinite.

In this split, in this attachment to the sensuous, and in this rising above the sensuous, it not only expresses the tension which runs through the world of our consciousness, - but it reveals by this means the original and basic polarity of Being itself; the dialectic which exists between the finite and the infinite, between the absolute idea and its representation and incorporation inside the world of the individual, of the empirically existent.

(Cassirer, cited in Gilbert, 1949, p. 609, emphasis in the original)

Cassirer's pupil, Susanne Langer (1895-1985), further explores these ideas of symbolisation. In her schema she separates discursive symbols contained in language and presentational symbols that include 'images, gestures, and rites' (Langer, 1942/1960, p. 218). Langer considers that the distinguishing factor of human existence is the need to symbolise experience. Thinking involves the act of symbolisation, a process that continues when waking and sleeping. Furthermore, it is the ability to symbolise that enables thinking to develop, 'for if the material of thought is symbolism, then the thinking organism must be forever furnishing symbolic versions of its experiences, in order to let thinking proceed' (Langer, 1960, p. 41). 
For Langer, this non-discursive symbolisation involves the reception of information. Although we are continuously confronted with streams of entirely new data, we make these familiar by attaching them to previous encounters of objects and interactions and create forms or symbols around our experience. Therefore, symbols form around idiosyncratic sensations, enabling us to make sense of those unique experiences. This 'rests on the fact that we promptly and unconsciously abstract a form from each sensory experience, and use this form to conceive the experience as a whole, as a thing' (Langer, 1942/1960, p. 90, emphasis in the original). Hence small parts of an object, or minor and seemingly unrelated incidents, constellate into a gestalt.

Symbolising experience into a thing, according to Susanne Langer and her colleague John Dewey, leads to the creation of a variety of forms. Form is a way of articulating the indescribable, of encapsulating or of seeing an idea.

This is what it is to have form. It marks a way of envisaging, of feeling, and of presenting experienced matter so that it most readily and effectively becomes material for the construction of adequate experience on the part of those less gifted than the original creator.

(Dewey, 1934, p. 109) 
How, though, does the symbolic imply the existence of an identity beneath phenomena?

Hans-Georg Gadamer (1900-2002) addresses this question by arguing that art sits between the real and the ideal. Therefore, what we are dealing with in art, Gadamer says, is something that is an imitation of reality. $\mathrm{He}$ claims that art's function is to 'bridge the chasm between the ideal and the real' (Gadamer, 1986, p. 15) and derives his ideas from the ancient Greek context where a symbol was 'a token of remembrance' (Gadamer, 1986, p. 31) that was given as an act of hospitality. This artefact could be used at any time as a reminder of an original connection. He concludes:

In its original technical sense, the symbol represented something like a sort of pass used in the ancient world: something in and through which we recognize someone already known to us.

(Gadamer, 1986, p. 31)

Therefore, a symbol speaks of something more than what it is. As we engage with symbols, and work with them constructively and actively, they complete something within our psyche. How, though, does this occur? And, what is the nature of this 'constructive activity' (Gadamer, 
1986, p. 37) that enables us to discover what lies beyond the surface of a symbol?

To address this question I turn to Roland Barthes (1915-1980) and his thinking about what exists beyond a symbol. He investigates the rich mythologies that attach themselves to signs.

\section{Myth-making}

Within the modern scientific frame, myth is considered as being synonymous with error or untruth. Dictionary definitions confirm this view by noting that myth is a 'widely held but false belief' (The Concise Oxford English Dictionary, 2002). And yet some scholars disagree with this assessment and consider myth to be an important and far from false element of contemporary life. With this in mind, anthropologist Ronald Wright argues that myths may be grounded in fact and that they provide a means of charting our way through life.

Myth is an arrangement of the past, whether real or imagined, in patterns that reinforce a culture's deepest values and aspirations. Myths create and reinforce archetypes so taken for granted, so seemingly axiomatic, that they go unchallenged. Myths are so fraught with meaning 
that we live and die by them. They are the maps by which cultures navigate through time.

(Wright, 1993, p. 5)

Because of this, myths enable us to make sense of complex situations by 'helping us to get beyond the chaotic flux of random events, and glimpse the core of reality' (Armstrong, 2005, p. 7). In this way they move us beyond the confusion of disorder by provoking 'what if'; a question that allows for new possibilities to be envisaged (Armstrong, 2005, p. 9).

Myth, then, is as much part of our modern landscape as it was of the landscapes of the past. Twentieth-century literary theorist Roland Barthes' large array of publications include works that speak directly about the development of myth, and in them he explores how myths are created and developed in the contemporary world.

Barthes shows the movement in language analysis from semiotic investigation to myth-making, claiming that myth shifts the focus from the micro-analysis of signs and codes to more macro-interpretation. Myths can take the form of words, a photograph, cartoon, an action or even a work of art, and generate stories at a meta-level which are at once 'anonymous and slippery, fragmented and garrulous' (Barthes, 1977b, 
p. 166). Yet, in spite of the ability of myth to shift and adapt, through the process of myth-creation, symbols adopt a global meaning that suggests meaning beyond the symbol itself.

Barthes' work explains how this movement occurs and describes how the familiar and ordinary can take on mythical proportions. Essentially, myth involves a kind of 'language-robbery' (Barthes, 1972, p. 131) where the historical idea of an object takes on greater mythological intent. The process of myth-making sees ideas used in everyday life transformed into meta-language (Barthes, 1972, p. 144).

Myth is created, according to Barthes, as the form of a symbol is stripped of its historical meaning. This stripping does not signal the demise of the symbol but rather creates an opportunity for it to acquire new meaning, whereby 'the form has put all this richness at a distance: its newly acquired penury calls for a signification to fill it' (Barthes, 1972, p. 118). Therefore, as symbols are recontextualised, new myths become attached to them. 
How do we read myths? Barthes suggests that we need to take them as they present themselves and look for meaning within them, rather than in the historical context that generated the original symbol. Barthes claims that myth itself is an 'inextricable whole made of meaning and form, [and] I receive an ambiguous signification: I respond to the constituting mechanism of myth, to its own dynamics' (Barthes, 1972, p. 128). Myth naturalises images by freezing them to the point where they are 'not read as a motive, but as a reason' (Barthes, 1972, p. 129, emphasis added). In this way, myth extends a symbol giving it a life of its own, where the myth itself becomes the tool for making sense of phenomena.

For example, Ziems (2004) demonstrates how this process works in advertising. He uses as an illustration a paper towel which in the normal course of daily events, cleans up messes. However, through myth-making by astute advertisers, the towel assumes greater sacerdotal proportions as a vehicle for wiping away life's conflicts. The paper towel

virtually soaks up all the little accidents and irregularities of everyday life. In doing so, it helps us pretend that some everyday conflicts never took place.

(Ziems, 2004, p. 211) 
This process of myth-making also occurs within organisational life, as links are made between what should be done (the ideal) and what can be done (the real) (Abravanel, 1983). Similarly, Guillet de Monthoux explores this dynamic by claiming that myths are more than 'amusing fables' (Guillet de Monthoux, 2004, p. 37). They are means of conceptualising life experiences, thereby providing a vehicle for reflection, and for understanding chaotic circumstances. There are ideas inherent in ancient Greek myth in particular that incarnate 'an absolute idea into a conceptual figure' (Guillet de Monthoux, 2004, p. 37). Furthermore, no attempt is made to present these concepts in a logical or rational way, but the myth 'frequently involves fantastical elements (e.g. man-eating ogres) subject to neither the constraints of logic nor empirical falsifiability' (Pondy, 1983, p. 159).

Myth-making that is generated by symbolisation begs further justification. Although I have tried to set the stage for an organisational aesthetics research methodology, it is appropriate here to pause and reflect on the problem left unresolved. Further, although my analysis has indicated a tidy progression from perception and sensation to symbol and then myth, 
it hides a deeper struggle in the relationship between the physical and metaphysical.

\section{Tensions between the Physical and Metaphysical}

The question concerning the physical and metaphysical returns to the problem of appearance, and asks: Is what we see all there is to see, or is there something other than phenomena to be observed? Further, if there is appearance beyond appearance, what is the nature of that beyondappearance and what form does it take?

To address these questions I focus on Friedrich Nietzsche (1844-1900) and his musings on myth and society. Nietzsche turned to the ancient Greeks to make sense of modern culture with the quest to determine the character of the metaphysical. He asks whether metaphysical activity is a selfdeceptive enterprise that assuages feelings of existential angst and therefore able to be eliminated; or whether it is a necessary element of human existence that provides a sense-making framework?

His early work centres on Greek myth and in particular explorations of the relationship between Apollo and Dionysus - Apollo, self-controlled; 
Dionysus unencumbered and chaotic. For Nietzsche, it is the Dionysian that opens the possibility of the metaphysical and, in particular, music 'is the metaphysical complement to everything that is physical in the world; the thing-in-itself where all else is appearance' (Nietzsche, 1871/1956, p. 97). This statement sets the scene for a discussion on the metaphysical problem. What is concealed beyond phenomena and how does the thingin-itself relate to what we perceive?

Nietzsche's agenda is to find a justification for affirming only the physical. His turn to Greek tragedy is a way of reflecting back to us moderns that our struggle has been to stay completely with outward appearance and not to look for anything beyond the physical. This poses a problem for Nietzsche. He considers human existence is grounded in aesthetics (Nietzsche, 1871/1956, p. 9) and that art inevitably leads to the metaphysical, for it is in this activity that humanity finds solace (Nietzsche, 1871/1956, p. 50). However, Nietzsche's ambivalence towards the metaphysical is paradoxical. 
On the one hand, he conceives of a world that is purely appearance.

Consequently, the Greeks understood the true meaning of existence because of their ability to engage with surface phenomena.

Oh, those Greeks! They knew how to live. What is required for that is to stop courageously at the surface, the fold, the skin, to adore appearance, to believe in forms, tones, words, in the whole Olympus of appearance! Those Greeks were superficial - out of profundity!

(Nietzsche, 1887/2004, § 4, emphasis in the original)

Yet, in spite of this profundity, Nietzsche also acknowledges that existence devoid of metaphysics is too dreadful to consider. James Porter, in his commentary on Nietzsche's work, notes that it is the need to look beyond the surface and into the folds behind appearance that gives human existence a sense of meaning. Paradoxically, the metaphysical quest brings with it the anxiety of chaos, in that it implies Dionysian uncertainty and lack of control. On the other hand a world without existential meaning gained through the metaphysical, is too horrific to contemplate, because it is pointless and nihilistic (Porter, 2000, p. 19).

Therefore, for Nietzsche, the inclination to see beyond the physical is a human tendency born of the need to make sense of our world. His investigations into Greek tragedy provide a meaning-making lens on 
modern life. Like the Greeks, we moderns imagine that our objective scientific world-view rejects the metaphysical, but at the same time we are drawn inexplicably towards the metaphysical, or, as in the words of James Porter, the 'unhinderable recidivism' of the metaphysical (Porter, 1995, p. 481) continually pulls us beyond the appearance of a phenomenon.

Here indeed is a paradox, that the denial of myth encourages the development of myth. Again, Porter (2000) aptly writes of this contradiction.

One of the paradoxes operated by Nietzsche ... is that myth becomes credible only when it is no longer believed in. Perhaps the 'skeptically minded' Greeks never really believed in their myths. If so, then Nietzsche adds a further twist: this distrust was only theoretical; they only believed that they did not believe in their myths; in practice, they did. (Porter, 2000, p. 160, emphasis in the original)

This sometimes attraction, sometimes ambivalence, and at other times antipathy towards myth-making and the metaphysical form the backdrop to organisational aesthetics. Here is a desire for an aesthetic language that embraces more than just surface inquiry (Taylor, 2002), as well as being alert to the manipulative underbelly of an aesthetic captured by a market place hungry for inventive ways of selling products (Adorno, 1963/2000; 
Hancock, 2002). These elements will be explored further in the next chapter, where I argue for an aesthetic approach that is sensitive to musical awareness.

\section{Aesthetic Organisational Research}

At the outset of this chapter I commented on Henry Mintzberg's work on organisational structure. I made the claim that his linking of the real and ideal is an aesthetic rather than a scientific undertaking. His move from specific organisational structures sees him formalise his thinking around a symbol: a model of five zones. However, Mintzberg goes further. He argues that the number five is not selected by chance. Rather, this number has ancient numerological significance resonating with the human psyche.

Mintzberg writes:

The number 'five' has appeared repeatedly in our discussion. First there were five basic coordinating mechanisms, then five basic parts of the organization, later five basic types of decentralization. Five is, of course, no ordinary digit. 'It is the sign of union, the nuptial number according to the Pythagoreans; also the number of the center, of harmony and of equilibrium.' The Dictionnaire des Symboles goes on to tell us that five is the 'symbol of man ... likewise of the universe ... the symbol of divine will that seeks only order and perfection.'

(Mintzberg, 1979, p. 300) 
With his model, Mintzberg has deliberately employed a number deeply rooted in ancient numerology and mythology which belies his intent that through scientific rationality the truth can be uncovered by logical inquiry. Mintzberg's work would therefore gain the approval of Giambattista Vico. As noted in the second chapter Vico considered that looking back into history, and inquiry through the exploration of myth, heroic poetry and language, enable the human community to uncover meanings that lie below the surface of that which is immediately visible (Vico, 1744/1999, p. 44).

Mintzberg's unwitting aesthetic turn in his use of symbolism encapsulates the tenor of this chapter. If we accept Mintzberg's implied view that an organisation is more than the collaboration of a community of people around a common goal and that it has significance rooted in cosmologies and mythologies of the past, how do we discover this mythological dimension?

To understand this relationship between the rationality of organisations and the propensity for the mythological, I argue for a unified approach that resolves the traditional duality which separates aesthetics into either 
engagement with art or the sensate examination of human existence. Through this I propose an aesthetic that is developmental, progressing along a continuum beginning with perception and sensation, then to symbolisation and finally to myth-making. The idea behind this sequence has been to show the tensions between the physical and metaphysical: appearance and the thing-in-itself. Implied in this has been the idea that the logic of sense leads to a metaphysical approach. Deleuze's solution was to show that the perceptual and systolic contraction around a sensation allows for new symbols to be created that can stand alongside existing ones. The problem is, though, how to proceed while holding the physical and metaphysical in a mutually supportive tension?

This latter question forms the basis of the next chapter which examines the place music has in the search for an aesthetic methodology. I discuss current organisational research methodologies that focus on aesthetic reasoning. As mentioned by Nietzsche in his analysis of Apollo and Dionysus, it is music that makes the connection and it is to a discussion on musical aesthetics that I now turn. 


\section{ChAPTER 4 AESTHETIC INQUIRY AND ORganisatIONAL IDENTITY}

- Art and Temporality

- The Schwung of the Ideal and the Real

- Organisations as Symbolic Texts

- The Foundations of Organising

- Music and Conducting Organisational Research

1. Interacting with the Parts and the Whole

2. Space and Time

3. Non-sounding Elements

- Aesthetic Inquiry 


\section{Art and Temporality}

In the introductory chapter, I discussed Karl Weick's imperative that we see organisations as processes rather than as fixed entities, as verbs rather than nouns. This requirement is encapsulated in his definition of organisations as 'multiple, heterogeneous flows of diverse viscosity moving at variable rates' (Weick, 1979, p. 42). However, several questions emerge from this claim. Firstly, if we adopt Weick's metaphor of a flowing stream, how do we examine both surface movement and undercurrents not immediately visible? Secondly, if organisations are processes, is there a coherent epistemology that validates temporality? Thirdly, given the heterogeneous environment within which organisations exist, how can the researcher discover threads of meaning within this heterogeneity?

Weick and his colleagues' solution to these problems is to turn to sport because it 'thrives on verbs and images' (Wolfe et al., 2005, p. 205). The dynamic and fluid temporal environment within which sport is played provides an ideal platform for concepts to be isolated and transferred into the organisational arena. 
An aesthetic view makes similar claims, but instead focuses on the arts. Notwithstanding their shared temporal environment, the raison d'être of sport and that of the performing arts are different. These differences can be summarised under the notions of intentionality (the actions of the sports person or artist) and concretisation (the perceptions of the audience); concepts that I will introduce here but will discuss in detail in the next two chapters.

Intentionality sees the focus of sport on efficiency and economy of movement, which enable the athlete to score the goal, bowl the ball, or hit the target more effectively than his or her opponents. On the other hand, in art, considerations of tension and release may require the artist to repeat a phrase, an action, or harmonic progression in order to build further cycles of tension and release. For, as Willis elegantly summarises, artistry involves 'making a pattern in a ... swirl of events [that] can bring moments of transcendence or transformation' and instead of aiming for efficiency, the artist's goal is to convey a 'heightened awareness, the holding of time, control and insight' (Willis, 1990, p. 15, emphasis added). 
The second important difference is in the role of the concretising audience. In sport they are spectators, on-lookers of the spectacle being played before them. However, in the arts the audience are co-creators, an activity which 'demands a special attitude and exertions' (Ingarden, 1964, p. 199). Hence, art-making as a creative enterprise occurs in the dynamic relationship between the artist and perceivers.

Given these key differences between sport and art, and if organisations are temporal phenomena that change over time, I argue that they can be approached like any temporal art form such as drama, dance or music. Furthermore, I claim that idealised phenomena like works of art speak about the daily vicissitudes of life, and by extension, organisational reality. Bergson's aesthetic insights make a poignant contribution to this idea in his exploration of comedy. Rather than shielding us and idealising experience, he claims that art confronts us with the rude realities of life.

So art, whether it be painting or sculpture, poetry or music, has no other object than to brush aside the utilitarian symbols, the conventional and socially accepted generalities, in short, everything that veils reality from us, in order to bring us face to face with reality itself.

(Bergson, 1935, p. 157) 
For Bergson, art is not a stylised vision of life, but rather a provocative stimulus that, through symbol, reveals reality. In what follows I propose an explanation for how this translation occurs.

Roman Ingarden (1893-1970) and his writings on phenomenological aesthetics teases out the theoretical elements that underpin this link between art and life. The appeal of Ingarden's work is that it is grounded in existing phenomena and deals with human actions and motives in works of art - in particular, music. In doing so, Ingarden's phenomenology turns away from Husserl's transcendental approach to embrace what Embree calls 'realistic phenomenology' (Embree, 1997, n.p.). Added to this, Ingarden's ideas translate well into organisational research because of his notion that art, and music in particular, is grounded firmly in the present. He sees works of art as living phenomena containing elements that can be singled out for analysis, and by doing this analysis, a dynamic relationship is established between the perceiver and perceived. Aesthetic organisational research begins with the same premises: that organisations are dynamic environments, and that the researcher starts with evident phenomena and proceeds beyond these to discover deeper meanings. 
As an aesthetic phenomenon, music is the most esoteric and ephemeral of all the arts. My claim is that, rather than presenting a problem, this adds to the adaptability of musical aesthetics into a research method because organisations, too, are temporal phenomena that are both determinate and ephemeral. So, while the complexities of organisational life have been explored from psychological (Schein, 2004) and sociological (Casey, 1995) viewpoints, musical aesthetics provides another way of investigating the cultural milieu that encompasses organisational identity. This aesthetic approach adds to these traditional fields of study by offering insights into the ways non-rational and symbolic elements contribute to organisational identity.

To make this claim, it is important to first discuss the link between unique subjective experience and generalised objectivity. To do so, I begin by examining social constructionism and the interplay between the real and the ideal.

\section{The Schwung of the Ideal and the Real}

In their exposition of social constructionism, Berger and Luckmann (1967) argue that the sociological task is to discover the nature of reality as it is 
lived in everyday life. In their work they ruminate on the differences between subjective and objective knowledge and show how one leads to the other. They suggest that objectification - or 'objectivation' (Berger \& Luckmann, 1967, p. 50) - occurs through the construction of signs; and signs become objective depictions of unique subjective experiences. This move between subjective instrumentality and objective signification is volatile and fluid because of the 'detachability' (Berger \& Luckmann, 1967, p. 51) of signs from the original event.

Language is the most symbol-rich form through which objectivity takes place and Berger and Luckmann claim that, through language, generalisations can occur as the objective sign is removed from the idiosyncratic event. Because of its flexibility, language is able to move from the particular to the general in a process of typification and anonmyzation. Typification, or 'idealization' as Schutz and Luckmann claim in a later iteration of the concept (1974, p. 278), provides for the original event to move beyond the specific to the generic, while anonmyzation removes the event from its source. In other words, rather than being attached to a particular experience, knowledge is objectified 
when it is separated off from the original experience and given wider meaning than the event itself.

Kenneth Burke's symbolic approach to language enlarges this idea. He holds that language is bicameral - or as Carter terms, double-edged (Carter, 1997) - in that stories are recounted within a specific time-space dimension and yet are paradoxically time-less. Therefore, the time-bound idiosyncratic story and the time-less generic essence of the story mean that 'language is already operating in two modes at once, the linear and holistic' (Carter, 1992, p. 6). Extending this further, Burke suggests that words offer something else that is inherent yet silent within a narrative. He writes that stories contain philosophic concepts that inform the unique story (Burke, 1961). Therefore, we not only tell stories, but our stories also tell us.

Burke's view offers a lens that helps make sense of the symbolic actions inherent in narratives. Consequently art, text, and narrative all revolve around the movement from uniquely subjective experiences to the generic meaning we derive from them. 
The social constructionist agenda, then, is that social structures can be revealed through the objectification of particular encounters. However, the difficulty with a search for generalisability is that subjective experience can become slave to objectivity. Furthermore, by subsuming subjectivity to generalised objectivity, enriched existential meaning is limited, as unique experiences require validation by an objective measure.

Ingarden grapples with this problem, noting that in aesthetic engagement a similar process occurs. He, too, distinguishes between the idiosyncratic and the generic by using the terms real and ideal. By real he means a particular work of art with all its unique features and flaws. However, an ideal object is 'ontically independent of any cognitive act directed at it' (Ingarden, 1931/1973, p. 10), and in so doing, argues for generalisable characteristics which are timeless and not subject to change.

In this regard, Ingarden notes that for aesthetic knowledge to become objectified (idealised), the perceiver seeks to create neutral properties - or an 'axiologically neutral skeleton' (Ingarden, 1964, p. 207) - that give voice to a work of art. Ingarden turns this notion of neutrality back onto the 
work of art, claiming that it is this that gives an individual piece its unique identity.

Therefore, Ingarden contends, the process of engagement is far from linear. Rather, there is a dynamic interplay between the real and the ideal with the ideal informing the real and vice versa. Susanne Langer agrees with this approach. As described in Chapter 3, she considers symbol creation as central to human identity and this process leads to 'a dialectic interplay between subjective and objective elements in human experience' (Langer, 1962, p. 13). However, rather than this interplay presenting a unitary flow from the subjective to objective, each informs the other.

Thus, concepts are, following Langer, abstractions of symbolic experience (Langer, 1962, p. 63). Furthermore, symbols enable us to go beyond individual surface expression to observe the form in its totality 'in a single instance' (Langer, 1962, p. 64), helping us see the relationship between the parts and the whole. Langer goes further to say that not only do symbols reflect our experience, artistic symbols also help shape our experience (Langer 1962, pp. 93-94). 
Following this line, organisational theorists see a place for dramaturgical enactments as ways of exploring the dynamics of organisational life (Barry, 1994; Taylor, 2003), which then suggest interventions for revitalisation projects. In particular, Steve Taylor (2004) offers an approach in which artistic and aesthetic expression can be combined in a form of action research. He shows, in a personal case study, his feelings about his work-life (of being fired from a job) explored artistically in a dramatic play. To justify his approach, he quotes Langer's assertion that 'the primary function of art is to objectify experience so that we can contemplate and understand it' (Langer, cited in Taylor, 2004, p. 81). The objectivity inherent in Taylor's dramatic works is then turned back on the participants, be they actors or audience, so as to enhance their individual work-life experiences. So, while acknowledging the desirability of objectivity, the aesthetic lens also respects, values, and even preserves subjective engagement, thereby allowing for the toggling to and fro between the subjective and objective, rather than a unitary move towards objectivity.

Extending this idea, Gadamer contends that Schiller's notion of play sees the dynamic interaction between individual aesthetic encounters and the 
structure that gives it generic meaning. He writes that play, whether it is children having fun together, a sporting event, a drama, or even a religious ritual, is a 'process that takes place in between' (Gadamer, 1975/1999, p. 109, emphasis in the original), where the individual actions of each player interact with the generic rules of the game, thereby enabling the observers to make sense of the action. Hence individual acts become ritualised, presenting 'a meaningful whole' (Gadamer, 1975/1999, p. 109). Paradoxically though, as the individual plays within prescribed rituals, he or she is drawn into the game's 'dominion and [the game] fills him with its spirit' (Gadamer, 1975/1999, p. 109). In this way the actor attends to the rules of play but at the same time has an enhanced personal experience that transcends the generic form of the game.

The notion of play, then, belies the dichotomy inherent in the social constructionist approach. Rather, the two poles collapse in a continuous interaction, one with the other. Or in a phrase appropriated from Paul Willis, the schwung of the subjective-objective relationship represents 'stable instability' (Willis, 2000, p. 58) in their interplay where the ideal and the real are in a volatile, dynamic relationship. 
In summary, organisational aesthetics revolves around the real and ideal, with each informing the other. Figure 4.1: The Continuous Interplay between the Real and the Ideal depicts this interaction with two semicircular arrows, with the real impacting on the construction of the ideal which in turns informs the real.

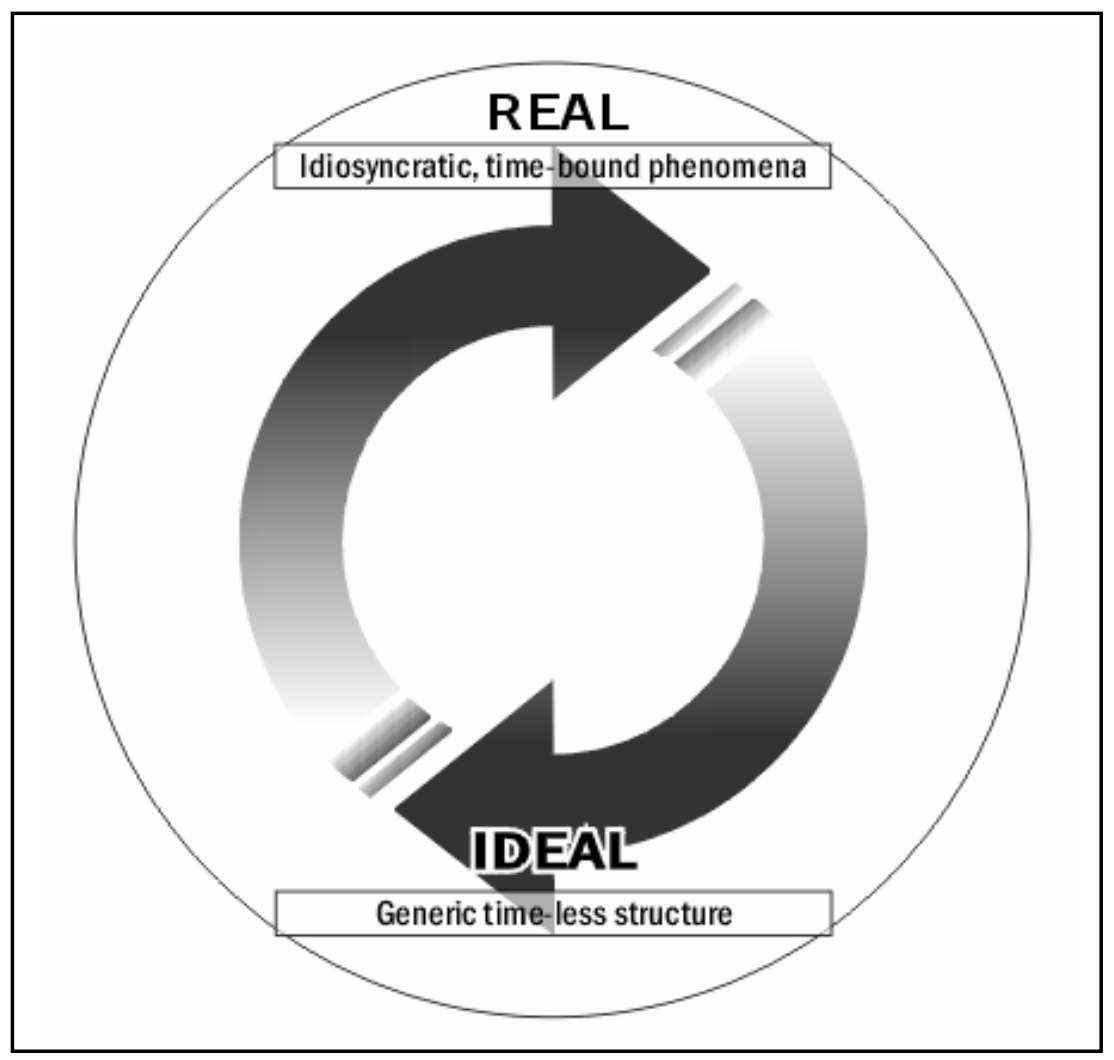

Figure 4.1: The Continuous Interplay between the Real and the Ideal

With this awareness of the relationship between generalised aesthetic values and particular artistic manifestations established, I now turn to a discussion on the symbolic nature of organisations. 


\section{Organisations as Symbolic Texts}

As mentioned above, Bergman and Luckmann contend that language is the most sign-saturated form that humans have to convey meaning, and it is language that 'crystallize[s] and stabilize[s]' (Berger \& Luckmann, 1967, p. 53) subjective experience. Further, in their inimitable words they write that 'language is pliantly expansive', able to 'typify' and 'anonymize' unique subjective experiences into an objective whole (Berger \& Luckmann, 1967, p. 53). Therefore, seeing the entity organisation itself as a linguistic form (a text) that is both typical and anonymous might assist the researcher in discovering its ontic foundations. In the context of this study, and of Ingarden's usage, the word ontic is defined as elements which are evident, as opposed to ontological issues which address the nature organisational being. Hence an organisation's ontic identity can be revealed through the textual approach.

Taking this line, in his editorial foreword to the 1999 special issue of the journal, Studies in Organizations $\mathcal{E}$ Societies, which deals with the textual nature of organisations, Stephen Linstead teases out a number of core ideas surrounding the concept of organisations as text. Text here refers 
not just to language but also to other symbolic forms. He argues that seeing organisations as symbol-rich texts enables the researcher to grapple with 'their emergence, ambiguity and paradoxicality, in a living and mobile rather than a fixed and propositional sense' (Linstead, 1999b, p. 5). Texts, then, in all their diverse manifestations form the ontic identity of organisations and 'result from action and produce further action' (Czarniawska, 1999, p. 16).

Further advances in this concept are explored in the May 2004 special issue of the journal Organization where the link between organisational identity and text is investigated. In their introduction, Linda Putnam and François Cooren note that organisational discourse goes beyond the mere exchange of information in a functional sense. Rather, it 'also addresses the mode of being or fundamental origin of an organization' (Putnam \& Cooren, 2004, p. 324, emphasis in the original). Thus text in its widest sense allows for an examination of the ontic foundations of an organisation and may in turn reveal its ontological identity (Feenberg, 2000, p. 449). 
Following up on these insights in October 2004, the Academy of Management Review published a special topic forum on language and organisation (Boje, Oswick, \& Ford, 2004). Here, articles emphasise the nature of organisations as entities that generate and interpret texts as a way of creating identity. Interestingly, the trend in several of these articles is away from post-modern multiplicity of narratives, to seeing how meta-texts are formed (Robichaud, Giroux, \& Taylor, 2004) and to how institutions are shaped through embedded discourse (Phillips, Lawrence, \& Hardy, 2004). This shift from text to meta-text changes the focus from what is demonstrably ontic towards reflections on an organisation's ontology. The questions underpinning these articles are: 'What lies at the foundation of organisational life?' and 'How do we know it?

While these questions form the basis of this study, beneath them lies a further problem relevant to the research community, that of discovering the textual identity of an organisation. Aesthetic inquiry aids with this discovery by focusing on both the idiosyncratic and the generic. But how does aesthetics translate into organisational knowledge? Or put more formally, what are the elements of aesthetics that help provide a 
framework for understanding the ontic foundations of organisational behaviour?

\section{The Foundations of Organising}

In the previous section I claimed that an organisation, defined as text in the broadest sense, not only includes discursive narratives but also symbolic representations. Rationally, organisations exist in time and space in an identifiable locale whether that be actually in a geographical location or virtually as an internet website. But knowing the physical make-up of an enterprise, including its array of strategic intentions, staffing structures and stakeholder relationships, does not advance our knowledge of organising at an ontic level. Aesthetics can assist in this exploration by offering engagement with art as an exemplar for organisational analysis.

To make this shift between domains, though, requires the ability to discern the foundational elements of each area, to map those features, and then to observe the translation of ideas from one to the other. Tsoukas (1991) terms this a shift from homomorphism, where elements are seen to 
be discrete and belonging within a particular discipline, to isomorphism, where similarities between areas are discerned.

The translations across domains can be best observed through metaphor. Tsoukas argues that new and interesting metaphors emerge where there is 'domain incongruence' between the two fields. The fact, then, that organisations and art forms are quite different is beneficial in this pursuit.

What is required for mapping between domains is for the particular elements of both areas to be identified (Gentner, 1983). As comparisons are made and areas of dissimilarity rejected, transfer between zones can be achieved. Tsoukas maintains that this process is dynamic and that, as the researcher continually shuttles between those elements that are different and those that are similar, an analogue emerges that shows where the commonalities exist. However, he offers the caveats that sometimes the proposed model breaks down because insufficient elements are transferable. Furthermore, he maintains that while at a conceptual level translation from one domain to another might be evident, ultimately a model's usefulness can only be determined empirically (Tsoukas, 1991, pp. $576 \& 577)$. 
My claim is that structural mapping can be achieved between music and organisation, where the base domain of the art form music can provide metaphoric insights into the target domain of organisation. To assist in this search, Roman Ingarden's musical aesthetic offers particular insights. In his 1986 work Ingarden interrogates the nature of music by firstly asking the question: 'Does music exist?' On the surface this question seems absurd. Music is ubiquitous. Whether sitting in a concert, working out at a gym, or even travelling in an elevator, we find that music is everywhere. The radio airwaves are replete with music and dedicated television channels play music videos 24 hours per day, 7 days a week. Music is so ever-present that we don't think to question its nature.

So too with organisations. While, following Ingarden's lead, we could express doubt about organisational existence, the fact that we are born, educated, employed, retire and even die within the confines of organisational activity, confers on them existential validity. The universality of organisational existence, then, is taken as a given.

To return, Ingarden accepts that music does in fact exist, but presses the point about the nature of that existence by questioning how it exists. In 
response to this question, Ingarden explores what lies at the foundation of musical phenomena. Following Ingarden's lead in linking all cultural products under the one question, in what follows I use the same notions to discover the ontic base of organisational existence. In making this connection, Ingarden writes:

The fact that a musical work is a cultural product does not settle the question of its ontic status, for of course the question is wider than this and not confined to musical works. It includes all cultural products and not necessarily just artistic ones: here belong products of the social life those of the economy (e.g., currency), political life (e.g., state institutions), those of intellectual life (all products of scientific investigations).

$$
\text { (Ingarden, 1986, p. 57) }
$$

Here Ingarden signals the necessity to investigate the ontic nature of all forms of cultural expression. Whether we consider a work of art, a manufacturing plant or a service industry, they are all works of human creation and can, therefore, be examined under the aesthetic spotlight. So, the limitations of the functionalist definition that sees organisations as bounded, legal entities which exist for the purpose of creating and distributing goods and services (Inkson \& Kolb, 2002, p. 7) are mitigated by the aesthetic view that seeks to locate the existential elements of organisations. 
Recent steps in this direction include those taken by Cook and Yanow (1993) who, although they resist seeing them anthropomorphically, claim that as entities organisations are capable of learning. Further, they argue that a firm develops a definite culture from the collective activity of its members and that this culture is distinct from the sum of its members. They extend this idea by claiming that knowledge resides within an organisation itself, and is transferred, often tacitly, to new members. Action research models also make this assumption, namely that collective learning can develop as individuals reflect on their behaviour (Dickens \& Watkins, 1999; Isaacs, 1999; Torbert et al., 2004, p. 121).

Confirming this view, Nace (2003) introduces an historical analysis of the rise of corporate power by discussing the development of his home-based publishing business into a corporation. He writes of a small firm, of which he had control, transmogrifying into a larger more 'sophisticated, complex, adaptive, continually evolving system - a sort of mindless, yet intelligent being - governed by an array of internal and external programming' (Nace, 2003, p. 8, emphasis added). His deliberate use of the biological metaphor accounts for the enduring adaptability of modern corporations. They exist, says Nace, as 'robust-capable' bodies that 
'survive' and 'adapt to' changing environmental conditions (Nace, 2003, p. 226).

Taking an aesthetic approach, Strati, too, concurs with this assessment (Strati, 2002). By adopting the hypertext metaphor, he notes that organisations are able to adapt known ways of existing in response to the dynamic and fluid environments within which they exist.

These descriptors strengthen the case for seeing organisations as more than a heterogeneous gathering of people around a common cause. They move us towards seeing them as unique, albeit symbolic entities, which can be examined like other animate or inanimate bodies.

As a symbolic art form, music offers aesthetic insights that can link into organisational behaviour. The task here is to map the elements of which music as an art form consists, and then to use that structure to discover the existential elements of an organisation's foundations. In line with this, therefore, I will examine the idea of organisation as a cultural product similar to other human forms of identity-making, like music. How, though can this link be made? 


\section{Music and Conducting Organisational Research}

The organisational research epistemology that I propose attends to aesthetics grounded in immediate sensate response and traditional artsbased aesthetics. Hence the polarity between the logic of sensation and the intellectual engagement with art can be bridged and a 'unity within this divergence' (Deleuze, 1990/2001, p. 260) can be achieved as the aesthetic researcher works with the musicological and performance traditions. So to conduct organisational research using an aesthetic approach, both the lived experience of organisational actors and the cognitive engagement with the symbolic inform each other. This enables a shift away from seeing aesthetics as either 'affectively based [and] too irrational' (Bergson, 1935; Singer, 2003, p. 3) or 'cerebral' and thereby 'profoundly ascetic' (Willis, 1990, pp. 16 \& 17). How, though does this work in practice?

Ingarden's discussion on the ontic nature of music offers insights into where the parallels with organisational research occur. These facets further strengthen the notion of interplay between elements rather than fixed positions, and translate from music into organisational life. They are: interacting with the parts and the whole; understanding time and 
space; and working with non-sounding elements. I will examine each of these issues in turn showing their importance to aesthetic research.

\section{Interacting with the Parts and the Whole}

In order to explain the ephemeral nature of music, scholars tend to break the art form down into a number of elements where concepts of rhythm, melody, harmony, texture and dynamic can all be isolated for the purpose of analysis. Ingarden, however, aptly states that treating these rudiments in isolation does not represent music as an art form. Rather, when we listen to, or perform music, the result is 'an organic connection (that is, flowing from the essence of these elements) binding them into a totality of a single work' (Ingarden, 1986, p. 50).

According to Ingarden, this flies in the face of the positivist tendency for atomisation and reduction. In his view, we engage with music's fluidity and attend to the way in which the elements interact with each other. In order to perceive the gestalt in music, Ingarden separates the 'auditory object' (the individual sounds and musical lines) from the 'auditory aspect' (the listener's experience of the musical work as a whole) (Ingarden, 1986, 
p. 12, emphasis added). In attending to the auditory aspect, our emotional response is to the whole rather than to the separate elements.

When listening to music, we focus on the entire structure rather than the specific beats, notes, or chords. Individual tones that occur within a melody, or that make up part of a chord, only make sense within their context of the larger whole. Hence, whether the pitch of a note is defined as either the tonic or leading tone depends entirely on its relationship to the overall design of a piece (Köhler, 1947, p. 121).

A further element that Ingarden investigates is the relationship of the written score to the musical work. He categorically declares that the score in itself does not constitute the music. Rather, it is a symbolic representation full of gaps or 'areas of indeterminateness which can be removed only in performance' (Ingarden, 1986, p. 116). He concedes that, yes, the score may form the ontic base of a musical work, but it requires a 'subjective conscious operation' (Ingarden, 1986, p. 36) of a performance for it to have any meaning. A piece of music's identity may therefore include the written score but must be perceived as a whole within performance for the perceiver to derive any meaning from it. 
Similarly, as a dynamic culture, an organisation is created through the individual parts interacting as a totality. In order to discover the organisation's ontic identity, the researcher examines the relationships of the parts with each other, observing their interplay. Furthermore, although an organisation's visible symbols such as its reports to stakeholders, mission statements and management charts may provide some kind of foundation for its existence (McPhee, 2004, p. 361), these elements are not the organisation. Rather, its existence is determined by performance in space and time.

\section{Space and Time}

In relation to space, the important issue to resolve is determining whether, or how much, the space within which events occur determines the identity of the form, whether that be artistic or organisational. Ingarden claims that the space in which music is performed has no bearing on the ontic identity of the music itself. But he also argues that although this identity does not change relative to its performance space, nonetheless aesthetic engagement with the music may vary according to that space. 
A musical work is 'ontologically secure' in terms of its identity in spite of the space within which it is performed, and yet that same space makes it possible for the performance to take on a unique and fluid identity. Space, of necessity, must be secondary because if a work is only a 'here-and-now aesthetic phenomenon' (Ingarden, 1986, p. 19) it would have no meaning for listeners who rely on generic form to anchor their perceptions.

However, space may affect our spontaneous engagement with an artwork, even though the work itself does not change. When attending a performance, the listener ignores some elements of the space in which the music is performed, whether that be a dedicated concert hall, an outdoor site or an adapted space, because they are not essential to the music's existence (Ingarden, 1986). And yet because of acoustic variations, that same space may alter particular elements in the performer's execution and the audience's reception of the work, thereby adding to the uniqueness of each performance.

What Ingarden's view implies is that space is heterogeneous and that within a live context there are differences in the ways performers and readers constitute space. Similarly, while organisations may be identified 
with a particular space like a building or website, the physical location itself does not constitute the enterprise. Space is therefore 'processual, constituted ... in practice temporally contingent in open-ended multiple flows' (Crouch, 2003, p. 1946). This makes life difficult for organisational theorists who wish to align space with identity. In what way, then, does space and its use constitute the unique character of an enterprise?

The transitory nature of space causes Dewsbury to ask how the researcher might develop theoretical concepts that 'have the potential for making coherent grasps of the world's theatre of multiplicities' (Dewsbury, 2003, p. 1912). He suggests a solution based on the separation of existential being and the execution of specific tasks. Dewsbury notes that human being occurs before space is constituted in the acts of human endeavour, but that it is human doing that constitutes community which is bounded in space. He eloquently notes that the coincidence of human being and doing creates 'the moment where world and individual, folded together, call each other into existence' (Dewsbury, 2003, p. 1910).

The aesthetician then asks, what are the behaviours being exhibited and what is the relationship between actions and space within which they take 
place? Furthermore, what is the effect of the constituted space on the life experiences of the organisational actors?

These questions are further extended with the notion of time. Ingarden's discussions reveal that time can be perceived as a totality, backwards as well as forwards. To explain this sense of heterogeneity, Ingarden thinks of a musical moment being performed in the present as having both a 'backward reflex' (Ingarden, 1986, p. 72) and a 'future' (Ingarden, 1986, p. 77).

By backward reflexivity, Ingarden means that we make sense of musical phrases in retrospect. Thus, when we listen to a passage 'a modification of the preceding phrase [occurs] in the light of the one that succeeds' (Ingarden, 1986, p. 72). As the term reflex implies, the listener thinks backwards not by way of deliberate intention but rather as a spontaneous response. The listener is, therefore, continually referring back to previous phrases in order to make fuller sense of the expressed present. In this way, the identity of music is codetermined by the past and the present. 
However, while continually referring to what has happened before, the listener is also anticipating the future development of the work. For instance, new harmonic directions are implied by an individual chord such as the addition of a minor 7th to a major triad, creating the expectation of either a harmonic transition or change to another key centre.

Present sounds, therefore, rely both on the experienced past and on the anticipated future. Further, Ingarden theorises that the greater our ability to listen retrospectively while at the same time expecting the future, the more we will make sense of an entire piece of music. He employs the term codetermination to explain his thesis.

The deeper this mutual codetermination, the wider its base in the neighboring phases: the more cohesive the structure of the work or its particular section.

(Ingarden, 1986, p. 73)

In this way, Ingarden claims that understanding musical time is a 'motley qualitative continuum' (Ingarden, 1986, p. 63). Hence musical meaning is derived from attending to present sound and to the deeper structures that provide the context for those sounds. 
Similarly, for Bergson, it is not the quantitative succession of notes that we attend to; rather we engage qualitatively with a melody as an entirety.

Therefore, each individual note within a tune suggests the entire melody.

We can thus conceive of succession without distinction, and think of it as a mutual penetration, an interconnexion and organization of elements, each one of which represents the whole, and cannot be distinguished or isolated from it except by abstract thought.

(Bergson, 1910/1971, p. 100)

According to Bergson, music offers us insights into the way we place ideas side-by-side and perceive them simultaneously (Bergson, 1910/1971, p. 101). Karl Weick's groundbreaking work on sensemaking also works with this idea of backward reflexivity. For Weick an important element in the process is to look back retrospectively on behaviour and synthesise meaning from numerous experiences (Weick, 1995, p. 27). Thus he claims that:

Sensemaking never starts. The reason it never starts is that pure duration never stops. People are always in the middle of things, which become things, only when those same people focus on the past from some point beyond it.

(Weick, 1995, p. 43, emphasis added)

However, Ingarden's musical aesthetic is an expansion of this idea in his notion of anticipation. How can the future be anticipated? While Weick 
implies that activities have a future as well as a past because we are continually in the 'middle' of something, this sense of future possibility does not provide us with the tools of prognostication.

Albert and Bell (2002) toy with the idea of prediction in their case study of the Branch Davidian cult's tragic demise in Waco Texas in April 1993. They postulate that an awareness of musical rhythmic structures may have helped predict cult leader David Koresh's behaviour and may have, helped avoid the disastrous consequences of that behaviour. My colleagues and I critiqued this analysis by noting that awareness of musical harmony and in particular cadence points could provide a better means of analysis (Barry, Bathurst, \& Williams, 2003). Underpinning our assessment was that both an awareness of the past and an anticipation of the future are aesthetically, not rationally, determined. In our rejoinder we posit that cadences come in different guises and that distinguishing between a full close and interrupted cadence, in the case of Waco, would have enabled the FBI to take alternative and less drastic action. In our response we reiterate the question that Albert and Bell consider, which is also at the heart of managerial anxiety (Weick, 1979, p. 43) namely, when is an appropriate time to act? 
The reader, although apprised of the problem of timing, is probably no further ahead with a solution. My position is that music cannot help us predict the future. The aesthetics lens is simply that: a way of looking. It provides a basis for understanding the world as we find it, and assures us that there is a future, albeit an indeterminate one.

Ingarden offers a way forward in this debate. He notes that in performance a piece of music is marked by 'an internal, immanent, quasitemporal structure' (Ingarden, 1986, p. 65) meaning that it occurs within an immediate temporal context. However, music is also supratemporal. By this Ingarden means that music exists as a temporal phenomenon outside linear time. Therefore, the notion of supratemporality makes the idea of prediction a flawed enterprise. In other words, organisations exist within their own time zones that may or may not relate to wider notions of time. This is where Albert and Bell go awry. They assume homogeneous time (not realising that the Cult and FBI both operated according to their own supratemporality), and then attempt to harmonise the two. 
Having then canvassed notions of space and time, what about the hidden elements? The third area of investigation that Ingarden explores in terms of music's identity is its non-sounding elements.

\section{Non-sounding Elements}

Throughout the discussion so far, it has been assumed that music has something to do with organising sound into a beautiful form.

Introductory music texts also begin with this assumption (Berstein \& Picker, 1966, p. 1; Holst, 1967, p. 1). It is curious, then, that Ingarden considers non-sounding elements as contributing to an aesthetic of music.

Along with the sounding elements previously noted, such as melody, rhythm, harmony and texture, Ingarden claims that there are nonsounding components that are hidden, but essential to music's identity. Beginning with temporality, which I have previously investigated, Ingarden adds other features which can be summarised as form, emotion and content.

Form is the underlying structure of a piece of music, an abstraction that can be replicated in multiple works (Ingarden, 1986, p. 95). Forms of 
music range from simple binary or ternary structures to the more complex fugal and sonata forms.

Among these, the predominant form, especially since the 18th century turn to classical ideals of balance, symmetry and logic, has been sonata form. (This is not to be confused with the Sonata, which is usually a fourmovement work performed by an instrument.) Whatever the musical idiom - Sonatas, Concerti, Overtures or Symphonies - sonata form was a primary structural device used by composers.

Although it seems oxymoronic, sonata form has a binary-ternary shape. It has two major sections, namely the beginning Exposition, where generally two themes are stated, and a concluding Recapitulation where these themes are restated. What sets sonata form apart, however, is a middle section between the Exposition and Recapitulation known as the Development. Although this middle section is marked by thematic (melodic) development, of more importance are the harmonic twists and turns it contains. Tonal dissonance is pushed to a point where any sense of home is lost to the listener. The listener is rescued from the feeling of 
collapse and disorientation by the Recapitulation - a return to the main themes and of more significance, a return to the home (tonic) key.

Figure 4.2: A Synthesised Plan of Sonata Form shows the progression between the three sections. The melodic themes are indicated with the $\dot{\alpha}$ and $\beta$ nomenclatures. Below these are numbers in Roman numerals I and $\mathrm{V}$ and, following musicological convention, these numbers represent harmonic relationships and give meaning to the structure. There are no such numbers in the Development section because this is marked by the collapse of tonality.

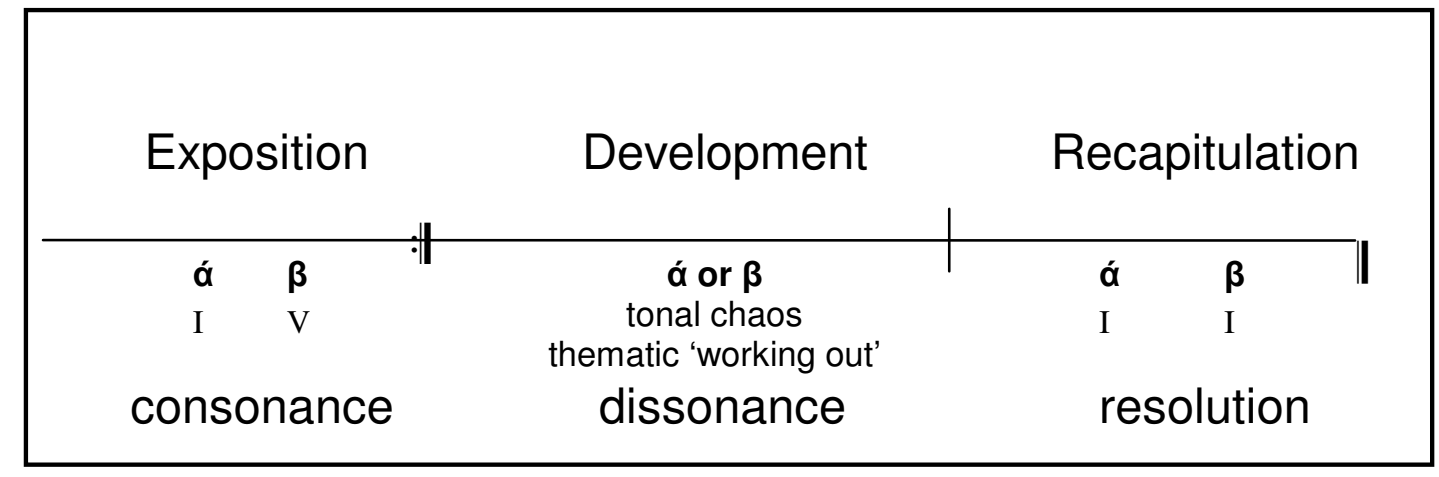

Figure 4.2: A Synthesised Plan of Sonata Form

Inherently sonata form is contradictory. It offers both the stability of symmetry but also harmonic unpredictability. The Development section is 'a passage of great tension' (Webster, 2001, p. 692) and pushes tonality 
to the edge of chaos while at the same time offering the hope of return to that which is known and familiar.

The enduring quality of sonata form is not only attested to by its survival through the Romantic period and into the 20th century, but also in its currency as a contemporary consulting tool. Miha Pogačnik, an internationally renowned concert violinist, employs works from the classical repertoire, and in particular expressions of sonata form, in his consultancy among business leaders. He makes links between musical and organisational development with the aim that through engagement with these works, participants will come face-to-face with 'stories about transformation and development' (Bjerring, 2004, p. 2).

An understanding of the aesthetics of form can, therefore, provide a way of articulating sensate experiences, which, in turn, can speak about larger sociological concerns. Awareness of musical structure not only enhances cognitions of time and space but also addresses deeper metaphysical issues. The collapse of tonality in the sonata form's Development section goes beyond the symmetry and rationality established in the two outer sections by extending into non-rational elements. Therefore sonata form, 
'bring[s] into play contrasted and even opposed ideas' (Davie, 1965, p. 61) thereby revealing something of the human journey that traverses periods of instability, collapse and psychic darkness, to the discovery of a renewed sense of stability. Furthermore, it is in this that the relationship between music as a symbolic art form and organisations as human creations can be explored, for the ineffable and tacit may be teased out through an understanding of musical knowledge.

This raises a problem of describing the indescribable - if music addresses issues hidden beneath the surface of the human psyche, how can these be explored? A solution to this can be found in the relationship link between design conventions and the existential meaning that lies beneath them, a link made through emotional response.

A further non-sounding element that all music carries, Ingarden claims, is emotion (Ingarden, 1986, p. 98). Here, though, the notion of emotion is more complex than the Baroque doctrine of affections (Harman, Mellers, \& Milner, 1971, p. 439), where a particular key designated an emotional response. Rather, emotion here refers to sensate responses deep within the human psyche. Therefore, building on an awareness of form that 
brings into sharp relief the 'architectonic side of beauty in music' (Hanslick, 1968, p. 173), a structural recognition also helps listeners and performers connect sensate experiences with the symbolic. It is the language of symbol that enables music to speak, thereby facilitating its translation across the musical boundary into organisational life. Hence beyond the aesthetic of form, music provides for an engagement with life outside itself.

While attending to the formal design is an intellectual activity, the sensate experience of music also offers a language which connects formal structures with 'a more complete abstraction of the sensory aspects of our encounters with the world' (Witkin, 1974, p. 42). This abstraction should not be seen as merely an alternative language. For, as Sharpe notes, paradoxically 'music says nothing but its manner of saying it speaks volumes' (Sharpe, 2000, p. 74). What, though, is the nature of that language?

Susanne Langer does not think this to be a language of specific feelings; rather, she considers music as language of symbol that expresses deeper 
emotional patterns of tensions and resolutions. In making this association between life experiences and the symbolic, Langer notes that,

there are certain aspects of the so-called 'inner life' - physical or mental - which have formal properties similar to those of music - patterns of motion and rest, of tension and release, of agreement and disagreement, preparation, fulfilment, excitation, sudden change, etc.

(Langer, 1942/1960, p. 228)

We should not make the mistake, according to Langer, of assuming that musical forms and symbols correspond directly to definitive language. She argues that 'music articulates forms which language cannot set forth' (Langer, 1942/1960, p. 233). The interface, therefore, between music and human experience is the way in which it unlocks the meaning of ineffable experience. Langer concludes that 'because the forms of human feeling are much more congruent with musical forms than with the forms of language, music can reveal the nature of feelings with a detail and truth that language cannot approach' (Langer, 1942/1960, p. 235).

Therefore, while emotional responses are idiosyncratic and not quantifiable, they are nonetheless present. Although emotional language is not embedded in music, paradoxically music elicits emotional 
responses. For instance, sadness is not stated in the use of a minor key but may trigger sadness on the listener's part (Carr, 2004, p. 233).

The third non-sounding element is the extra-musical stories that lie beneath a work. This notion of content brings with it elements of story as well as the degree of complexity of a work (Ingarden, 1986, pp. $105 \& 113$ ).

Story as an organising component in music embraces large ideas such as programmatic narratives and even titles of works down to smaller elements such as leitmotifs that are associated with characters or events outside the music. These narrative elements have an organising quality and include works like Vivaldi's Four Seasons (1725), which is a set of four concerti each given as a title the name of one of the four seasons. Some individual movements also contain titles such as 'Summer storm' and 'Sleeping drunkards'. Beethoven's Symphony No. 6 in F Op 68 Pastoral (1808) is organised in a similar fashion, with each movement having a title. For example, the first movement Allegro has the subtitle 'The cheerful impressions excited by arriving in the country'. Berlioz's Symphonie Fantastique Op 14 (1830) is a fully-fledged autobiographical narrative that tells of the fortunes of a young artist. For each of these examples the titles 
and narratives exist alongside the formal musical structures employed by the composers.

The notion of content embraces a whole raft of organisational narratives beyond the officially sanctioned ones. The researcher's task is 'deciphering and overturning the master cultural narratives that convey subtexts of dominant meanings that lay beneath the primary ones' (Thomas, 1993, p. 24). Artefacts too, such as organisational timelines, contain inherent narratives that help bring certainty in the midst of unpredictability (Yakura, 2002, p. 959).

Roland Barthes also makes this point in his use of the metaphor of a woven fabric to describe the plurality of a text. Texts, such as organisations, cannot be reduced to a single monodic reading or even several parallel readings but rather are inter-textual, representing a 'stereographic plurality of its weave of signifiers' (Barthes, 1977b, p. 159, emphasis in the original). Hence an array of stories, some tacitly known, may exist within organisations, and they may interact polyphonically with one another. 
In summary, the ontic foundations of organisations include both the 'sounding' components of evident phenomena, and also less explicit and 'non-sounding' elements. Attending to underlying structures - the ways in which emotions are expressed - and narrative elements that are not part of the official organisational story becomes part of the inquirer's task.

\section{Aesthetic Inquiry}

I began this chapter by reframing Karl Weick's sporting solution to the problem of temporality with an aesthetic approach. I have explored the ontic and ontological dimensions of organisational life and I have proposed that musical aesthetics differs from sport in both the intentionality of the artist and the concretisation by the audience. Musical aesthetics offers ways of approaching research that attend to particular dimensions of identity by questioning the nature of organisational existence and posing that organisations are similar to musical texts and possess all the attendant symbolic elements of text. In particular, I argued that an organisation's symbolic being can be examined by seeing the parts within the whole; examining its time-space dimensions; and being aware of its non-sounding elements of form, emotion and content. 
In taking this line I suggest that the research process involves an active interplay between the real and ideal. In Figure 4.1: The Continuous Interplay between the Real and the Ideal, I showed this interaction by using two rotating semicircular arrows. By integrating notions of text, the symbolic dimension can now be added to the diagram, where text is viewed as being both ideal and real, and in which both poles are embraced. In Figure 4.3: The Symbolic Interface between the Real and the Ideal, text is placed at the centre of the diagram and although the real and the ideal are separated, this barrier is shown by means of a dotted line, to be permeable. The symbolic representation of text is real and ideal, straddling both, allowing the idiosyncratic and generic to inform each other. 


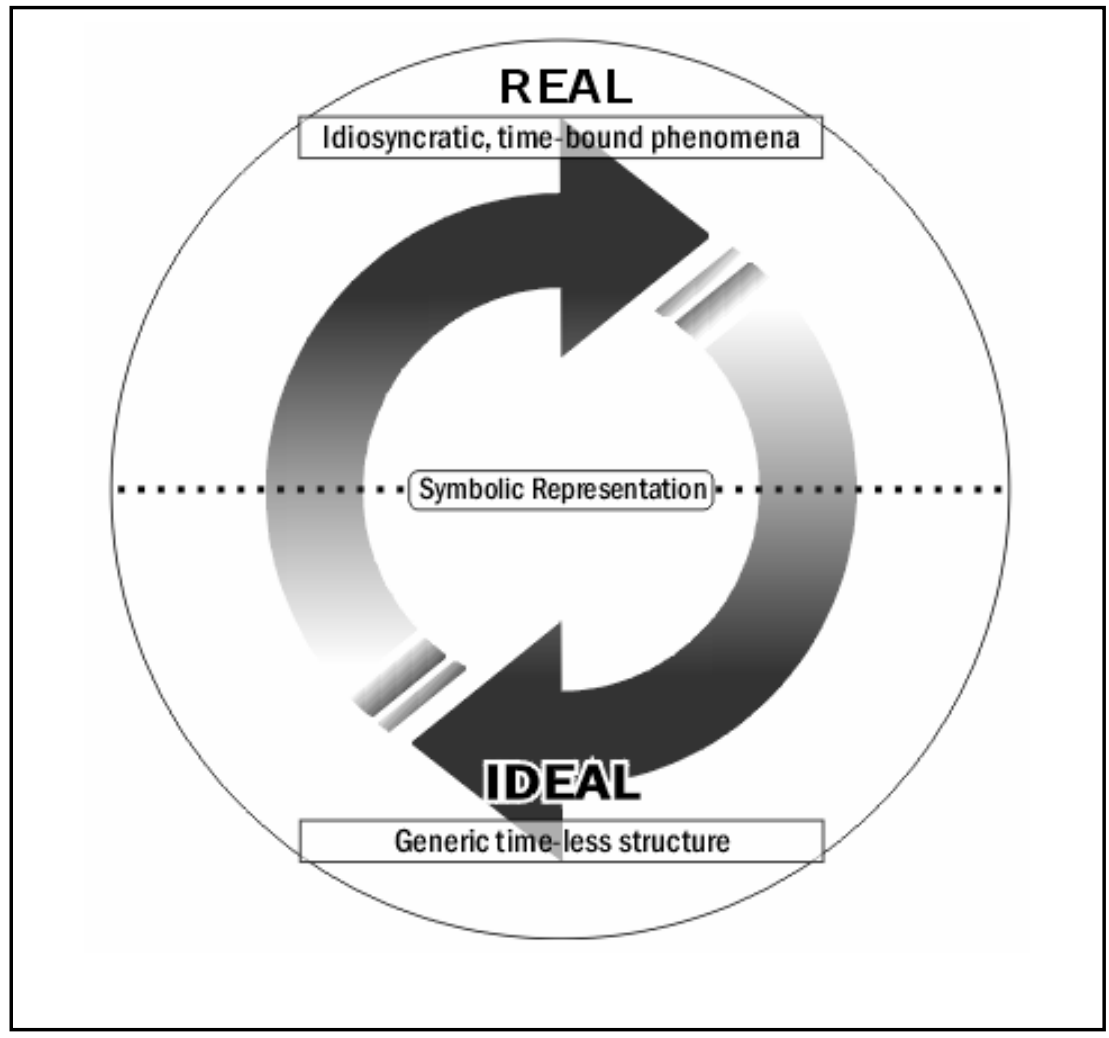

Figure 4.3: The Symbolic Interface between the Real and the Ideal

In the next chapter I explore these ideas further by investigating the

relationship between the researcher and the researched through aesthetic ethnography. Here I will suggest that this is akin to the relationship between the artist and perceiver. In doing this I will identify and discuss two key factors that the researcher needs to consider when using the aesthetic lens. These two elements include the way an artist intentionally presences the work of art and the other is the response of the perceiver in concretising it. The two processes of presencing and concretising will form the basis of a discussion on organisational research practice. 


\section{CHAPTER 5 OVERCOMING MUTENESS: MAKING THE HIDDEN KNOWABLE}

- The Problem of Muteness

- Aesthetic Ethnography

- The Research Site

- Symbol and Perception

- Organisational Identity: Presencing and Intentionality 


\section{The Problem of Muteness}

Because organisational aesthetics is only in its formative years, there is a dearth of works that make up a substantial canon to act as methodological guides. Perhaps this paucity of literature is the result of the complex nature of this kind of inquiry which revolves around the senses. Virginia Postrel has coined the term 'prearticulate' (Postrel, 2003, p. 6) to account for this state. Postrel's implication in using this term is that intuitive, sensate responses are so innate and immediate, that people are unable to verbalise them coherently. The task, then, of eliciting responses at this ephemeral and tacit level, is daunting to researchers.

For Steve Taylor (2002), this difficulty people have of talking about their sensations is akin to their being aesthetically mute. He isolates the problem as 'a preference for thinking over feeling' (Taylor, 2002, p. 823) and argues that because of the traditional research focus on instrumental rationality, when research subjects are asked direct questions about their feelings, they are unable to translate these into thoughts and then ultimately into words. Muteness, though, does not indicate an inability to respond aesthetically, but instead signals a lack of language with which to 
articulate perceptions. The task confronting the aesthetic researcher is to seek ways in which individuals can access and talk about their experiences and to devise research methods that enable organisations to give up their secrets.

How might researchers deal with the difficulty of muteness? In this chapter I offer a solution by proposing an ethnographic approach. I suggest an aesthetic ethnography that focuses on the temporal world of the enterprise and seeks to locate the symbolic within the daily experiences of organisational actors. By enlarging the claim that organisations are cultural products that can be engaged with like any other work of art, I focus on how organisations are presenced as living phenomena. Further, because aesthetic research works at the precognitive level (see, for instance, Baumgarten's gnoseologia inferior and Vico's immaginazione of Chapter 2) aesthetic ethnography relies on the researcher's ability to tease out subjective perceptions from respondents. This requires the researcher to develop an empathetic relationship with subjects and to create a suitable context to turn their muteness into unbridled expression. 
Aesthetic inquiry begins within that which is immediately evident and draws conclusions based primarily on these received phenomena. In light of this, it is not surprising that the published research in organisational aesthetics springs from qualitative paradigms, adapting and adopting existing methods. For example, David Barry explores art-based symbolism through an analogical constructivist approach (Barry, 1996); Steve Taylor uses action research as a way of reflecting on aesthetic experience (Taylor, 2004; Torbert et al., 2004); while Antonio Strati champions social constructionism as his preferred epistemology (Strati, 1999b, p. 188).

However, much still needs to be done to avoid the trap of seeming to be irrational and idiosyncratic and, therefore, irrelevant to the academy. These accusations can be summarised in Alan Singer's (2003) repositioning of literary aesthetic criticism as a rational activity. He notes that,

the current presumption [is] that the aesthetic, in its complicity with class-based ideologies of distinction, its political disinterestedness, and its irrationalist, sensuous decadence, can no longer serve the socially responsible purposes of literary study.

(Singer, 2003, p. 2) 
To avoid this charge being applied to the organisational aesthetic community, significant gains have been made in systematising methods and encouraging political activism. Hence a growing array of practitioner activities have been spawned that deploy art-based means of exploring organisational dynamics and change programmes, as well as providing tools for personal reflection. Drama (Taylor, 2003), model making (Barry, 1994), dance (Picart \& Gergen, 2004), photography (Boje, 2003), and music (Nierenberg, 2003) have all been used as means of investigating constructions of the Self in relation to Other, both individually and within organisational and wider political life. In all these, the challenge has been to propose research practices that uphold standards of rigour and rationality and yet retain the integrity of the ephemeral nature of aesthetic response.

In this regard, Pasquale Gagliardi (1996) notes that aesthetic reception occurs both in situ by embracing the physicality of the organisation including its artefacts, architecture, and layout; and in visu, by attending to immediate perceptions as they occur. By beginning with these perceptions of phenomena, the researcher is able to be present to the site (Gagliardi, 1996, p. 372). However, Gagliardi also goes beyond the 
immediacy of these reactions by exploring aesthetics within a framework of the ancient Greek notions of logos, ethos and pathos. In particular, the third emotional element of pathos allows for explorations of the ineffable and holistic rather than just the lineal and logical dimension of abstract logos. Further, Gagliardi notes that:

The more the pathos is distinctive and idiosyncratic, the more it constitutes a special bond between members and can turn into an extraordinary resource for coordination.

(Gagliardi, 1996, p. 573)

So, for Gagliardi, it is the emotional element that forms the backdrop for organisational aesthetics. This, though, raises further questions as to how emotionality is expressed, especially between organisational actors and the researcher.

Antonio Strati and Pierre Guillet de Monthoux offer a schema that explores this conundrum (Strati, 1999b; Strati \& Guillet de Monthoux, 2002). They propose ways of going beyond logic and linearity by suggesting three areas of research methodology to assist in discovering how aesthetic understandings inform organisational research. The first is an 'archaeological' approach (Strati, 1999b, p. 189), where the researcher examines all the organisation's artefacts, both permanent and ephemeral, 
and seeks to discover wider meanings in these symbols. A second way, the empathic-logical, sees the researcher becoming fully immersed in the life of the organisation and seeking to discover a language to describe phenomena. The end product is a report crafted using 'logico-analytical methods' (Strati, 1999b, p. 190) with minimal embellishment.

The third method Strati terms the empathic-aesthetic approach. Here the researcher fully immerses him- or herself in the life of the organisation, integrating his or her own past experiences with current observations. He or she then 'write[s] an open text which describes the active process of reconstructing lived experience and re-evokes this experience according to the aesthetic canons of writing which govern the architecture of the arguments developed' (Strati, 1999b, p. 190, emphasis in the original). This focus on empathy highlights the relationship between the researcher and the researched. To be empathetic and to construct an 'open text' necessitates a sharing of feelings between two parties, a position that flies in the face of the researcher objectivity that is inherent in Kant's notion of disinterested interest (Kant, 1790/2000, p. 48). 
The aesthetician is required to understand and work with this subjectiveobjective dichotomy and the developing and dynamic relationship within the research setting, and the resulting textual construction can best be explored in the parallel context of the relationship between the creative artist and art appreciator. Nietzsche, in his critique of Kant, claimed that Kant's notion of disinterestedness looks at art only from the perceiver's point of view, and not from the artist's. Nietzsche writes:

Kant, like all philosophers, just considered art and beauty from the position of 'spectator', instead of viewing the aesthetic problem through the experiences of the artist (the creator), and thus inadvertently introduced the 'spectator' himself into the concept 'beautiful'.

(Nietzsche, 1887/1994, p. 78)

The effect of this is to dull the emotions and, according to Nietzsche, 'castrate the intellect' (Nietzsche, 1887/1956, p. 256, emphasis added).

This idea of disinterestedness is based on the discomfort that philosophers - 'from India to England' (Nietzsche, 1887/1994, p. 81) - have with sensual experience. Nietzsche takes a different view. For him, aesthetic experience brings with it the promise of happiness - 'une promesse de bonheur' (Nietzsche, 1887/1994, p. 81) - a state that relies primarily on sensate rather than intellectual responses. Therefore, for Nietzsche, 
aesthetic engagement is by definition interested. In agreement with this, Monotti states:

There is never really a disinterested subject, or if there is, there will always be as many subjects that are somehow interested, and therefore the objectivity of a pure judgement of taste is always an abstraction too far removed from reality itself to be in any way helpful.

(Monotti, 2002, p. 8, emphasis in the original)

This notion of interestedness has considerable implications to research practice. While in stepping aside and acting as a disinterested perceiver, the researcher is able to act as critic (Jackson, 2001, p. 62), the empathic approach could potentially compromise the researcher's objectivity, thereby making theoretical claims invalid. So implied in the critiques of disinterestedness is the status of the researcher who may be become a coproducer of meaning rather than just an objective perceiver. Instead of avoiding this problem, aesthetic researchers seek for ways to explore constructions of both the researched Other and the researcher Self. It is this relationship between the researcher and researched that is central to aesthetic ethnography. 


\section{Aesthetic Ethnography}

As a method, aesthetic ethnography embraces traditional ethnographic approaches and within this framework seeks for particularly artistic processes to conduct research. Although, typically, ethnography is the domain of anthropologists, this method has been adopted by social scientists in a variety of disciplines from public relations, politics, and culture, through to market research (Culyba, Heimer, \& Petty, 2004; Kondo, 1990, 1997; Kunda, 1992). It is a useful tool for organisational analysts as it assists the researcher to penetrate beyond surface rhetoric, into the heart of the organisation itself. It may also provide a springboard to extend past mere naturalistic inquiry and ethnographic reporting, to more critical elements, enabling the researcher to 'make broad theoretical statements' (Casey, 1995, p. 5). Therefore, as a discipline, ethnography seeks to codify and describe the behaviours of social groups and link 'micro-level, interactional processes with macro-level structures' (Schwartzman, 1993, p. 4).

Ethnography draws on the anthropological strategy of producing field notes which record incidents, exchanges and developments as they occur, 
and which are regularly written whilst in the field. Over time these notes form the basis for the researcher's published reflections. Much of the ethnographer's task, therefore, focuses on matching writing strategies with the intended audience (Van Maanen, 1987). Thus when constructing the findings, the ethnographer considers three elements: data collection, writing strategies and audience reception (Worden, 1998, p. 23).

Recent developments in ethnographic method, though, have questioned its viability as a research tool. In spite of the plethora of ethnographic approaches appearing in sociology, qualitative methods are nonetheless still considered marginal by some sectors of the academic community (Barley, 2006, p. 19; Culyba et al., 2004, p. 375). Some of the areas of current concern revolve around the unscientific nature of qualitative methods and, more particularly, the relationship between the researcher and researched discussed in the previous section. How biases are expressed and explored, the inevitable empathy the researcher develops for the subjects, and the degree to which the researcher's personal experience can skew findings, all compound to give cause for concern by a positivist view that still holds sway in some parts of the academy (Culyba et al., 2004, p. 381). As a result, ethnography is often used alongside 
quantified data analysis and is included to strengthen these findings rather than as a discrete method with its own integrity.

Contradictorily, two other developments have tightened ethnography's focus as a more rigorous method and these developments represent contemporary attempts to make ethnography a more relevant tool and to sharpen its application. The first of these is critical ethnography, a name not to be confused with the school of critical theory out of Frankfurt. Rather, 'critical ethnography is conventional ethnography with a political purpose' (Thomas, 1993, p. 4). It might be better described as activist ethnography, which stands as a polar opposite to a quietest approach where the ethnographer simply describes what he or she sees. Critical ethnography seeks for systemic change and makes no apologies for its social and organisational critique.

The other element is grounded ethnography. This method grew out of research into the musical tastes and social habits of young people and its interest is in the sensations and perceptions of the research subjects (Willis, 1990). It is primarily an aesthetic method, but eschews the ascetic approach of traditional aesthetics. Rather, it relies on the active 
involvement and willing disclosure of the subjects' gut reactions, and as Willis describes metaphorically, it is an 'aesthetics of informal cultural practices [which] put sensuous human activity at the heart of things in the multiple performances of consumption rather than fixed performance of a score' (Willis, 2000, p. 79). Grounded ethnography is, therefore, a method that is comfortable with fluidity and continually changing perspectives.

Aestheticians have gone beyond these developments and further strengthened the field by producing ethnographies in more artistic ways, including poetry, film and dramatic performance (Jones, 1998; Linstead, 1999a; Picart \& Gergen, 2004). Because these are oriented towards live settings and involve the audience emotionally, they are able to achieve the social critique of critical ethnography as well as the sensuous engagement of the subjects in the grounded approach. However, these leave unexamined two issues explored by Finley (2003); namely, the researcher's status as an expert, and the contradictions inherent in political critique.

Regarding the problem of the researcher as an expert, Elliot Eisner argues that ethnographers necessarily need a degree of expertise in the area they are researching. For instance, if research is in an arts-based field, then 
knowledge of that art form is important in order to nuance elements that are hidden to outsiders (Eisner, 1997). However, if the researcher displays expertise, this can also inhibit the freedom of the research subjects. Or, as Lofland and Lofland argue, 'the investigator who assumes the role of socially acceptable incompetent is likely to be accepted' (Lofland \& Lofland, 1995, p. 56, emphasis in the original). Thus, the ethnographer walks a tightrope by being expert enough in the field in order to recognise and assess the importance of events as they happen but at the same time displaying sufficient incompetence so that the subject is privileged.

Similarly, political action is problematic. While critical ethnography may provide a critique that is transformative, it may also inhibit the very change it promotes, because it may alienate the ethnographer from the people who continue to work in the enterprise once the research has been completed. Consequently activism may prevent rather than promote the desired outcome of community building (Finley, 2003, p. 287).

Aesthetic ethnography seeks to overcome these difficulties by focusing on the developing sensations and perceptions of the subjects (grounded ethnography) along with a critique of organisational functioning (critical 
ethnography). Where aesthetic ethnography differs from the critical and grounded approaches, then, is in its ability to take the organisation as a whole and allow critique to grow from the relationship between the ethnographer and the organisational actors. In this way the integrity of the enterprise is preserved, offering insights from within the organisation. Beyond these features, where aesthetic ethnography adds to the field is both in its temporal approach and in its ability to hold in a dynamic tension the relationship between the researched and researcher.

These latter issues are two important considerations. Firstly, the notion of temporality is foundational because it acknowledges backward reflexivity, allowing the ethnographer to shuttle between the present and past. Previous experiences can be revisited in the light of new encounters, thereby continually enriching the picture. Secondly this awareness of temporality helps the researcher explore his or her changing levels of emotional attachment and monitor the state of relationships with the many people within the site. In the next chapter this will be discussed in more detail, but to summarise here, I propose three movements that explore these dynamics by focusing on three core elements. The first is researcher-focused (Self), the second examines the responses of the 
subjects (Other), and the third seeks for communal description (We). Hence this kind of aesthetic inquiry not only seeks to understand the 'native view' (Hatch, 1997, p. 201), it also explores the researchers' perceptions and allows for critical engagement that promotes some kind of political outcome.

Observation and interviews are tools available to the ethnographer to discover the ways individual actors construct and make sense of their organisation. Hence 'their ways of experiencing and interpreting their world' (Hatch, 1997, p. 221) is the research focus. However, aesthetic ethnography goes beyond observation and reporting to developing a particularly empathic awareness (Strati, 1999b) that allows for interpretation and evaluation.

Aesthetic ethnography begins with the assertion that organisations are cultural products similar to other human creations (Dyck, Starke, Mischke, \& Mauws, 2005), whether they be works of art or other elements of social life (Ingarden, 1986, p. 57). This beginning opens up some key differences with traditional ethnography. The first difference is that aesthetic ethnography is as much about reading as writing; where the symbolic text 
of the organisation is analysed and described. The second difference is that the identity of the researcher and his or her developing understandings of the site are as important as the natives' view.

With this in mind, I now turn to discuss the research site for this study. I examine the life of a symphony orchestra, explorations which occurred during a time when the particular company was undergoing governance change.

\section{The Research Site}

As mentioned in the first chapter, my background is as an orchestral musician and music teacher. My undergraduate studies included musicology, music education and performance, which led to my first jobs as a secondary school music teacher and part-time orchestral viola player. My intention back then was to develop my knowledge of the orchestral repertoire and then take up further education as a conductor, with the view of embarking on a conducting career. Instead, life's twists and turns took me into the Christian ministry, while I maintained musical involvement in chamber music performance. Underpinning these life 
experiences is an abiding interest in organisations and the ways in which individuals relate to the systems within which they enact their work-life.

In undertaking this research, I was interested in how musical theory and performance inform organisational theory and practice, hoping to discover the translation of aesthetic ideas and ideals from the concert platform to the manager's desk. Prompts for this came from the intervening 20 years of work experiences.

The practice of leadership as a minister, working within established institutional traditions, gave an apt comparison to orchestral leadership. Both churches and orchestras operate with similar constraints. They have a professional group (ministers and musicians) that rely on a large body of committed volunteers to support and promote their work, many of whom offer extensive business expertise.

My experiences as a musician and minister revealed that there are often tensions between these two ideals. For instance, the minister and the musician are in paid roles and are expected to provide leadership as a function of their day-to-day activities. And yet willing stakeholders also 
assume ownership of their church or their orchestra and believe that they are better qualified than the minister or musician to deal with the strategic and managerial issues confronting the organisation. More specifically, within orchestras, the artistic/business split is often heralded with, 'Musicians should get on with improving their artistry and leave the governance with the more worldly-wise'. It is this position, then, that provoked this study. What happens when the artists do have control over the governance of their company?

The Auckland Philharmonia presented what I considered an ideal case, because for its 25 years of existence, it has operated as a cooperative, thereby presenting some fascinating management puzzles. For instance, institutionally, it is led by the Secretary of the Society. This elected musician became, in effect, the orchestra's Chief Executive Officer (CEO), meaning that on-stage he or she could be a rank-and-file musician under the direction of the section principal, yet off-stage be the most powerful person in the enterprise. Therefore, the major office holders such as the Music Director, General Manager and Orchestra Manager all came under the Secretary's direct supervision and authority. 
It seemed that these cooperative musicians were comfortable with their leaders enacting both subordinate and superior roles within the same organisation. What I was interested in was how this paradoxical arrangement worked. I considered the possibility that an aesthetic approach offered a way of understanding these complexities, for, it seemed to me that this approach would enable me to hold together contradictory elements inherent in this arrangement.

This aesthetic approach posed several questions that needed to be resolved. The questions pertained to how to read an organisation as a cultural product, and to the nature of the relationship between the artists, the work of art and the perceiver. Furthermore, because a musical group was the focus of my research, I wanted to observe the shifts between the real and the ideal, thereby turning back on the orchestra some of its tacit and experiential musical knowledge. An orchestra is in its own right an art form in that on stage its performance protocols are highly ritualised; and yet it strangely represents a finely honed industrial machine with its strict hierarchies. The advantage of studying an orchestra is that it represents a stylised snapshot of the modern organisation and therefore an apt lens through which to examine other non-artistic institutions. 
Strangely, this also represents a disadvantage. Symphony-orchestra protocols are so fixed and traditional that they may not provide a suitable exemplar of the changing and flexible nature of contemporary organisational life. My hope, though, was that I would gain insights from the Auckland Philharmonia study that would provide further insights into generic organisational issues.

On beginning the research, I considered adopting Strati's schema that emphasises an inductive approach in which the researcher develops a heightened sensate awareness. Strati maintains that aesthetic research requires the researcher to activate 'his/her sensory and aesthetic faculties in order to gather qualitatively rich data from self-observation, intuition, analogy, relived experience and, often, description' (Strati, 1999b, p. 73). Strati's strength is his emphasis on the developing bond between the researcher and the researched. However, a gap still exists in the link back into aesthetic theory and in providing a philosophically nuanced taxonomy.

In order to devise a method that captures Strati's empathic approach, as well as creating logical research steps, I instead extended Roman 
Ingarden's ideas on the nature of music, as described in the previous chapter. Ingarden separates the work of the artist, who presences the work, from the members of the audience, who concretise the piece. The two different activities of presencing and concretising provide the tools to examine the relationship between, on the one hand, the research site and the actors within it, and, on the other, and the researcher's developing critical engagement. To make these connections, though, requires the ethnographer to think symbolically.

\section{Symbol and Perception}

Aesthetic ethnography requires the researcher to work with the symbolic. In line with this, 20th-century management practice has gradually moved away from utilitarian functionalist tasks, to interacting with symbols. As Starkey (2003) claims, 'the notion of management as the negotiation of meaning, as the management of systems of symbols, is becoming increasingly significant' (p. 206). This poses a difficulty for the researcher faced with the numerous symbolic cues expressed within organisations. How to read them and make sense of the relationship between a symbol and an organisation's identity is a problem Strati is also alert to. He notes 
that there is a tendency for ethnographic research to be captured by the need to use scientific tools and produce quantifiable data. The trouble with this, he argues, is that researchers may lose sight of tacit organisational phenomena that questionnaires and statistical analysis do not elicit (Strati, 1999b, p. 66).

According to Strati, the aesthetic researcher's task is to become immersed in an organisation to the point where he or she is able to discover 'nonmental' elements. He notes:

Every non-distinct representation is sensory, and sensory knowledge is the complex of representations which avoid distinction. The confused representations that determine the aesthetic judgement constitute knowledge that is wholly different from knowledge created by drawing analytical distinctions among representations so that they can be divided into the species and measures that intellectual judgement needs.

(Strati, 1999b, p. 108)

Symbolic awareness leads to an holistic view and it is this ability that is at the heart of aesthetic research. To accomplish this, the aesthetic researcher must necessarily become sensitised and alert to multiple and even paradoxical elements. 
Consequently, the researcher does not keep an objective distance but rather actively engages in the life of the organisation to the point of being 'startled, amazed, moved, surprised; [where] s/he may cry, laugh, reflect, succumb to mere inquisitiveness, grovel or imitate' (Strati, 1999b, p. 138) but at no time is he or she aloof, on the fence, or detached. Instead, to reaffirm Nietzsche's view cited above, the 'experiences of the artist' (Nietzsche, 1887/1994, p. 78, emphasis added) are the things that the aesthetic ethnographer seeks to discover. Furthermore, in the midst of uncovering these experiences the researcher is also confronted with what to do with his or her feelings - how should he or she interact with them, be with them, and then draw conclusions from them?

Strati offers a solution that engages the researcher in a process of involvement that leads, ultimately, to an ethnographic narrative. The researcher firstly freely engages with the organisation and allows his or her perceptions to be fully alive. Secondly, as the researcher becomes involved in the organisation, his or her powers of intuition and imagination lead to a self-reflective process where comparisons can be made. Thirdly, as the researcher shares the experiences of the subjects, he or she is then able to form hypotheses that seek to explain behaviour and 
motivations. Fourthly, the design and reporting of findings are continually re-negotiated as original readings are revised and new positions are argued for. Finally, the researcher is able to choose whether to construct knowledge around cognitive, aesthetic or emotional approaches.

The advantage of this method is that it assists the researcher and the researched to enter into a collaborative relationship. It enables a full exploration of the field of study where both parties participate actively in discovery and presentation. Its weakness, though, is its inability to guide the researcher through the journey of discovery so that he or she can engage critically with experiences as they occur. Furthermore, it relies on an intuitive approach that is idiosyncratic and not easily transferable within the research community.

In order to strengthen this approach and to provide some of the missing elements, I propose a way of examining organisation as a phenomenon that intentionally presences itself and that can be reconstructed through the researcher's aesthetic engagement. 
In Chapter 4, I offered a definition of 'organisation' used in a standard management text by Inkson and Kolb which sees organisations as legal entities which exist for the purpose of creating and distributing goods and services (Inkson \& Kolb, 2002, p. 7). Although this definition focuses on the dual elements of the institutional and social, it still begs the question of identity. Even Karl Weick's aphorism 'stamp in verbs' signalling a shift from seeing organisations as static entities to seeing them as processes (Weick, 1995, p. 187) only goes part of the way in helping the researcher understand how to engage with organisations. In order to make gains in research design, I will discuss in the following section the notion of intentionality that explores how organisations manifest their existence.

\section{Organisational Identity: Presencing and Intentionality}

The research journey necessitates a relationship between the researcher and the researched. The aesthetic method that I describe likens this to the relationship of an artist with the developing work of art and the audience of perceivers. In this section I describe the concept of presencing which Ingarden uses to describe the process by which artists create symbols out of their imagination. 
The concept of presencing, also referred to as intentionality, has its roots in Husserl's phenomenology. For Husserl, every conscious act is embedded in the primordial, and in order to discover the elements that make up a phenomenon, a process of phenomenological reduction is necessary. This requires a 'return to the world as it manifests itself in primordial experience ... the world of immediate experience' (Kockelmans, 1967, p. 34, emphasis added). Therefore intentionality, rather than being a response to an object, is the object which results from consciousness. Reactions to the object involve reflexive cognitions that analyse the manifestation of the object itself; hence, 'consciousness appears to be not pure interiority, but should be understood as a going-out-of-itself, as ek-sistence' (Kockelmans, 1967, p. 36). Consequently, objects do not shape consciousness but rather consciousness shapes our objective world.

For Husserl, then, intentionality and consciousness are synonymous because consciousness implies an object to be conscious of.

Consciousness is intentionality. For there to be mental events, there must be an Ego serving as the subject of these mental events, and, in order for there to be an Ego, there must [be] an intentional, constitutive act capable of synthesizing and unifying the stream of consciousness.

(Banchetti-Robino, 2004, p. 77, emphasis in the original) 
Thus intentionality (presencing) is the process by which the subject brings into existence his or her perceptions.

Understanding this notion of intentionality assists researchers in discovering the essence of the organisation. In taking this line, the researcher inquires into the way organisational actors construct their enterprise, by attending to both rational and symbolic expressions. Phenomenological explorations of the arts offer exemplars as to how this may be accomplished.

Take a painting, for instance. Intentionality does not imply merely the existence of a two-dimensional image - paint on a canvass. Rather, as Richard Wollheim claims, 'I am visually aware of the surface I look at, and I discern something standing in front of, or (in certain cases) receding behind something else' (Wollheim, cited in Nanay, 2005, p. 250).

Therefore in art there is paradoxically both a surface appearance of what is immediately obvious, and a surface (or surfaces) behind that surface. Therefore there are further 'folds' (Nanay, 2005) in the fabric of a work, beyond what is immediately obvious, that are part of its identity. 
Ingarden explains this idea by using the concept of layers within works of art. In order make an 'eidetic analysis' of art (Ingarden, 1983, p. 20), Ingarden argues that it is necessary to engage with these layers, an idea he explores in detail in his magnum opus, The Literary Work of Art (Das

Literarische Kunstwerk), first published in 1931. Here he interrogates how literary works exist, asserting that there are four strata to language, summarised by Rieser as, 'the sounds of the words; the meaning of the sentences into which the words are combined; the schematized aspects of the presented objects; and the represented objects themselves' (Rieser, 1986, p. 163). These strata are not to be considered as static layers, but rather, they interact polyphonically to produce a whole (Ingarden, 1931/1973, pp. 369-372).

When he turned to music, though, Ingarden considered there to be only one layer, sound. On this issue Ingarden is obscure. As explored in the previous chapter, Ingarden claims there are sounding and non-sounding elements that make up music's identity. In this instance, then, the nonsounding elements of form, emotion and content create further folds in the structure and, in my opinion, indicate other strata to music. 
How, then, can this notion be applied to organisational research? When writing about strata or layers within organisations, theorists tend to think in terms of hierarchy. Steps in the chain-of-command or layers of culture are represented as discrete entities rather than as polyphonic interactions. Hierarchies are often depicted as flow charts that allow people to see where individuals fit within a structure (Jaques, 1965). Similarly, culture has been represented as levels of identity that lie beneath the surface of an enterprise and include the espoused beliefs and assumptions that exist below the more obvious and tangible artefacts (Schein, 2004).

The problem with this hierarchical view is that it presents a static picture, where people see themselves as being positionally situated above, beneath or alongside colleagues. This approach likens organisations to a building's superstructure that must remain stable and resistant to adaptation for the construction to survive (Colombo \& Delmastro, 2002; Mintzberg, 1979, p. 131). However, just as an artwork's 'skeleton does not constitute the whole work of art' (Ingarden, 1964, p. 207), so hierarchical organisational charts do not represent the 'primordial experience' (Kockelmans, 1967, p. 34) of the organisation but instead are symbols of 
metaphysical qualities only rarely realised either in art or in organisational life (Ingarden, 1931/1973, p. 293).

Ingarden claims that, far from being static, art is a living relationship between the artist and the work of creation. He argues that the artistic object and the artist undergo transformation in the creative process.

For I am here concerned only with the thesis that it is a process which often undergoes several phases, in which there is a constant contact and encounter between the acting experiencing artist and a certain object, or rather two objects: the work of art in course of creation and the physical foundation undergoing change through his influence. Moreover both these elements undergo correlative mutually dependent changes.

(Ingarden, 1975, p. 266)

Taking this line in organisational aesthetic research leads to the view that, rather than being fixed, enterprises are presenced dynamically with people and processes being in a state of continual transformation. The challenge for the researcher is to elicit organisational layers and uncover the sounding and non-sounding elements as they continually interact. Where Schein is apt to see a disjuncture between visible artefacts, espoused beliefs and the underlying assumptions, this polyphonic interaction preserves the relationship between the visible and the hidden. 
Further, the artefacts and the underlying non-sounding elements of form, emotion and story inform one another and together presence the enterprise.

A symphony orchestra offers a site where these elements can be investigated in that it is a complex phenomenon comprising a number of layers of being that work together to create its identity. As an institution it has attracted the attention of theorists such as 'economists, public policy analysts, sociologists, psychologists, and nonprofit management experts, as well as musicologists' (Lehman, 1995, p. 37). Orchestras have also provided a rich resource into understanding the political struggle between financial profit and artistic integrity (Castañer, 1999, p. 389).

Signalled by Drucker (1993), the orchestra has now become a tool for managers to discover alternative ways of leading (Koivunen, 2003). Hence conductor Roger Nierenberg founded the consultancy The Music Paradigm (Nierenberg, 2003) to explore the conductor-leader nexus; while the New York-based Orpheus Chamber Orchestra demonstrates an alternative approach taking the view of the musician as leader (Seifter \& Economy, 2001). 
Much of this orchestral literature, however, is naïve and does little to scrutinise some of the deeper issues that musicians face. For instance, although symphony-orchestra players are highly motivated as individuals, they suffer from low job satisfaction 'ranking ninth, behind mental health workers and beer sales and delivery teams' (Wichterman, 1999, n.p.). Furthermore, because door sales rarely meet expenditure, orchestras rely on offering low wages for the musicians, and continual requests for generous donations to balance their books. However, in order for the orchestras to maintain a high public profile, they are obliged to pay internationally renowned conductors high fees. This means that musicians continually struggle for financial recompense and often there is a vast difference between the salary of a player and that of the conductor (Tindall, 2004).

These issues place the orchestra alongside other business enterprises and reveal a common struggle for job satisfaction, leadership enactment and financial reward. However, orchestras also differ from other firms in that their core business is carried out in performance before the public's gaze. My hope in carrying out this study was that the aesthetic lens could assist 
in developing an understanding an orchestra's dynamic existence, and as a result, offer insights into the wider business community.

Therefore, an orchestra offers a number of different texts. There is the public face of the orchestra in performance and its private life behind the glare of the stage lights. Alongside this is the group as a self-managing body, delegating and supervising administrative functions to hired staff. This complexity is further enlarged in the orchestra's many stakeholder groups that have varying levels of control of its daily affairs. Issues of governance, funding, community support, and management are everpresent; often competing interests are evident; and sometimes the goals of various stakeholder groups may be incompatible. Aesthetics, then, helps us understand this polyphony of voices, and avoids the trap of trying to present a monologic view of an enterprise.

How, then, does the researcher discover the layers of identity within an enterprise like an orchestra? By observing how the organisation presences itself, the researcher can begin to engage empathetically with its members, and in this way encourage them to give voice to their perceptions. Hence the artistic skill of bringing into existence eidetic perceptions is the first 
step in overcoming aesthetic muteness. The problem for the researcher, though, is how to determine whether what is seen is an unfettered explanation of the world as it appears. The next step in identifying hidden elements is in the response of the perceiver. This process is termed by Ingarden as 'concretisation' and involves the researcher in a journey of reconstruction. It is this that will be the subject of the next chapter. 


\section{ChAPTER 6 CONCRETISATION: EXPLORING Perception}

- Educating the Senses

- Concretisation: Research Movements

- First Movement: Emotional Attachment - / Focus

- Second Movement: Cognitive Detachment - You Focus

- Third Movement: Integrated Synthesis - We Focus

- Aesthetics and Social Transformation 


\section{Educating the Senses}

In the previous chapter I discussed the process of presencing, where the artist creates a work out of eidetic perceptions, by intentionally bringing into existence images that are formed in the imagination. In this chapter I shift focus from the artist to the perceiver - the audience, and by extension, the researcher. The problem confronting the organisational researcher is to determine whether what is seen is an unfettered exposure of the world as it is, or if there is something other for the researcher to discover that is not immediately obvious. A further question is how the researcher can go beyond perception to theory development, thereby contributing to intellectual and social development.

The problem confronting aestheticians is one of insight - of being able to see beyond phenomena in order to make sense of the work of art. When looking at a painting or listening to a piece of music, the uneducated perceiver, whether he or she be a viewer or listener, may be unaware of the strategies the artist has used to create the work. Issues that could be considered in a painting, for instance, could include how the artist has constructed perspective and depth of field. Similarly in music, the 
listener, for example, needs to be alert to how the use of a particular harmonic progression affirms or contrasts with the home key-centre. Beyond that, a consideration of the genre within which the work is produced is an important factor in understanding a work of art. Mitchell (1987) argues that the educated perceiver is cognisant of these kinds of structural elements and that, within a painting for example, there is the 'artful planting of certain clues' (Mitchell, 1987, p. 41) placed there by the artist with which the perceiver can interact. The perceiver's role is to make coherent meaning of the evident, as well as the implied invisible elements within the work. Furthermore, Mitchell claims paradoxically that 'we can never understand a picture unless we grasp the ways in which it shows what cannot be seen' (Mitchell, 1987, p. 39). Within a work of art, then, there are both explicit and implicit ideas that perceivers connect with in order to make sense of the piece. Therefore, Mitchell claims, if 'the innocent eye is blind' and if our 'eye' is not educated first, then we will not fully see what is there (Mitchell, 1987, p. 38). Adopting this argument within a musical setting, it could also be said that if the ear is not educated then we will not be alert to the sonorities of organisational life. 
Here is the heart of the problem that aesthetic research seeks to address, namely the developing education of the perceiver so that the unknown can become known. This process, though, necessitates a connection developing with the author; a relationship that calls into question Barthes' proclamation that the author is dead and that 'a text's unity lies not in its origin but in its destination' (Barthes, 1977a, p. 148, emphasis added). My claim is that to privilege the destination over the author is to undermine the role the author plays in presencing the work, thereby limiting its meaning both to the individual perceiver and, beyond him or her, to society at large.

The process of identifying the hidden elements, and of discovering authorial intentions within a work, is termed by Ingarden as concretisation and involves the researcher in a journey of discovery. However, this is not a voyage into truth-finding, rather one of seeking out multiple perspectives.

In this regard, Friedrich Nietzsche's aesthetic philosophy requires the perceiver to examine a work of art from multiple angles, claiming that 'the more perspectives one can take up, the more adequate one's view of the 
world will be' (Schoeman, 2003, p. 356). For Nietzsche, the aesthetician's task is not the search for truth. As Deleuze contends, 'Nietzsche replaced the ideal of knowledge, the discovery of truth, with interpretation and evaluation' (Deleuze, 1965/2001, p. 65, emphasis in the original). In line with this, the task of the contemporary organisational aesthetician is to first identify the multiple phenomena of organisational life and then to attribute meaning to and assess the relative importance of those phenomena. Therefore Deleuze writes:

Interpretation establishes the 'meaning' of a phenomenon, which is always fragmentary and incomplete; evaluation determines the hierarchical 'value' of the meanings and totalizes the fragments without diminishing or eliminating their plurality.

(Deleuze, 1965/2001, p. 65)

Concretisation, then, involves this process of education and discovery, where the researcher oscillates between the parts and the whole, in order to derive broad conclusions without destroying the integrity of the individual elements. In this way the researcher is then able to interpret and evaluate the relative importance of phenomena. 


\section{Concretisation: Research Movements}

While presencing looks at how the artist brings an artwork into existence, concretisation is the process by which the work becomes alive to the audience. According to Ingarden, this involves a relationship forming between the work of art and the perceiver that is active and living. Thus the perceiver engages in a reading process that gradually unpacks the meaning of the work.

Therefore, the research process is 'not a collision of dead matter but a living encounter full of activity' (Ingarden, 1975, p. 266) where the perceiver undertakes a voyage of both discovery and reconstruction of the work.

The experience starts either with a sense-perception of a certain physical foundation of a work of art (a painted surface, a lump of stone, and so on) whose certain details enable the observer to 'read' the shape of the work. Whereupon the work comes to be constituted in his receptive experience.

(Ingarden, 1975, p. 266)

The process of concretisation sees the researcher beginning with the site at face value, and gradually working with it until it takes on identifiable shape. 
Concretisation presumes that all works of art have 'areas of indeterminateness' that require the perceiver 'to render it concrete' (Ingarden, 1964, p. 199, emphasis in the original). For Ingarden, art contains a schematic structure that is both evident, as well as latent. Thus a work's potentiality 'demands a special attitude and exertions in the observer' (Ingarden, 1964, p. 199) in order to complete that which is implied. In other words, the audience is required to do some of the work in bringing the piece into existence and it is on these special 'attitudes and exertions' (Ingarden, 1964, p. 199) that I focus.

Before analysing Ingarden's paradigm of aesthetic engagement, it is important to pause here to consider the place of the reader in the realisation of texts. This relationship between author and reader acknowledges that there is an 'interactive space' between the text and reader (Bennett, 1995, p. 4). The reader's task is to fill this space. Musically, the idea of filling space includes going back to the beginnings of notation where live sound is represented in written form. For instance, notational schemes from the Baroque period offered only minimal information, requiring the performer to imaginatively create the missing information through improvisation. Here, a keyboard accompaniment 
would contain just a figured bass line with a series of numbers beneath it.

It was the task of the keyboardist to complete the missing notes by improvising within the style and mood of the composition.

The realization - the actual playing - of such a figured bass varied according to the nature of the composition and the taste and skill of the player; he might play simple chords, introduce passing tones, or incorporate melodic motives in imitation of the treble or bass parts.

(Grout, 1960, p. 273)

These improvisational elements allowed the musician to perform for the specific context. Over time, for the written score, a convention of abbreviations developed that saw certain common numbers omitted.

Thus the performer was required to become even more inventive as to the way he or she gave voice to often scant information. Below, in Figure 6.1: An Example of Figured Bass, is a typical example of figured bass conventions. The numbers above show the full version of the chord while the numbers below depict the more conventional abbreviated system. 


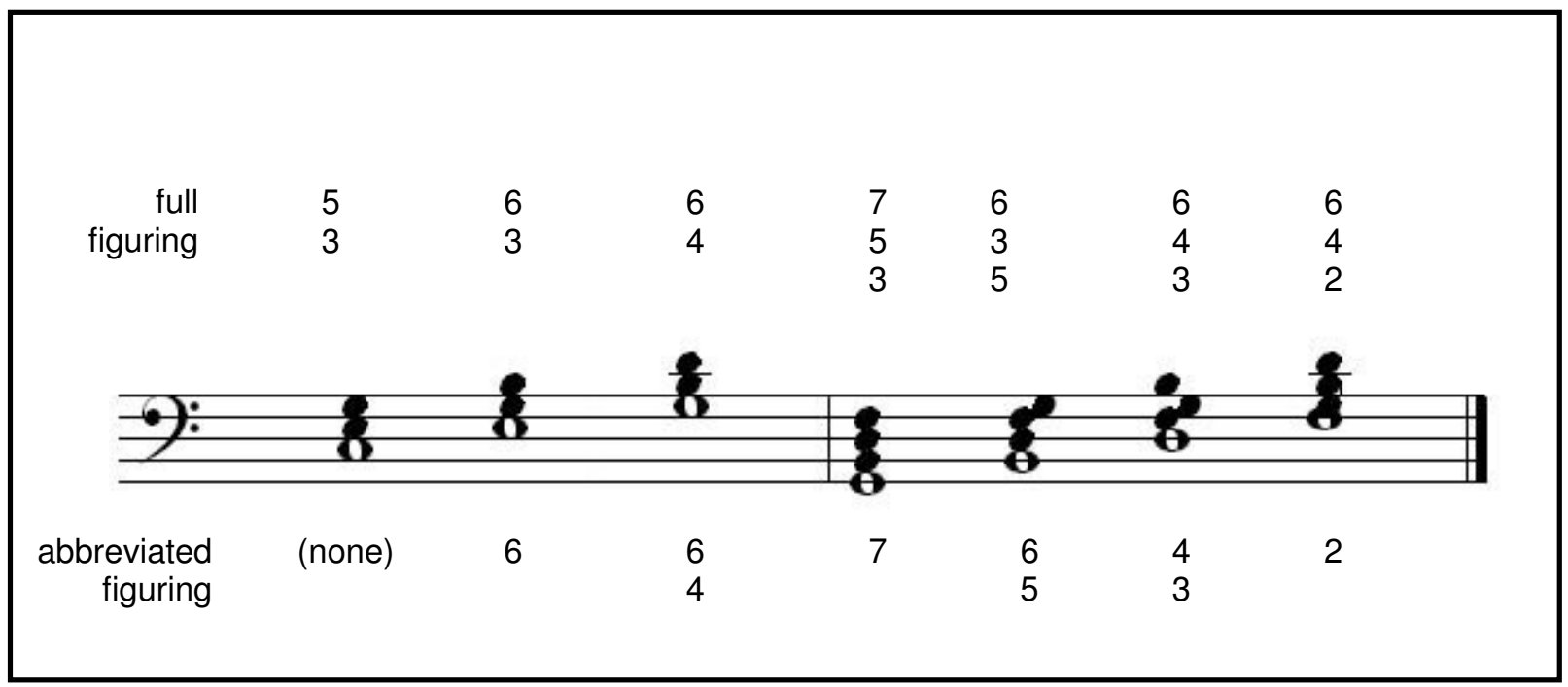

Figure 6.1: An Example of Figured Bass (Williams \& Ledbetter, 2004)

The concept of assuming that textual information is limited and requires a reader to give it meaning is further explored by discourse theorist Wolfgang Iser. Iser is one of the major proponents of contemporary reader response theory. Like Ingarden, Iser writes that the perceiver in reading texts is required to exert effort to bring a text into reality. Just as the Baroque musician realises a suggestive musical line into a full-bodied performance, the reader, according to Iser, 'stages' and 'performs' the text in his or her imagination. Iser insists that this is no mere copy, but rather that the reader creates the text. Therefore, 'it is the recipient's performance that endows the semblance with its sense of reality' (Iser, 1989, p. 244). 
This process of concretisation, then, acknowledges a turn from 'reader-asconsumer ... dependent upon the recognizable, overdetermined, development of a lisible text' (Monin, 2004, p. 56) to an aesthetician who is in a co-creative relationship with the author and text (Iser, 1989, p. 249).

Reader response is more than that which is implied in the semiotic tradition, or the 'mechanical structuralist notion [of] decoding' (Scott, 1994, p. 468). What is required is an agreed reading strategy (Scott, 1994, p. 474) that enables organisational researchers to make aesthetic sense of phenomena. It is crucial, says Iser, that we 'search for structures that will enable us to describe basic conditions of interaction, for only then shall we be able to gain some insight into the potential effects inherent in the work' (Iser, 1995, p. 21). This process of concretisation requires the researcher to attend to the text and the interpretive clues contained within it, and also to authorial intentions, by considering the context within which the text was originally generated.

To explain this, Ingarden argues that the perceiver goes through a process of a developing engagement with a work of art. This can be summarised as a series of steps beginning with the listener as 'naïve spectator', 
following which the perceiver begins to see the work as a piece of art in its totality and then examines the strata within the work. This analysis leads to a more critical engagement with the work and finally to an evaluative judgement of it as either high art or kitsch (Ingarden, 1975, p. 268).

Translating this process over into organisational research, I have created a three-step model, with each phase equating to a movement with its own focus and orientation. The word movement here has multiple meanings. Firstly, it carries with it the idea of journey, of movement from one state to another where the researcher gradually uncovers layers of meaning and develops a deeper and deeper understanding of the site. Secondly, the word is also part of musical language, where a movement is an entire section of music with its own unique characteristics but is part of a larger work such as a symphony, concerto or sonata. In this case, each movement, or step, aligns itself with the aesthetic research process and begins with Emotional Attachment, moves to Cognitive Detachment and concludes with Integrated Synthesis. With each movement the researcher becomes more intimately acquainted with the organisation and as a result is increasingly able to make evaluative judgements. Through the process the researcher changes from self-absorption (an I focus), to a consideration 
of the context (a you focus), and finally to an inclusive co-creative orientation (a we focus).

Further, although for ease of description I have explained this notion of movement as a lineal progression, in practice the process is not this tidy. A third layer of meaning is inherent in the word which embraces backward reflexivity - continual movement between the present and the past. The researcher, in taking this approach, shuttles among the three areas of focus - I, you, we - and continually revisits his or her perceptions in the light of new experiences and events.

Taking the lineal approach, at each of these stages, questioning strategies change in line with Schumacher's emphases noted in Chapter 1. The question 'What do I see, hear and feel?' signals the first movement of Emotional Attachment. Cognitive Detachment asks 'What do you see, hear and feel?' whilst in the final phase of Integrated Synthesis the question becomes 'What do we see, hear and feel?' With the caveat that in reality these research movements are volatile and that the researcher may revisit earlier ideas, Table 6.1: Research Movements, Focus and Questions 
below shows the three movements, and the focus and questions that spring from each stage.

Table 6.1: Research Movements, Focus and Questions

\begin{tabular}{lll}
\hline STAGE & Focus & RESEARCH QUESTIONS \\
\hline First Movement & Emotional Attachment & $\begin{array}{l}\text { What do I feel? } \\
\text { What do I see and hear? }\end{array}$ \\
Second Movement & Cognitive Detachment & $\begin{array}{l}\text { What do you feel? } \\
\text { What do you see and hear? }\end{array}$ \\
Third Movement & Integrated Synthesis & $\begin{array}{l}\text { What do we feel? } \\
\text { What do we see and hear? }\end{array}$ \\
\hline
\end{tabular}

\section{First Movement: Emotional Attachment - I Focus}

The process of engaging with an artwork is similar to organisational

ethnography. The ethnographer begins by seeing the group being

researched as unique and 'begins by examining even very commonplace

groups or processes in a fresh and different way, as if they were

exceptional' (Goetz \& LeCompte, 1984, p. 2). Similarly, Ingarden speaks

of an initial arresting emotional involvement when approaching a new

work of art. At this stage, the aim is to experience as much of the work as

possible. Although we may initially overlook certain elements, there is an 
almost insatiable appetite for more. It's as if the art work charms us and draws us into itself so that 'we feel only that it has allured us to itself, impelled us to give attention to it, to possess it in a direct, intuitive contact' (Ingarden, 1961, p. 296). Much of our emotional experience is still in germ form and we desire to sate ourselves in order to 'consolidate the possession of it' (Ingarden, 1961, p. 296).

During this phase the perceiver becomes aware of a new state of consciousness - not one that is time-bound, but rather one integrated with the artwork, a 'scheduled whole' (Ingarden, 1961, p. 298), where the researcher is acutely aware of elements within the work that demand attention. Ingarden describes this as:

our new 'present,' filled up with the preliminary emotion and with the continuance of the aesthetic experience, [we] lose all distinct connection with our direct past and future within the course of 'daily life'.

(Ingarden, 1961, p. 298)

Ingarden illustrates his ideas with a discussion of the 2nd-century BCE sculpture, Venus de Milo. We are taken, Ingarden says, with the sculpture in its entirety - the beauty of line and shape which cohere together in harmonic whole. There are, though, blanks in the work, for the sculpture 
is bereft of its arms. Ingarden notes that this absence may improve our aesthetic responses because we are free to observe the shapes of her body unencumbered by the arms. Furthermore, this and other blemishes on the surface of the work do not detract from the piece but rather require the perceiver to 'complete' it in his or her imagination (Ingarden, 1961, pp. 292-295). This active involvement in the work by the perceiver leads to the two questions that form the core of this movement and revolve around the emotionally charged researcher, who asks, 'What do I see and hear?' and 'What do I feel?'

Research begins, then, with a naïve 'reading' (Lindseth \& Norberg, 2004, p. 149) of the environment where the researcher tries to take in as much of the gestalt of the organisation as possible. However, observation must at some point give way to interpretation, where the task of the ethnographer is not only to observe but also

to decode human experience - to move from unstructured observations to discover the underlying meanings behind behaviour; to understand feelings and intentions in order to deduce logical implications for strategic decisions.

(Mariampolski, 1999, p. 78, emphasis added) 
This process leads to the second movement in which the researcher becomes detached and begins to engage cognitively rather than merely emotionally with the site.

\section{Second Movement: Cognitive Detachment - You Focus}

In the shift from naïve spectator to cognitive analyst, the researcher takes on a new guise. Here the ethnographer is concerned with structural issues (Schwartzman, 1993, p. 4) and penetrates beyond surface phenomena into the various layers of the organisation which are then held up for critical examination. The questions the researcher focuses on in this movement are 'What do you see and hear?' and 'What do you feel?'

Ingarden notes that what propels us into this stage is that we either notice some deficiencies in the work that 'calls to be filled' (Ingarden, 1961, p. 302) or observe new details that invite further, closer examination. Out of this more critical analysis something new begins to emerge - a new understanding and appreciation of the work itself. Ingarden thinks of this development as either examining discrete categories or alternatively harmonising structures. 
In this whole perceptive process there is accomplished two kinds of formation of qualities grasped: a. into categorical structures, b. into qualitative harmony structures. (Ingarden, 1961, p. 304, emphasis in the original)

It is worthwhile pausing here to see what Ingarden means by these two terms and observing how they inform this part of the research process.

By categorical structures, Ingarden means that there is an interpretive shift from perceiving the work of art as it appears (for example a piece of stone or paint on a canvas) to seeing its representation (the shape of the stone or colours on a canvas representing a human body). A structural shift occurs by way of a 'peculiar community of experience' (Ingarden, 1961, p. 305, emphasis in the original) in which the perceiver confers on the art work existential meaning. However, this bestowal is paradoxical in that it is 'peculiar', or in other words, idiosyncratic and specific, and yet it relies on a 'community of experience' which implies agreed meanings derived from sharing sensations and perceptions. Therefore the idiosyncratic and shared significances work together to create meaning.

In organisational research, attending to categorical structures includes the analysis of particular symbols, documents, reports, interviews and direct 
observations, all which point to specific organisational features. The aesthetic lens makes it possible to view these components as a meaning set. In practical terms, though, how does this interpretation take place? A clue might be found in the hermeneutic tradition espoused by phenomenologist writers, a tradition that has grown out of the analysis of ancient texts.

Literary theorists claim that when reading an ancient text, hermeneutics (or interpretation) cannot take place until we have first engaged in the exegetical process. Initially we must get behind the text, to examine its 'historical and sociological context' and try to see 'the intent of the author' (Nissen, 2002, p. 73). For instance, biblical scholars claim that only once we have done this, and examined the actual content of the message, are we then equipped to think hermeneutically, and that if we do not take time to exegete texts, we may be blind to elements that do not suit our world-view (Fee \& Stuart, 1986, p. 21). Furthermore, exegetical method focuses on the rhetorical mores of the time of writing rather than the time of reading (Thurén, 2001). 
Therefore, texts do not occur in isolation. Rather, they spring from a community that is grounded in a world-view and cultural mores, which can be encompassed in the overarching idea of genre (Monin \& Monin, 2005). So even to contemplate the idea of style implies a generic construct that is recognisable beyond idiosyncratic readings.

Iser's understanding of the reader's response agrees with this approach. He claims that the reader 're-presents' the text from the environment 'out of which it arose' (Iser, 1989, p. 244). This is not, though, an individual project. Carrying out textual exegesis involves an interpretive community (Kahl, 2000, p. 422) who, in spite of cultural differences, reach agreed meanings.

Thus in the organisational context, the researcher addresses specific textual cues from the author's view. For instance, to elicit this information, the researcher may ask questions such as: 'Who said what?' 'What is their status and relationship with the entire body?' 'What was said?' 'How was it said?' Only once the exegetical task has been embarked on, can the hermeneutic activity of meaning making be addressed. 
This, then, brings into focus the second element of cognitive activity where individual concepts cohere together into a whole. For Ingarden this second notion of qualitative harmony structures indicates that structural qualities do not remain as isolated, individual elements, but rather cohere and 'become harmonized into a single whole' (Ingarden, 1961, p. 305). Elements, then, lose their individuality and combine together producing something new. For example, in music individual sounds may be of certain measurable wavelengths. Sounding together, they may be said to be at an interval of a third or fifth apart. However, as they lose their 'peculiarity and independence ... a reciprocal modification of the coexisting qualities may lead to the appearance of an entirely new quality' (Ingarden, 1961, p. 305). So, the notes may then take on the identity of a major or minor chord thus establishing their qualitative relationship within a musical piece in its entirety.

As I have already noted, the companion to exegesis is hermeneutics. Within the research milieu this involves a dialogue with phenomena and an 'interpretation [that] permeates every activity, with the researcher considering social, cultural and gender implications' (Dowling, 2004, p. 36, emphasis added). Hermeneutics moves the reader beyond an initial 
naivety and instead of asking what a text says, the question becomes, 'What does it mean?' (Geanellos, 2000, p. 114) thereby attributing significance to phenomena.

Although for analytical purposes I have separated the two tasks of exegesis and hermeneutics, they are nonetheless part of the same sensemaking practice and can occur as parts of a single reading. In line with this, Tesera Okure (2000) notes that all textual readings are culturally embedded and that no definitive reading can be scientifically arrived at. Rather she claims that exegesis and hermeneutics proceed in tandem as we, from within a particular cultural milieu, interact with the text as we find it.

Inevitably, [we] view ... events 'first hand' through [our] cultural and personal filters and expectations. It is also not possible to devise 'purely' objective tools for interpreting reality, past or present. Forged by conditioned human beings, these tools are conditioned themselves. Our exegetical studies, like all other human undertakings, are subjective in the etymological sense of the word, that is, influenced by the subject who does them.

(Okure, 2000, p. 448)

This way of arriving at a harmonic reading of texts where something new may emerge has its roots in the Gadamerian hermeneutic circle and 'refers 
to a circular process of hermeneutic interpretation where meaning is always negotiated between one's own preconceptions and those within the horizon of the other' (Tate, 1998, n.p.). Hence the part and the whole continually refer to each other (Gadamer, 1999, p. 291).

Returning, then, to the idea of this movement - Cognitive Detachment - a combination of exegesis and hermeneutics offers a process whereby layers of the organisation can be examined. Ingarden's notion of layers in music is that there is only one stratum: sound. In the previous chapter I contested this view, claiming that even Ingarden considered sounding and non-sounding elements to be part of music's identity. So taking the musical analogue further, this represents layers of organisation that the researcher investigates. 'Sounding' elements are those that are obvious and instantly discernable while 'non-sounding' features are deeper structural phenomena that are present but not immediately accessible.

Cognitive Detachment, then, does not imply an objective state totally divorced from the research subject, but rather involves an intense search for the elements of the site that are not directly obvious. This is how aesthetic ways of knowing differ from scientific methodologies. Where a 
scientific approach seeks for distance and objectivity, aesthetics sees the researcher and the researched intimately and empathically involved. This, though, is the difficulty with aesthetic research: how does the tacit and implied yield its identity?

In dealing with this problem, aesthetic researcher Antonio Strati (1999) relies on Michael Polanyi's thoughts about the acquisition of knowledge to inform his methodology. To attempt to understand the nature of tacit knowledge, Polanyi distinguishes between 'focal awareness and subsidiary awareness' (Polanyi, cited in Strati, 1999b, p. 95). Focal awareness deals with all the instruments at hand - that which the individual can sense and which are immediately knowable and quantifiable. Subsidiary awareness, on the other hand, involves knowledge that is not as easily articulated but nonetheless is crucial to any enterprise.

To tease out this distinction between focal and subsidiary awareness, Polanyi writes of a 'from-to knowing' where the seen object leads to unseen elements, thereby undergoing 'phenomenal transformation' (Polanyi \& Prosch, 1977, p. 35). Polanyi illustrates this by thinking of our 
reception of an image through a stereoscope. We are cognisant (focally aware) of the two separate images on disk, but when we look through the device, the two merge into a single three-dimensional image. Therefore, according to Polanyi, we make 'acts of tacit inference' (Polanyi \& Prosch, 1977, p. 39), derived from the explicit nature of the two separate images.

Taking this analogy beyond the visual into the musical, a mere fragmentary motif may suggest an entire theme or repetitive leitmotif. Similarly, although a harmonic chord may lack a complete set of notes (for instance its 5th may be missing), listeners infer meaning based on the context within which the chord is played.

Tacit knowledge, then, resides in individual actors, teams and the entire organisation (Cook \& Yanow, 1993). The challenge for the researcher is to assist people to disclose this tacit knowledge, or subsidiary awareness, in order to build a more complete soundscape of both what they hear directly and what they sense intuitively.

To discover this, the researcher looks for synergies and relationships that stakeholders have not been aware of. For instance in an orchestra, the 
nature of the tensions between the artistic and the business arms can be explored. Those involved may wish for separation, but the aesthetic researcher may instead find synergies or ways of explaining how the polarities work in relationship together.

Once elements have been held up for analysis and new synergies are explored, the perceiver comes to what Ingarden calls 'a convictionmoment concerning the whole aesthetic object as a harmony of qualities' (Ingarden, 1961, p. 312, emphasis in the original). Now evaluative judgements can be made concerning the organisation in its entirety. I call this final part in the research process Integrated Synthesis.

\section{Third Movement: Integrated Synthesis - We Focus}

The move to Integrated Synthesis brings the perceiver back to the original emotionally charged feelings of the naïve inquirer, only now informed by critical analysis. This, though, does not lead to cynical disengagement, but rather provides a springboard for the perceiver to communicate his or her understanding of the work to others so that they too can 'share these 
values' (Ingarden, 1961, p. 268). The questions in this movement are, 'What do we see and hear?' and 'What do we feel?'

In the process of synthesising the work, we 'experience a centre of crystallization' (Ingarden, 1961, p. 300, emphasis in the original) where the work takes on new significance. We see the work as a whole again and seek to further enlarge our enjoyment of it, because it is the analysis that has gone before that gives a wider appreciation of the work's value. For Ingarden, 'this process is characterized by a peculiar searching disquietude, a changeability full of dynamism' (Ingarden, 1961, p. 307, emphasis in the original). The perceiver is transformed in this process and the conviction moment observed in the previous movement enables the perceiver to translate discoveries into his or her world-view (Ingarden, 1961, p. 312).

When evaluating a work of art in its entirety, an approach is to see it in terms of its fit, the outcome of which evaluates a work in terms of its wider functionality and contribution to society. Here we determine the purpose for which the artwork exists in the present moment and evaluate the work's usefulness in terms of both of the context within which it is viewed, and its of social function. Therefore evaluation of the work on 
'moral, ethical, and political grounds' (Richards, 2004, p. 272) makes it possible to establish the link with society.

This transformation begins with the researcher and embraces the researched. When we encounter a work of art, critically examine it, and then make evaluative judgements, we as perceivers are changed (Ingarden, 1975, p. 262). We observe how the work coheres and recognise that our own thinking and possibly even our world-view have changed as a result of the investigation. Thus the researcher and the researched have experienced a transformative relationship.

During this final stage of synthesising all the various issues that have been explored, the researcher also looks for underlying structural determinants. As these are explored, theories begin to emerge that have wider societal implications.

In the case of the Auckland Philharmonia, several elements present themselves for analysis. These elements will be explored in the next three chapters. They include the need for artistic freedom set alongside responsible leadership and sound fiscal management. Added to this is a 
further issue that provoked the most discussion among orchestral members, namely the kind of governance structure that would best suit the company as it confronted the implications of declining grants from the corporate and public sector. These elements point to deeper issues relating to the orchestra's place in society and its reasons for continued existence. In the face of other leisure activities that compete for public support in the same market, what social function does an orchestra perform? These questions will be explored in the next chapters and will be examined aesthetically.

In summary, this schema represents a journey from being an outsider and distant naïve spectator, where the researcher is fully alert to multiple experiences. From this point the researcher moves to an inside, or more informed position. Here at this central stage of involvement, strata are examined and a critical eye is cast over the organisation through interviews, observation and discussion. Once the researcher becomes saturated, he or she steps back and becomes an informed outsider at which point evaluative judgements are made and findings are narrated. 


\section{Aesthetics and Social Transformation}

In studying organisations, following Ingarden's aesthetic, I have proposed that researching involves working with the duality of presencing and concretising. Presencing is the work of the organisation - how it symbolises its existence and transforms these symbols into concepts and artefacts that can be understood by stakeholders. The other element of concretisation is the researcher's task of bringing to the fore or recreating the meanings of the symbols.

Beyond attention to beauty and ugliness, and an examination of strata, aesthetics is concerned ultimately with a global view of an object. Having achieved this view, it is important to address the ultimate meaning of the discoveries, and seek for ways in which society can benefit from the newfound knowledge gained through critical analysis.

Ultimately, aesthetic constructs ask, 'how can aesthetic knowledge be said to have a social significance?' (Bernard-Donals, 1994, p. xi). So in approaching the methodology of aesthetic research, it seems to me that two questions are paramount; namely how does aesthetic awareness interact with society, and secondly, how does this effect social change? 
The method that I have explored proposes a way forward: it is concerned with 'the way in which the human mind comes to consciousness in a relationship with objects or other human subjects' (Bernard-Donals, 1994, p. 18). Thus, aesthetic research has to do with an individual's lived senses of, and responses to, organisational phenomena. As these phenomena are explored, new possibilities for social expression may arise. The following three chapters will show how an ethnographic exploration of the Auckland Philharmonia using the methodology I have described here can make the development of an aesthetic language possible and, it is hoped, lead to social change. 


\section{CHAPTER 7 FIRST MOVEMENT: EMOTIONAL ATTACHMENT}

- Setting the Scene

- The Auckland Philharmonia

- Getting Started

- Beguiling Theatre

- A Cacophony of Competing Sounds

- Spilling the Beans 
In this chapter I employ the method discussed in the previous chapters and show its use in an ethnographic study of a symphony orchestra: the Auckland Philharmonia (AP). I discuss the first movement of Emotional Attachment to introduce the issues facing the orchestra during a governance review and restructure. Specifically, I examine my initial sensations and perceptions as a researcher, and seek to answer questions around these by asking, 'What do I feel?' and 'What do I see and hear?'

My intention throughout is to show that by example, a single case can become a model from which more generalised conclusions about the nature of organisational behaviour can ultimately be drawn. In support of this view, Pierre Guillet de Monthoux (2004), in his exploration of the aesthetic tradition, notes that:

Examples of the specific are a starting point for an aesthetic judgment. From the level of everyday cases, such as individual experiences in a hospital, university, and festival, people are elevated to the level of the universal. Instead of subsuming, humans judge or reflect on matters of aesthetics on the basis of single cases only.

(Guillet de Monthoux, 2004, p. 23)

In this chapter I set the scene with a description of orchestras from an organisational standpoint followed by a brief overview of the Auckland 
Philharmonia. I then discuss the early stages of my research and some of my first impressions. I focus on the contradictions of on-stage synergy and off-stage cacophony and examine some of my responses to these incongruities.

\section{Setting the Scene}

I began this research optimistically. Studying the Auckland Philharmonia (AP) captivated my interest because it represented a return to my roots as a musician, and affirmed my life-long fascination with the orchestral music repertoire. In my early career, music was my life. Although my career journey took me into pastoral ministry in my late 20s, I began my working life as a secondary school music teacher, a part-time orchestral musician and a choral and youth orchestra conductor. These activities gave me an insider's view on the organisational culture of orchestras, including their mores and practices.

An orchestra is an interesting study, not least because most of its life is carried out in the public eye. Due to finding restrictions and the need to work to a very tight time frame, a two-hour concert represents the culmination of individual preparation on the part of each musician, and 
up to eight hours spent in full orchestra rehearsal. This public face, though, is not confined just to concert performances and rehearsals but also includes meetings of stakeholders such as advisory committees and friends.

A string of poor performances and unfavourable reviews can jeopardise the success of future concerts and impact on how the enterprise operates off-stage. The inadequacy of financial resources can become the excuse for poor performance. Yet funding agencies are often reluctant to support an orchestra declining in public favour. Under tightened fiscal conditions, relationships among players can become toxic which, in turn, can impact negatively on the quality of on-stage performance. Hence, it could be said that the degree to which the orchestra succeeds in performance can determine how it functions in private, which in turn determines how it operates in public. Therefore, there is a continual interplay between offstage and on-stage performance.

Beyond this, orchestras are fascinating studies in leadership practice. The popular perception of the orchestra is that the conductor is the boss. Managerially, the conductor is at top of the organisation's hierarchy and is 
an important focal point in marketing strategies. This is further complicated by a continual flow of 'new bosses (guest conductors)' (Atik, 1994, p. 22) who typically work with the band over several concerts before moving on. Hence players are required to make adjustments to suit the requirements of each new boss. This simplistic view, though, does not take into account the dynamics between the rank-and-file players and their section principal. Neither does it tease out the conundrums in the relationship of the players with their Concert Master, who, as a first violinist sits at the front and leads the orchestra; and of the Concert Master with the conductor.

Further, to call the conductor 'boss' belies the changing face of orchestral life in which players are exercising more initiative in the management of their enterprise. For example, the evolving status of the conductor on the international scene is reported in a New York Times article (Pogrebin, 2003) which describes how the musicians of the New York Philharmonia lobbied their Board to have Lorin Maazel's contract as Music Director extended because of the collaborative working style he established with the orchestra. Pogrebin contrasts this with the orchestra's relationship with the previous Music Director, Kurt Masur, whose departure was 
surrounded by bitterness and acrimony because of his dictatorial leadership style. Signalled in this story is a change from a conductor as boss, who demands and expects compliance, to a conductor as negotiator who is required to work alongside the musicians, facilitating their performance.

These complexities pose a problem for the orchestral researcher who may only see the orchestra through an idealised 'romantic' lens (Koivunen, 2003, p. 21). As noted in Chapter 5, Peter Drucker sees the orchestra as an exemplar for contemporary managers to model their practice on. However, this approach misses important elements that lie beneath the surface. If all that is known of orchestras is that which is observable by the public, with the conductor being the dominant actor, how are we to discover its backstage life?

Xavier Castañer attempts to tease out some of the back stage drama by his examination of industrial action taken by members of the Barcelona Symphony Orchestra (BSO). In his case study analysis, Castañer sees a disconnect between the artistic and managerial (Castañer, 1999, p. 390). His study explores the competing discourses of arts and business showing 
them to be equally powerful and persuasive with neither able to yield to the other. Castañer concludes that for the BSO to move forward, conductors were required to become socialised into the orchestra's culture rather than expecting the musicians to change and adapt to the conductor. Furthermore, he argues that BSO managers needed to become more innovative in the development of the orchestra's strategic direction.

Gary Rudd's analysis of an orchestra follows along similar lines. He observes that the symphony orchestra is organised discursively in terms of two different codes where artistic and business principles are in competition, but with the business code often gaining ascendancy (Rudd, 2000).

These analyses do not, however, adequately explain the issues that underscore an orchestra's dilemmas. Seeing the artistic enterprise as a battle between management and musical polarities neatly places people within two monologic communities. Here, all that is required to sort out their problems is to bang some heads together and get them talking to each other. Problem solved! However, in my conversations with musicians and managers from the Auckland Philharmonia, I found a much more 
diverse discursive environment, and positioning people as either artistic or managerial seems to me to be a shallow descriptor that does not nuance important underlying ideas.

Beyond the players, supporters within the classical music community consist of people who volunteer their services because of their love for orchestral music. Even those in paid employment suffer from poor remuneration because of their passion for the art form, preferring to work among artists rather than seeking higher-paid positions in another sector. These stakeholder groups comprise numbers of interested people who hold firm opinions about their orchestra.

As a researcher, I, too, began from a similar position of interest. I am a regular concert attendee and have observed the growth in the artistic stature of the AP over the last 15 years. What interested me about this orchestra in particular was its cooperative structure. I was keen to discover how these musically creative people managed themselves within this structure. 
Like other orchestras, the Auckland Philharmonia in rehearsal and performance adheres to universally accepted mores. In spite of its cooperative management style, on stage, strict chain-of-command protocols operate, and even though section principals might on occasions speak directly to the conductor, no rank-and-file musician has this right. So, both in rehearsal and performance, the $\mathrm{AP}^{\prime}$ s orchestral functions are highly ritualised and every element of a concert keeps to the prescribed custom. Dress-code, arrival on stage, the order of the programme items, the way of acknowledging applause are determined by long-established rituals that are observed world-wide and the AP is no exception.

The formal context within which the orchestra operates, then, is pure theatre. Like other orchestras, an AP concert is a dramatic event for public consumption and from beginning to end the players present themselves as a highly polished, united team, all striving for artistic excellence. Audiences too, collude in this drama. Absolute silence during a performance, not clapping between movements, yet offering ecstatic outbursts of applause at the end of pieces, are all behaviours required of an audience to make a concert fully participatory. 
As mentioned in Chapter 5, what captivated me about the AP was the disruption of these dramatic power relations off-stage. There appeared to be a confusion of roles, because an elected musician was Secretary of the Cooperative Society, meaning that on-stage he or she could be a rank-andfile musician, but off-stage the same person was essentially the CEO of the ensemble. Where Atik's (1994) analysis equates the role of the conductor with that of a boss, implying a tidy hierarchy, I became curious to see how the AP musicians coped with the contradictions inherent in their organisational structure. On-stage the AP musicians adhered to the strict hierarchies orchestras operate under; yet off-stage their cooperative ideals meant a different leadership dynamic was at work. I wanted to observe the translation, if any, of practices from the concert platform to the manager's desk.

\section{The Auckland Philharmonia}

The Auckland Philharmonia is one of two fully professional symphony orchestras in New Zealand. Whereas the AP is situated in Auckland, New Zealand's largest metropolitan area, its counterpart, the New Zealand Symphony Orchestra (NZSO) is peripatetic and operates out of the capital 
city, Wellington. The AP draws its support from a variety of sources. Box Office receipts and the creative arts funding agency, Creative New Zealand, provide the majority of its income. Other sources of income include hires, where the orchestra accompanies choral, opera and ballet productions; corporate sponsorship; funding from metropolitan Auckland local bodies, consisting of four cities and three semi-rural councils; and social events run by the Guild and Friends. In 1998 the orchestra operated with a budget of $\$ 4.5$ million. Proportions of funding have remained stable over the last 15 years and these are summarised below in Table 7.1: Sources of Auckland Philharmonia's Funding (1998).

Table 7.1 Sources of Auckland Philharmonia's Funding (1998)

\begin{tabular}{|lr|}
\hline & \\
\hline FUNDING SOURCE & $\begin{array}{r}\text { \% OF } \\
\text { TOTAL }\end{array}$ \\
\hline Box Office and Hires & $52 \%$ \\
Creative New Zealand & $21 \%$ \\
Sponsorship & $16 \%$ \\
Auckland Local Authorities & $5 \%$ \\
Donations (Including Friends and Guild) & $\underline{6 \%}$ \\
Total & $\overline{\mathbf{1 0 0} \%}$ \\
\hline
\end{tabular}


Attracting funding in the art sector in New Zealand has become an increasingly competitive enterprise. Creative New Zealand, central Government's arts' funding agency, supports arts organisations throughout the nation. The AP, smaller regional orchestras in Wellington and Christchurch, and other artistic groups, vigorously contend for available funds and are increasingly forced to apply to private corporate organisations for support.

The NZSO and the Royal New Zealand Ballet, however, are funded under a totally different regime. As State-owned bodies, they are funded directly by the Government through the Ministry of Arts and Culture. In 2000 the NZSO received $65 \%$ of its funding from this source, whereas in the same year the AP received $21 \%$ of its budget from Creative New Zealand. Musicians in both the AP and NZSO are of world-class standing and both orchestras have a growing reputation on the international stage. It is not surprising, then, that the AP musicians are resentful about the NZSO's favoured status.

As an ensemble, the Auckland Philharmonia comprises 68 core players, four cadets and a number of on-call musicians for large-scale works. For a 
symphony orchestra its history is short, beginning some 25 years ago when its predecessor, the Symphonia of Auckland, went into liquidation.

In 1980, upon hearing of the impending demise of their orchestra, 19 players of the Symphonia rallied together and formed a Cooperative Society to protect existing assets from being plundered by potential creditors. This 'Phoenix Group' as they were dubbed, consisted of a remnant of young players from the old Symphonia. Their experiences of a Board of Directors that controlled the orchestra without reference to the players, and of a Music Director they considered lazy and past his prime, meant they were determined to take control of their new orchestra, and to do so they took on part-time jobs and worked for minimal remuneration until they gained a foothold on the city's artistic calendar.

Since those shaky beginnings, the AP has become a full-time operation with some 260 to 280 calls per year. A call is defined as a three-hour event where the players are required to come together, either for a rehearsal or for a concert. Along with a retainer, players are remunerated on the basis of the number of calls they attend, and the orchestra guarantees a minimum of 250 calls annually to its permanent players. This is a fairly 
standard number of calls, as most orchestras work from 250 to 350 calls per year.

From the outset, the Philharmonia was a cooperative enterprise with the entire body of permanent players forming the management committee. All artistic decisions were made by the Cooperative as a whole, including programming, hiring new players, and disciplining under-performers. According to one of the founding members, these formative years were exciting and creative. Social events and parties often morphed into quasiSociety meetings where the orchestra's future was endlessly and enthusiastically discussed. New ideas were floated and the fledgling band had a sense of cohesion and purpose.

Administratively, the Cooperative Society established itself under the nomenclature the Orchestral Committee and created small committees to supervise managerial and artistic issues. These were the Administrative Council and the Artistic Development Committee. In what follows, I show the structure of the orchestra through a series of charts created in November 2001 by the then General Manager. Facsimiles of these are reproduced below. The first, Figure 7.1: AP Society Structural 
Relationships (2001), shows the structure of the society with the Orchestral Committee acting as the foundation of the enterprise. Out of this group came the two key committees: the Administrative Council and the Artistic Development Committee. Although the Secretary and Music Director sit at the top of the two strands, the directional arrows point upwards showing the Orchestral Committee as the source of authority within the structure.

\section{Society Structure}

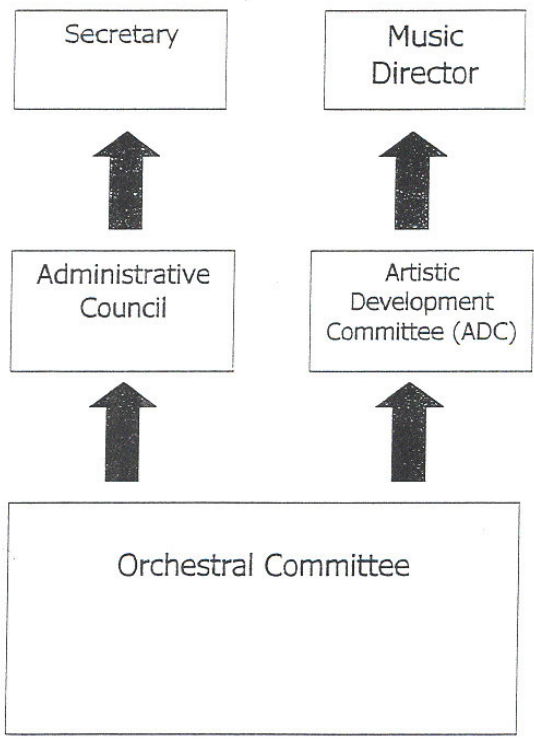

Figure 7.1: AP Society Structural Relationships (2001) 
The responsibility of overseeing matters relating to employment relations was given to the Administrative Council. This group comprised of twelve members: six elected musicians for a two-year term, along with the General Manager, Orchestra Manager, Music Director, Secretary of the Society, Emeritus Concert Master, and Concert Master. The Administrative Council was charged in the 2000 Constitution with 'represent[ing] the majority view of the Orchestral Committee at all times and in all matters relating to the policies and objects of the Society'.

All artistic concerns - including programming, disciplining underperformers and the probation and recommendation for tenure of new players - became the concern of the Artistic Development Committee (ADC). This committee comprised delegates from the main sections of the orchestra (strings, wind and brass) and could augment membership according to the presenting issues. For instance, extra members of the ADC reflected the instrumental section of a probationary player. Where disciplinary action was required, the under-performing musician would be evaluated by peers in his or her section. The Music Director was able to advise the ADC, but when decisions came to be made, his vote was only one among many. All decisions of the Administrative Council and the 
ADC were referred back to the Orchestral Committee, who could overturn any recommendation of these committees.

A Board of Advisors, consisting of 20 men and women with experience as leaders in the business community, met monthly to monitor the orchestra's budget and offer advice on strategic matters. Another group, the Foundation, took responsibility for raising and investing capital in order to create a fund on which the orchestra could draw during lean times. The Guild was formed from individual donors and the group of Friends comprised enthusiastic supporters who volunteered their services in preparing bulk mailings and selling programmes on concert nights.

Structurally then, the Orchestral Committee of the entire 68 tenured musicians was the heart of the enterprise. Figure 7.2: AP Board Relation and Structure (2001) shows the Society at the top of the enterprise with the Board of Advisors, Music Director and Management being directly responsible to the Society through its Secretary. The names of personnel have been removed from the chart for reasons of confidentiality. 


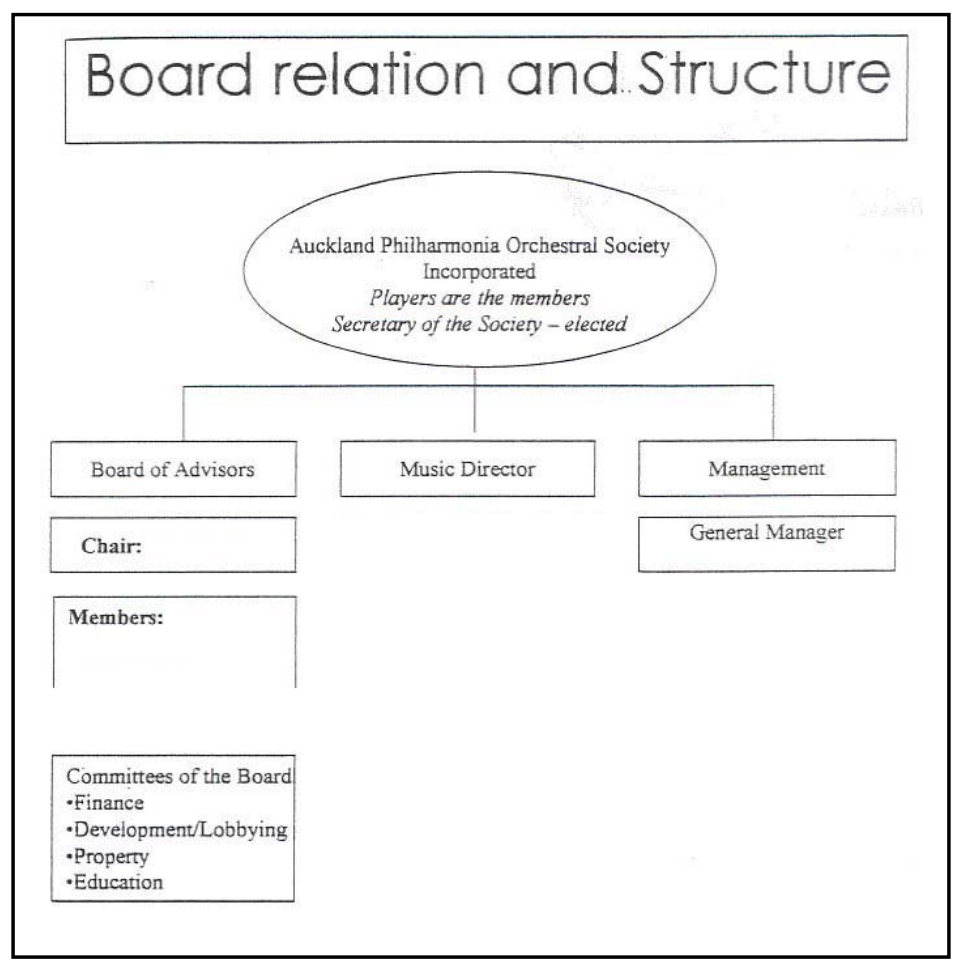

Figure 7.2: AP Board Relation and Structure (2001)

A further chart, Figure 7.3: AP Lines of Accountability (2001), shows the Society in the centre with arrows pointing into and away from it to reflect the central role of the Society, and the relationship of the players with the various stakeholder groups. In this diagram, the Funders, Sponsors and Audience are in the upper most box, signalling their utmost importance to the success of the orchestra. The Music Director's role sits alongside the Society showing an equal relationship. 


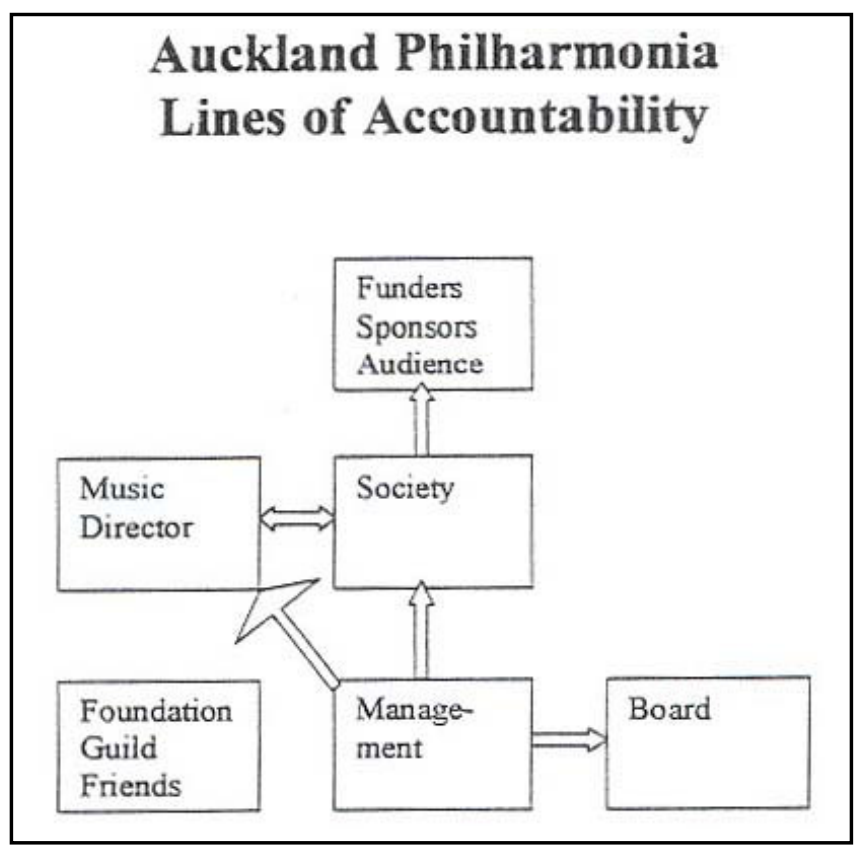

Figure 7.3: AP Lines of Accountability (2001)

The Management Team took its lead from the Society and Board with the General Manager heading that department. Figure 7.4: AP Management Team Structure (2001) shows the lines of accountability. The Orchestra Manager looked after the day-to-day affairs of the orchestra ensuring that there was a full muster of players and that each musician had a complete set of scores before the first rehearsal. The Development Manager's primary responsibility was fund raising, while the Artistic Administrator sourced and hosted visiting artists and made a contribution to programming. The Marketing Manager took care of advertising, focusing 
on print, television and web-based media; and the Business Manager maintained the accounts and ran the office.

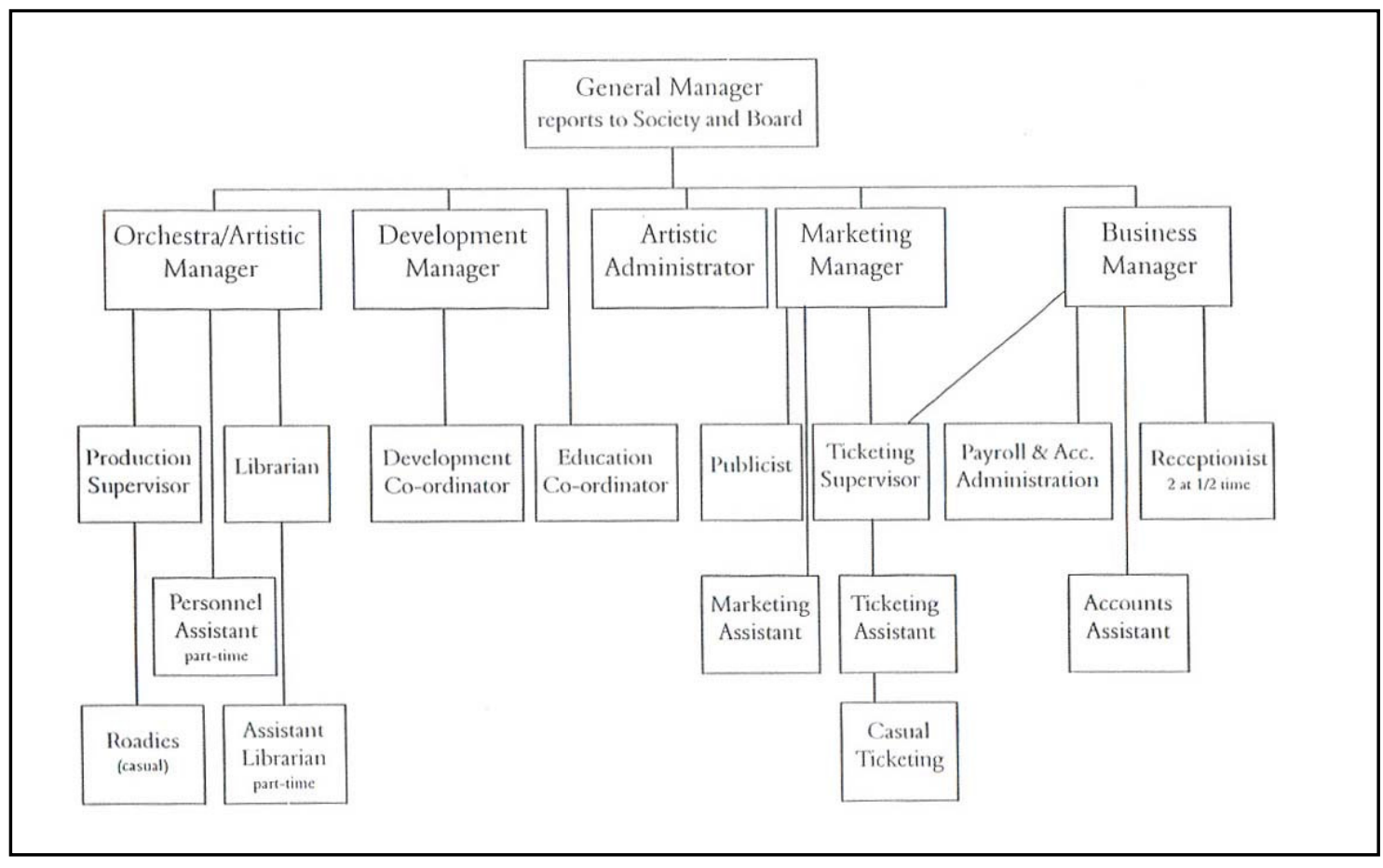

Figure 7.4: AP Management Team Structure (2001)

Finally, the chart that demonstrates the way in which the orchestra managed its finances reflects a fascinating arrangement. Here, in Figure 7.5: AP Budgetary Control (2001), the Society, Board and Management are shown as circular entities. The Society retains its dominant position at the top, with the overlapping circles revealing a mutually supportive relationship among the three groups. 


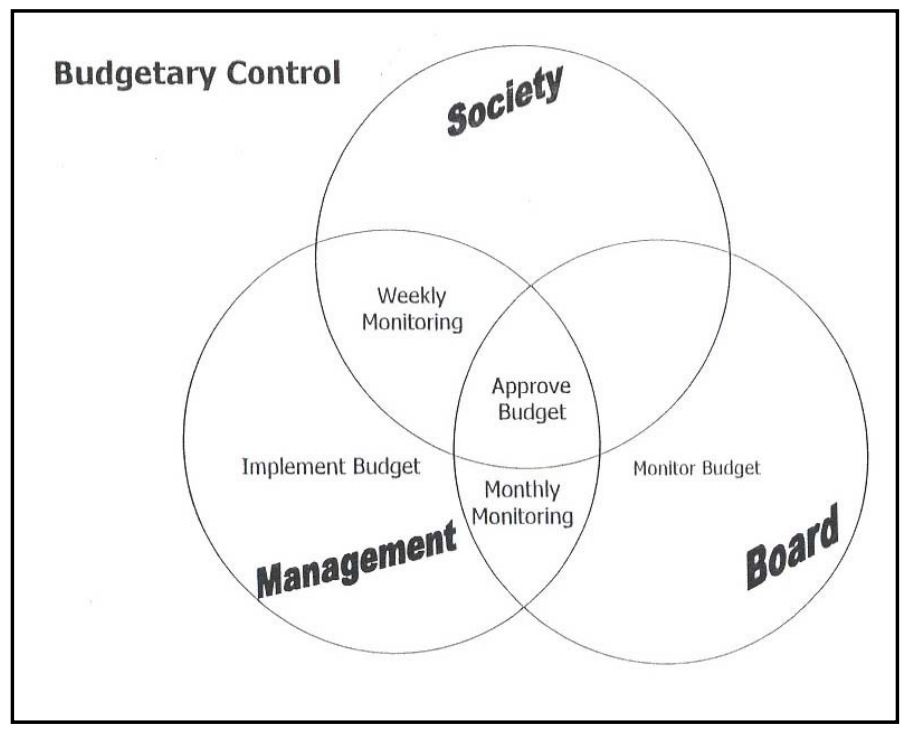

Figure 7.5: AP Budgetary Control (2001)

However, after about 20 years of growth and operating with the Society as the pivotal entity out of which all other activities were derived, enthusiasm for the Cooperative began to decline. In the late 1990s the orchestra had grown from one with a core of 45 players to one with 68 players, and the early 2000s saw an increasing groundswell for the structure to adapt to a new business climate in which the orchestra found itself competing alongside various other community interests for scarce funds.

Players were informed by members of the Board of Advisors that corporate donors and Creative New Zealand were demanding higher levels of accountability than in the past, and expected that the orchestra's 
governance structures would more closely reflect those of their organisational world. The Board of Advisors considered the size of the Cooperative too big and unwieldy to provide adequate strategic management, and pressed for more artistic power to be placed in the hands of the Music Director, a more formalised Artistic Committee which would oversee player standards and a General Manager empowered to make operational and commercial decisions without continual reference to the Society.

Because of New Zealand's small population, a steady supply of players, especially section principals and soloists, needed to be recruited from overseas. By its 20th anniversary, the orchestra had changed dramatically from a part-time homogeneous ensemble of 45 core players of mainly New Zealanders, to a full-time operation with a cohort of 68 tenured musicians representing a variety of cultures and experiences.

Although welcomed by all stakeholders, this growth came with a number of fiscal and governance challenges. The initial enterprising spirit and cooperative ideals of the Phoenix Group became increasingly diluted by players from Europe, Asia and North America, more familiar with 
orchestras that adhered to traditional corporate hierarchies. Many of these newcomers believed the cooperative system to be the reason that the orchestra was not growing in its artistic reputation. They considered that the Music Director must be empowered to discipline under-performers without reference to the Society. Similarly, they maintained that small committees charged to oversee the probation and ratification of players should be able to act without the threat of their decisions being overturned by Society members who, they considered, had vested interests in protecting the status quo.

As a result, during 2003 the orchestra underwent a review conducted by three men from the Board of Advisors. These three were the Chairperson of the Board of Advisors, a lawyer with experience in corporate law, and a former chairperson of the Board of Advisors. Each was selected on the basis of their longevity as leaders and advisors within the administrative arm of the orchestra and because of their professional expertise outside the orchestra.

The three advisors negotiated a new form of governance with the orchestra. The ad hoc Board of Advisors, hitherto drawn from the 
business community, became a fully-fledged Board of Directors with the power to oversee artistic and strategic matters. The most important change in this regard was that, whereas the Board of Advisors numbered around 20 people whose roles were to listen and to offer advice, the new Board comprised four musician representatives, three people from the business community and a further chairperson drawn from this latter group. The Board was granted executive authority and, in order to overturn decisions, the Society representing the Cooperative now required a $75 \%$ majority as opposed to the simple $50 \%$ majority needed in the past.

Another significant change was in the status of the Music Director. In the past his opinion had been just one voice among many. Now in matters of hiring and firing musicians, on the Artistic Committee, his opinion carried a weighting of four votes, whereas each of the other five members had one vote. These changes represented a significant dilution of the authority of the Society over the governance of its orchestra.

My research coincided with the debates surrounding the institution of these changes. In what follows I apply the aesthetic research methodology discussed in the previous chapters and cast an aesthetic gaze 
on some of the events that occurred between two Annual General Meetings held in April 2003 and May 2004 respectively, and show how aesthetics can give insights into the conundrums of organisational change and development.

\section{Getting Started}

To gain access to the Auckland Philharmonia I relied in the first instance on a colleague's contacts. He had been an office-holder and administrator and is still a contract musician. He introduced me to the then General Manager, who responded warmly to my approaches, and in December 2002 I had my first meeting with her, describing the project and outlining my objectives. We agreed that I would make formal application both to her and to the Secretary of the Society.

Over the next three months I wrote to the Secretary requesting access, and sought approval from the Victoria University of Wellington Human Ethics Committee to carry out the study, commencing on 31 March 2003. With sanction granted from both the University and the Orchestra, I began my research-proper at the 2003 Annual General Meeting (AGM) on the evening of 28 April. (Appendices A to D contain the Information and 
Consent Forms used to gain permission from the organisation and individuals to conduct the research.)

I initially felt uncomfortable; as if I were an intruder. The orchestra had only been told on the day of the 2003 AGM of my research and that I would be 'hanging around'. This, though, coincided with a period of considerable angst among the musicians because the orchestra was in the throes of a governance review. Decision making had become cumbersome with the large core of 68 musicians having input into the process. The committee system had all but disintegrated with the Artistic Development Committee unable to make decisions on player ratification without the threat of the Orchestral Committee overturning its advice.

From many I felt suspicion and only learned some months later that a few of the musicians had questioned among themselves why I was 'snooping around'. As a result of these feelings of dis-ease, I considered that my first task was to gain their confidence. I therefore set about to build rapport (Spradley, 1979, p. 78) by socialising with them. Going for coffee, sitting chatting, and just being around and visible, were strategies I employed to develop trust with the musicians. 
Orchestral players spend most of their working time rehearsing, making them unavailable for conversation. My challenge became how to make the best use of the limited free time they had, to speak with them and learn their stories. In a typical week in preparation for a subscription concert, the orchestra would rehearse a full day on Monday and Tuesday, half a day on Wednesday, finishing at lunch time, and then holding a preconcert run-through in the venue on Thursday morning. Subscription series concerts are held on Thursday nights. Other concerts featuring less serious music, or where the orchestra provides accompaniments for local choirs, take place on Saturdays and Sundays either during the afternoons or evenings.

It soon became obvious that talking to musicians after rehearsals was a futile enterprise. I noticed that as soon as their commitment for any day was fulfilled, they quickly dispersed, some to carry out teaching duties in schools or universities, others to run small business operations. The only times, then, that they were available for spontaneous conversation were scheduled breaks, and at lunch times on full-day rehearsals. 
I employed a number of different strategies to catch people during their breaks. One was to position myself in the café next to the orchestra's rehearsal venue, and with coffee at the ready, wait to see who turned up and then engage them in conversation. Another was to wait in the rehearsal room and then talk with a musician while he or she packed their instrument and then walk out with them. Out of courtesy, my question, 'can I join you for a coffee?' was never declined.

I used this strategy during lunch breaks too, and, walking to and from a restaurant, provided an additional excellent time to elicit information. Only once my request to join a group for lunch was declined. On this occasion, the pair, deep in conversation, did not want to be disturbed by an interloper, but invited me to join them some other time.

A further ploy was to sit around the Green Room during rehearsals. The Green Room is a dedicated space for performers to prepare, away from the gaze of the public. In the $\mathrm{AP}^{\prime} \mathrm{s}$ case, it is situated below the stage in their rehearsal venue. At any time there could be a group of musicians, not needed for a particular piece, sitting around waiting to be called for the next number being rehearsed. This proved a more relaxed place for 
conversation because time was not restricted in the same way as during lunch and tea breaks. The problem here was that I often came across the same people. Usually it was wind, brass and percussion players who would not be required. It was much harder to catch string players in this manner because they usually play through most of the orchestral repertoire and, therefore, rehearsed most of the time.

Another common tactic was to hang around after concerts at the venue's bar. In this setting the mood was convivial and musicians were more ready to talk. The buzz of a completed performance, enhanced by a little alcohol, relaxed the tensions that I felt from them during the day. These occasions were opportunities to gain a sense of how individuals were responding to current happenings and enabled me to make interview appointments. Further to these face-to-face meetings I also engaged in email conversations with several musicians to clarify issues and set up meeting times.

Alongside these unplanned exchanges, I also attended administration meetings. There were several committees of musicians that met regularly. Administrative Council's role was to ensure a full complement of players 
for concerts by reviewing leave entitlements and employing contract players. The Artistic Development Committee was on occasions called to audition new players, recommend probationary periods, and advise on ratification. The whole cohort of permanent players formed the Orchestral Committee which met monthly. This body was ultimately responsible for all matters of the Incorporated Society, including hiring and firing permanent musicians and was the nerve centre of the Cooperative enterprise.

I attended three meetings each of the Orchestral Committee and Administrative Council. However, as internal conflicts and differences of opinion among the musicians became more severe, I was approached by the Secretary with the news that my continued access had been withdrawn.

A similar situation arose with the Board of Advisors. I attended three early-morning monthly meetings but during the period of reconstitution, my access to the new Board of Directors was rescinded. Although they were sensitive to my need for access so that I could continue my research, Board members considered their need for absolute confidentiality to be a 
higher priority. New leadership protocols and lines of communication needed to be established and they considered that the presence of a researcher would inhibit the free flow of discussion.

I did, however, have full access to management team meetings. These involved two groups: the entire administration staff, and a smaller group of department managers including the Marketing, Artistic, Orchestral and General Managers. I attended three each of these meetings as well as a day-long one-off strategy planning retreat.

When it came to formal interviews (see Appendix E - Interview Schedule for a list of questions used to begin conversations), I wanted to canvas a wide cross-section of orchestral stakeholders. In all I interviewed twentytwo people: eight musicians, eight managers, two members of the Board of Advisors, a conductor, a composer-in-residence, and two former staff members - an administrator and a former General Manager. Apart from the two members of the Board of Advisors, who confessed to being musically illiterate, having become involved in the AP only as a result of encouragement from their respective wives, all the administrative staff I 
interviewed were aspiring artists in their own right, having involvement in music, drama or the visual arts.

The musicians proved to be the most difficult to schedule interviews with. After initially agreeing to an interview, two pulled out at the last minute and one did not show up. With the eight I was able to interview, on most occasions I made a personal approach. Here I spoke to them directly, requesting an hour of their time. I plied my request with the undertaking 'I will fit in with your schedule' and this was usually sufficient to counter any reticence on their part.

Interviews were conducted in the venue of each interviewee's choice and most often this was a coffee shop and occasionally a small room in Philharmonia Hall, the orchestra's rehearsal venue. The benefits of using a café were that it provided a neutral venue and a confidential space. However, often ambient music and road noises proved an added difficulty in fully attending to the conversation.

After access to the committees was denied, several people acted as key informants (Marshall, 1996) keeping me up to date with developing 
events. In all, I spent about 200 hours in observations, interviews and concert attendance.

When it comes to reporting on discoveries, the ethnographer's challenge is ‘how to represent and make understandable a large collection of observations of day-to-day work or practice' (Carlile, 2002, p. 447). Finding a way to write the findings in a compelling and informative way is, therefore, a universal problem. Van Maanen claims that ethnographic writing can be either realist, written in the third person, or confessional firstperson accounts. He also poses a further option, impressionistic writing, which combines the others into a hybrid of first- and third-person accounts (Van Maanen, 1987). These categories are useful stylistic guides because they assist in engaging the readers' cognitive and affective domains, which are both essential elements of aesthetic ethnography.

To begin, I started both a diary to record events and conversations, and a reflective journal to use as a think-pad on which to make notes about my developing ideas. Apart from the formal interviews which were taperecorded, I noted the content of events and meetings in the diary in situ because I was unable to make video or audio recordings. My strategy at 
meetings was to sit in an obscure place and quickly jot down information on note paper and then transcribe these notes into electronic form either during the day at a nearby internet café or at the end of each day at home. The exception to this was that a colleague was granted permission to videotape a three-hour rehearsal in May 2004 which became the basis for exploring about the ways leadership is practiced among musicians in rehearsal. These explorations formed the basis for a presentation at the Second Art of Management Conference which will be discussed below.

As an aid to my developing thinking, I also prepared a number of conference papers and used these as reflective pieces in which I could experiment with theoretical frameworks. The first of these was a paper delivered at the Academy of Management Seattle Conference 2003, where I presented a co-authored paper On organisational harmony (Bathurst, Barry, \& Williams, 2003). In this paper we posited that an awareness of musical dissonance can aid in understanding the continual interplay between tension and resolution; dissonance and consonance. We proposed that this makes possible a more astute awareness of the benefits of dissent among organisational actors. 
At the Second Art of Management \& Organisation Conference in Paris 2004, I presented three papers. The first of these, Developing structural competence: Using aesthetics to understand temporal organisational structure (Bathurst, 2004), proposes that music provides insights into temporal structural movement. Many of the concepts explored in this paper are discussed in this thesis in Chapter 4.

The second paper, Acquiring an aesthetic language (Bathurst \& Barry, 2004), was an observed conversation between me and David Barry in which we discussed the need for an aesthetic language that we, as organisational researchers, could use in our work. In this conversation we reflected on the ephemeral nature of aesthetic response and wondered if visual representation has more resonance with research subjects than trying to elicit information verbally.

The third paper, Exploring leadership among musicians (Bathurst \& Williams, 2004) used the video recording made in May 2004. In it we described how communication occurred within the AP in rehearsal. Here we noted how the traditional orchestra's strict hierarchy was disrupted and observed the conductor giving and receiving advice from the musicians. 
In July $2005 \mathrm{I}$, along with two colleagues, presented at the 8th International Conference on Arts \& Culture Management in Montreal Letting go of the rei[g]n: Developments within an orchestra in a time of change (Bathurst, Williams, \& Rodda, 2005). This paper, which summarised the history of the Auckland Philharmonia, offered Kenneth Burke's dramatistic turn as a theoretical lens, and was subsequently accepted for publication by the International Journal of Arts Management (Bathurst, Williams, \& Rodda, Forthcoming). In particular, we examined the results of the orchestra's restructuring and probe into the reasons that it did not have the desired results.

These papers, the research diary, and journal, all became reference points for my developing thinking. I regularly returned to the diary to review past events and replayed recorded interviews so that I could revisit the contexts of the conversations rather than just relying on the transcriptions. To assist in this process, I converted the analogue tape-recordings to digital format. This enabled me to use my computer as a tool to toggle between significant portions of the interview whilst I was writing and reflecting, thereby helping me keep close to the original context of the recordings. In this way my sensations and perceptions grew out of the 
actual environment rather than relying on discursive readings (Hansen, 2002).

\section{Beguiling Theatre}

The first movement of aesthetic research sees the researcher becoming emotionally attached to the site, leading him or her to have an almost insatiable appetite for more. This was certainly the case for my research with the Auckland Philharmonia. I enjoyed being back in familiar territory, and even hearing the sounds of the orchestra tuning reconnected me with my past musical experiences.

As noted above, an orchestra is a hierarchical body whose rehearsal and performance mores universally are adhered to. Although today's conductors tend to be less dictatorial than those of generations past, they nonetheless wield considerable power. In spite of its cooperative management style, on stage the Auckland Philharmonia was no exception to this rule. Players did not speak with the conductor during rehearsals. The only person with direct access to him was the Concert Master. I noted that even though the AP's Concert Master is female, the title retains its masculine nomenclature. On occasions, principals spoke with the 
conductor but no rank-and-file musician made a direct request or offered comment.

These elements of leadership and follower-ship were explored in a coauthored presentation at the Art of Management Conference in Paris 2004 (Bathurst \& Williams, 2004) referred to in the previous section. In this presentation we showed video clips of the AP in rehearsal, noting the exchanges between principals and members of their sections, and interactions between the conductor and principals. Most of the time the conductor was in absolute control, but on request from a principal wind player, he changed his time pattern to clarify the tempo following a pause in the music.

In performance, similar universal protocols reigned. The Concert Master was the last musician to come onto the stage and her role was to tune the orchestra. Once the orchestra was ready, the conductor entered, with the orchestra standing as a mark of respect. After the conductor had signalled them to be seated, the musicians would ready themselves and begin playing when he (there never was a female in charge during the research period) raised his baton. 
However, the dignity of these formal public events was at odds with the life of the orchestra away from the public eye. The AP owns a converted movie theatre in suburban Auckland and this is where it rehearses. Philharmonia Hall, as it is now named, is a renovated art deco building. Its interior is flood-lit by strong suspended lamps, but when the orchestra is not rehearsing, it has a dingy, dank feel about it. The Library and Music Director's office are sited in the front foyer area and both spaces are cramped and have an untidy appearance.

The Green Room is located beneath the main rehearsal area. Because of this location there is very little natural light in the room. It is brightened, though, by several large paintings on loan from the James Wallace Charitable Arts Trust. These works transform an otherwise bland space, giving it an artistic flavour.

Beneath the Green Room is a basement which floods during heavy rains, a not infrequent occurrence in Auckland. Over time the floods have damaged the building's foundations but a lack of funds has meant a permanent solution to the problem has not yet been found. 
Administration offices are located in a converted early-1990s bungalow next to Philharmonia Hall. These rooms are small, and files and desks are crammed into every available space.

These buildings give the impression that the AP is struggling financially. During 2003 a feasibility study was carried out to make the main concert venue, the Auckland Town Hall, its rehearsal location. However, in spite of the benefit to the orchestra of a raised profile in the centre city, the costs entailed in making this move proved prohibitive.

As already noted, my research began with the 2003 AGM. This was held in the rehearsal area of Philharmonia Hall. For the meeting, a table was positioned on the floor where the musicians usually sit to rehearse, whilst the attendees were seated in an elevated area at the back of the Hall, a space usually designated for small audiences to observe the orchestra in rehearsal.

The format of the AGM included an address from the Chairperson of Creative New Zealand, the $\mathrm{AP}^{\prime}$ s primary funding body; formal speeches by the chairs of key stakeholder committees; and the financial report 
tabled by the Society's auditor. Supper in the Green Room concluded the evening.

During supper one musician gave an explicit response as to why he continues in this role in spite of having other career options open to him. He said, 'The thrill and sheer excitement that playing in an orchestra can generate is something that is difficult to replicate.' This had also been my experience. I found that performing in large ensembles inspired transcendent sensations making me acutely aware of being part of something far greater than my Self. I, too, found orchestral playing exciting and stimulating.

And yet as my research began to progress, this idealism was soon to be shattered. As I began listening to stories, overhearing conversations, and observing meetings, I became aware of an environment marked by conflict, factionalism, and in-fighting. My curiosity about the relationship between musical theory and performance, and management practice, soon became subsumed in an attempt to understand the reasons for the toxic environment within which the AP operated. 
I set out wanting to see how the musicians used their artistry in management. However, what I confronted was an ensemble that was troubled and on the brink of collapse. It seemed that their dissonance had become self-perpetuating and that there was no repose or resolution in their internecine battle. My quest to observe the translation of creative and aesthetic notions from the performance platform to the manager's desk instead became a search to understand the dysfunction within the orchestra.

While I was attending concerts and rehearsals I continually asked the question: 'What am I hearing and feeling here?' Seeing and hearing classical works being performed with élan and artistry captivated my musical imagination but did little to inform me about the off-stage organisational dynamics. This beguiling piece of theatre seemed like a cover for competing ideologies being played out behind the scenes. So the feelings of inspiration and admiration became mixed with disdain, despair and even anger at the musicians for their inability to step back from the brink of self-destruction. 
In order to make aesthetic sense of the organisation as an entity and to move beyond its beautiful and beguiling public appearance, I needed to confront its ugliness, its off-stage identity. In this search behind the fold of cohesive performance, I began to discover a cacophony of competing sounds, each demanding the right to be heard.

\section{A Cacophony of Competing Sounds}

As I began my research, I became aware of a number of different viewpoints and competing ideologies all seeking dominance. I experienced these as a cacophony of sounds, persuasive metaphors each claiming legitimacy over the others. In the next section I discuss these cacophonous sounds and to preserve privacy, I use pseudonyms for directs quotes.

The 2003 AGM was replete with references to the 'Philharmonia family'. This metaphor implied a close-knit community focused on the common goal of exploring and promoting orchestral music. And yet several key speeches challenged this rhetoric. For example, the guest speaker, the Chief Executive of Creative New Zealand, the organisation responsible for 
the majority of the orchestra's funding, offered an alternative to the family metaphor. She said that the AP should consider itself to be part of a greater 'ecology' rather than a 'family'.

I found her shift in emphasis from the sociological to the biological curious. Her stated intent was to encourage the orchestra to look beyond itself to the wider artistic community. However, I wondered if her speech contained a veiled threat that funding regimes were set to change. She said that the orchestra as an art form is 'an endangered species' and quoted from a recent Financial Times article saying that 'classical music is terminally ill'. She noted that there is the on-going problem of gaining and holding an audience and that the AP needed to be savvier in its approach to the community. Implied in this was the need to undertake a change in governance that would cement the orchestra's place in Auckland and give greater confidence to funding agencies that monies were being well spent.

Similarly, the Society Secretary noted extemporaneously at the end of his prepared speech that 'the orchestra only survives due to the trusting relationships musicians have with each other and that have developed 
over time.' Again, I considered this an unusual statement given that it seemed to be self-evident. Why did he need to make this claim when successful performance inevitably relies on musicians trusting each other?

Supper following the AGM provided some initial illumination. As I mixed with groups of people around the gathering, several musicians passed comments like, ‘Were you at this afternoon's [Orchestral Committee] meeting?' and 'You should've been at this afternoon's meeting; that would've been an eye-opener!' The regular monthly meeting that afternoon had been acrimonious and some had expressed consternation at the proposed governance review, believing that the values within which the Cooperative operated were being put at risk. But of even greater concern was a heated debate over the appointment of a principal player.

The orchestra has a policy of trialling principal players over a period of three to six months. The Artistic Development Committee (ADC) oversees the probationary period and in the process canvasses players to gauge the suitability of the candidate. At the end of the trial phase, the ADC advises the Society whether or not the player is suitable for tenure, 
or that the trial should be extended, or that the candidate is unsuitable. In this instance, the ADC was unanimous in its recommendation that the player was suitable and that he be formally welcomed as a tenured member of the orchestra. However, the Society meeting that afternoon overturned this advice, requiring the player to undergo a further trial pending one small technical issue in his playing being corrected. An uproar ensued, with some players feeling outraged because there were those in the Society who had voted against the ADC on a seemingly petty issue.

The Secretary's concluding remarks in his AGM speech were a veiled reference to the division that had occurred. I said to him over supper that as a member of the public, I did not understand the nuances of his reference to 'trusting relationships'. He replied 'the players will know exactly what was meant!' He argued that the musicians should have trusted in the ability of the ADC to make a wise and well-considered recommendation and should, therefore, have agreed with it in principle. He felt that members who voted against the initiative lacked trust in their colleagues and had sabotaged an important decision. This non-ratification became, over the next few months, the issue which gave more urgency to 
the governance review and provided the reason for musicians to express their dissent.

More sounds from the cacophony assaulted my senses. Later in the week over lunch, one player, disillusioned by what he considered to be the poor and declining standard of the orchestra, proclaimed the need for more discipline among the players.

Georg It's like being in a rugby team. There is always a referee. When someone does something wrong the ref brings out the yellow card. Three yellow cards and then there's the red card and the player is sent off. We need something like this. Some players are not putting in the required effort to improve their performance. They are not practising and this is lowering the standard of the whole orchestra. What we need is a policeman, a policeman!

And yet an enforcer seemed to me to be counter to the cooperative spirit.

When I asked another musician about this, she was dismissive. She considered the Music Director upbraiding them for coming unprepared to rehearsals counterproductive, and that the purpose of rehearsing was to achieve a sense of 'ensemble'. 
Marie Well that's why we're there to rehearse; we can't practise everything at home by ourselves. It's about ensemble. He (the Music Director) doesn't understand that we could learn how to play together a lot better. It is not just about every [instrumentalist] being perfectly prepared. It would help of course. There's no denying it.

Furthermore, Marie claimed that there was little incentive to come to rehearsals fully prepared because of low remuneration. This placed greater emphasis on her sight-reading skills even in performance, a stress that she was prepared to trade off against her low wage.

Marie I do a lot of teaching because I am not happy just earning $\$ 30,000$ a year and so I'm never prepared enough for the orchestra. Like right now I'm rushing I'll go and teach. If I earned more I could give up the students and spend the afternoon maybe just having some time off and maybe doing some practice. I don't do any practice. That would horrify [other members of the orchestra] ... we're there all the time and we are all trying to earn some extra money ... and I haven't got time to do that practice and so there is always a element of stress when I'm performing on a Thursday night because I am good at carrying things off ... because I have done it for years, but it is always pretty borderline. Sometimes it's the skin of my teeth and it's the stress on your body, it tightens up, because you're almost sight reading.

Another musician complained to me that the off-stage environment had become abusive. Some players were openly hostile to each other and she had once observed a colleague shutting the door in the face of a disliked 
opponent. Still another said that, in the future, if a particular player spoke to her again in the same insulting manner as he had done recently, she would make an official harassment complaint.

I found these reported incidents difficult to understand as they offended my code of ethics and sense of propriety. I wondered at the contradictions I was experiencing, and pondered on how a dysfunctional group like this could perform sublime music. During a conversation in the Green Room, a musician succinctly summarised this problem. He said that the current climate of in-fighting 'definitely' affects the on-stage performance.

Charles When you are sitting next to someone [on stage] you have just had a disagreement with, you don't play so well. You don't give of your best and don't make an effort to produce the best sound you possibly can.

I asked him how I, as an outsider, would pick up this by just listening to them perform. He said that it would be in the quality of the performance, in their sense of 'ensemble' and in their ability to remain cohesive.

These ruminations were reflected in the comment the General Manager (GM) made to the Administration Council after a strategic planning 
meeting. The issue of the non-ratification of the probationary player was raised. The committee acknowledged that the non-ratification had increased the climate of bitterness and had further entrenched players in their respective positions. It seemed to the GM that the orchestra was playing a double game of appearing to the public to be a cohesive ensemble but behind the scenes was deeply divided. This was tantamount to hypocrisy and she considered that the orchestra needed to deal with the crisis urgently and stop getting her to do their 'dirty work'.

GM You must deal with [this crisis] and you must deal with it now. You are not on the front line. You go along in your beautiful suits and play wonderful music but I have to do your dirty work. I want this crisis in the orchestra to go away. I want it resolved!

\section{Spilling the Beans}

Surrounding all these cacophonous sounds competing for air time, was a climate of suspicion and aloofness. A conversation with one of the players, with whom I had studied with as an undergraduate 30 years previously, further alerted me to their suspicions. During a morning break she quietly checked out my credentials. 
Annie Are you allowed in those [Society] meetings?

Ralph Yes I am

Annie Don't leak them to the media will you?

Annie's reservations were grounded in the fear that disclosure of troubles could impact on the orchestra's ability to attract and retain much-needed sponsorship funding.

Another said to me that a friend had cautioned her about being too disclosing in an interview. This musician questioned my discretion and whether I would pass on information to the GM. I assured her that all conversations were totally confidential and reminded her of my ethical undertaking on the permission form she had signed. She nonchalantly replied, 'Well I don't care if I lose my job anyway.'

It seemed to me that this battle of attrition was occurring almost in isolation from the rest of the world. Right beside Philharmonia Hall is a workshop in which disabled people are employed making toys and performing process tasks. They run a café as part this operation. It was this coffee shop in which I regularly positioned myself waiting for the mid-morning and lunch breaks. Food was often prepared just in advance 
of morning tea when musicians descended en masse to order their snacks. On one occasion, whilst preparing for the onslaught, one of the disabled staff members dropped and broke a plate. She was distraught. Instead of chastising her though, the supervisor wrapped her in her arms and said soothingly, 'It's all right. It's all right.'

This scene dramatically contrasted with what I was observing at the orchestra. I said to myself, 'I wish all those musicians could have observed that. This is how real people treat each other!' To confirm this opinion, one of the Board of Advisors said at the close of an interview, 'In business you have politics, but in arts organisations there's blood on the floor!' He considered that the musicians were incapable of managing themselves and needed help from members of the business community more practised in leading large enterprises.

I experienced these cacophonous sounds as vignettes and found it difficult to identify any coherent underlying themes. I kept asking myself, 'what am I hearing here?' and 'how do I make structural sense of all these ideas competing for airtime - how do they fit together?' 
A solution presented itself when I was least expecting it. On 22 July 2003 I had mixed with the players during their morning break, still unable to discern how the ideas related together thematically. I was lingering in the foyer at Philharmonia Hall and musing on the problem, listening to the orchestra rehearsing the first movement of Beethoven's Symphony \#3 Eroica. They were playing through passages in the Development section of the movement with its dramatic clashing chords and sustained dissonances, when I experienced an epiphany, a flash of inspiration.

It dawned on me that what I was experiencing with the orchestra at the organisational level was a sustained period of development: a season of collapse when any sense of home and certainty was being destroyed. I began to ponder whether this collapse would eventually resolve into an improved orchestra, or whether the ensemble was beyond renewal and would ultimately collapse. I considered that themes should be evident within each vignette and that the motifs I was hearing were just snippets of information that belonged to larger ideas. It was hearing this segment of the Eroica that opened my thinking to the possible structural underpinnings of their angst. This symphony encapsulated the connection between art and experience that I argue for in Chapter 1. 
Beethoven's use of cross rhythms, his melodic explorations and use contrasting harmonies all contributed to my developing understanding of the orchestra's cacophony.

In summary, until this moment, a number of issues swirled around, all of which caused uncertainty. It was difficult to make any sense of events and I found myself being attracted to each successive voice. This only added to my confusion. It seemed to me that cacophonous sounds within the orchestra were struggling for thematic identity and I now needed to step back to analyse the degree of importance of each one.

My idealistic view of the orchestra, followed by my shattered illusions about its cohesion, led me to consider the enterprise as immature and unprofessional. But this value-judgement threatened to lead me to cynicism and ultimately to despise the musicians as a 'bunch of nohopers'. The competing metaphors of 'family', 'ecology', 'policeman', 'practised professional', only reinforced my notion that there were powerful interest groups within the band seeking to wrest control of the enterprise. I pondered on the reasons for their interest and several overriding questions emerged. 
Firstly I pondered why people from the business community would want control of an artistic organisation with which they had little residual affinity? Secondly, what motivated players new to the ensemble to wish to oversee the demise of an established cooperative culture that had been successful, and impose a governance structure that distanced players from the heart of their organisation? Finally, and more obliquely, how does musical aesthetics help make sense of and create order out of this cacophony? And as an extension to this last issue, how much should I allow outlying incidents outside the hermetic environment of the orchestra, such as the incident with the café staff member, influence my developing thinking? As my quest to discover the underlying themes intensified, these questions propelled me out of Emotional Attachment and into the next phase of my research, Cognitive Detachment. 


\section{ChAPTER 8 SECOND MOVEMENT: Cognitive DETACHMENT}

- Making Aesthetic Sense: Thinking Polyphonically

- Backward Reflexivity: The 2004 AGM

- Theme A: Artistic Freedom

- Theme B: Rigorous Fiscal Management

- Theme C: Responsible Leadership

- Theme D: Sound Structure

- Themes and Motifs

- Interlude 
The stage of Cognitive Detachment represents withdrawal: the researcher steps back from the site to critically examine presenting issues. The notion of detachment does not, though, indicate that the researcher is disengaged, but rather that he or she is thinking more critically and analytically.

When examining a work of art, the perceiver starts off as a naïve and yet curious inquirer. He or she may be intrigued, provoked or emotionally stimulated, but nonetheless uninformed. This next phase represents a change, where the perceiver becomes more discerning about the way the work is constructed. Here the aesthetician inquires about its sociological and historical context, its authorial intention, and seeks to uncover the layers within the work. Translating this into the organisational milieu, the challenge is to make sense of these layers by uncovering discourses within the enterprise. Following Ingarden's notion of sounding and nonsounding elements, this stage looks at both the articulated public issues and the less obvious back stage elements, and seeks to find explanations for each idea. 
In the previous chapter, I discussed the Auckland Philharmonia's 2003 Annual General Meeting (AGM), and introduced the reasons for the governance review that the orchestra was undertaking. I presented the problems underlying the relationships within the orchestra and noted that the enterprise had become factionalised, and that groups were engaged in a war of attrition.

Here I probe beyond my initial reactions to examine the organisation from the members' perspectives. This represents a shift in focus to questioning the sensations and perceptions of the actors within the organisation. The key questions with which to discover these are, 'what do you feel?' and, 'what do you see and hear?'

In order to elicit a response, I regularly asked of musicians and administrators: 'If this organisation were a piece of music, how would it sound?' The strategy behind this question was to probe the individual's sensations by linking feelings with imagined sound. Further, I wanted to see whether each respondent could articulate any kinds of shape or structure for those sounds, thereby requiring them to shift from immediate sensation to more formalised perceptions. 
Responses were varied. In the first instance, a typical initial reaction was 'That's a very interesting question ...' followed by a pregnant pause. Some then chose to liken the orchestra to a familiar piece of music or composer. In one instance an interviewee, Tim, said, 'It sounds like a badly performed version of Ein Heldenleben by Richard Strauss!' Tim went on to talk about the players of the orchestra being out of time and out of tune with each other and that the factions within the group were impairing its performance. He considered the orchestra to be lacking leadership and thought that the Music Director should be given more power to discipline under-performers. He highly valued the skills of the current (MD) and despised those who resisted increasing the conductor's status.

I asked Tim what his preferred sound was for the orchestra. He replied, 'a well performed version of Ein Heldenleben'. The choice of piece intrigued me. Ein Heldenleben is a musically complex tone poem requiring a largescale Romantic-sized orchestra able to perform cohesively. I noted to Tim that this programmatic work describing the hero's journey is autobiographical, with Strauss himself claiming the role of hero. I mused whether Tim linked the hero of the tone poem with the MD, whom he 
described as 'the real boss' of the orchestra. When I later pointed this out to Tim as we passed in the Green Room, he was dismissive about the irony of this connection.

Another respondent laughed cynically when I asked the question about how the orchestra sounded and exclaimed, 'It's like a piece of Prokofiev very depressing!' On several further occasions musicians gave a less descriptive analysis by bluntly declaring, 'It's a cacophony!' Here their intention was to show that the orchestra was so divided, it lacked any kind of discernable structure, with everyone 'doing their own thing'.

On two occasions respondents said they could not answer the question but could draw what they thought the orchestra looked like. One drew a line graph showing a declining trajectory while another constructed a picture with scribbles, lines and circles. In this latter case, the respondent, Louise, wanted to show a divided group with 'a lot of extremes, full of noise.' Figure 8.1: A Divided Orchestra shows a facsimile of her drawing. 


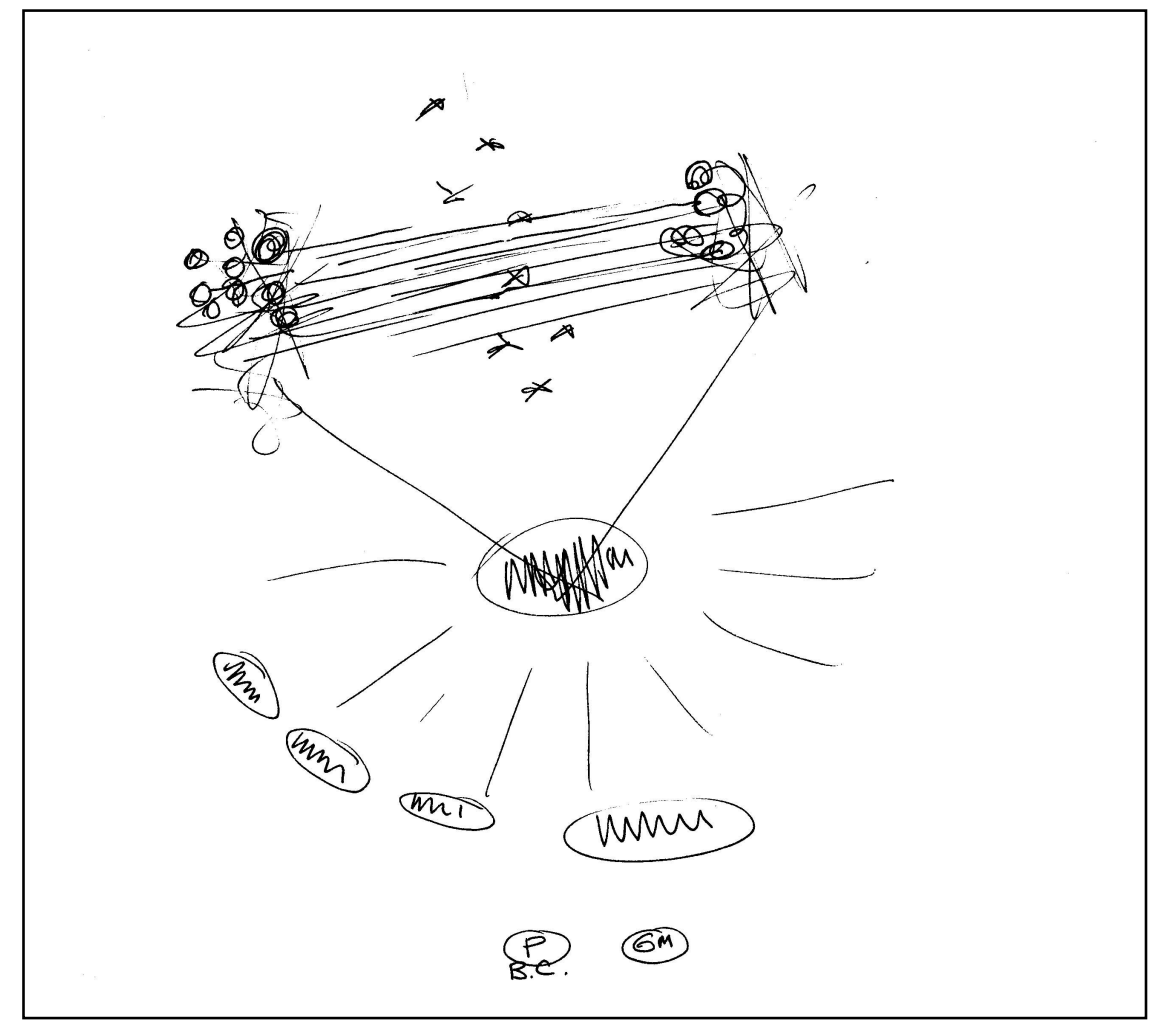

Figure 8.1: A Divided Orchestra

At the top Louise positioned the musicians in two loosely affiliated groups with disconnected strands 'moving past each other'. She placed a few non-aligned musicians as crosses in between the two larger groups. Her ideal was that the players would form one united orchestra, shown with the two lines connecting a shaded circle in the middle of the chart. Beneath, the ensemble is linked to the various stakeholder groups such as the Guild, Friends, and Board. The President of the Guild (P), Board Chair (BC) and General Manager (GM), sit beneath these groups. 
In her chart, Louise wanted to show a shift from her current perception of the orchestra as a troubled group (shown by the disconnected lines at the top), to a new improved scenario (with the shaded circle in the middle of her chart). Louise considered that it was the task of the General Manager and Board Chair to bring the groups together, adding, 'but if they're not clever enough to put the two groups together then you won't ever get the magnificent togetherness that the orchestra is capable of.' She considered that, given the current inability of the governing body to build a cohesive group, it seemed unlikely that the existing leaders would be successful.

Each of these descriptions: a cacophony, a badly performed piece of music, a line graph, and the drawing of disconnected lines are provocative descriptions but they do not tease out the elements that contribute to the images. To make this next step of critical analysis, the aesthetician is required to press beyond surface descriptions in order to examine how thematic threads fit together. This necessitates the researcher thinking polyphonically, allowing each theme to be expressed without reducing any to a single idea. 


\section{Making Aesthetic Sense: Thinking Polyphonically}

In order to understand the nature of the events as they developed, I

resisted the urge to see events as being in either-or binary categories and

opposing polarities. As noted in the previous chapter, although this

tendency is common in the orchestral literature, it lacks depth of analysis.

Positioning people on the bi-polar continuum of business or arts, and then

noting how one gains ascendancy over the other, defies the multiplicity

present in the discourses. A more musical approach is seeing the

environment as a polyphonic interweaving of different and sometimes

contradictory themes occurring concurrently.

Polyphony can be defined as 'the combination of melodies that are

rhythmically independent' (Harman et al., 1971, p. 48) and is often

contrasted with monophony where only a single melodic line exists, or

homophony where a melodic line is supported with a harmonic

accompaniment of the same or similar rhythm. Polyphony, then, is a

complex interweaving of melodic lines that have diverse characters. No

single line is of greater significance than the others and the lines may

move in and out of prominence. At times even a hint of a motif, or 
melodic idea, can suggest the entire theme, and in this way 'several parts can claim the character of a main part' (Frobenius, 2004, n.p.). In summary, polyphonic music can contain a number of themes and contrasting motifs within themes. In spite of this diversity, they all link together into a cohesive whole, based on an implicit formal structure.

Musical polyphony has its roots in Greek drama. Here the tragic form 'confronts the spectator directly with a multitude of voices, each with an equal claim, in principle, to truth and authority' (Barrett, 2002, p. xvi). Rather than clarifying and simplifying ideas, dramatic polyphony has the effect of 'producing opacity and ambiguity in the language of the plays' (Barrett, 2002, p. xvi).

Taking this line poses a problem for the organisational researcher who tries to decrease ambiguity in an attempt to simplify and clarify. Rather, the aesthetics of polyphony relishes rather than reduces uncertainty, thereby allowing the texture to be thickened instead of being diminished. Ultimately sense is made, once the layers of organisation are explored, by the researcher observing how the themes that comprise the polyphonic texture cohere as a gestalt. Therefore polyphonic thinking allows 
continual reference to a variety of themes, which make sense within the context of the complete whole.

In this chapter I undertake this task of examining the polyphonic strands that describe the organisational life of the Auckland Philharmonia during its period of governance restructure. However, because the orchestra was so factionalised, seeing it as neat polyphony with easily identifiable themes belied what I found. As I noted in the previous chapter, it occurred to me as they were rehearsing Beethoven's Eroica Symphony that the orchestra was in a state of sustained development. In this symphony, the Development section of the first movement makes up over half its length, and rather than working out just one idea, Beethoven includes motifs from all the main ideas and sometimes these ideas are explored simultaneously. Further, Beethoven deliberately obfuscates the listener by overlaying the regularity of the triple metre (3-4 timing) with duple accents (2-4 timing) that contradict the rhythmic certainty. The resulting thematic, harmonic and rhythmic confusion serves to add emotional intensity which is only ultimately resolved at the final coda. 
In order, then, to make sense of the complexities, I begin my analysis by going forward by 12 months from the 2003 AGM to the 2004 AGM. In particular, I consider the 2004 Chairman of the Board of Directors' speech, for, in it, he summarises the main ideas that the orchestra struggled with during the previous year. It also contextualises events, showing how elements fit together.

Just as making sense of a piece of music requires an ability to think backwards, the aesthetic ethnographer deploys a similar strategy of backward reflexivity, using the past as a lens on the present. Therefore, the Chairman's 2004 speech is a reference point with which to explore ideas as they evolved throughout the previous year.

Throughout my description I will use material from my diary accounts of the meetings as a primary resource. This will be supported by text from formal interviews.

\section{Backward Reflexivity: The 2004 AGM}

The first AGM I attended was on held 28 April 2003 and the next one, held on the 14 May 2004, provided a context to show development over the 
previous year. I was able to make comparisons and observe the changing climate of the orchestra as it confronted changes in governance and management style.

One of the most striking differences between the two AGMs was the almost complete absence of the term 'family' in the second meeting. As mentioned in the previous chapter, many of the speakers during the 2003 AGM spoke of the 'Philharmonia family' as a way of describing the ups and downs of life in the orchestra. While the word 'family' was alluded to in the 2004 meeting, there was a sense that a whole new regime was in operation.

The Chairman of the Board of Directors' report in 2004 was an opportunity to hear about this new state of affairs and the official version of the reasons for the restructuring. His report outlined the reasons that changes were necessary from a managerial, artistic and financial point of view. He addressed the issue of orchestral governance and the changes that were made so that the musicians could focus on their artistic role and leave managerial tasks to others. (See Appendix F for extensive extracts from the Chairman's speech.) 
In Chapter 6, I noted that before hermeneutic meaning-making can occur, it is necessary to complete the exegetical task. This process examines both the logic of particular claims as well as observations and assumptions, and then draws conclusions based on these ideas.

The Chairman's speech was replete with motifs that formed the basis of themes that had been worked out in the orchestra over the previous year. He claimed that the orchestra had returned to a 'more conventional hierarchical governance structure' necessitated by the needs of a 'modern and professional orchestra in a changing commercial environment where the standards of governance have been raised'. Thus commercial realities mixed with tried-and-true hierarchical management systems would now provide a more secure operating environment. In the body of his speech he discussed the operating deficit as a key reason for making these changes: it had become a matter of change or die.

He went on to explore the recent history of the orchestra through the language of emancipation. The musicians had been beset with 'trials and tribulations' but were now 'free to pursue their musical careers'. They are, after all, 'free spirits' who need to be 'unshackled from and unburdened 
by the day to day operation,' and the new structure would allow them to perform with 'freedom, passion and excellence'.

Set against this, he noted that by the end of the financial year the orchestra had a 'trading loss of $\$ 341,000$ '. He advised that to correct this aberration and create a financially secure operation a new structure was needed. Within this insecure economic environment where specialist fund-raisers and managers were required to fill the orchestra's coffers, the musicians would be released to focus on their artistry, and the new Board would concentrate on the big-picture strategic issues.

Why did the Chairman refer to these particular issues? During that year the orchestra had adopted a governance style that empowered small committees to act on its behalf, diluting the power of the cooperative. What were the drivers that led to these significant changes? Rather than taking words at face value, the exegete poses questions about the nature of language - how it is used and the context that generated it. Therefore, to make sense of his speech I go back to conversations with musicians, and, later in the chapter, to two Society meetings held in May 2003 when the orchestra began its governance review. I have selected the conversations 
and meetings specifically because they help contextualise the Board Chair's speech to the 2004 AGM.

In Figure 8.2: Backward Reflexivity: A Backward Summary of Key Events, I show graphically how my thinking developed. I have positioned six events outside the circle which encompasses the May 2004 AGM. The 2004 AGM is situated at the bottom of the diagram and its dotted perimeter line indicates that this meeting is the event out of which reflections on other prior and future events are generated. The black circle for the 2003 AGM is set above this and other events cluster around it, showing their chronological immediacy to that first AGM. Events are not positioned linearly but are placed above and below each other. Further, most of the arrows emanate from the bottom circle and point upwards to visually demonstrate the process of retrospective thinking.

So rather than placing the events on a timeline, I have positioned them above the large circle to show that backward reflexivity is not a linear process and that my reflections on events did not occur in sequence. The one arrow that points back to the large circle refers to the Personal Grievance (PG) lodged in February 2004. Although this PG did not 
become public knowledge until after the AGM (hence the arrow pointing back into the circle), it formed part of the backdrop of the Chairman's speech. The September 2004 suspension of the constitution is joined with an arrow pointing out from the circle. In this instance the May 2004 AGM becomes anticipatory of this turn.

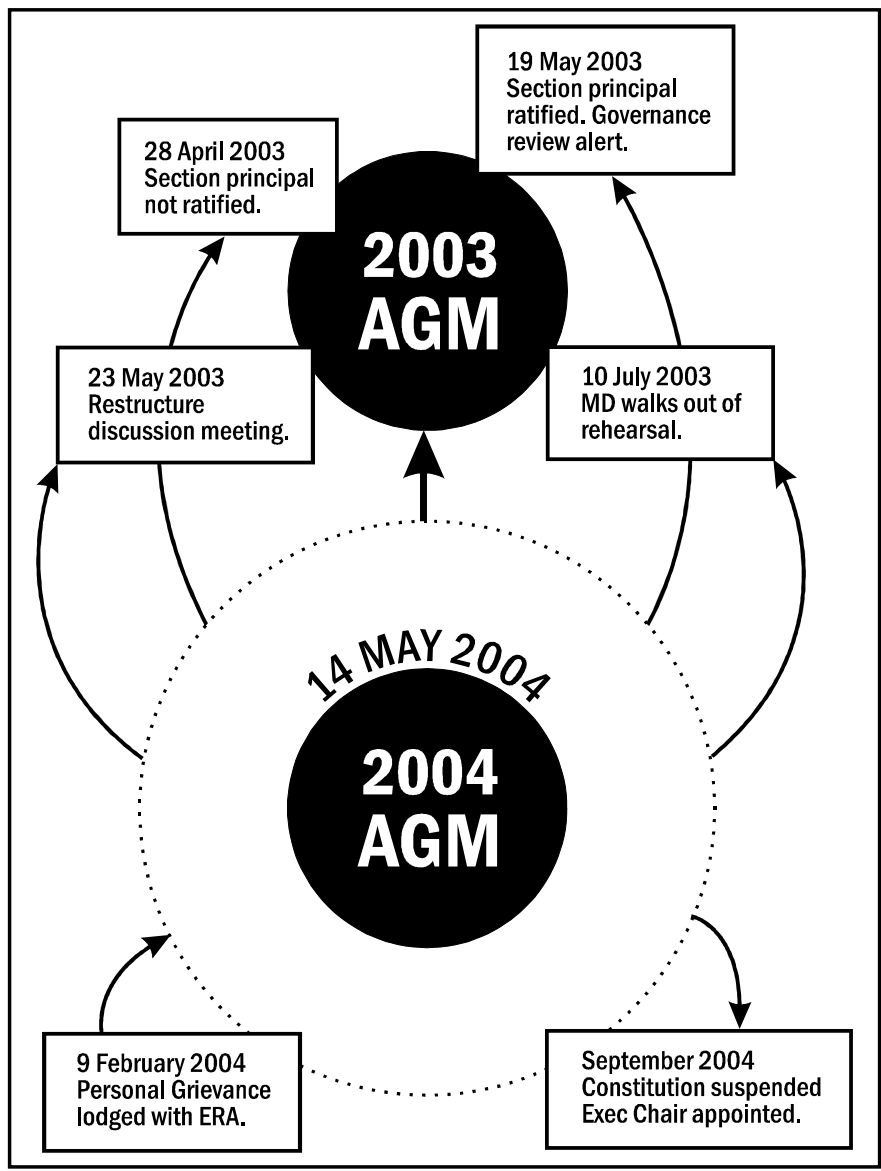

Figure 8.2: Backward Reflexivity: A Backward Summary of Key Events

The events that I describe in what follows are snapshots, and where appropriate I will fill them out by referring to other encounters, 
conversations and interviews. In the case of meetings, I positioned myself in a corner of the room to be unobtrusive and quickly wrote notes capturing as much detail as possible. At times I was able to write direct quotes while at others, because of the pace of the meetings, I was only able to sketch statements and events as they unfolded. Where I refer to my notes, I use the title Field Notes, whereas direct quotes have titles or pseudonyms beside them for the sake of confidentiality. Below I examine the discursive themes that interweave polyphonically within the orchestra, namely 'artistic freedom', 'wise fiscal management', 'responsible leadership', and 'sound structure'. At times, these themes are constructed by highlighting smaller contrasting motifs.

\section{Theme A: Artistic Freedom}

In his 2004 AGM speech, the Chairman Chris said that the musicians needed artistic freedom where they would be liberated from the daily running of the enterprise in order to explore, develop and strengthen their artistic expertise. Thus, separation from the humdrum of management and decision making - the minutiae of institutional governance - would enable them to produce a superior musical product. To make this claim, 
he had picked up some of the murmurings among the players that standards were falling.

To arrest this decline, during a rehearsal in July 2003, the Music Director walked out in protest against some players who had come unprepared. One player said to me that they were 'conductor-less for $1 \frac{1 / 2}{2}$ hours until someone prized him out of his office'. Opinions were divided about the benefits of his strategy. Section principals I spoke with complained that some of the rank-and-file players were turning up to rehearsals without having practised their parts. One principal player said he admired the Music Director for his action, claiming that 'the point needed to be made' and this was the 'time to make a stand'. However, a rank-and-file player said that she thought the action infantile and that the Music Director's petulance further eroded any sense of goodwill some of these players might have felt towards him.

While many of the rank-and-file musicians acknowledged that standards were not as high as their off-shore counterparts in Australia, North America and Europe, they were prepared to live with this because they were free of the strictures that board-controlled orchestras impose on 
players. For these musicians, artistic freedom came from a sense of ownership.

In an interview, Marie spoke of the importance of retaining the cooperative ideal even though that meant low pay and consequent low standards. She compared the AP with their immediate rival, the Wellington-based New Zealand Symphony Orchestra (NZSO). As described in the previous chapter, the NZSO is largely funded directly by central Government and is a peripatetic band which services New Zealand's main centres. Further, the NZSO is corporately governed with little player input, and although the NZSO is rated by the general public artistically more highly than the AP, Marie preferred performing with her orchestra because she had ownership of the enterprise.

Marie I think in New Zealand it is quite hard to be in an arts organisation because there's not a lot of money and kudos and particularly the NZSO gets Government funding and they have a sense of being the national orchestra. We struggle up here [in Auckland] with a sense of who we are and I think the one thing that makes us unique is that we own ourselves. I am happy to accept poor pay and bad working conditions because I am making the decisions and I can go along with it and even if I am in the minority I can have my say, I've got a voice so I can put up with all sorts of crap. I have to because I am involved. 
In support of this, Ben, a one-time composer-in-residence with the AP, spoke of the difference in working climate between the two orchestras: the $\mathrm{AP}$ and the NZSO. He finds the AP musicians warm, enthusiastic and generous. The NZSO is quite the reverse. When rehearsing his commissioned works, NZSO musicians appear to him to be cold and uninvolved; very disinterested in his music and in him as a person. He attributed these differences to the fact that the AP was self-governing and therefore more connected to the inner workings of their orchestra. Many of the players I spoke with expressed no desire to belong to the NZSO, even though they were as skilled as the NZSO players. Notwithstanding its status as the 'national' orchestra, the NZSO's Wellington base and its travelling mandate made it an unattractive option.

Another AP player, though, questioned the claim to ownership of the rank-and-file players. Roger considered that owners included the ticketpaying public, advisors, board members and funding agencies. To limit ownership to a few musicians who could hand-pick their favorite soloists and conductors, would reduce the orchestra to an underpaid amateurish group with no artistic future. 
Roger It's not our orchestra, it never has been. It belongs to the public first of all who pay the ticket prices, it belongs to the funders, it belongs to the good advisors who support us and it also belongs to the players. If it was just our orchestra, we wouldn't have any of the other support base and we would be earning about five bucks a year!

Beyond these entrenched positions, there were others who had a more philosophical view of the nature of artistic freedom. Jenny saw the orchestra as a combination of 'suits and anarchists' working collaboratively and willingly together. Suits provide the business expertise while the musicians she saw as being anarchists. My field notes from a discussion meeting on 3 June 2003 summarises her concept.

\section{Field Note}

Jenny talked about the various faces of the orchestra. She spoke of anarchist collectives and that the players 'were like this - wearing jeans, tee shirts and sneakers - artists are individualists'. The Board, though, are suits with gold watches and white shirts. 'This is a different face and this is the face that we want in front of the public, especially donors.'

I questioned Jenny later about what she meant by the word anarchist. She explained it by drawing similarities between the orchestra and the cooperative formed in the Spanish town Mondragon. The Mondragon community, which began in 1956 with five engineers and a priest, is a cooperative venture now comprising over 23,000 members (Boje, 1998). 
Jenny considered that, like Mondragon, the Philharmonia needed to foster an environment where people with particular abilities in administration and financial management would offer their skills for the advancement of the orchestra's artistic mandate. As artists they could then focus on their primary performing tasks. This did not mean separating the two, however. Her belief was that even musicians could take on some of these managerial functions if they had talents in this area. She did not see any role as being fixed but rather conceived of a fluid environment where people would take on tasks while they had the energy and motivation for them, and then hand them over to others 'when they needed to move on'.

Nevertheless, this was not Chris's understanding. Chris is a lawyer and was one of the members of the Board of Advisors. In my interview with him he described an industrial model where, under the new structure, musicians would be required to lift their level of commitment and quality of individual skills. He noted that in the face of declining standards the new board was going to be more insistent on improving quality. Noncompliant players would be forced to resign because the new Board of Directors would be empowered to take such drastic action. In order to 
deal with this issue he considered there was a greater need for rigorous fiscal management. This theme was reiterated by other business advisors.

\section{Theme B: Rigorous Fiscal Management}

The orchestra was being pressurised by sponsors and its primary funding agency, Creative New Zealand, to make structural changes. Governance modifications had to be made, and the three men from the Board of Advisors conducting the review threatened the immediate withdrawal of $\$ 500,000$ if their wishes were not followed. Within its total budget of $\$ 4.5$ million, this nearly $10 \%$ drop of income represented a considerable threat and, along with the existing unsustainable operating deficit, would cause the demise of the orchestra.

In an interview with one of the advisors, Bill described some of the orchestra's financial history. About seven years earlier, the then local Member of Parliament and Leader of the Opposition, Helen Clark, had approached the General Manager (GM) asking for his 'wish list'. The GM informed her that they needed an extra $\$ 3$ million per annum to create a secure operating environment. In 1999 when the Third Labour Government was elected to office, Clark, now both the Minister for the 
Arts and Prime Minister, allocated $\$ 84$ million to the arts sector. The Philharmonia, though, only managed to secure a one-off grant of $\$ 350,000$. However, Bill was surprised to find that instead of retiring debt, the musicians voted for a wage increase, effectively wiping out any benefits the additional grant would bring. For him this was evidence of a need for people with safer hands to run the operation. Clearly, by selfishly consuming the financial gains to benefit themselves, the musicians did not give evidence of the ability to manage their own finances.

Nevertheless a conversation with the former General Manager, Bruce, offers an alternative view. Early in its existence the orchestra had been rehearsing in the evenings with musicians receiving low wages and taking part-time jobs to supplement their income. They had been losing their better players to overseas orchestras and were in danger of downgrading their product. When he became GM, Bruce's primary objectives were threefold. Firstly he decided to pay the musicians enough so they could afford to rehearse during the day; secondly the orchestra offered a raise in pay to stem the flow of player attrition; and finally Bruce increased the core members to a body of 68 musicians. The Creative New Zealand grant offered them the opportunity to form a fully professional orchestra and 
press towards cementing their international reputation. In all, these changes added another $\$ 1$ million to the annual operating budget and a serious effort was made to acquire financial support from alternative sources.

Bruce commented that all artistic organisations struggle to secure funding. Furthermore, it was vital to always keep close to insolvency so that donors would continue to provide funds. A wealthy operation could not make a compelling enough case for grants. Bruce said that the orchestra had always operated in a financially responsible manner and that audits commissioned by the Auckland City Council, another major funder, showed it to be in excellent shape.

Further conversations with Bruce yielded a rich resource of inner conviction regarding financial management. A number of years earlier he had read The Cross and the Switchblade, (1967) an account of David Wilkerson's running of a rehab in downtown New York for recovering addicts in the 1960s. The story tells of a therapeutic community reliant on public goodwill and charitable donations for its survival. There were times when that organisation, Teen Challenge, was on the brink of closure 
but was rescued at the last minute by some generous benefactor. Bruce said that when he became General Manager of the Philharmonia, he reread this book remembering the similarities between Wilkerson's situation and his own, and realised that 'One must have faith to run an arts company, and the ability to transfer that faith to the entire orchestra family, especially its funding bodies and musicians.'

The Cross and the Switchblade became his bible. Just as Wilkerson had experienced supply albeit often at the eleventh hour, so Bruce knew that funds always came in to cover an immediate shortfall. For Bruce it was an article of faith: money always arrives when it is needed. So for him, suggestions by the business advisors that financial management needed an overhaul were contemptible. 'Those guys don't know anything about the running an arts company,' he said dismissively.

Bruce Any fool knows that if you don't have a healthy deficit in an arts company, funders such as the Arts Council and Auckland City cut your funds and give them to some other bleeding heart. It is keeping the deficit under control ... that riding the edge of the wave without falling off, that is the art of running an arts company. 
So, within the theme of fiscal responsibility which interacted polyphonically, there were two differing motifs. One held that rigorous fiscal management required a plan that kept the orchestra with a credit buffer; the other taking a pragmatic approach to debt servicing that ensured the enterprise could continue to operate at least within the short term. This brings into relief the next theme which explores the nature of leadership.

\section{Theme C: Responsible Leadership}

Another theme interweaving with fiscal responsibility is responsible leadership. The Philharmonia administrators and managers meet regularly to discuss institutional matters and develop strategy. In a meeting on 3 May 2003 it became obvious that there were rumblings of discontent among the musicians. The Society Secretary came to the meeting to inform the team that that he intended resigning. One manager, Jean, said she hoped the resignation would force the orchestra to look at its underlying management issues. The non-ratification of a musician (a section principal) came as a blow to those wanting a more corporate style of governance. The Artistic Development Committee had recommended his ratification but the Orchestra Committee consisting of all 68 musicians, 
refused to accept this advice. The GM considered that the non-ratification and the subsequent resignation of the Secretary created an opportune moment to increase pressure for a change in governance. She believed that the hierarchies that existed on-stage in performance should directly translate into the governance structure and that the musicians were out of line in declining to ratify the section principal.

Jean This is a watershed moment in the life of the orchestra.
We've put efficiency structures in place. Orchestras
everywhere are hierarchies. We have the Music Director,
Concert Master and section principals. They all have their
place.

The managers felt that they had been expending energy on keeping the orchestra functioning without the cooperation of the players and considered the musicians to be incompetent when it came to organisational matters. In spite of the Society legally being the employer, the management team considered the musicians to be irresponsible and childish. In reaction, one manager said that as a group they had amassed enough experience and leadership skills to manage another arts organisation. My field notes pick up the events of the meeting. 


\section{Field Note}

[The GM] thanked [the Secretary] for all his work and [he] responded by saying that he thought the management team was far more committed to the orchestra than the players were. Several staff members responded spontaneously.

Brian Some of the players have mutinied.

\section{Field Note}

[A manager] spoke with considerable emotion about the toll of the current crisis on her. She has just got over the crisis from late last year where it took quite a lot of energy persuading the musicians to accept the re-appointment of their Music Director. (The Music Director had sought a mandate for a $1 / 3$ controlling vote in the artistic affairs of the orchestra. They refused to give him this power but a document was drawn up and signed by every member that entrusted him with artistic control 'in spirit'.)

The current crisis of the non-ratification of the section principal is the first test of this document.

This crisis comes on top of the heavy workload in preparing their annual application for government funding [through Creative New Zealand].

Jean I'm feeling a bit overwhelmed with the Creative New Zealand application and this current crisis.

Brian They are behaving like teenagers.

Henry Well we can all continue to run something else in the arts sector.

Jean We are looking at the dissolution of the Society.

\section{Field Note}

Jean said that some players (the progressives) had threatened to resign and some had threatened to go to the media with the story. 
The managers clearly considered the orchestra to be at fault. A group of players, termed the 'traditionalists' by the managers, were resisting moves towards a more corporate structure. However, leadership in the cooperative was much more complex and changeable than that of the management team.

A special meeting on 19 May 2003 was called to discuss the sudden resignation of the cooperative's Secretary. The Secretary is the one musician empowered to act on behalf of the cooperative's incorporated Society - the governing council comprising all 68 tenured players - in signing official documents and liaising with managerial and administrative staff. He participated in meetings of the Board of Advisors and played a significant role in the orchestra's strategic development. His resignation letter cites a lack of mutual trust among the players and the subsequent crisis that resulted directly from the section principal's nonratification. Below is an extract from his letter explaining his view.

... As I mentioned at the AGM, our system relies on a high degree of trust and respect for one's colleagues. When that trust and respect is there, the system works brilliantly. When it is absent, as at present, the system breaks down. The Society is quite clearly in crisis and if things continue on their current path then the only inevitable outcome is a dissolution of the Society. That outcome will produce no winners ... 
The meeting of 19 May had been called to vote on the Secretary's

successor and to re-consider the section principal's ratification. Because

the ratification issue had become so contentious, the normal six week

stand-down period between declining ratification and reassessment was

waived. The following extract from my field notes summarises the

meeting. All names are written as pseudonyms to preserve anonymity.

\section{Field Note}

The Green Room is a basement-level large room in the Aotea Centre (tonight's concert venue) two floors below stage level. I arrived at 2.05 $\mathrm{pm}$ and the musicians had already gathered. Some were sitting on the chairs and sofas while many were sitting on the floor. Although quite big, the room was not set up to accommodate such a large group in this kind of meeting format. There was such a loud hum of airconditioning and someone asked [the orchestra manager] to get it turned off because they could not hear the proceedings. I stood at the back of the room behind a pillar. (The air-conditioning remained on.)

The Chairperson (Kerry) was reading out a letter he had written to the Society. He reviewed the process since December of how the orchestra had got to this impasse over the section principal's ratification. He read that he felt their relationship with [the Music Director], as formalised in December, was being compromised. He was interrupted by Marie who declared that he had no right as Chair to make personal comments or persuade others of his viewpoint. An uproar ensued with many others indicating they too wanted to speak to this issue. Kerry defensively insisted that he was not trying to put forward his personal opinion but others disagreed with him.

One speaker outlined the agreement with [the Music Director] as being the Music Director's right of veto for any player being ratified, rather than insisting that the Society follow his every recommendation. Another said that this process was an example of the Society working in the way it was constituted and that [the Music Director] was fully aware and in agreement with this process. Another person said that [the Music Director] was, 'mature and wise enough not to be put out by the Society retaining its right to keep to its processes. He has a short-term future with the orchestra and will be moving on in, say, 
four years. On the other hand, [the section principal] could be with the orchestra for a long time and it is important that we make a correct choice - one that we are all happy with.'

Marie commented about small groups having secret meetings with board members and that this was detrimental to the functioning of the Society. Helen shouted with hands cupped around her mouth, 'Put the motion Kerry!' while Janet raised her hands and shouted 'Yay!'

The chairman had been overruled by many vociferous voices and he put the issue to the vote: 'That the [section principal] be ratified.' The orchestra uses pre-printed voting forms but because of the haste in which the meeting had been convened, no forms had been prepared for this issue. Players were asked to tear off the bottom portion of a second voting paper on the Secretary's replacement and write 'Yes', 'No', or 'Abstain' on it. One Asian man near me was totally confused and had to be instructed several times by Teresa as to what he should do.

Putting the issue to the vote effectively quelled any debate on the processes at the centre of the issue.

When the vote was finally announced, the musician had been ratified. Everybody applauded.

Immediately following the formal ratification of the musician, two candidates for the position of Secretary gave campaign speeches in support of their candidacy. The vote was taken and before the meeting dispersed, two representatives from the Board of Advisors gave notice of the forthcoming governance review. Notes from my diary describe their input.

\section{Field Note}

\section{Governance Review Alert}

Bill and Steve came and presented a summary discussion document 
about how they see the repositioning of the management of the orchestra. The document gave a timetable of future Society meetings that allow for questions to be answered and for viewpoints to be heard. They stressed that the proposed new structure was not designed to take away power from the Society whose members would all be voting on the changes anyway. However, they should see this as a way of 'delegating authority and showing respect for that authority'.

They handed out the document and said that this was not a 'governance' document as that title was too formal. It should be viewed as an 'empowerment of decision-making authority'. The last page included an organisational chart which they termed a 'wiring diagram'.

At the conclusion of the meeting the musicians went on stage for their pre-concert rehearsal.

Two elements of this meeting were immediately apparent. The first of these was its chaotic nature with people over-talking and shouting each other down. This revealed an incoherent cacophony. It was clear that many players were angry and wanted to vent their feelings. It was difficult, though, to discern any kind of consensus. The meeting was so confused that one of the players, for whom English was his second language, had difficulty in deciphering voting instructions.

The other element was the invitation by the two business advisors to attend restructuring meetings. In contrast to the musicians, they spoke in a reasoned manner, hinting at the proposed changes by using the language of human decency (the proposed new structure would delegate 
authority and show 'respect for that authority') and science ('a wiring diagram' was attached to the meeting notice showing the form a new structure might take).

The contrasts in leadership styles were immediately apparent. The musicians showed little respect for one another by over-talking and shouting. This produced a chaotic meeting where even simple instructions were difficult to comprehend. By comparison, the men from the Board of Advisors were seductively reasonable. They had come prepared with documentation to show where they considered changes needed to be made, and a proposed time frame for discussions to occur. This reasoned approach enabled them to sell the idea that 'sound structure' was of prime importance. The new structure would enable the orchestra to move beyond its cacophonous stalemate to a position where a new unified enterprise would appeal to sponsors.

\section{Theme D: Sound Structure}

A fourth theme that forms the polyphony is that of sound structure. A meeting convened the following week, on 23 May 2003, and led by three members of the Board of Advisors shows the importance of the structural 
dimension to the orchestra. The meeting's purpose was to describe the new governance structure and answer any questions and address concerns of the Society members.

The meeting began with the newly elected Secretary introducing the reason for the meeting. My field notes pick up the story.

\section{Field Note}

Graham, the newly elected Secretary to the Society, began by giving an analogy of the Society's history. It had started at an old shack and had gradually improved its lot until now it is living in a mansion. Its ultimate aim is to live in a palace.

Graham Now we live in a mansion and we need help to manage the mansion. We share the care of the mansion with people who look after us. So we employ a cook, cleaner and gardeners to do this work for us. We have a vision though, and that is the palace.

Following this introduction, the three advisors took over the meeting.

Steve, an investment analyst who had been in an advisory role for a number of years, began by introducing himself jokingly as one of the 'gardeners'. He said that the other advisors, Bill and Chris, were two other 'gardeners' and then went on to explain why there was need for a new structure. 
Steve Why this restructure? All the stakeholders are becoming more and more important and demanding. A lot of pressure is being applied for us to have good governance there's a lot of pressure from the outside.

Steve went on to say that funding agencies like Auckland's local councils and Creative New Zealand were applying pressure for a new style of governance. Bill too, reinforced the need for the review by threatening that private sponsors would immediately withdraw funding if changes were not made. Turbulent negotiations surrounding the Music Director's renewed contract the previous December had threatened to become public knowledge, and this, in turn, had the potential to frighten off existing and potential sponsors.

Bill The situation [last year with the Music Director] came very
close to putting it on the street. If you guys want to self-
destruct then we will take $1 / 2$ million dollars with us today.

\section{Field Note}

An orchestral member (Jeannie) interrupted to set the record straight saying that they had not been aware that [the Music Director's] contract hadn't been signed and that they had not been informed by [the Secretary]. Once they knew, they were able to solve the problem successfully.

Bill interrupted.

Another member requested that Bill listen to everything Jeannie had to say. 
After this Bill continued with his explanation.

Bill What let us down was the process. We have no cash reserves and we're running close on a knife-edge. Two people owe us $\$ 200,000$ each and we are short on cash.

\section{Field Note}

Bill said that if this situation was to continue the Board would walk out.

Jeannie said she objected to criticism on the [Music Director] issue.

Jeannie $\quad \ldots$ because the strength of our structure resolved the issue in the end.

Bill What we're saying is that the problems are endemic. This is because of the size of the Orchestral Committee now. In the past you could sit around the table and talk over issues, now it is not possible with 70 members. Views are becoming entrenched between two groups with some in the middle.

\section{Field Note}

Bill noted that the London Philharmonia and Louisiana Philharmonia have adopted a similar structure to what is begin proposed - three elements

- a board of players and non-players

- decisions are not ratified by the whole group

- orchestral meetings were for information, not for decision making.

Bill It's not a case of if but when you make the change. Sooner or later it's going to hit the public arena. There are several issues that [another board member with a great pedigree of training and experience] noted.

- Untimely and potentially risky decision making

- Substantial equity and brand value that we've got to protect 
- There is a lack of clear levels of responsibility. We are up against the perception versus the reality of governance.

\section{Field Note}

Government funding agencies are requiring more accountability.

The orchestra 'is not delivering'.

Communication can be dramatically improved.

They don't want to lose the sense of 'family' with the cooperative nature of the orchestra.

They can make a sensible structure.

The advisors proposed that the new governance structure should mirror the corporate world, thus guaranteeing a stronger donor base. The existing cooperative structure was out of step with the rest of the business community and as the orchestra modified its structure, leaders from within the band could be nurtured and coached to suit the new environment.

Bill This is how corporates function.

\section{Field Note}

The proposed board is not interested in artistic matters.

Sanctions and controls will still happen in general meetings of the Society. 
Bill There are a lot of people in this organisation with so much talent. We on the board want to use the talent that is available. At the moment we don't see them.

However, this was not universally accepted by the players. Some objected to a new structure being imposed on them and they considered that existing policies adequately covered all possible contingencies. Further, some felt that peeling the business functions off was contrary to the cooperative spirit.

Player I think financial and artistic matters are entwined.

\section{Field Note}

[Another musician] made the comment that in the past they had an executive committee that performed the functions of what is being proposed. Why then do they need a new structure because the constitution can already handle such a structure?

Bill was dismissive of the cooperative's attempts to adapt their structures. Currently there was no structure in place that kept the board informed.

Bill You guys are in a mess and you're just adding mess on mess.

\section{Field Note}

People requested speaking rights by raising their hands. There was much over-talking by Steve and Bill. 
Following these interchanges, Chris, a lawyer, was called on to give his assessment of the organisation and describe the new structure from a legal standpoint. (Later in the year Chris was to become the Chairman of the newly constituted Board of Directors.)

He began his talk by drawing a number of loosely arranged circles on a whiteboard. These circles, he said, represented the cooperative as he currently saw it: its legal identity and the various committees of artists who managed particular elements of the Cooperative's affairs. He said that the circles were unconnected because currently the organisation was 'like a group of amoeba without any structure'. He added his agreement to Bill's assessment that indeed they were in a mess! Figure 8.3: The Amoeba Structure of the Orchestra shows the diagram he drew on the whiteboard. 


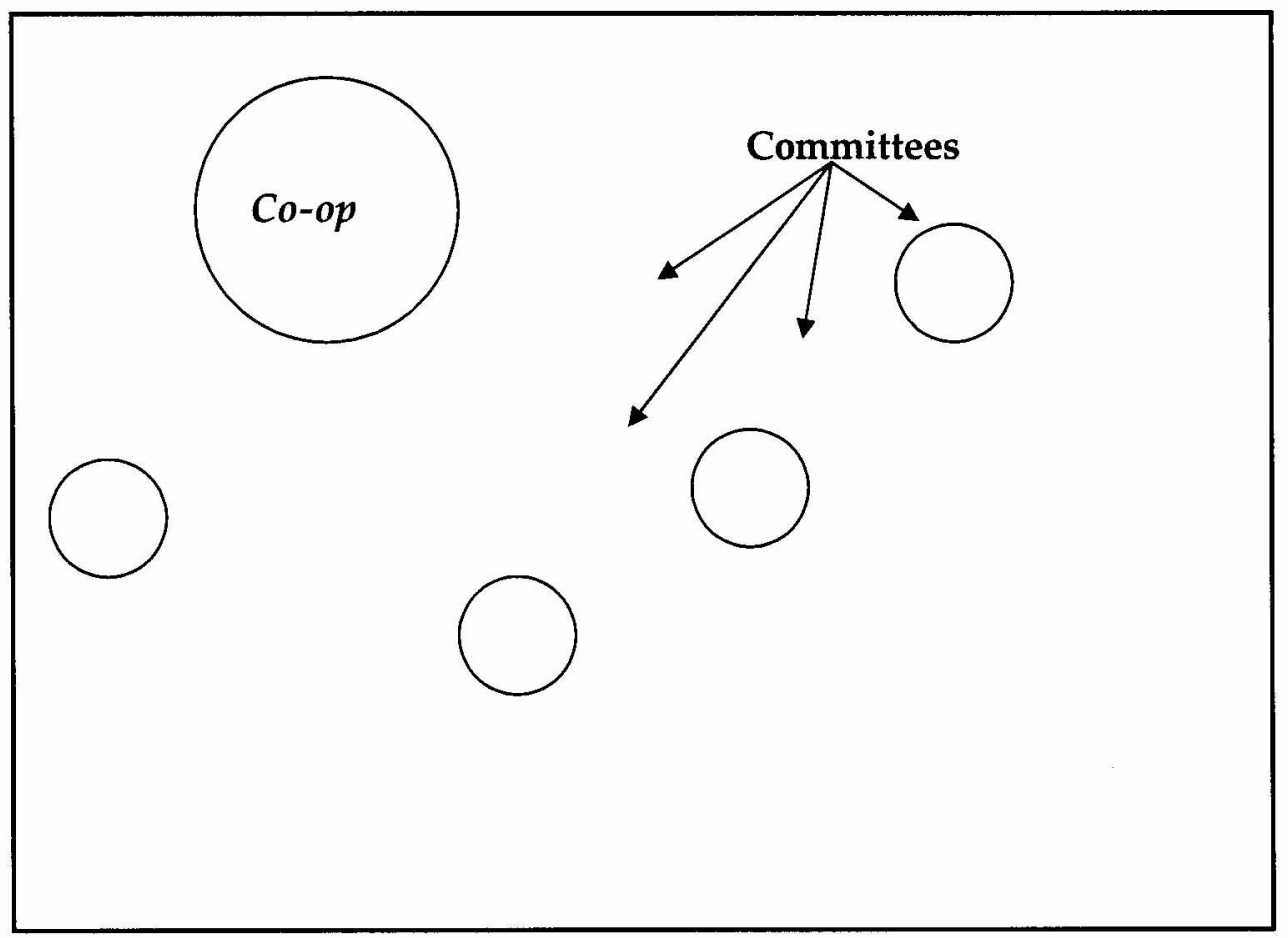

Figure 8.3: The Amoeba Structure of the Orchestra

After he had drawn the amoeba diagram he described the problems the organisation was facing that called for a new structure. He said that the cooperative had become self-absorbed and therefore was 'sick'. 'Healthy' organisations, on the other hand, look out beyond themselves, he said.

\section{Field Note}

Artistic issues have an internal focus.

Chris We have to have an external focus. Right structure will encourage us to develop an external focus. If we are not well our focus is internal. When we feel well and are on top, we have an external focus...

When the structures are right there's nothing behind me to worry about... 
But you guys are a mess. Now you have to worry about what is behind when you apply to organisations for funding...

I would like to get to the point where banks tender to become financial donors of the orchestra. How good is that?

\section{Field Note}

Chris then drew an alternative diagram on the white board.

Chris began his second diagram with a circle at the top centre of the whiteboard. Then he drew a box under the circle and two curved lines out from the bottom corners of the box. As he drew the diagram, he spoke of the new structure having two connected 'arms' of arts and business. At the end of the two arms he drew a circle and likened these to either 'open hands' or 'closed fists'. He spoke of the 'business' arm as being run by enthusiastic volunteers who donate their time and expertise for the sake of the cooperative.

When his diagram was complete, he had drawn a stylised human skeleton with the various groups connected. Figure 8.4: The Lawyer's Proposed New Structure as a Human Skeleton shows his completed diagram. 


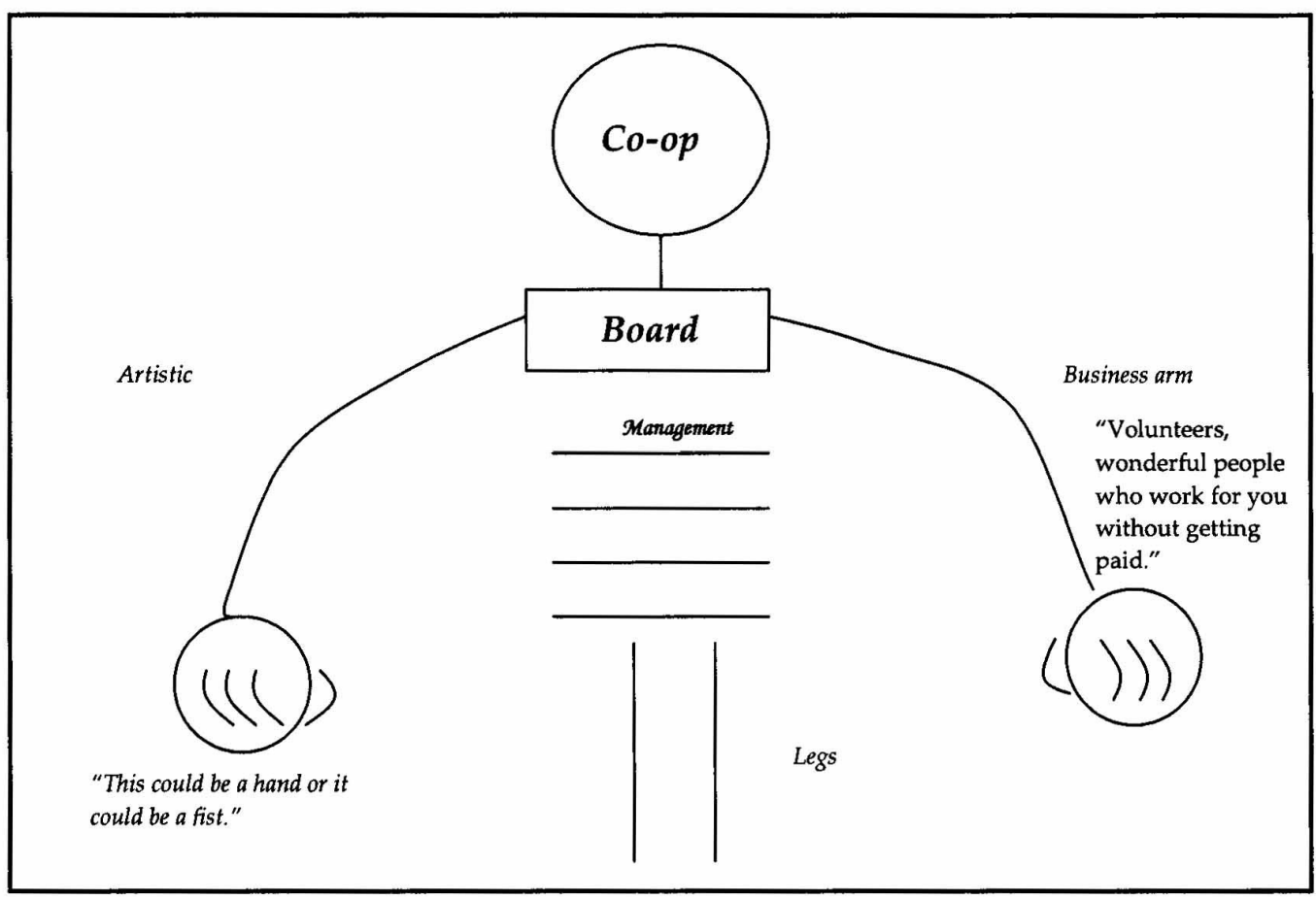

Figure 8.4: The Lawyer's Proposed New Structure as a Human Skeleton

Immediately following Chris's speech, several members of the group applauded and Steve said, 'I like that. It's really well done!' However, others were not so pleased and one musician objected to being called 'a mess'. Another said that they were not an amoeba but rather saw themselves organised in a triangular fashion with the Cooperative, Management and the Board of Advisors being at each point of the triangle. Another expressed discomfort at the 'business artistic split', while someone else said that the structure looked 'mostly good, but I still don't feel a sense of trust'. 
Other members of the cooperative, though, were in favour of the proposal.

One said that it was based on other cooperatives and it was a logical step

in their development. Chris added to this by saying that, if the new

structure wasn't adopted willingly, it would be forced on the organisation

by their funding bodies. He then encouraged them to take a 'positive

attitude' to the change.

Tony Logic dictates we have to embrace this. This model is being used by other orchestras so we are not reinventing the wheel and we know it works.

Chris We can't stay where we are. If we don't make it, it's going to be forced on you. It can't be cosmetic change because the only people you will fool are yourselves. [Tinkering with the structure] is more of the same. It's only cosmetic and doesn't address the structure. Grapple with change! Take a positive attitude!

Chris then went on to say that he noticed the cooperative was divided into three groups. One group had already perceived that change was necessary and was in agreement with the new model. Another group, he said, 'are persuadable' while a third group, 'are in the corner and you can break out of it'. He then finished with his hope that they would become a 'successful' cooperative thereby attracting further successful artists into their midst. One member ruefully replied that they were already successful. 
Chris We want you to be successful. Success attracts success. You don't see Graham Hart [a well-known millionaire] drinking a beer down at the pub with a road worker. He would probably meet with another millionaire and together they can put together something bigger and better. We want you to be successful so that other successful people will be attracted to the cooperative.

Player We are already successful!

\section{Field Note}

At the end of the meeting [a musician said to me] that he thought it was an excellent presentation, that the charts explained things really well. He was pleased that they were getting this advice free of charge.

\section{Themes and Motifs}

To recapitulate, a number of discursive themes interacted polyphonically within the orchestra. At times one theme took on prominence only at a later point to be superseded by another. I have demonstrated that, at this level of analysis, there is no unifying idea. Rather, the themes only added complexity, in that within each theme itself, there were competing notions. Some understood artistic freedom to involve separating musicians away from managerial tasks while others believed that it entailed the freedom to choose to participate when it was appropriate. Rigorous fiscal management for some meant retiring debt and creating a surplus, and yet to others, to 
do so would have been a suicidal action spelling the end of generous donations.

The theme of responsible leadership played out in the context of a competent management team able to deal with the vicissitudes and complexities of daily administration. Many of the musicians, though, considered that in the midst of their cacophony, they had tried-and-true mechanisms for decision making that had worked well for them over the past 25 years. Sound structure was a fourth theme that lay alongside the responsible leadership theme. Some of the musicians believed their structure to be adequate and resisted attempts to position the orchestra as a leaderless amoebic enterprise. Yet the advisors considered the cooperative to be the source of the orchestra's problems and were of the opinion that the structure was in urgent need of overhaul.

Within these overarching themes, smaller, sometimes contradictory motifs interjected, further thickening the polyphonic texture. Some of the motifs that continually interpolated were family, cooperative and corporate, business and arts. Beyond these prominent motifs a less obvious and yet equally important idea was ownership. The orchestra was being asked if it was 
owned by the musicians or whether the benefactors and music-loving public had a greater claim to ownership. This latter motif was only suggested during several interviews and was not overtly stated during any of the conversations or meetings, and yet it became an important concept in terms of which the orchestra re-examined its new structure.

What is not evident at this stage, though, is the form to which the polyphony adheres. If, as I have suggested, the orchestra was going through a sustained period of development where themes and motifs interacted chaotically, then the aesthetics of musical form suggest that a period of resolution and calm would follow. This prompted a search for an underlying form that held the orchestra together organisationally.

A rational approach suggests that when people of such diverse and entrenched views begin to lobby aggressively for their position, there must be either a parting of the ways or a restructuring of such dramatic proportions that dissenting voices would be compulsorily retired from the organisation. Taking this line, it did not seem possible to me that the orchestra could sustain a quality artistic product while working in such an embittered environment. And yet the ensemble performed concerts of 
such sublime proportions that I was left profoundly moved. For instance, the memories of the first concert of the 2004 subscription series (18 February) where the AP performed the Brahms Symphony No. 1, Op. 68, stay with me even at the time of writing this chapter, 18 months after that concert. A reviewer for the weekly publication New Zealand Listener concurs, writing:

During it all, the Auckland Philharmonia played right up to the wire, eager to please, united in the effort to make this first concert of the series a winner, and showing with every note and movement what it is that makes live performance so much more exciting than sitting at home in splendid isolation with nothing but a CD player and a volume button.

(Lees, 2004, p. 64)

A performance of this standard suggests that the $\mathrm{AP}$ was through the worst of its troubles and that the restructuring of the previous year was successfully embedded. That being the case, it seemed to me that an underlying form as suggested in the Chapter 4 discussion on development and sonata form would be easy to discern. Theoretically, the interweaving chaos of the polyphonic themes as a period of development that resolves itself into calm recapitulation where the players regain their sense of stability and purpose in performing high-quality music for an appreciative audience should have been evident. However, this was not the case. 


\section{Interlude}

Soon after the new constitution was instituted in October 2003, it began to fracture. In December of that year the Music Director seized on the power he had been granted under the new regime and unilaterally issued letters of warning to three principal players he deemed to be underperforming. While for two of the players a satisfactory improvement was noted and the complaint withdrawn, a third took offence at the warning and decided to take legal action.

Emboldened by a letter of support signed by 32 musicians, a Personal Grievance claim was lodged with the Employment Relations Authority on 9 February 2004. The legal issue at the heart of the claim was the employment status of the 68 core musicians: were they salaried staff, under the authority of the Employment Court, or self-employed contractors and therefore outside its jurisdiction? Those in support of the musician who had been disciplined claimed the former; that they were indeed salaried staff, and that due process had not been followed by the Music Director. The importance of this position cannot be underestimated, as a judgment for the plaintiff could signal a change in 
taxation status which up until this time had allowed the musicians to claim for personal expenses as self-employed musicians.

The unilateral nature of the Music Director's letter of warning and the legal action only served to exacerbate the conflicts within the ensemble. During the first half of 2004 the newly formed Board became distracted by the employment case and lost sight of its primary function of securing stable income for the orchestra. Members of the traditionalist camp pressed for a re-election of officers and in March proposed a motion of No Confidence in the Board. Although the existing Board survived, it inevitably became weakened by this action. Troubles between the emasculated Board and factionalised orchestra came to a head in August 2004 when the GM asked a former Chairperson of the Board of Advisors to step in and mediate. Her first action was to suspend the new constitution and in September an Executive Chair was appointed to oversee all the orchestra's affairs, including the Board functions.

Therefore during 2004, the polyphonic environment became increasingly dense. Instead of clarifying the issues, events over the course of the year made it much more difficult to perceive a unifying structure or gestalt. 
The dissonant environment had become further entrenched, escalated by another wave of conflict.

By December 2004, the issues raised in the Chairman's speech at the May 2004 AGM that began this chapter began to take on new significance. Issues he canvassed, such as the orchestra adopting a conventional hierarchy, musicians as free spirits being free to concentrate on perfecting their art, the changing commercial environment within which the orchestra operated, and the tenuous financial situation that the deficit implied, all took on new significance, but were no less easy to read.

Unravelling these complexities called for another phase in the research process. The questions, 'what do you feel?' and, 'what do you see and hear?' enabled me to discover the layers of polyphony operating in the orchestra. Beneath these themes, the sense of mistrust was palpable. Mistrust among the players, the mutual mistrust of the business advisors and some musicians towards each other and mistrust shown towards me the researcher, revealed an atmosphere of suspicion. And yet the group remained sufficiently cohesive to be able to continually mount high quality performances. 
While this process of Cognitive Detachment makes critical analysis possible, a further step in synthesising the elements was required. Here the task is to collaboratively discover how the strands fit together into a gestalt and to define the underlying drivers beneath the polyphony. The next chapter which explores Integrated Synthesis discusses this process. 


\section{CHAPTER 9 THIRD MOVEMENT: INTEGRATED SYNTHESIS}

- Developing a Shared Understanding

- Aesthetic Theory Building: Play and Irony

- The Quest for the Dionysian Spirit 
The third movement in the research process brings together the strands from the previous two movements. The first movement of Emotional Attachment where the focus is on the researcher's sensations and perceptions is followed by the second movement of Cognitive Detachment. In the second movement, the researcher seeks to identify the sensations and perceptions of the research subjects and uncovers the various thematic layers of the artwork or enterprise. The third movement of Integrated Synthesis sees the now educated and informed aesthetician step back, and make evaluative decisions based on the in-depth investigations of the second movement.

There is also a return to the emotionally charged reactions of the first movement, where the perceiver recognises a new set of feelings for the artwork or organisation. These may be a complex array, reflecting the researcher's experiences of both the beautiful and the ugly through the investigative process, and could include feelings as wide ranging as admiration, awe, respect, disdain, contempt and even scorn. Furthermore, at this last stage of synthetic engagement, the perceiver makes evaluative judgements by asking how the piece works in terms of its contribution to 
aesthetic awareness, be that artistic or organisational. For Ingarden, this involves assessing whether the piece is high art, kitsch, or something in between; whereas for the organisational researcher, it entails considering the contribution of the findings to the broader task of theory development.

The first two research movements see the focus begin with the researcher, an $I$ focus, and then shift onto the researched, a You focus. This third movement shifts the focus again, this time onto a shared We focus and poses the questions, 'What do we see and hear', and 'What do we feel?' The purpose here is to go beyond describing the various elements that comprise the enterprise, to embrace a wider gestalt by discerning its place in the wider community: 'the world in which this Being exists' (Rehn, 2002, p. 46). In order to locate this identity, the ethnographer engages in a collaborative process of analysis and description.

At this stage, the skill required of the ethnographer is that of building a community of knowledge around the researcher and the researched, in which the two work together in a theory-building search. Whereas in the second movement the emphasis was on seeking to locate the polyphonic strands, here the search aims to discover the underlying harmonies that 
make it possible for the enterprise to cohere. Any one of the polyphonic strands has the potential to become the dominant voice and, in organisational life, splinter off, thereby factionalising and ultimately destroying the enterprise. In the case of the Auckland Philharmonia, in spite of the competing themes - artistic freedom, rigorous fiscal management, responsible leadership, and sound structure - each pressing for dominance, the orchestra still retained its integrity and continued to perform sublime music. The third research movement inquires into this coherence in the face of disparate themes.

In this chapter I describe my attempts at building this collaborative community of knowledge and developing collective theory building. I then go beyond that process and propose a tentative theory that seeks to explain the Auckland Philharmonia's coherence by drawing together strands introduced in the preceding chapters. The language of aestheticians such as Schiller's play impulse, Deleuze's diastole-systole, Barthes' myth-making, Nietzsche's eternal return, and Rorty's search for irony, coalesce into the language of ancient Greece: the quest for the essence of the Dionysian spirit. First I discuss the project of researching collaboratively. 


\section{Developing a Shared Understanding}

Collaborative learning comes from the Action Research stable of methodologies and enables both the researcher and the researched to think reflectively and learn collectively (Schön, 1983; Torbert et al., 2004).

To do this successfully, there must be space available to discuss, deliberate, and engage in dialogue, so that ideas can be shared. However, this proved to be especially difficult in the Auckland Philharmonia during the period analysed.

During formal interviews, I followed up the question, 'If this organisation were a piece of music, how would it sound?' with discussions that explored possible formal descriptions. To gauge reactions among the musicians, I suggested that the orchestra might be akin to Sonata Form and that the troubles being experienced with negotiating a new governance structure were similar to the Development section within that form. I wondered aloud whether the chaos they were experiencing would ultimately be resolved into a new period of calm. Usually my suggestion was treated dismissively, resulting either in a blank stare, spontaneous laughter or the blunt statement, 'That's a bit far-fetched!' My sense was 
that, instead of seeking for an artistic explanation, the musicians were searching for rational reasons for the struggles they were experiencing. Further attempts to probe interviewees for their awareness of underlying form proved fruitless, leaving me wondering how I was going to coconstruct a theoretical language with the orchestra.

Other means of working collaboratively were thwarted. Beyond individual interviews, musicians did not have the time to spend with me, and their suspicions about why I was 'snooping around' resulted in their adopting a defensive attitude towards me.

Along with this, members of the new Board of Directors formed in October 2003 were unwilling for me to sit in on their meetings, thereby preventing spontaneous dialogue occurring after their formal discussions. Through their new Chairman, they expressed the need for two months' space to settle into their governance role without feeling the pressure of a researcher analysing their every move. The Chairman reassured me that access would be granted after this initial period, but following repeated phone calls to him in March and April of 2004, when he said they still needed more time to work in camera, I realised that to keep pushing for 
access would only serve to alienate me from the orchestra. Later events were to show that this strategy was the wisest, given that the Board had become so dysfunctional, it was suspended and a temporary Executive Chair was appointed in its stead.

Although I had access to musicians at the usual after-concert venues, these occasions were not conducive to serious brainstorming and discussion. Furthermore, the new Artistic Committee that had been formed to oversee the standards of existing players and to vet the quality of newcomers, was not open to me attending meetings.

I reflected on why access was denied, given that during my first forays into the organisation I had been welcomed, and that I posed no threat to the enterprise. In spite of the fear the musicians expressed that I might 'go to the media,' my formal agreement with the orchestra as outlined in the information sheets and consent forms (see Appendices A to D), prohibited me from taking this sort of action. Additionally, because my agenda was to carry out academic inquiry, disclosing information to a third party was the furthest thing from my mind. 
I concluded that the problem of access went back to my initial entrance into the organisation. The orchestra had been informed by its manager that I would be conducting research among them and that they would be 'seeing me around'. This was a mistake. I should have made my own sales-pitch, so that right from the start I would not be seen to be aligned to any faction within the enterprise.

Before I began my work with the orchestra, the General Manager had instructed the Orchestra Manager to announce my arrival and describe my research to the musicians. But because I had not met with the Orchestra Manager prior to commencing the research, I was subject to his benevolence to sponsor me into the organisation. But this kind of sponsorship can be as much a hindrance as a help. The risk here is that a sponsor may either not be empathetic to the research, and may thereby unwittingly sabotage the process before it even begins, or be already politically aligned by the mere fact of his or her longevity within the enterprise, thus compromising the researcher's independence. So using this method of introduction into the Auckland Philharmonia meant I unwittingly became aligned with a faction within the Management team, and was seen to be sympathetic to one group over another. 
If I had done my own promotion, I would have stood or fallen on my own credibility. This is a risky strategy because, without a sponsor, I may have been isolated from the outset. However, relying on my own ethos and persuasive ability may have been a better strategy. I could also have outlined my key research objectives to the entire body, and in so doing could have alleviated any residual suspicion, avoiding the possibility of being seen as a puppet of one or other party.

Though I had been thwarted from working in the way the method suggests, an alternative to collective analysis presented itself in the form of a biennial arts management conference. The International Conference on Arts \& Culture Management (its AIMAC acronym is derived from its French title: Association internationale du management des arts et de la culture) draws both academic and practitioner participants (AIMAC, 2005). This conference presented an ideal opportunity to co-author a paper with Lloyd Williams (a former General Manager of the AP and a current contract musician with the orchestra) and Anne Rodda (the then General Manager of the AP), which charted the recent history of the orchestra and proposed a theoretical framework within which to analyse some of the presenting issues (Bathurst et al., 2005). Because of its emphasis on both 
theoretical and practical applications, the AIMAC conference provided a stimulus for collaboration, and preparing the paper allowed for in-depth analysis from key participants, including the Executive Chair, in the evolution of the orchestra.

As we worked through our investigation of the events of the years leading up to and including the governance review, we discussed the need for a theoretical frame that could be used to explore possible reasons for the unfolding events. We finally settled on Kenneth Burke's dramatistic concepts as a way of exploring the reasons for the environment becoming so troubled. Burke aligns the human community at a micro, idiosyncratic level, with a larger guilt-redemption mythology (Burke, 1961). For Burke, when communities begin breaking down, in order for satisfactory resolution to take place, and for the community to move on, someone must be found to take the blame for the failure. In Burke's description, guilt can only be atoned for by a scapegoat and, in taking the blame, this person provides for the expiation of the problem, thereby allowing redemption to occur. 
We considered that the environment within the Auckland Philharmonia had become toxic because of the intransigence of the political factions, and the blame people attributed to each other. The Progressives blamed the Traditionalists for not being musically skilled enough to improve the artistic standing of the orchestra. The Traditionalists blamed the Progressives for enabling the Music Director, for whom they had little respect, gain substantially more power than they thought his skills deserved. Individuals blamed each other for being abusive and manipulative; and some of the musicians blamed the business advisors for lying about their intentions, and for seeking to gain control through deceitful and unethical means.

Our analysis posited that finding a suitable scapegoat would enable the orchestra to move on to a new period of stability. Among the possible candidates, we proposed that the musician who had been disciplined and consequently took legal action was the most likely contender. However, even beyond a satisfactory conclusion to the legal issues surrounding this case, and after the musician's departure, the orchestra still continued to flounder. 
Before submitting the paper to the AIMAC conference's Scientific Committee for review, we shared our ideas with the AP's Executive Chair. Although she agreed with the order of events we outlined, she was resistant to the use of a redemption frame. She considered the notion of scapegoating to be passé and not able to account for the complexities of the issues involved in the governance review. So after making some minor adjustments resulting from her feedback, we submitted the paper for the July 2005 conference.

Some two months after the paper had been presented to the conference, I discovered that some of the musicians were unhappy with the tenor of our work. Some objected to particular phrases which suggested the Traditionalists were afraid that they could not meet the improved standards the Progressives were demanding.

Another stakeholder took more formal action by writing to the Chair of my employer's Human Ethics Committee, requesting an inquiry into the ethical status of the paper. It was claimed that 'The selection by the lead author ... of co-authors who were themselves the subjects of the study is 
seen as publishing a subjective and biased paper without the objectivity of separating the researchers from the subjects.'

And yet it is this collaborative action that is the hallmark of the third research movement of Integrated Synthesis. Since the entire orchestra was not involved in this analytical phase, the former and current General Managers' participation made a reflective examination possible, albeit only at a senior level of the organisation. However, what further justifies my position, is that both these people are still contract musicians who perform from time to time with the orchestra and this kept them in touch with many of the issues being grappled with by the players.

Following the AIMAC conference, a revised version of the paper was submitted to the International Journal of Arts Management, which at the time of writing has been accepted for publication (Bathurst et al., Forthcoming). However, as I reflected on the case, I too found Burke's dramatistic approach limited in its application. We had unwittingly fallen into the trap of imposing a theoretical lens without it growing organically from within the case. This reservation led me to consider the theory-building process and so I began searching for a more encompassing theoretical 
position that could account aesthetically for the developments within the orchestra.

\section{Aesthetic Theory Building: Play and Irony}

The ability to think theoretically is an important part of the Integrated Synthesis movement. In the previous section of this chapter I described the difficulties I encountered in developing a shared understanding of the Auckland Philharmonia with both the musicians and those charged with governance roles. As a result, and excluding the collaboration involved in preparing the AIMAC paper, I was left alone with the task of integrating the identified strands into a gestalt. What, then, are the precursors and considerations that contribute to the process of aesthetic theory building?

When interacting with art at this Integrated Synthesis stage in the process, and in the absence of a community of actors who can share ideas together, the questions I ask are: 'Does this work?' and, 'How does this work?' When engaging at an artistic level, by work, I mean the way in which the piece as a whole persuades me of its coherence, and then I reflect on its impact on my sense of being. In other words, the notion of work stimulates an 
existential search for meaning by inquiring into the impact of the piece on the perceiver's sense of being. The artwork becomes a tool to move the perceiver intellectually, emotionally and socially. This, though, is not a one-off single act of inquiry. Rather, it is volatile and active, developing over time.

In answer to the question, 'Does it work?' about Auckland Philharmonia, there is no doubt that the AP coheres as a unified whole. In spite of its offstage identity as a chaotic organisation marked by disparate groups intent on enacting their contrary ideals, its on-stage identity seems coherent.

Assessments from outside the daily life of the orchestra explore some of the issues confronting the enterprise. In November 2005 the orchestra celebrated its Silver Jubilee and the music critic, William Dart, who writes regularly about the ensemble in the Auckland metropolitan daily newspaper, The New Zealand Herald, expressed confidence in the orchestra's continued existence (Dart, 2005). His view confirmed some of the convictions I had begun to develop, that the AP would press through its period of conflict and become even more skilled in performance. Dart notes in a suggestive understatement that 'The AP has had more than its 
share of woes this year' (Dart, 2005). He believed that, in spite of these troubles, the orchestra would continue as Auckland's pre-eminent performing arts body. In support of this view, Dart quoted a conversation he had with the recently appointed Artistic Administrator, Anthony Ernst, who also expressed confidence in the orchestra's longevity as an artistic enterprise. Dart reported that Ernst came to the AP in July 2005 after working one year with the Sydney Symphony. Ernst's impressions were that the AP still retained the sense of enthusiasm that hallmarked its early years.

[The musicians] never lose sight of the fact that it's about the music. There's none of that jaded thing that you get with even the biggest orchestras. They are a very generousspirited and committed bunch.

(Dart, 2005, p. B5)

However, nine months earlier an exposé of the orchestra, published in The New Zealand Herald in February 2005, told a contrary story. A leaked confidential report listed a quite different set of qualities.

Terms that characterise the organisation include: conservative, ambivalent about quality, faction-ridden, reactive, uninterested in reality, suspicious, resistant to authority, self-indulgent (even self-serving), inward-looking, fearful.

(Barton, 2005, p. B6) 
The spirit of generosity in one report is countered by an attitude of parsimony in another. It seemed that its on-stage coherence protected the orchestra against its demise, enabling it to maintain itself in a constant state of growth and development. In this sense, then, the orchestra works as an entity.

Having established that the orchestra works, the aesthetic researcher then asks 'How does it work?' This question is more difficult to deal with. It is this question that shifts the researcher further into the theory-building process, and the importance of this question lies in the way it helps account for the contradictory elements within the identity of the enterprise. Here the researcher is confronted with paradox.

Susanne Langer notes that aesthetic theory is replete with paradox, and this is often expressed in polarities: 'emotion-reason, freedom-restraint, personality-tradition, instinct-intellect' (Langer, 1953, p. 17). This leaves the aesthetician with the choice of trying either to resolve paradoxes, or alternatively to acknowledge that this is the ground from within which aesthetic theory develops and to 'accept [paradox] as ultimate' (Langer, 1953, p. 17). 
Paradoxical thinking necessitates a shift away from the certainty that polar thinking provides. The shift is represented by the Schillerian idea of the play impulse, the nexus of 'becoming with absolute being' (Schiller, 1795/1965, p. 74), and of allowing ideas to oscillate between form and content; the parts and the whole.

Integrated Synthesis legitimises both the affective and intellectual engagement that Schiller advanced. Schiller's search was for a space within the polarities of baroque product and classical production (Benjamin, 1998, p. 82). This space acknowledges a continual oscillation between the finished product and the process by which that product comes into existence.

As an extension of this notion, organisational aesthetic theory can be strengthened by Rorty's concept of irony. Here an idea is interrogated by inquiring about what is beyond that concept. In Rorty's inimitable language, irony searches for the painted backdrop behind the painted backdrop (Rorty, 1989, p. 54); notions that are not seen but are nonetheless present, and that are yet to be seen and acknowledged. 
Irony has its roots in the Greek tragic theatre where the audience is let in on the ending of a hero's actions but without the hero knowing how things will pan out. Thus irony provides a tool for the audience to analyse dramatic action in the light of the expected outcome as the drama unfolds (Stanford, 1983, p. 113).

Rorty claims it is the language of irony that avoids positions becoming fixed. It is a language of doubt which at one time accepts the validity of a set of beliefs and firmly held positions, while at the same time 'constantly question[ing] and doubt[ing]' those assumptions (Rehn, 2002, p. 47). Rorty explains this fluidity by arguing that 'the terms in which [we] describe [our]selves are subject to change, always aware of the contingency and fragility of [our] final vocabularies, and thus of [our]selves' (Rorty, 1989, p. 74). For Rorty, the less certain the final vocabulary, the more open we become to actively negotiate meaning, and the less need we have for 'helpless passivity or a resort to force' (Rorty, 1989, p. 73).

In order to discover the elements that hold the orchestra together, and to determine its structural underpinnings, the aesthetician steps back to 
investigate beyond phenomena and examine the issues at work beneath the surface. For Rorty, at work is the interplay between the thing itself and the quest for a language that probes for the 'intrinsic nature' (Rorty, 1989, p. 74), the core essence of a phenomenon. This, Rorty argues, is a metaphysical pursuit, the quest for a language of finality that expunges doubt and uncertainty. This metaphysical quest, Rorty claims, is an everpresent tendency within the human community. But it is this metaphysical quest for a unitary view that is fixed and final that robs humanity of creativity.

Therefore, the task of the contemporary organisational aesthetician is firstly to identify the multiple phenomena of organisational life and secondly, to attribute meaning to, and assess the relative importance of those phenomena. In this regard Deleuze writes:

Interpretation establishes the 'meaning' of a phenomenon, which is always fragmentary and incomplete; evaluation determines the hierarchical 'value' of the meanings and totalizes the fragments without diminishing or eliminating their plurality.

(Deleuze, 1965/2001, p. 65)

Another way of expressing the state of continual flux and fluidity where nothing is ever final is also expressed in the Deleuzean idea of the 
diastole-systole rhythm of sense and perception explored in Chapter 3. And this in turn is similar to Nietzsche's notion of the 'eternal recurrence'; a condition of continual renewal (Nietzsche, 1901/1968, p. 255). But how does this theory of fluidity play out? For Nietzsche this entails the quest for the essence of the Dionysian spirit.

\section{The Quest for the Dionysian Spirit}

To return to the Auckland Philharmonia, given the polyphonic environment of sometimes competing and opposing views within which the orchestra operates, what stops the enterprise from self-destructing? Some of the narratives are so divergent that there seems to be no way for them to coexist. And yet the Philharmonia continues to function and perform concerts as it has done for over 25 years, and players continue to improve their artistry. So where do the synergies lie and how can the aesthetic researcher reach Integrated Synthesis? In the next section I discuss this question. All references to specific people are recorded as pseudonyms to maintain confidentiality. 
The ideas of the four themes of artistic freedom, rigorous fiscal management, responsible leadership and sound structure that interweave polyphonically in the Auckland Philharmonia, and which were explored in the previous chapter, for me, take on mythic dimensions, and these discursive myths underpin the enterprise. It is within these myths that the play impulse can be observed and some of the myths were explicitly stated in the visual images that depicted the orchestra as an amoeba and a skeleton, while others assumed a more metaphysical guise such as business and arts, and the corporate. Following Rorty, as one myth gains legitimacy over its counterparts, it makes a claim to rationality, rejecting its mythological origins, and, in so doing, tends towards closure and finality.

My exploration of the polyphonic themes playing out in the AP in Chapter 8 focused on the Chairman's speech to the 2004 AGM. He argued that the new structure offered artistic freedom to the musicians. However, this myth of liberation makes a claim to logic and rationality, ultimately leading towards control and closure.

Mythical transformation means that ideas take on greater significance than rational argument, a significance that is often tacitly accepted by 
participants regardless of their political persuasion. For instance, the men from the Board of Advisors chosen to promote the governance restructure represented the 'business community'. Their task was to liberate the musicians from the hassles of daily management and to promote sound business practice to ensure financial success, profitability and prudence. For them, artists lack business sense, and are unable to manage their financial affairs judiciously, requiring savvier agents from the world of commerce to enable them to work productively. Bill's succinct summary 'This is how corporates function' and Chris's clever juxtaposition of the amoeba and skeletal diagrams during the meeting described in the previous chapter, gave mythical credence to their advice.

Ruminations on the meetings I observed led me to question why Bill's pronouncement, 'This is how corporates function' was left publicly unchallenged - nobody in the meeting contested the veracity of the statement or called on Bill to justify it. The lone voice saying, 'I think financial and artistic matters are entwined' did not resonate with the musicians because it lacked an attending mythology. For, although for many years the orchestra had survived under its cooperative model where 
the artistic and financial were intimately 'entwined', this story of survival lacked the mythical potency of the corporate.

Privately though, some were disdainful of the corporate ideology. A musician said to me before a rehearsal that she resented being 'put down' by the men from the Board of Advisors. She said that now as she leaves home for work, her husband says cynically, 'Have fun at the corporation!'

Similarly, Marie, during an interview, described her feelings of dissatisfaction at the process which the advisors had employed to persuade them to accept the change. She spoke of being bullied, threatened and lied to about the scope of the proposed changes.

Marie Because, over the last however many years he's been around, he's bullied and threatened us - that's the way he works. He comes along and when he first initiated this a month ago he lied to us and he came along and said, 'I'm going to have this meeting soon and we're going to talk about governance and things. Just a few small changes are needed,' which was an absolute lie. He comes along a month later [proposing] the dissolution of the constitution.

In spite of these perceived manipulative tactics employed by the business advisors, no member of the orchestra publicly challenged the advisors 
with the ethics of their approach. What, then, made the idea of the corporate so compelling? Bill's use of the term 'corporate' and Chris's artistic rendering of that notion as a body, humanised the proposed structure, giving the mythology an almost tactile identity that had resonance with the group.

Underpinning the mythology was the promise that the power of the corporates would be unlocked and generous donors would be vying for the opportunity of funding the orchestra. The role the three advisors played was to help the orchestra become part of that larger body and ensure longevity and triumph over potential demise. However, what was ultimately being proposed was a structure that limited the ability of the musicians to manage their own affairs.

One year after the collapse of the new constitution, in October 2005, the AP adopted a new structure even more in harmony with corporate governance ideals. Rather than the Society being the sole proprietor of the enterprise, a new charitable trust was formed providing representation to three major stakeholders: the Society, the Auckland Philharmonia Foundation (which holds the capital assets and endowment fund), and 
representatives of local councils. The players have granted executive authority to the new Trust's Board of Directors via its Chief Executive Officer, a new position created to replace the General Manager; and membership of the Society is no longer a requirement for tenured membership of the orchestra. While the musicians have two representatives on the Board, one of these may not necessarily be one of their own. At the time of writing, one of their delegates is someone outside the band, a well-known city lawyer.

Alongside the myth of the corporates is another compelling mythology of sound structure. An important selling point of the new structure for the Philharmonia was that not only would there be competition among corporate organisations to become sponsors, but funding agencies would also have greater confidence in making grants if the structure changed to give power to a small board of directors.

For instance, during a meeting in June 2003 called to further discuss the new governance model, a musician, Jenny, spoke of being disappointed at the poor communication among the orchestra and with the Board of Advisors. She noted, too, that players had become blaming of one another 
using insulting language. One of the advisors took this as his cue to reinforce that a change in structure was necessary.

Jenny If the players and the Board are in communication then problems wouldn't arise.

Steve $\quad$ Yes ... the structure has to be sound.

Here we see the notion of structure moving beyond merely solving the problem of abusive communication to taking on redemptive qualities. Yet all the musicians I spoke with confessed that internal communication had become problematic. In answer to the interview question, 'if the Philharmonia were a piece of music, how would it sound?' responses ranged from 'it's a cacophony' to 'different sections of the orchestra are playing out of time,' while another musician encapsulated this idea as 'there is no sense of ensemble'.

However, the implication that a new structure would offer a panacea for these communication problems added potency to the myth of the corporate. The orchestra's amoeba-like existence could no longer cut it. What it needed now was to be connected - fused together in a way not 
previously experienced. The family had become dysfunctional and now their new corporate structure would take on soteriological dimensions.

Here it is prudent to pause and question why one myth is more persuasive than another. The musicians had tried deploying mythical expressions to promote understanding in their use of the two nomenclatures, 'suits' and 'anarchists'. However, the term anarchists, as an oblique reference to the Mondragon cooperative, held little currency among the players. Of the musicians I spoke with, only two had any knowledge of Mondragon and how it worked. Rather, the 'other orchestras', which follow a corporate management model, provided the more persuasive argument. Why, then, should the corporate myth have more appeal than the cooperative represented by the Mondragon community?

Myth draws its power from its mimetic potential. In the tragic form of the ancient Greeks, the chorus was essential (Wilson, 2000, p. 24) and held the capability of bringing the audience into the drama thereby allowing them to be transported, to become the tragic characters (Cronk, 1996). The Greek theatre had no proscenium, and the concentric circles of the theatre (see 
Figure 9.1: The Theatre of Dionysus in Hellenistic Athens) enabled a spectator 'to imagine himself, in the fullness of seeing, as a chorist' (Nietzsche, 1871/1956, p. 54). As the chorus and audience entered into the drama, they too became the characters within the tragedy. Thus, according to Nietzsche,

The dithyrambic chorus ... is a chorus of the transformed, who have forgotten their civic past and social rank, who have become timeless servants of their god and live outside all social spheres.

(Nietzsche, 1871/1956, p. 56)

For Nietzsche it is the chorus that is most closely aligned to the Dionysian spirit. It is the Dionysian that is most closely aligned to the tragic form and it is the Dionysian festival that enables the audience to enter into the work of the chorus (Nietzsche, 1871/1956, p. 66).

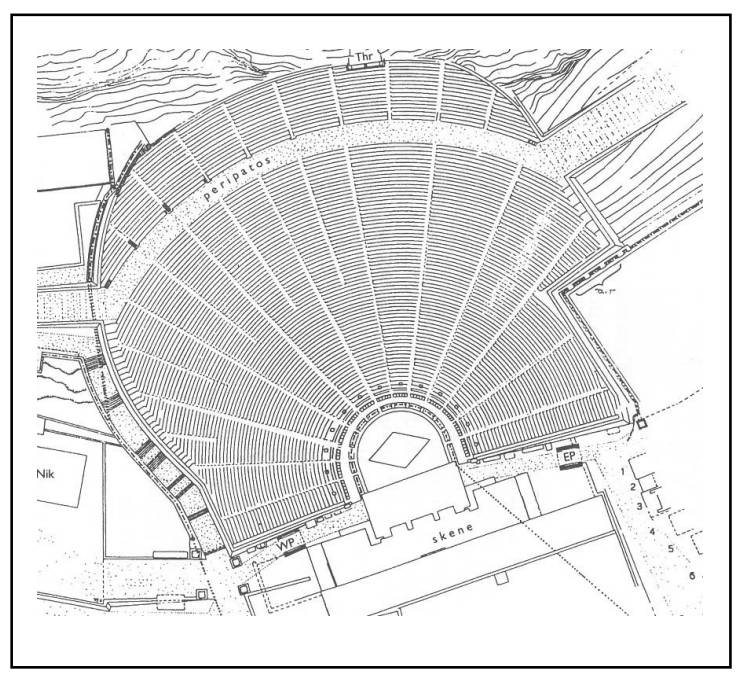

Figure 9.1: The Theatre of Dionysus in Hellenistic Athens (Wilson, 2000, p. 210) 
Because there was no proscenium, the chorus and the audience became blended into part of the action. The chorus's role was to comment on the action and to critique the actions of the hero. Here indeed, is irony playing out. The chorus and the audience are not only involved in the onstage action but they are often privy to knowledge which the actors do not have.

Furthermore, with no proscenium, there is no behind-the-scenes action hidden from audience view. For Nietzsche though, with the rise of Socrates through Euripides, the rational become privileged over the mythical. But along with this there is a consequent loss of the chorus and its ability to comment on and critique the action. Now there would be no more folds in the texture, and no further questioning.

Therefore, where there is no chorus, language tends towards the finality of rationality, and appeals to logic ensure that conversations become closed and stable. The dithyramb, the dramatic and poetic form through which commentary could be made, is unstable and indeterminate so it comes as no surprise to learn that it fell out of favour. So in the AP's case, the mythical transformed to the rational. No longer was the image of the 
corporeal body just another alternative metaphor; instead, it became the rational and final view.

In advocating artistic freedom, the implication in the Chairman's 2004 AGM speech was that the need for freedom is self-evident: all artists need freedom to devote themselves to developing their artistry, and this can be achieved by taking institutional power away from them. Furthermore, rigorous fiscal management and responsible leadership are core attributes of the corporate world. If 'this is how corporates function' then the orchestra is compelled to follow this track. Indeed, other orchestras like the Louisiana Philharmonic (cited by the Advisors as having made the transition from a cooperative to a corporate structure), so sound structure can be achieved by following this exemplar. However, this reference to an off-shore orchestra is more than an Aristotelian recourse to derived ethos. Rather, I think it is an appeal for legitimacy through logic, via mythmaking. Yet this same rationality robbed the musicians of direct ownership of their orchestra.

This exploration of the Dionysian spirit may, then, offer a way of seeing the Auckland Philharmonia. The Orchestra Committee of 68 players, who 
met monthly to administer the work of the Society, took on the identity of the dithyrambic chorus. Meetings I observed were volatile and often chaotic, and yet the ensemble had developed artistically into an orchestra of repute. I attribute this to the constant interplay of the Apollonian order with Dionysian excess. However, this creative schwung now became threatened by recourse to a rational approach to governance that removed the musicians from the mix.

Developments in the Philharmonia, then, represented a struggle to deny the chorus the power to continually question the validity of an ideology. Arguments in favour of the corporate model are an appeal to a state where the logic of rationality reigns over the uncontrollable yet creative Dionysian spirit. Instead of allowing form (structure) and content (artistic freedom) to coexist productively, the changes in governance saw the musicians sidelined, robbing the enterprise of the interplay between Apollonian order and hierarchy, and its more ecstatic Dionysian polyphonic counterpart (Waxman, 1996, p. 230). In its place, the myth of the corporate became the rational and preferred view that then dominated decision making, with the less favoured Mondragon cooperative exemplar being ignored. 
Once the voice of logic and rationality reigns supreme, a nihilistic tendency towards closure takes place. There is no place any longer for irony and the renegotiation of meaning; hence the creative Dionysian spirit is stripped of its ability to inspire and renew.

What are the implications for the leaders of the Auckland Philharmonia where, through careful management of myth, governance has shifted so radically from a cooperative to a fully-fledged corporate structure?

Initially, the certainty gained by removing the players from governance responsibility offers an ordered system for managing artistic and employment issues. The empowered role of the Chief Executive Officer reporting to the Board of Directors rather than to the Society has created a chain of command that mirrors the business community from which the Directors are drawn.

What, though, of the players? The AP could be set on a trajectory where, like their counterparts in the United States of America (USA), musicians become passive and disengaged from the artistic process. This has lead, in the USA, to an environment where 'Lack of access to honest, complete, and regularly communicated information contributes to [a] mutual lack of 
trust ... and to a perceived gap between "us" and "them" (Americanizing the American Orchestra, 1993, p. 71). A similar split between governors and players could occur at the AP, with a concomitant drop in artistic enthusiasm from the musicians.

On the financial front, how will funding agencies work with the newly constituted orchestra? The ambition of the advisors for corporate sponsors to be lobbying for preferred donor status has yet to materialise. At the time of writing, little has changed in the funding regimes over the last eight years, with only a $1 \%$ increase in the much-sought-after sponsorship dollar. Table 9.1: Comparison of Auckland Philharmonia's Funding - 1998 and 2006 shows these comparisons, using information gleaned from the orchestra's website (Auckland Philharmonia Orchestra, 2006). The orchestra now operates with a budget of $\$ 6.2$ million, an increase of $\$ 1.7$ million since 1998. The decline in percentage funding from local authorities, and in box office receipts is met, in the main, from donations, rather than from the envisaged increases from the corporate sector.

Table 9.1: Comparison of Auckland Philharmonia's Funding - 1998 and 2006 


\begin{tabular}{lrr}
\hline \multicolumn{1}{c}{ FUNDING SOURCE } & $\begin{array}{r}\text { \% OF } \\
\text { TOTAL } \\
\text { 1998 }\end{array}$ & $\begin{array}{r}\text { \% OF } \\
\text { TOTAL } \\
\mathbf{2 0 0 6}\end{array}$ \\
\hline Box Office and Hires & $52 \%$ & $50 \%$ \\
Creative New Zealand & $21 \%$ & $21 \%$ \\
Sponsorship & $16 \%$ & $17 \%$ \\
Auckland Local Authorities & $5 \%$ & $4 \%$ \\
Donations (Including Friends and Guild) & $6 \%$ & $8 \%$ \\
Total & $\overline{\mathbf{1 0 0 \%}}$ & $\overline{\mathbf{1 0 0 \%}}$ \\
\hline
\end{tabular}

Having an empowered executive makes rational sense for the smooth running of the enterprise, but a passive body of musicians makes little sense for improving an artistic product which relies on the creative investment of its players. Or, as seen through Nietzsche's eyes, the rise of the rational voice has robbed the orchestra of the irony of the dithyrambic chorus and the regenerative qualities of the Dionysian spirit.

It is too early yet to evaluate the course on which the AP is set. My abiding feeling, though, is one of gloom; a feeling that in letting go of the cooperative, an important element has been lost. My sense is that, instead of being free, the musicians have become bound to a constraining regime 
that will inevitably see a decline in creativity. Further research into the orchestra after the next 12 to 24 months could indicate how it is faring under its new structure.

Beyond the Auckland Philharmonia, what are the implications of aesthetic ethnography for further organisational research? In the next and final chapter I will explore the implications of this approach and suggest how it might impact on management practice within arts companies and in the wider organisational world. 


\section{Chapter 10 MANAGEMENT AND THE ARTistic ENTERPRISE}

- Managing Arts Organisations

- Funding Arts Organisations

- Integrating Governance and Funding 
I began this thesis with Pierre Guillet de Monthoux's suggestion that aesthetics could form the basis for an important new theory of organisation. This prognostication led me to define aesthetics as sense perception (Williams, 1983, p. 31) and propose that if aesthetics is to provide a lens through which organisations can be examined, it should include both the philosophies of art production and the existential examination of life that is alert to sensation. I have argued that organisations can be viewed as works of art and that reading strategies can be translated from beyond the art gallery and concert stage into a research strategy - aesthetic ethnography. In doing so I have adopted the view that aesthetics offers a convergent frame where both the sensations of lived experience and the perceptions of art are equally essential to understanding the use of aesthetics in organisational research.

In response to this core belief, I have suggested that, if there is to be a new theory of organisation that attends to aesthetic awareness, then it is important early in the development of the field that work should be done at the methodological level. I have maintained that a cogent theory of organisational aesthetics should spring from methodology. This can be 
achieved by refining ethnographic inquiry, so that theory building occurs in concert with empirical research. This process of moving from method to theory could give further research a reference point that will, over time, build a considerable canon of literature, ultimately spilling over into organisational practice.

My approach has been to observe the intersection between creating (the process of intentionality where an artist presences ideas within a work of art) and reading (the responses of an audience who concretises and makes sense of that work). Both elements - presencing and concretisation require a period of gestation to develop, and both are necessarily elements in organisational research. I claim that aesthetic ethnography is an ideal tool to observe the oscillation between creating and reading.

In order to develop a research method that attends to both presencing and concretisation, I have melded concepts from Greek antiquity into a history of aesthetic thought beginning with the early Enlightenment and Vico, Baumgarten and Kant. I enlarged this genesis of aesthetic thinking by focusing on a range of modern philosophers in order to define and analyse the nature of sensation and perception. Underpinning these concepts was 
the notion that aesthetics deals with ambiguity. Rather than forging a parsimonious view that attempts to disregard contradictions, aesthetics embraces paradox by taking a both-and approach. In this way polar opposites become part of the rich resource from which researchers and organisational actors can make sense of their enterprise.

Theoretically, then, the simple word and lies at the heart of the aesthetic view, for it is this conjunction that allows for the fluidity, the schwung, of the play impulse. By accepting instability, an aesthetic approach resiles from expressing and positioning concepts as polarities. Instead, volatility, complexity, multiplicity, and polyphony are terms that describe the schwung between poles, and it is this that is at the heart of aesthetic research.

I have suggested that music, in particular, is an apt art form to be translated into organisational aesthetics. Music as a performing art provides insights into the temporal nature of organising. Furthermore, it relies on both formal characteristics around which the sound is constructed, and also the idiosyncratic elements of individual pieces that possess a unique identity. Like music, organisations adhere to common characteristics, and yet each is uniquely different. Understanding this 
tension between static and fluid design, forms the basis of the aesthetics that I have propounded in this thesis. And it is this ability to think on a number of different planes simultaneously that aesthetics offers to organisational actors.

It is this necessity for music to be appreciated at both ideal and real levels that facilitates its translation into the milieu of organisational aesthetics. Research from this aspect requires the researcher to be alert to both the idiosyncratic and the generic; the parts and the whole; things present and things past, and, by implication, things future; the researcher Self and the researched Other; for it is this ability to think multi-dimensionally that is a core requirement of aesthetic ethnography.

Because of this temporal multi-layered orientation, I have offered a method that encourages the researcher to shift his or her focus from the Self to the Other and finally to a Community of people with a shared awareness. These three movements are titled Emotional Attachment, Cognitive Detachment and Integrated Synthesis. Although I have described them in a linear fashion, they are carried out in a fluid manner where the skill of backward reflexivity enables the aesthetic ethnographer to 
consider the past as the context from which the present moment springs, and to anticipate future developments in light of this reflexivity.

To better explain this, I have proposed several typologies - Sonata Form and the quest for the Dionysian spirit - to articulate how this research process occurs. The first of these, Sonata Form is an artefact that stylistically mirrors many of the viscidities of organisational life. Its structure contrasts the thematic and harmonic certainty of the Exposition and Recapitulation with the demise of these in the middle Development section. This sandwich-like structure helps explain in organisational life the ever-present tendency towards chaos and uncertainty, and the concomitant managerial strategies to control and predict. The design approach of Sonata Form is further strengthened by the Dionysian myth.

The Dionysian spirit as understood by Friedrich Nietzsche is a mythological explanation exploring the same tensions between order and collapse that Sonata Form expresses. The mythology of Apollonian order and symmetry, in tension with the chaos of Dionysian excess, explains Nietzsche's exploration of the eternal return and the will to power. For 
Nietzsche, when these two elements work together, there is a continual expansion of human creativity: the essence of the Dionysian.

My primary goal in this thesis is to show how these notions of fluidity and creativity, commonly recognised in the arts, can be used in organisational research. I have described ethnographic research I conducted into the life of a symphony orchestra, the Auckland Philharmonia, during a period of instability. The changes in governance that the orchestra undertook caused the enterprise to examine its core identity. In the process its Cooperative structure weakened and ultimately disappeared.

Lobby groups attributed the inability of the Philharmonia to attract increased funding to an outmoded governance structure that allowed all 68 tenured musicians to vote on decisions of strategic and personnel importance. These groups considered this to be unwieldy and argued that adherence to the Cooperative ideal had led to the breakdown of leadership within the band. The alternative prescription offered by members of the Board of Advisors, and endorsed by a significant number of musicians, caused an outcry from those wedded to the Cooperative tradition. This disagreement ran deep into the heart of the orchestra and 
the resulting battle of attrition evoked aggression, suspicion and resistance among the players to such a level that the very survival of the band was threatened.

After the collapse of the re-designed 2004 governance structure that had tried to incorporate equal player and non-player representation at Board level, another new constitution was devised in 2005 that removed the musicians from direct involvement in the governance of their institution. Furthermore, brand and asset ownership was transferred to a trust board whose membership lay outside the playing body. Hence, by the end of 2005, the Auckland Philharmonia ceased to be run and operated by its original Cooperative Society and instead became managed under corporate-style governance regimes. To further cement this change, the role of the General Manager was disestablished and was replaced by a Chief Executive Officer (CEO) who was given greater decision-making authority on behalf of the Board of Directors.

As described in the previous paragraphs, the aesthetic lens examines these changes from a symbolic rather than a purely rational view. In taking this line, when my research began, the AP was operating as a cooperative, 
with the Orchestral Committee concretising the intentions of the Society. However, both groups consisted of the same people, which meant that they acted out both roles of artist and audience. Under the new governance structure, the players are held at a distance, making, by analogy, the Board of Directors, Chief Executive Officer and Management Team the initiator-artists and the musicians the audience of participators who concretise the ideas promoted by the Board.

Underpinning my critique is a sense of disquiet as to the direction the AP is now taking. This uneasiness manifests itself in several issues that I will explore in this chapter. The first issue involves the nature of management in arts organisations and asks if conventional management strategies are appropriate when working with artists. The second issue leads on from this and inquires into the funding regimes of arts enterprises. In this regard I discuss the relationship between funding and control and question the rights to ownership that funding agencies claim over the artists. In the final chapter, I propose further developments of aesthetic ethnography by looking into the future of organisational aesthetics and identify some of the gaps still needing attention. 


\section{Managing Arts Organisations}

In observing the struggles of the Auckland Philharmonia to adopt a new governance structure, I became aware of my own ambivalence as to the new directions the organisation was taking. While I considered that the musicians needed assistance to help them out of the intransigence that had developed, I found myself growing considerably wary of the radical change from the Cooperative to a board-run model of governance. It seemed to me that administrative processes around the confirmation of players had become sloppy and that the role and authority of committees needed refining. Yet to shift so dramatically from one form to another as a means of resolving some of these issues tended towards overkill.

I began to question whether it was ultimately in the best interests of the orchestra to delegate managerial and governance roles to people not directly involved in artistic production. Central to my reserve was the belief that the new structure was based more on a formulaic adoption of a corporate structure than on the adaptation of an existing cooperative arrangement to a new set of fiscal and governance expectations. 
The benefit of artists working under cooperative regimes is that they, as producers, retain control over their product and are, therefore, better able to refine and renew their offerings in response to social and financial challenges. This ideology is rooted in a view that is best approached through ethics.

Stephen Cummings (2002) discusses the place of ethics in strategic thinking from a postmodern view. Like Nietzsche before him, he returns to the ancient Greeks. Cummings' focus is on the Greeks' separation of external code-driven approaches from an ethic based on inner character virtues. As a result, Cummings distinguishes between a deontic ethic that is motivated externally by fear of consequences, and an aretaic position that relies on the individual's ability to make choices based on inner virtues.

While in developing ethical positions, 'most societies incorporate elements of both of these [deontic and aretaic] modes' (Cummings, 2002, p. 184), in translating these ideas into organisational strategy, the modern organisation, Cummings argues, has tended towards a deontic identity leading to homogenisation; to copying other enterprises. However, he 
makes a case for an aretaic approach that sees enterprises developing and evolving internally driven strategies that are consistent with the existing and evolving ethos of that particular firm.

However, the AP took the reverse, deontic, route. The newly constituted structure was deliberately developed to be contiguous with organisational structures in the corporate sector. But what are the merits of developing a structure that removes from the equation direct interaction from the musicians, the original owners and developers of the AP brand?

The risk in alienating the artist-producers from their product is that this will rob them of their creative involvement. The alternative has its downside too, for when artists become so committed to an ideology that they lose the ability to manage themselves, they run the risk of selfdestructing. However, taking Nietzsche's line, where the Apollonian and Dionysian inform each other, then form and chaos work together, continually renewing each other. But to remove the Dionysian, thereby focusing solely on form, is to invite a tendency towards entropy, a state that Margaret Wheatley claims leads to systemic death (Wheatley, 1992, p. 76). 
The ideology of giving creators control over the means of production has its counterpart in empirical studies. In her investigations into environments that encourage intrinsically motivated behaviours, Teresa Amabile discovered that when individuals within organisations have an internal locus of control, they are freer to express their creativity than those who operate under more rigorous supervisory regimes. For Amabile:

Freedom is defined in this case as freedom to choose what to do and how to accomplish it. It involves a sense of control over one's work and ideas.

(Amabile \& Sensbaugh, 1992, p. 21)

By shifting the locus of control to people outside the artistic process, the AP has effectively denied the artists, the musicians themselves, the ability to create and recreate management systems and strategies. The promise of freedom to the musicians in the 2004 Chairman's AGM address and the subsequent loss of direct representation in the governance of their orchestra could, contradictorily, cost them the freedom they were offered.

What then are managerial strategies that arts organisation can institute to ensure the creative involvement of their artists? Beyond direct participation in decision making, arts companies are required to take 
seriously Nietzsche's advocacy for the Dionysian. This of necessity means that arts enterprises, and other organisations that value creativity, will continually live on the verge of the spontaneous and uncontrollable where the oscillation between stability and instability are expected and prized, rather than controlled or eliminated. In response, funding agencies are then required to change their supervisory regimes in recognition of these desired qualities.

\section{Funding Arts Organisations}

Like their counterparts in earlier times, contemporary arts organisations rely on generous contributions from wealthy patrons in order to survive. In New Zealand this patronage is derived primarily from the public purse. These contributions come in part from local and regional councils but in the main it is the central Government's agency, Creative New Zealand, that provides the majority support for performing arts companies such as the Auckland Philharmonia.

The AP stands out among other orchestrates in Australasia in that it derives much of its support (about $17 \%$ in 2006) from private corporate sponsors. Whereas other orchestras in Australia and the New Zealand 
Symphony Orchestra rely primarily on state or central government support, the AP has managed to successfully promote itself to a raft of corporate organisations who give generously.

In this regard, on April 11, 2003, a full-page advisement was published in The New Zealand Herald celebrating Telecom New Zealand's sponsorship of that year's Pops series. Telecom New Zealand is one of New Zealand's largest companies and this sponsorship agreement represented a significant coup on the Philharmonia's part. The advertisement contains the tag line: 'Mixing art and business isn't always easy - but it's making Auckland's favourite orchestra even more successful.' The advertisement goes on to state:

The Auckland Philharmonia is a cooperative. Each of its musicians is a part-owner. So while they're performing, they've also got a vested interest in finding new ways to run their business as efficiently as possible.

$$
\text { (“Appearing in concert," 2003, p. A7) }
$$

The advertisement acknowledges the cooperative governance structure and by implication confers legitimacy on it by equating the artistic process with business. Telecom New Zealand's underlying message in the 
advertisement is that arts and business are uniquely entwined and that the musicians are as interested in business as Telecom is in art.

And yet, events behind the scenes belied this rhetoric. One of the key selling points that ultimately persuaded the orchestra to renounce its cooperative governance style was that the ensemble would be better able to source new revenue streams if it delegated governance to its Board and CEO. In this way quality control could be assured and accountability guaranteed because business functions would be separated from the artistic process. This dilemma, whether to separate the artistic process from business practice, or to integrate the two functions, as the Telecom advertisement suggests, is a core issue facing funding agencies. The track that the AP finally settled on was to separate the two areas in the quest for artistic excellence. However, there are the risks in formalising this separation.

In their short but provocative book, Free Exchange, sociologist Pierre Bourdieu and visual artist Hans Haacke (1995) offer a verbatim account of a conversation they had together discussing the nature and function of art in society. In part of their exchange they discuss the problem of arts 
sponsorship, claiming that, when corporations become involved in arts funding, the donors' agendas are far from disinterested. Bourdieu and Haacke maintain that, rather than supporting art for its own sake, patronage becomes a tool through which donor organisations can influence wider public opinion. In this regard they discuss Cartier CEO Alain-Dominique Perrin's rationale for funding the arts.

PIERRE BOURDIEU: Does he say in black and white, 'It is to win over public opinion?'

HANS HAACKE: Yes. In his own words: 'Patronage [le mécénat] is not only a great tool for communication. It does much more: it is a tool for the seduction of public opinion.'

(Bourdieu \& Haacke, 1995, p. 17)

Behind what ostensibly is a mutually beneficial arrangement where artists gain continued support and donor organisations build social capital, is something more sinister which enables benefactors to use their fiscal power to exercise control. Bourdieu and Haacke suggest that, in situations where funding agencies, whether private or public, take control over the artistic product, there is a concomitant loss of social critique. This leads, according to Bourdieu, to 'self-censorship or, worse, a feeling of demoralization and demobilization' (Bourdieu \& Haacke, 1995, p. 82). In contrast, quoting Max Weber, they argue that artists have the purpose of 
'exemplary prophecy' (Bourdieu \& Haacke, 1995, p. 83) and where artists are hindered from provoking and challenging, society becomes emasculated.

It could be argued, though, that because of its ephemeral nature, music does not have the same power to challenge societal mores as, say, the visual or dramatic arts. Nonetheless, large ensembles do perform an important function in providing an instrument through which contemporary composers can experiment with the orchestral sound. This was the case when I began my research at the Auckland Philharmonia. A senior manager expressed to me that one of the orchestra's mandates was to perform music written by contemporary New Zealand composers.

Of the AP's 15 flagship subscriber concerts in 2003, 10 contained works by New Zealanders. At the time I considered this a bold programming initiative given that audiences do not always find new music readily accessible. While in eight cases these new works were short pieces and designated to be 'Snapshots', the other two works were substantial compositions of full symphonic proportions taking around 30 minutes each to perform. 
Both these major works required sophisticated listening skills that demanded concentrated focus from the audience. In both instances, conversations with other attendees (people who accompanied me and folk I sat beside) made it clear that there was reluctance on their part to engage with the compositions. Rather, they tolerated the new works so that they could listen to the rest of the programme of more conventional pieces.

The commitment to the local voice and to offering a platform for New Zealand composers began to change as the new governance regime took hold. By 2005, contemporary New Zealand music had all but disappeared from the schedule of the main subscription series, revealing a conservative turn by the new governors determined to build a healthy balance sheet.

This state of affairs is supported in other literature. The 2003 report commissioned by the American Symphony Orchestra League which investigates the condition of symphonic music in the United States of America (USA) ruminates on performing contemporary and local music. It argues that orchestras exist both for the general public and for the musicians, and claims: 'Orchestras that play and encourage the composition of music of our time enrich the repertoire and serve as a vital 
intellectual, cultural, and social force' (Americanizing the American Orchestra, 1993, p. 9). It further maintains that when orchestras perform contemporary music, their approach to the standard repertoire is renewed.

Where contemporary music is avoided by a reluctant management rationale afraid of a public backlash, the local voice is silenced and instead of the orchestra being 'stewards of a living tradition, [they become] caretakers of a museum of antiquities' (Americanizing the American Orchestra, 1993, p. 9). Or to put it more philosophically, the purpose of arts organisations like the symphony orchestra is to preserve and disrupt the canon. ${ }^{2}$ But when financial concerns take precedence over artistic integrity, the result is an orchestra that preserves, but does little to disrupt; and without disruption, opportunities for critique or challenge become limited.

Edward Arian, in his analysis of the effect on artists and the arts of the National Endowment for the Arts (NEA) in the USA, is critical of the

${ }^{2}$ This claim was made to me by an Arts Management student after her interview with an art gallery curator who explained the purpose of a gallery as being 'to preserve and disrupt the canon'. The statement is used here with her permission. 
outcomes that funding, through this organisation, has had on cultural development. He argues that the NEA has been captured by small groups of elite people who consume arts in order to build their public profile. He quotes Di Maggio and Useem, saying:

Elites have used the arts not only for aesthetic fulfilment and enjoyment but also for maintenance of their ever-threatened dominance of the class hierarchy. Thus arts events have provided the elite convenient occasions for the reaffirmation of its shared, distinctive higher culture. And elite families have passed art appreciation to their children as cultural capital, later a valuable asset in the pursuit of professional and managerial careers.

(Di Maggio \& Useem, cited in Arian, 1989, p. 23, emphasis in the original)

Furthermore, when musicians are required to simply perform so-called 'warhorses' from the standard repertoire, their playing standards and morale tend to decline.

Throughout his or her playing career, an orchestral musician performs works from the canon a number of times and is fully conversant with the technical difficulties and challenges of each work. For instance the Auckland Philharmonia performed Berlioz's Symphonie Fantastique in 2004 and 2005. Even though conductors may interpret the same work differently, there is little that places extra demands on the skills of a rank- 
and-file player, thereby reducing him or her to the status of a process worker. As Philip Hart noticed in his research into symphony orchestra musicians, 'the deadly routine of the automated production line has its counterpart in the artistically stifling life of a majority of symphony musicians' (Hart, 1973, p. 467). Later research concurs with this view (Allmendinger, Hackman, \& Lehman, 1996; Wichterman, 1999), revealing musicians lacking in energy and enthusiasm for their work. Hence creativity, along with morale, are compromised by continually revisiting works from the standard repertoire, and by not offering musicians the challenge of working at the limits of their skills.

Funding agencies are beholden, then, to take cognisance of the work environment of the artists they are supporting. To provide funding and then expect an equal or greater return in terms of either an improved public profile or control over the artistic process is an inherently flawed approach. For, to remove the artists from direct control over their art is to ultimately destroy that forum through which society is enriched, provoked and challenged. 


\section{Integrating Governance and Funding}

Managing and funding are two primary issues that arts organisations must continually confront. Furthermore, they are inexorably linked.

Agencies are increasingly reluctant to fund organisations that are seen to be untrustworthy or that have slipshod accountability procedures. Yet, as noted, to take the managerial responsibility away from the artists is to potentially rob an enterprise of its creativity. I argue, though, that arts organisations can successfully integrate the two.

In Table 10.1: Governance and Funding: A Model of Integration, I summarise the key components that of artistic management. These are labelled under two elements joined with the conjunction and. Hence form (stability) and chaos (instability) work together rather than being opposing polarities. Under the governance rubric self management and collective agreement go hand-in-hand with accountability and freedom.

Considerations of preservation and disruption, and control of the product by the producers and social critique form the issues that funding agencies need to consider. 
Table 10.1: Governance and Funding: A Model of Integration

\begin{tabular}{|lll|}
\hline \multicolumn{1}{c}{$\begin{array}{c}\text { FORM } \\
\text { (STABILITY) }\end{array}$} & AND & \multicolumn{1}{c|}{$\begin{array}{c}\text { CHAOS } \\
\text { (INSTABILITY) }\end{array}$} \\
\hline GoVERNANCE & Self management & Collective agreement \\
& Accountability & Freedom \\
FUNDING & Preservation & Disruption \\
& $\begin{array}{l}\text { Control of product by } \\
\text { producers }\end{array}$ & $\begin{array}{l}\text { Social critique ('exemplary } \\
\text { prophecy') }\end{array}$ \\
\hline
\end{tabular}

These sometimes contradictory elements require leaders able to work in the uncomfortable zone between order and chaos, for it is here that creativity occurs. The aesthetic lens helps leaders in the art sector understand the issues of funding, programming and the morale of musicians that have been canvassed above. In particular it enables leaders to deal with the paradoxes involved in providing sufficient freedom for the artists to work productively without taking away their control over the artistic process. In working with artists, aesthetically attuned leaders are able to encourage social critique while at the same time protecting the relationships with sponsors that have been established over time. 
This integrative view requires artists and managers to work together on matters of governance and funding. As the uncertainties implied in chaos and instability are successfully negotiated, enterprises will be able to devise business strategies that sustain their art forms.

This chapter has dealt with the practical implications of aesthetics for arts companies. However, there is still much to be done to develop research methodologies. In the next chapter I investigate the implications of my research beyond orchestras and other artistic endeavours. I examine the both-and view that underpins aesthetics, investigating its implications for organisational life and research outside the artistic world. 


\section{ChAPTER 11 The Music of Organisations}

- Contributions of Aesthetics to Management Practice

- Strengths and Limitations of Aesthetic Ethnography

- Future Directions: The Music of Organisations

1. Organisations as Ensembles

2. The Leader as Composer

3. The Sounds of Organisations

- Conclusion 
Organisational aesthetics is still in its infancy. As with any fledgling, it requires nurturance and support to help it grow into a fully developed identity. To accomplish this, much more needs to be done both theoretically and methodologically to build on existing practice. Conferences like the biennial Art of Management Conference (AOM) and the International Conference on Arts and Cultural Management (AIMAC) are venues which allow for explorations into the arts-business nexus. Further, the annual Standing Conference on Organizational Symbolism (SCOS) is an event that encourages academics to 'develop innovative views of organization and management, taking inspiration from a variety of different fields and disciplines' (SCOS, 2006, n.p.).

Alongside these formal events, networks of like-minded people are forming which give a home for arts-based researchers to support each other. One such group is the Aesthetics and Arts Organisation Research Network (AACORN) which uses email and blogging as a means of exploring provocative ideas about how the arts can impact on research methods. It is this kind of openness to new ideas with an interdisciplinary focus in AACORN and conferences such as AOM, AIMAC and SCOS that 
will enable organisational aesthetics to find a wider audience. To scope some of these future directions, I explore the wider applications of aesthetics to practitioners and researchers, and then summarise some of the limitations of aesthetic ethnography.

To begin, the question may be asked how aesthetics can be of any use to organisational actors and researchers. What assistance can it offer practicing managers and researchers in dealing with the vicissitudes they confront? In what follows I will discuss how aesthetics can influence the way organisations are led by focusing on management as an art.

Following that I will summarise a personal research agenda that will make a continuing contribution to the growing field.

\section{Contributions of Aesthetics to Management Practice}

My forays into the world of symphonic music and orchestral players can offer insights beyond the narrow confines of the orchestras and their governance. However, in this section I discuss the benefits of my research to managers working beyond the artistic milieu. Although there is a growing body of literature that investigates the arts-business nexus, it is 
not my purpose here to revisit these works. Rather, I propose to discuss the kinds of skills that managers could develop by attending to the aesthetic approach. In discussing these elements, my focus is on management practice, and I use the term manager synonymously with leader. Notwithstanding the large body of literature that promulgates and investigates the differences between leadership and management, my intention here is rather to explore generic aesthetic qualities that contribute to the artistry of organisational leadership and management.

Edgar Schein comments at the end of an article celebrating his 50 years of active research into organisations, that much of his work is artistic. He remarks that in the face of numerous conundrums he has observed as a consultant and academic, those engaged in organisational interventions 'need to trust their own artistic impulse' and that 'much of what we learn from experience remains tacit and can only be expressed artistically' (Schein, 2006, p. 299, emphasis in the original).

And yet Schein is tantalisingly silent on the nature of that artistry. The question remains, then, as to the specific qualities aesthetically alert managers might exhibit. I propose that the qualities discussed in this 
thesis - presencing and concretisation; backward reflexivity; and attention to both form and content - are all elements that contribute to the artistry of management.

Presencing and concretisation are dual artistic features discussed in Chapters 5 and 6 . The notion of presencing views a work of art from the artist's perspective and explores how the piece develops over time. Concretisation, on the other hand, looks at an artefact from the perceiver's point of view, noting that it is the audience of perceivers that brings the work into existence.

The aesthetics of management works at both levels. As artists, managers presence the organisation as a living, dynamic entity, through intentional acts. In the daily decision-making processes resulting from meetings and discussions with staff and other stakeholders, the aesthetically alert manager continually functions on the cusp of dissonance and consonance. Rather than taking a unitary approach, this interplay (schwung) between consonant stability and dissonant instability sees managers at times seeking resolutions, while at others allowing dissonance to increase in order to allow new directions to take shape. For the aesthetician-manager, 
artistry involves making continual assessments about how to allow disorder to take formal shape.

For example, an aesthetically aware leader will be cognisant of timing. Deciding when to intervene by taking control, and when to remain distant from events by letting them run their interrupted course, is an important issue of timing. Similarly, the aesthetician-manager is aware of the productive nature of dissonance. By being aware of discord within the enterprise and by seeing it as a necessary part of the whole, conflict becomes a way of provoking change and adaptation to the organisation's strategic direction.

Beyond intentionality, the aesthetically alert manager also concretises the organisation by uncovering the layers that constitute the enterprise, and by discovering the ways in which these layers interact polyphonically. The skills required are exegetical and hermeneutic. The aesthetic manager undertakes exegesis by inquiring into the context within which decisions were enacted, statements made and policies formed; such as who decided what and the reasons for that decision. The hermeneutic approach enables managers to then investigate the meanings of these acts. Here the 
aesthetically aware manager inquires into the effects of those acts and seeks for both the rational and mythical meanings underpinning them.

These qualities of presencing and concretisation have as their basis the notion that enterprises are temporal phenomena. Together with this awareness, the aesthetically aware manager uses skills of backward reflexivity by acknowledging that the present is informed by the past and indeed anticipates the future. Backward reflexivity, therefore, encourages managers to use irony, a concept discussed by Richard Rorty and explored in Chapter 9, as a way of continually questioning current ideology.

For example, through irony, a manager might be able to inquire behind prevailing opinions and to see existing practices as another fold in the fabric of the organisation. While this activity may be unsettling, it avoids the possibility of the organisation tending towards the nihilism of entropy.

A third quality aesthetically alert managers employ is to be aware of the continual interplay between form and content. In this way, the generic development of policies and procedures to cover all contingencies works alongside the idiosyncratic and sometimes chaotic events of daily 
organising. Nietzsche understands this as the interplay between the Apollonian and Dionysian: the order and structure of Apollo and the frenzy and disorder of Dionysus. Their continual interplay, Nietzsche claims, is a creative space of the eternal return (Nietzsche, 1885/1969, p. 179). Where managers are able to work with both, they are able to lead their organisations beyond the nihilism of finality into a state of continual re-creativity.

By attending to both form and content, managers are able to simultaneously consider the whole and the parts. In taking a global and local view of their organisation, they are able make adjustments to formal policies and practices as new events unfold, thereby allowing for the oscillation between the real and ideal, that was explored in Chapter 4. Given these claims about the nature of aesthetic management, how do they play out in situations beyond the artistic?

\section{Strengths and Limitations of Aesthetic Ethnography}

In his provocative text based on the 2004 Massey Lectures, anthropologist Ronald Wright (2005) opens with a discussion of Gauguin's large mural 
painting D'où venons nous? Que sommes nous? Où allons nous? Wright cleverly juxtaposes Gauguin's despair at hearing of the death of his daughter with his own despair at the degradation of the earth's environment by successive generations of voracious human settlement. Hence Gauguin's three questions of existential import ('Where do we come from?' ‘What are we?' ‘Where are we going?') become, for Wright, key points of inquiry into human existence in the 21st century.

Several things emerge from Wright's work that are relevant to this study. The first of these is his initial foray into aesthetics to scope the problem he intends discussing. For Wright this is more than illustrative, in that his aesthetic approach provides a springboard from which to explore the essence of what it means for humans to live sustainably in this age. The second is Wright's use of aesthetic language to investigate the past and, on this basis, to suggest how we might maintain human existence in the face of environmental degradation. Hence considerations of the past are seen to be necessary to understanding the present, and to anticipating the future. In the third place, in order to reinforce this relationship between aesthetic reception and thoughtful critique, Wright concludes his text with discussions of works of fiction. Novels by Huxley (1965), Orwell 
(1949/1989) and Coetzee (1982) provide a capstone for Wright's plea for a more judicious use of the earth's resources.

By discussing his history of human settlement on Earth between artistic commentary, Wright uses his aesthetic lens to awaken the imagination of his readers. He uses the symbolic, all of which are works of fiction, to alert us to specific environmental issues that have an impact on the way we live. In this way, Wright's text acts as the fulcrum on which the ideal and real oscillate. Each informs the other, leading, Wright hopes, to change in the way we live. Thus the social and aesthetic become intertwined.

The ultimate goal, then, of aesthetic inquiry is a measured response to the way we live: a 'tendency towards social action' (Welsch, 1997, p. 73) as opposed to seeing aesthetic engagement as a means of accruing social or economic capital. In this thesis I have made a contribution to this process by addressing some of the theoretical and methodological issues that underpin organisational aesthetics. However, there is still much to be done. Mienczakowski, Smith and Sinclair (1996) in their work on ethnodrama argue that the post-modern turn has opened up the field for the 
development of numerous social constructionist theories and methodologies. This opening, though, has come with a downside, namely that the de-authoring of texts has resulted in a theoretical canon than is more descriptive than critical.

The method that I have described addresses this issue in that it privileges both the author who presences and the reader who concretises the enterprise. Much still needs to be done theoretically, though, to strengthen this relationship whereby the author and reader are both agents in the process of change and development.

Arts-based leadership development activities that deploy the dramaturgical, plastic and performance arts are all significant steps along the way. Many of these interventions, though, occur away from work sites in retreat situations and often with senior executives, with little trickle-down of significant learning to other staff. Artistic processes can be so much more potent as researchers and consultants find ways of working closely together in devising effective activities for a wide range of organisations and their staffs. 
Further work also needs to be done to strengthen ethnography as a tool for aestheticians. In his prescription for future research and theory building within a post-modern context, Richard Rorty maintains that ethnography is an apt tool (Rorty, 1989, 1991). He argues for ethnography because it centres on people and seeks to discover how they live. Thus theories are developed in situ out of lived experience, rather than in isolation in the laboratory. Added to this, because ethnography is derived from anthropology, it respects and values the past as a means of examining the present. This idea represents a return to a core feature of this thesis, that backward reflexivity allows for the past to inform the present. Rorty claims that these kinds of investigation could provide insights into the way we want to live in the future; images that could become 'the model for a global society' (Rorty, Nystrom, \& Puckett, 1998, p. 48).

Any examination of a research method, though, should also include discussion about its limitations. Some of these include, validating the method from the point of view of the researched, and considering aesthetics in tandem with other methods. 
In order that research subjects cooperate willingly with the researcher, the methods used must have credibility in the eyes of the subjects themselves, not just the researcher's. In the research I conducted among the members of the Auckland Philharmonia, when I asked about the relationship between musical form and organisational structure several of the musicians were dismissive. In Chapter 9 I noted that in interviews where I suggested that their organisational chaos was similar to the Development section within Sonata Form, a typical response was, 'That's a bit farfetched!'

In this instance the gap was too great between my, the researcher's tolerance for new ways of looking at problems, and the acceptance of those views on the part of the researched. For this method to work, though, the cooperation and even collaboration of the research subjects is required. In future projects, it will be important to find ways to prepare subjects to be willing participants.

Aesthetic ethnography could work well with other methods and these synergies could also be explored in future research projects. For instance, narrative analysis could strengthen this approach. Nanette Monin's (2004) 
work on scripture reading where researchers attend to levels of narrative beneath the dominant reading will strengthen the relationship between exegetical and hermeneutic reading strategies discussed in Chapter 6.

Further, aesthetic ethnography could be strengthened through using a formal written questionnaire early in the process. Results from the timely administration of this kind of survey could alert the researcher to issues of immediate concern to research subjects, thereby helping shape the direction of interviews.

What of the future for aesthetic research? In the next section I explore some research directions that will enrich the field.

\section{Future Directions: The Music of Organisations}

Conducting research at the Auckland Philharmonia and writing this thesis have been an enriching experience. It has given me insights into the aesthetic process and enabled me to see organisational life from new perspectives. And yet there is still much to be done to refine, extend and advance our understanding of the relationships between arts and business. My study of the AP offers a small yet focused contribution to 
the field. However, it is limited in that it is an aesthetic analysis of an artistic enterprise. Questions remain at theoretical and empirical levels that need exploration in order to further develop aesthetic ethnography as a method. These issues form the basis of my research plan for the next few years.

At the theoretical level, there is still much to be teased out about the ways in which musical awareness impacts on our understanding of organisational behaviour. Of immediate interest are ensemble formation, developing a compositional approach to leadership, and discovering organisational sound.

In scoping some of the foundational issues the AP was confronting, I noted in Chapter 7 that some of musicians had become disaffected with their Music Director. They considered him to be technically skilled but was unable to inspire a sense of ensemble with the orchestra. This concept of ensemble provoked my thinking about how the music of organisations can be explored in future research. 


\section{Organisations as Ensembles}

In Chapter 7 I quoted one of the players, Marie (a pseudonym) who explained that the reason for the whole orchestra rehearsing together was to achieve a sense of ensemble and that coming individually prepared to rehearse was insufficient to achieve this. The role of the Music Director was to work at a deeper level towards creating a sense of ensemble.

Marie Well that's why we're there to rehearse; we can't practise everything at home by ourselves. It's about ensemble.

A sense of ensemble that develops within performance situations requires being sensitive to each developing moment, and of not only being aware of individual playing, but also the sounds of playing partners as well as the overall orchestra's performance in that moment. Essential things that musicians are continuously alert to are, being in tune and in time with each other. The ability to continually adjust individual sound while in performance necessitates being continually alert to Self and Other.

Austin and Devin (2003) argue that it is this phenomenon of ensemble that lifts enterprises beyond the technocratic to the artful. In spite of this claim, they also note that ensemble is difficult to analyse, writing that: 'It cannot 
be extracted for analysis, because a process without it will no longer be artful making' (Austin \& Devin, 2003, p. 129). But could the notion of ensemble be explored without atomising and thereby destroying it?

An aesthetic approach to the idea of ensemble formation may offer a solution. In particular, further theoretical investigations into Nietzsche's concept of the Dionysian spirit could assist in this investigation.

Nietzsche's deployment of Apollo and Dionysus has still not been well understood. Some have considered his Dionysian references to favour unbridled amoral behaviour (Barth, 1964/2003, p. 8). This is to misread him. Instead, Nietzsche conceived of a condition where Apollonian order and Dionysian excess merged into a third dimension that blended the two. In his later work, Nietzsche came to see that Apollonian form gave order to the chaotic Dionysian, which is the essence of the will to power, a state that he confusedly termed Dionysian. Thus,

this opposition of the two gods was repudiated, and the will to power was proclaimed as the one and only basic force of the universe. This fundamental principle, which Nietzsche still called 'Dionysian,' is actually a union of Dionysus and Apollo: a creative striving that gives form to itself.

(Kaufmann, 1974, p. 282) 
The tension between creativity and nihilism for Nietzsche is not found in the Apollonian-Dionysian dialectic where one is 'a negation of the other' (Bishop \& Stephenson, 1999, p. 413), but, rather, in another creative state of ensemble. My intention, therefore, is to conduct further research into how the melding of order and chaos into a sense of Dionysian ensemble could play out in the organisational arena.

The idea of ensemble formation also questions the nature of leadership. In Chapter 5 I claimed that the prevailing idea of the influence of musical awareness in organisational studies focuses on the orchestral conductor as a model of contemporary leadership. This is an appealing metaphor because it affirms the leader as the central figure in a team. My interest, though, is to work with an alternative image: the leader as composer.

\section{The Leader as Composer}

What are the strategies composers employ when constructing a musical piece that could offer insights into organisational strategy formation? To answer this question, I am interested in investigating the two essential compositional tools of consonance and dissonance in leadership. 
One of the most important elements of music is harmony and it is harmonic structure that establishes the chord sequences and eventually the melodic lines of musical compositions. Musical harmony, though, does not imply an absence of conflict. Rather, it relies on dissonance and the resolutions of those tonal clashes for the music to develop a sense of shape and form.

As a consequence, a leader as composer would be alert to difference. Therefore divergence and variation are the raw materials a leadercomposer would rely on in order to develop a sense of music within an organisation. This requires an active imagination to see possibilities in dissimilarity and to be aware of the constant oscillation of dissonance and consonance (intense harmonic chaos alternating with calm repose).

In this regard questions for future research could include how an increase in dissonance in an organisational ensemble could impact on its strategic direction. Furthermore, how would teams locked in a continual dissonant cycle seek resolution into a new state of consonance? These theoretical elements of ensemble formation and the compositional approach lead to 
further empirical study. For instance, a question I am interested in exploring is: 'What are the sounds of organisations?'

\section{The Sounds of Organisations}

How organisations appear to the eye is well canvassed in the symbolic literature, but how they sound to the ear is not well understood. To begin this investigation, an analogical approach (Barry, 1994) could be adopted within a pseudo-laboratory context where small groups of organisational actors could work together with a composer-consultant to produce soundscape caricatures of their sense of the sounds of their firm. I envisage this being done using music technologies, where keyboards attached to computers with specialised software can record sounds that are suggested by participants. In this way participants could immediately hear what they are feeling, thereby making an immediate connection between sensation and perception.

Beyond this experimental domain, aesthetic ethnography is ideally suited to further tease out the nature of an organisation's music. It is my intention to continue working with this method within companies beyond the arts sector. My aim is to refine the ideas of movement and backward 
reflexivity so that organisational actors can develop an even more refined sense of their firm's identity.

Further ways of exploring an organisation's sound will also involve theoretical explorations into how the polyphonic parts impact on changing understandings of the whole. Musical polyphony, as explored in Chapter 8 validates sometimes opposing voices and sees contradiction as necessary parts of the overall texture. While identifying dominant themes is important, locating voices that are submerged, hidden, or even silent within enterprises will inform future theoretical and methodological explorations.

Beyond this, the ways in which form and content interact over time; and the centrality of imagination and perception assist in making an organisation's sound audible. This could be accomplished by considering the notion of harmony as an underlying phenomenon. Musical harmony is constructed from the bass line, which in turn draws on acoustic fundamentals which are often only implied. Thus, discovering the drivers of an organisation's harmony will be an important factor in locating an organisation's sound. This suggests that strategic directions could begin 
somewhere in the depths of an organisation and grow organically

upwards. Responses to this notion could include a reframing of how

visionary ideas are devised. This has important implications to leadership

practice as those charged with communicating vision and devising

innovative strategies harmonise with those who implement the

organisation's mission.

In conclusion, in Table 11.1: The Music of Organisations, I offer a summary of these ideas. This table demonstrates the musical notions of Ensemble, Composition and Sound, and alongside each I have placed theoretical ideas that are implied by these concepts.

Table 11.1: The Music of Organisations

\begin{tabular}{|lll|}
\hline & \multicolumn{1}{c}{ Musical CONCEPT } & THEORETICAL INVESTIGATION \\
\hline ENSEMBLE & Keeping time & Dionysius and the 'eternal return' \\
& Being in tune & \\
CoMPOSITION & Dissonance & Appreciation of difference \\
& Consonance & Valuing similarity \\
Sound & Polyphony & Sound-scapes \\
& Harmony & $\begin{array}{l}\text { Awareness of underlying } \\
\text { elements }\end{array}$ \\
& & \\
\hline
\end{tabular}




\section{Conclusion}

Organisational aesthetics is an exciting new field of study for

organisational scholars. It links processes that are fundamental to human identity - art making - with important contemporary pursuits of leadership practice and academic research. Aesthetics offers an integrative approach that links traditionally disparate disciplines. Along with this, it offers insights into the art of leadership that will enrich organisational life.

Finally, if Guillet de Monthoux is correct in proclaiming aesthetics as the new theory of organisation, then perhaps this theoretical development will help mitigate the coldness and narrowness of heart that 'the man of business' possesses, signalled by Schiller over 200 years ago (Schiller, 1795/1965, p. 42). As organisations seek to become more creative and innovative, there will be an associated call for the rise of leaders as artists and artists as leaders, able to show the way ahead. The field of organisational aesthetics is well placed to offer both theoretical and practical inspiration for this artistry to grow. 


\section{APPENDICES}

- Appendix A - Organisation Consent Form

- Appendix B - Organisation Information Sheet

- Appendix C - Participant Information Sheet

- Appendix D - Participant Consent Form

- Appendix E - Interview Schedule

- Appendix F - Extracts from the 2004 Chairman's AGM Speech 


\title{
Appendix A - Organisation Consent Form
}

\author{
VICTORIA UNIVERSITY OF WELLINGTON \\ Te Whare Wananga o te Upoko o te Ika a Maui
}

Victoria Management School

Victoria University of Wellington

P.O. Box 600

Wellington

New Zealand

\section{Organisation Consent Form}

This consent form will be held for a period of three years.

Title: $\quad$ The translation of notions of musical theory and creativity into organisational behaviour.

Researcher: Ralph Bathurst.

I have been given and have understood an explanation of this research project. I have had an opportunity to ask questions and have them answered.

- I agree to Ralph Bathurst attending meetings, rehearsals and social occasions of the Auckland Philharmonia.

- I agree to Ralph Bathurst interviewing staff the Auckland Philharmonia for the purpose of conducting research.

- I understand that this will involve him collecting data from staff.

- Members of the Auckland Philharmonia will be advised of this research taking place at the commencement of the data gathering period.

- An opportunity will be given to the General Manager or her or his deputy to read the final draft of the thesis and withdraw any information that might be commercially sensitive.

Signed:

Name:

(please write clearly)

Date:

Approved by the Victoria University of Wellington Human Ethics Committee

On 31/03/2003 for a period of 3 years, from 15/04/2003. 


\title{
Appendix B - Organisation Information Sheet
}

\author{
VICTORIA UNIVERSITY OF WELLINGTON \\ Te Whare Wananga o te Upoko o te Ika a Maui
}

Victoria Management School

Victoria University of Wellington

P.O. Box 600

Wellington

New Zealand

\section{Organisation Information Sheet}

Title: The translation of notions of musical theory and creativity into organisational behaviour.

To: General Manager of the Auckland Philharmonia

My name is Ralph Bathurst. I am a student at The Victoria University of Wellington enrolled in a PhD programme in the Victoria Management School. I am conducting research for my thesis on the way in which musicians use their knowledge of music to inform their ways of managing and leading. The purpose of my study is to see how notions of music theory and performance translate in to management practices and to see if these might have any universal application beyond a musical environment.

I would like to conduct ethnographic research within the Auckland Philharmonia in order to learn more about the ways musicians manage. The things I am looking for surround the way people respond to the various situations that might occur as musicians and go about their role of leader and manager. I am interested in their unique experience and wish to know more of the background of these experiences.

I would like to visit management meetings, social occasions and rehearsals and would then like to interview individual members of the orchestra. Interviews would typically take about an hour and would be arranged with the individual to take place in their own time. I would prefer to audio tape the interviews but this would be done only with the consent of the participant.

The information I collect will be confidential. It will only be available to my supervisor, the individual participant who supplies it and me. In my final report, anonymity will be preserved. Opportunities will be given to the General Manager to read the final draft of the thesis and withdraw any information that might be commercially sensitive. Alongside publication in academic journals and conferences, at the conclusion of my project, I will make myself available to the Philharmonia to run a seminar in which I will share my findings and models that might have emerged through my research. This seminar will be 
for approximately one hour and will be run at a time that is convenient to the Philharmonia.

Thank you very much for your time and help in making this study possible. If you have any queries or wish to know more please feel free to make contact with me. My contact details are:

Work: 443-9799 ext. 9570

Home: 480-3108

Email: batman@xtra.co.nz

My supervisor is: $\quad$ Professor David Barry

Victoria Management School

Victoria University of Wellington

P.O. Box 600

Wellington

Phone: 4-463-5141

Email: David.Barry@vuw.ac.nz

For any queries regarding ethical concerns please contact:

The Chair, The Victoria University of Wellington University of Auckland Human Subjects Ethics Committee, Hunter Building, P.O. Box 600, Wellington, New Zealand.

\section{Approved by the Victoria University of Wellington Human Ethics Committee}

On 31/03/2003 for a period of 3 years, from 15/04/2003. 


\title{
Appendix C - Participant Information Sheet
}

\author{
VICTORIA UNIVERSITY OF WELLINGTON \\ Te Whare Wanang a o te Upoko o te Ika a Maui
}

Victoria Management School

Victoria University of Wellington

P.O. Box 600

Wellington

New Zealand

\section{Participant Information Sheet}

Title: The translation of notions of musical theory and creativity into organisational behaviour.

To: $\quad$ Member of the Auckland Philharmonia

My name is Ralph Bathurst. I am a student at The Victoria University of Wellington enrolled in a PhD programme in the Victoria Management School. I am conducting research for my thesis on the way in which musicians use their knowledge of music to inform their ways of managing and leading. The purpose of my study is to see how notions of music theory and performance translate in to management practices and to see if these might have any universal application beyond a musical environment.

I would like to interview you in order to learn more about your understandings of your ways of making music and of managing. The kinds of questions I would like to ask you surround your responses to various situations that might occur for you as a musician and a leader. I am interested in your unique experience and wish to know more of the background of these experiences.

You are invited to participate in my research and I would appreciate any assistance you can offer me.

Interviews would take about an hour and I may want to speak with you again to clarify some of the things discussed in the interview. This second interview if required would take no more than an hour. Interviews will be conducted in an office space designated by you. I would prefer to audio tape the interview but this would be done only with your consent. The audio tape recorder can be turned off at any time during the interview. You can withdraw any information you provide at anytime up to October 312006.

The information I collect will be confidential. It will only be available to my supervisor, the individual participant who supplies it and me. In my final report, anonymity will be preserved. All collected data will be kept locked in my office filing cabinet. Tapes will be wiped and hard copies destroyed at the completion of my project. 
Please fill in the Consent Form and I will get it from you at the start of the interview. All information you provide in an interview is confidential. You will not be identified in any of the research findings when they are presented in academic journals and conference seminars. I will also make myself available to the Philharmonia to run a seminar in which I will share my findings and models that might have emerged through my research.

Thank you very much for your time and help in making this study possible. If you have any queries or wish to know more please feel free to make contact with me. My contact details are:

Work: $443-9799$ ext. 9570

Home: 480-3108

Email: batman@xtra.co.nz

My supervisor is: $\quad$ Professor David Barry

Victoria Management School

Victoria University of Wellington

P.O. Box 600

Wellington

Phone 4-463-5141

Email: David.Barry@vuw.ac.nz

For any queries regarding ethical concerns please contact:

The Chair, The Victoria University of Wellington University of Auckland Human Subjects Ethics Committee, Hunter Building, P.O. Box 600, Wellington, New Zealand.

\section{Approved by the Victoria University of Wellington Human Ethics Committee}

On 31/03/2003 for a period of 3 years, from 15/04/2003. 


\title{
Appendix D - Participant Consent Form
}

\author{
VICTORIA UNIVERSITY OF WELLINGTON \\ Te Whare Wananga o te Upoko o te Ika a Maui
}

Victoria Management School

Victoria University of Wellington

P.O. Box 600

Wellington

New Zealand

\section{Participant Consent Form}

This consent form will be held for a period of three years.

Title: $\quad$ The translation of notions of musical theory and creativity into organisational behaviour.

Researcher: Ralph Bathurst.

I have been given and have understood an explanation of this research project. I have had an opportunity to ask questions and have them answered.

I understand that I may withdraw myself or any information traceable to me at any time without penalty up to October 31, 2006 without giving a reason.

- I agree to take part in an interview for this research.

- I understand that the interview will be audio taped.

Would you like to attend a seminar to hear the findings of my research?

(Please circle)

Signed:

Name:

(please write clearly)

Date:

Approved by the Victoria University of Wellington Human Ethics Committee

On 31/03/2003 for a period of 3 years, from 15/04/2003. 


\section{Appendix E - Interview Schedule}

\section{Interview Schedule: A Guide for Conversations}

This interview schedule does not represent actual questions but the kinds of things I want to cover in conversations with the participants.

\section{Bio-Data}

- Age

- Gender

- How long with the organisation

- Primary artistic role

- Managerial role

\section{Musicianship}

- What does it mean to you to be a musician?

- How do you distinguish this from "being musical"?

- I would like to find out from you your ideas of musical creativity.

- Can you tell me an experience of when you have felt most creative?

- Can you describe for me activities that squash your musical creativity?

\section{Group Work}

- I want to find out what you do when you play in a group - orchestra, or small ensemble.

- What elements make up a successful group performance?

- What elements inhibit a successful group performance?

\section{Managerial Style}

- Often in a piece of music there are clashing, dissonant chords. These are part of the composer's intentions to create tension. I'm interested in exploring with you times in your management groups when you have become aware of dissonance or tension.

- Can you tell me about an event where dissonance has occurred?

- What was the outcome?

- I'm also interested in your ideas of being 'in tune' and 'out of time' with your colleagues.

- Can you describe for me a situation where you felt 'out of tune' with your colleagues?

- What did you do when you realised you were out of tune or had 'played a bum note'?

- How do you distinguish between 'good' dissonance that builds tension and being out of tune and needing to get back in tune?

- Can you describe for me a situation where you felt 'out of time with your colleagues?

- What did you do to get back into time with them?

\section{Creativity in Management}

- We spoke earlier about your ideas of creativity as a musician.

- Can you tell me an experience where you felt you were being creative in your management team?

- How was this experience different or the same as your experiences of musical creativity? 


\section{Appendix F - Extracts from the 2004 Chairman's AGM Speech}

On 3 July 2003 the Society adopted a new constitution and governance structure. Its introduction was preceded by many months of consultative meetings with the Society and its stakeholders. The process was neither simple nor easy as it involved a very substantial shift from 'self governance' to a more conventional hierarchical governance structure. These changes were driven by the demands of operating a modern and professional orchestra in a changing commercial environment where the standards of governance have been raised, are more transparent and which our major support organisations, such as Creative New Zealand, Auckland City Council, the Auckland Philharmonia Foundation, our donors and commercial sponsors now require of us. These changes are intended to set the musicians free to pursue their musical careers and promote and achieve the growth and development of the artistic excellence of the Orchestra ...

The second important matter to arise out of the affairs of the Orchestra in 2003 was the trading loss of $\$ 341,000$, leaving the Society with net assets of only $\$ 41,000$. [The] General Manager's report, has detailed the principal areas where these losses have been incurred. The losses are both disappointing and unsustainable. The Board has and continues to take steps to arrest loss making activities, operate profitably and rebuild the working capital of the Orchestra to a prudent and acceptable level.

The third point is that, in this process of transition, it has become apparent that the Orchestra has operated in an economic environment which lacks a financial structure that delivers security of operation. Without financial security, the focus of the Board will always be deflected to a greater or lesser extent from the promotion and achievement of long term strategic goals. A structured financial security will be achieved if the Board can develop more high valued long term financial commitments from its existing and new stakeholders ...

... Finally may I salute the musicians. There is no question of their passion to work together as an orchestra. This is evidenced by the reputation of, and good will attributed to the name of the Auckland Philharmonia in Auckland and elsewhere in New Zealand and around the world. But I want to acknowledge the generosity of their spirit and commitment to the music over and above all the other trials and tribulations that go with the management, administration and organisation of an institution such as the Auckland Philharmonia. To breathe life into the music, the musicians need to be free spirits, unshackled from and unburdened by the day to day operation and running of the Orchestra itself. This is not always possible in the real world and despite the distractions which flow from all of the changes which have been put in place in the year 2003, the musicians have none the less lifted themselves above all of this and continued to 
play music at the highest level. It is my intention, and that of the Board, to put in place structures which will continue to promote and support the musicians and allow them to play with freedom, passion and excellence. 


\section{REFERENCES}

Abravanel, H. (1983). Mediatory myths in the service of organizational ideology. In L. R. Pondy \& P. J. Frost \& G. Morgan \& T. C. Dandridge (Eds.), Organizational symbolism (pp. 273-293). London: Jai Press.

Adorno, T. W. (1963/2000). Culture industry reconsidered. In B. O'Connor (Ed.), The Adorno reader (pp. 230-238). Oxford: Blackwell.

Adorno, T. W. (1997). Aesthetic theory (R. Hullot-Kentor, Trans. Vol. 88). Minneapolis: University of Minnesota Press.

AIMAC. (2005). 8th International Conference On Arts and Cultural Management [Website]. International Association of Arts and Cultural Management. Retrieved November 15, 2005, from the World Wide Web: http://www.hec.ca/aimac2005/welcome.htm

Albert, S., \& Bell, G. G. (2002). Timing and music. Academy of Management Review, 27(4), 574-593.

Alison, A. (1790/1968). Essays on the nature and principles of taste. Hildesheim: Georg Olms Verlagsbuchhandlung.

Allmendinger, J., Hackman, R. J., \& Lehman, E. V. (1996). Life and work in symphony orchestras. The Musical Quarterly, 80(2), 194-219.

Amabile, T. M., \& Sensbaugh, S. J. (1992). High creativity versus low creativity: What makes the difference. In S. S. Gryskiewicz \& D. A. Hills (Eds.), Readings in innovation (pp. 19-28). Greensboro, North Carolina: Center for Creative Leadership.

Americanizing the American Orchestra. (1993). Washington DC: American Symphony Orchestra League.

Appearing in concert. (2003, April 11). The New Zealand Herald, p. A7.

Arian, E. (1989). The unfulfilled promise: Public subsidy of the arts in America. Philadelphia: Temple.

Armstrong, K. (2005). A short history of myth. Edinburgh: Canongate.

Atik, Y. (1994). The conductor and the orchestra: Interactive aspects of the leadership process. Leadership and Organization Development Journal, 15(1), 22-28. 
Auckland Philharmonia Orchestra (2006). [Website]. Auckland Philharmonia Orchestra. Retrieved May 15, 2006, from the World Wide Web: http://www.akl-phil.co.nz/index.php/ps pagename/homepage

Austin, R., \& Devin, L. (2003). Artful making: What managers need to know about how artists work. Upper Saddle River, New Jersey: Prentice Hall.

Banchetti-Robino, M. P. (2004). Ibn Sina and Husserl on intention and intentionality. Philosophy East $\mathcal{E}$ West, 54(1), 71-82.

Barley, S. R. (2006). When I write my masterpiece: Thoughts on what makes a paper interesting. The Academy of Management Journal, 49(1), 16-20.

Barrett, J. (2002). Staged narrative: Poetics and the messenger in Greek tragedy. Berkeley: University of California Press.

Barry, D. (1994). Making the invisible visible: Using analogically-based methods to surface unconscious organizational processes.

Organization Development Journal, 12(4), 37-48.

Barry, D. (1996). Artful inquiry: A symbolic constructivist approach to social science research. Qualitative Inquiry, 2(4), 411-438.

Barry, D., Bathurst, R. J., \& Williams, L. (2003). Cadences at Waco: A critique of "Timing and Music". Academy of Management Review, 28(3), 367-368.

Barry, D., Brearley, L., Guillet de Monthoux, P., Hatch, M. J., \& Whiteman, G. (2004). Aesthetics, art and management: Not for philosophy does this rose give a damn. Paper presented at the Academy of Management Conference, New Orleans.

Barth, K. (1964/2003). God here and now (P. M. van Buren, Trans.). London: Routledge.

Barthes, R. (1972). Mythologies (A. Lavers, Trans.). New York: Hill and Wang.

Barthes, R. (1977a). The death of the author (S. Heath, Trans.), Image, music, text (pp. 142-148). London: Fontana Press.

Barthes, R. (1977b). Image, music, text (S. Heath, Trans.). London: Fontana Press. 
Barton, C. (2005, February 26). Orchestral manoeuvres in the dark. The New Zealand Herald, pp. B6-B7.

Bathurst, R. J. (2001). Searching for dialogue in organisational life. Unpublished Masters, University of Auckland, Auckland.

Bathurst, R. J. (2004, September 7-10). Developing structural competence: Using aesthetics to understand temporal organisational structure. Paper presented at the Second Art of Management \& Organisation Conference, Paris.

Bathurst, R. J., \& Barry, D. (2004, September 7-10). Acquiring an aesthetic language. Paper presented at the Second Art of Management \& Organisation Conference, Paris.

Bathurst, R. J., Barry, D., \& Williams, L. (2003, August 1-6). On organisational harmony. Paper presented at the Academy of Management Conference, Seattle.

Bathurst, R. J., \& Williams, L. (2004, September 7-10). Exploring leadership among musicians: An interactive seminar. Paper presented at the Second Art of Management \& Organisation Conference, Paris.

Bathurst, R. J., Williams, L., \& Rodda, A. (2005, July 3-6). Letting go of the rei[g]n: Developments within an orchestra in a time of change. Paper presented at the 8th International Conference on Arts \& Culture Management, Montreal.

Bathurst, R. J., Williams, L., \& Rodda, A. (Forthcoming). Letting go the reign: Paradoxes and puzzles in leading an artistic enterprise. International Journal of Arts Management.

Behrens, R. R. (1998). Art, design and gestalt theory. Leonardo, 31(4), 299303.

Benjamin, W. (1998). The origin of German tragic drama (J. Osborne, Trans.). London: Verso.

Bennett, A. (1995). Introduction. In A. Bennett (Ed.), Readers and reading. New York: Longman.

Berger, P. L., \& Luckmann, T. (1967). The social construction of reality: A treatise in the sociology of knowledge. London: Penguin Press.

Bergson, H. (1910/1971). Time and free will: An essay on the immediate data of consciousness (F. L. Pogson, Trans.). London: G Allen and Unwin. 
Bergson, H. (1911). Matter and memory (N. M. Paul \& W. S. Palmer, Trans.). London: Allen and Unwin.

Bergson, H. (1911/1998). Creative evolution. Toronto: General Publishing Company.

Bergson, H. (1935). Laughter: An essay on the meaning of the comic (C. Brereton \& F. Rothwell, Trans.). London: MacMillan.

Berlin, I. (2000). Three critics of the Enlightenment: Vico, Hamann, Herder. London: Pimlico.

Berlin, I. (2003). The counter-Enlightenment [Dictionary]. The Dictionary of the History of Ideas. Retrieved July 11, 2005, from the World Wide Web: http://etext.lib.virginia.edu/cgi-local/DHI/ot2wwwdhi?specfile=/texts/english/dhi/dhi.o2w\&act=text\&offset $=5742664 \&$ query=enlightenment\&tag=THE+COUNTER-ENLIGHTENMENT

Bernard-Donals, M. F. (1994). Mikhail Bakhtin: Between phenomenology and Marxism. Cambridge: Cambridge University Press.

Berstein, M., \& Picker, M. (1966). An introduction to music. Englewood Cliffs, New Jersey: Prentice-Hall.

Bishop, P., \& Stephenson, R. H. (1999). Nietzsche and Weimar aesthetics. German Life and Letters, 54(4), 412-429.

Bjerring, S. (2004). First you have to win their hearts - then we can talk business [E-Journal]. Learning Lab Denmark. Retrieved February 14, 2005, from the World Wide Web:

http://www.lld.dk/publications/quarterlyonline/2004issue4/hjerteogbusiness/en\#portal-top

Boje, D. M. (1998). Ten solutions to transform Victorian capitalism into democratic capitalism [Website]. Retrieved August 10, 2004, from the World Wide Web: http://cbae.nmsu.edu/mgt/handout/boje/solviccap/

Boje, D. M. (1999). What is postmodern organization science? [Journal]. Tamara: Journal for Critical Postmodern Organization. Retrieved June 30, 2003, from the World Wide Web: http://www.tamarajournal.com 
Boje, D. M. (2003). Bush as Top Gun: Deconstructing visual theatric imagery [Website]. David M. Boje. Retrieved April 23, 2004, from the World Wide Web: http://peaceaware.com/papers/Bush Top Gun.htm

Boje, D. M., Oswick, C., \& Ford, J. D. (2004). Language and organization: The doing of discourse. Academy of Management Review, 29(4), 571577.

Boje, D. M., \& Rosile, G. A. (2003). Life imitates art: Enron's tragic and epic narration. Management Communication Quarterly, 17(1), 85-125.

Bourdieu, P., \& Haacke, H. (1995). Free exchange. Cambridge: Polity Press.

Bowra, C. M. (1957). The Greek experience. New York: New American Library.

Brosnan, M. J., Scott, F. J., Fox, S., \& Pye, J. (2004). Gestalt processing in autism: Failure to process perceptual relationships and the implications for contextual understanding. Journal of Child Psychology \& Psychiatry \& Allied Disciplines, 45(3), 459-469.

Burke, K. (1961). The rhetoric of religion: Studies in logology. Boston, Massachusetts: Beacon Press.

Cairns, G. (2002). Aesthetics, morality and power: Design as espoused freedom and implicit control. Human Relations, 55(7), 799-820.

Carlile, P. R. (2002). A pragmatic view of knowledge and boundaries: Boundary objects in new product development. Organization Science, 13(4), 442-455.

Carr, D. (2004). Music, meaning, and emotion. Journal of Aesthetics and Art Criticism, 62(3), 225-234.

Carroll, N. (2000). Philosophy of art: A contemporary introduction. London: Routledge.

Carter, C. A. (1992). Logology and religion: Kenneth Burke on the metalinquistic dimension of language. Journal of Religion, 72(1), $1-17$.

Carter, C. A. (1997). Kenneth Burke and the bicameral power of myth. Poetics Today, 18(3), 343-373. 
Casey, C. (1995). Work, self and society after industrialism. London: Routledge.

Cassirer, E. (1944). An essay on man: An introduction to a philosophy of human culture. New Haven: Yale University Press.

Castañer, X. (1999). The tension between artistic leaders and management in arts organisations: The case of the Barcelona Symphony Orchestra. In M. Fitzgibbon \& A. Kelly (Eds.), From maestro to manager: Critical issues in arts and culture management (pp. 279-416). Dublin: Oak Tree Press.

Caygill, H. (1995). A Kant dictionary. Oxford: Blackwell Reference.

Chong, D. (2002). Arts management. New York: Routledge.

Coetzee, J. M. (1982). Waiting for the barbarians. Harmondsworth: Penguin Books.

Cohen, I. J. (1987). Structuration theory and social praxis. In A. Giddens \& J. H. Turner (Eds.), Social theory today (pp. 273-308). Cambridge: Polity Press.

Colombo, M. G., \& Delmastro, M. (2002). The determinants of organizational change and structural inertia: Technological and organizational factors. Journal of Economics \& Management Strategy, 11(4), 595-635.

The Concise Oxford English Dictionary. (10th ed.)(2002). Oxford: Oxford University Press.

Cook, S. D., \& Yanow, D. (1993). Culture and organizational learning. Journal of Managerial Inquiry, 2(4), 373-390.

Cronk, R. (1996). Mimesis and the aesthetic experience [Website]. Art on the rebound: A collection of essays on art and culture. Retrieved October 7, 2003, from the World Wide Web: http://www.westland.net/venice/art/cronk/mimesis.htm

Crouch, D. (2003). Spacing, performing, and becoming: Tangles in the mundane. Environment \& Planning A, 35(11), 1945-1960.

Culyba, R. J., Heimer, C. A., \& Petty, J. C. (2004). The ethnographic turn: Fact, fashion, or fiction? Qualitative Sociology, 27(4), 365-389.

Cummings, S. (2002). Recreating strategy. London: Sage. 
Czarniawska, B. (1999). Management she wrote: Organization studies and detective stories. Studies in Cultures, Organizations $\mathcal{E}$ Societies, 5(1), 13-41.

Dart, W. (2005, November 23). Happy returns and few regrets for city icon. The New Zealand Herald, p. B6.

Davie, C. T. (1965). Musical structure and design. London: Dennis Dobson.

Dean, J. W., Ottensmeyer, E., \& Ramirez, R. (1997). An aesthetic perspective on organizations. In C. L. Cooper \& S. E. Jackson (Eds.), Creating tomorrow's organizations: A handbook for future research in organizational behavior (pp. 419-437). New York: J. Wiley.

Deleuze, G. (1965/2001). Nietzsche. In G. Deleuze (Ed.), Pure immanence: Essays on a life (pp. 53-102). New York: Zone Books.

Deleuze, G. (1990/2001). The logic of sense (M. Lester \& C. Sitvale, Trans.). London: Athlone Press.

Deleuze, G. (2002). Francis Bacon: The logic of sensation (D. W. Smith, Trans.). Minneapolis: University of Minnesota.

Descartes, R. (1637/1985). Discourse on method (F. E. Sutcliffe, Trans.). Harmondsworth, Middlesex: Penguin Books.

Dewey, J. (1934). Art as experience. New York: Capricorn.

Dewsbury, J.-D. (2003). Witnessing space: 'Knowledge without contemplation'. Environment and Planning A, 35(11), 1907-1932.

Dickens, L., \& Watkins, K. (1999). Action research: Rethinking Lewin. Management Learning, 30(2), 127-140.

Dorfles, G. (1969). Myth and metaphor in Vico and in contemporary aesthetics (E. Gianturco, Trans.). In G. Tagliacozzo \& H. V. White (Eds.), Giambattista Vico: An international symposium (pp. 577-590). Baltimore: The Johns Hopkins University Press.

Dowling, M. (2004). Hermeneutics: An exploration. Nurse Researcher, 11(4), 30-39.

Drucker, P. (1993). Tomorrow's manager: More of an orchestra conductor than an administrator. Success, 40(8), 80. 
Dyck, B., Starke, F. A., Mischke, G. A., \& Mauws, M. (2005). Learning to build a car: An empirical investigation of organizational learning. Journal of Management Studies, 42(2), 387-416.

Edström, O. (2003). A different story of the history of Western music and the aesthetic project [Journal]. Mayday Group: Action for Change in Music Education. Retrieved November 29, 2004, from the World Wide Web:

http://www.siue.edu/MUSIC/ACTPAPERS/v2/Edstrom03.pdf

Eisner, E. W. (1997). The new frontier in qualitative research methodology. Qualitative Inquiry, 3(3), 259-263.

Elias, N. (1992). Time: An essay (E. Jephcott, Trans.). Oxford: Blackwell.

Embree, L. (1997). What is phenomenology? [Website]. Center for Advanced Research in Phenomenology. Retrieved February 11, 2004, from the World Wide Web: http://www.phenomenologycenter.org/phenom.htm

Fee, G. D., \& Stuart, D. (1986). How to read the Bible for all its worth: A guide to understanding the Bible. London: Scripture Union.

Feenberg, A. (2000). The ontic and the ontological in Heidegger's philosophy of technology: Response to Thomson. Inquiry, 43(4), 445-450.

Feldman, S. P. (2000). Micro matters: The aesthetics of power in NASA's flight readiness review. Journal of Applied Behavioral Science, 36(4), 474-490.

Finley, S. (2003). Arts-based inquiry in QI: Seven years from crisis to guerrilla warfare. Qualitative Inquiry, 9(2), 281-296.

Foucault, M. (1991). On the genealogy of ethics: An overview of work in progress. In P. Rabinow (Ed.), The Foucault reader (pp. 340-372). London: Penguin Books.

Frobenius, W. (2004). Polyphony [Dictionary]. Grove Music Online. Retrieved August 9, 2004, from the World Wide Web: http://www.grovemusic.com/shared/views/article.html?section=mu sic.42927\#music.42927

Gadamer, H.-G. (1975/1999). Truth and method (J. Weinsheimer \& D. G. Marshall, Trans. 2nd ed.). New York: Continuum. 
Gadamer, H.-G. (1986). The relevance of the beautiful: Art as play, symbol and festival. In R. Bernasconi (Ed.), The relevance of the beautiful and other essays (pp. 1-53). Cambridge: Cambridge University Press.

Gadamer, H.-G. (1999). Truth and method (D. G. Marshall, Trans. 2nd ed.). New York: Continuum.

Gagliardi, P. (1996). Exploring the aesthetic side of organizational life. In S. R. Clegg \& C. Hardy \& W. R. Nord (Eds.), Handbook of organization studies (pp. 565-580). London: Sage.

Geanellos, R. (2000). Exploring Ricoeur's hermeneutic theory of interpretation as a method of analysing research texts. Nursing Inquiry, 7(2), 112-119.

Gentner, D. (1983). Structure-mapping: A theoretical framework for analogy. Cognitive Science, 7(2), 155-170.

Giddens, A. (1990). The consequences of modernity. Stanford, California: Stanford University Press.

Gilbert, K. (1949). Cassirer's placement of art. In P. A. Schilpp (Ed.), The philosophy of Ernst Cassirer (pp. 605-630). New York: Tudor.

Goetz, J. P., \& LeCompte, M. D. (1984). Ethnography and qualitative design in educational research. Orlando, Florida: Academic Press.

Gottlieb, A. (2001). The dream of reason: A history of Western philosophy from the Greeks to the Renaissance. London: Penguin Books.

Griffiths, P. (2005). Serialism [Website]. Grove Music Online. Retrieved June 23, 2005, from the World Wide Web: http://www.grovemusic.com/shared/views/article.html?from=searc h\&session search $\mathrm{id}=293185080$ \&hitnum=1\&section=music. 25459

Gross, S. W. (2002). The neglected programme of aesthetics. The British Journal of Aesthetics, 42(4), 403-414.

Grout, D. J. (1960). A history of Western music. London: J. M. Dent and Sons.

Guillet de Monthoux, P. (2000). The art management of aesthetic organizing. In S. Linstead \& H. Höpfl (Eds.), The aesthetics of organization (pp. 35-60). London: Sage. 
Guillet de Monthoux, P. (2004). The art firm: Aesthetic management and metaphysical marketing. Stanford, California: Stanford University Press.

Hampson, N. (1968/1990). The Enlightenment: An evaluation of its assumptions, attitudes and values. London: Penguin Books.

Hancock, P. (2002). Aestheticizing the world of organization: Creating beautiful untrue things. TAMARA: Journal of Critical Postmodern Organization Science, 2(1), 91-105.

Hancock, P. (2005). Uncovering the semiotic in organizational aesthetics. Organization, 12(1), 29-50.

Hansen, H. (2002). Narrating research. Paper presented at the Academy of Management Conference, Denver.

Hanslick, E. (1968). The effects of music. In L. A. Jacobus (Ed.), Aesthetics and the arts (pp. 170-182). New York: McGraw-Hill.

Harman, A., Mellers, W., \& Milner, A. (1971). Man and his music: The story of musical experience in the west. London: Barrie and Jenkins.

Hart, P. (1973). Orpheus in the New World: The symphony orchestra as an American cultural institution. New York: Norton.

Hassard, J. (1996). Images of time in work and organization. In S. R. Clegg \& C. Hardy \& W. R. Nord (Eds.), Handbook of organization studies (pp. 580-598). London: Sage.

Hatch, M. J. (1997). Organization theory: Modern symbolic and postmodern perspectives. Oxford: Oxford University Press.

Hepburn, R. W. (2002). Data and theory in aesthetics: Philosophical understanding and misunderstanding. In A. Berleant (Ed.), Environment and the arts: Perspectives on environmental aesthetics (pp. 24-38). Aldershot: Ashgate.

Hirschhorn, L. (1988). The workplace within: Psychodynamics of organizational life. Cambridge, Massachusetts: MIT Press.

Holst, I. (1967). An ABC of music: A short practical guide to the basic essentials of rudiments, harmony, and form. London: Oxford University Press.

Holzhey, H., \& Mudroch, V. (2005). Historical dictionary of Kant and Kantianism. Lanham, Maryland: Scarecrow Press. 
Humphreys, M., Brown, A. D., \& Hatch, M. J. (2003). Is ethnography jazz? Organization, 10(1), 5-31.

Husserl, E. (1910/1965). Phenomenology and the crisis of philosophy (Q. Lauer, Trans.). New York: Harper \& Row.

Husserl, E. (1917). Pure phenomenology, its method and its field of investigation [Website]. University of Notre Dame Press. Retrieved March 7, 2004, from the World Wide Web: http://www3.baylor.edu/ Scott Moore/essays/Husserl.html

Husserl, E. (1927). Phenomenology [Website]. Encyclopedia Britannica. Retrieved 23 December, 2004, from the World Wide Web: http://babbage.clarku.edu/ achou/EncyBrit.pdf

Huxley, A. (1965). Brave new world. New York: HarperPerennial.

Ingarden, R. (1931/1973). The literary work of art: An investigation on the borderlines of ontology, logic, and theory of literature (G. G. Grabowicz, Trans.). Evanston, Illinois: Northwest University Press.

Ingarden, R. (1961). Aesthetic experience and aesthetic object. Philosophy and Phenomenological Research, 21(3), 289-313.

Ingarden, R. (1964). Artistic and aesthetic values. The British Journal of Aesthetics(4), 198-213.

Ingarden, R. (1975). Phenomenological aesthetics: An attempt at defining its range. The Journal of Aesthetics and Art Criticism, 33(3), 257-269.

Ingarden, R. (1983). Selected papers in aesthetics. Washington DC: The Catholic University of America Press.

Ingarden, R. (1986). The work of music and the problem of its identity (A. Czerniawski, Trans.). London: Macmillan.

Inkson, K., \& Kolb, D. (2002). Management: Perspectives for New Zealand (3rd ed.). Auckland: Pearson Education.

Isaacs, W. (1999). Dialogic leadership. The Systems Thinker, 10(1), 1-5.

Iser, W. (1989). Prospecting: From reader response to literary anthropology. Baltimore: The Johns Hopkins University Press.

Iser, W. (1995). Interaction between text and reader. In A. Bennett (Ed.), Readers and reading. New York: Longman. 
Jackson, B. (2001). Management gurus and management fashions: A dramatistic inquiry. London: Routledge.

Janik, L. G. (1983). A Renaissance quarrel: The origin of Vico's antiCartesiansm. In G. Tagliacozzo \& D. P. Verene (Eds.), New Vico studies (pp. 39-50). New York: The Institute for Vico Studies.

Jaques, E. (1965). Too many management levels. California Management Review, 8(1), 13-20.

Jones, J. (2004). Fragments of the universe [Newspaper]. The Guardian. Retrieved May 30, 2004, from the World Wide Web: http://www.guardian.co.uk/arts/features/story/0,11710,1222057,00.h $\underline{\mathrm{tml}}$

Jones, S. H. (1998). Kaleidoscope notes: Writing women's music and organizational culture. Qualitative Inquiry, 4(2), 148-178.

Kahl, W. (2000). Intercultural hermeneutics-Contextual exegesis: A model for 21st century exegesis. International Review of Mission, 89(354), 421-433.

Kamerman, J. B. (1983). Symphony conducting as an occupation. In J. B. Kamerman \& R. Martorella (Eds.), Performers and performances: The social organization of artistic work (pp. 43-56). Massachusetts: Bergin \& Garvey.

Kant, I. (1781/1968). Immanuel Kant's critique of pure reason (N. K. Smith, Trans.). London: Macmillan.

Kant, I. (1790/2000). The critique of judgment (J. H. Bernard, Trans.). New York: Prometheus Books.

Kaufmann, W. (1974). Nietzsche: Philosopher, psychologist, antichrist. Princeton, New Jersey: Princeton University Press.

Kockelmans, J. J. (1967). What is phenomenology? Some fundamental themes of Husserl's phenomenology. In J. J. Kockelmans (Ed.), Phenomenology: The philosophy of Edmund Husserl and its interpretation (pp. 24-36). New York: Anchor Books.

Köhler, W. (1947). Gestalt psychology: An introduction to new concepts in modern psychology. New York: New American Library.

Koivunen, N. (2003). Leadership in symphony orchestras: Discursive and aesthetic practices. Tampere: Tampere University Press. 
Kondo, D. K. (1990). Crafting selves: Power, gender, and discourses of identity in a Japanese workplace. Chicago: University of Chicago Press.

Kondo, D. K. (1997). About face: Performing race in fashion and theater. New York: Routledge.

Kunda, G. (1992). Engineering culture: Control and commitment in a high-tech corporation. Philadelphia: Temple University Press.

La Bier, D. (1986). Modern madness: The hidden link between work and emotional conflict. New York: Simon and Schuster.

Lancaster, K. (1997). When spectators become performers: Contemporary performance-entertainments meet the needs of an "unsettled" audience. Journal of Popular Culture, 30(4), 75-88.

Langer, S. K. (1942/1960). Philosophy in a new key: A study in the symbolism of reason, rite, and art. Cambridge, Massachusetts: Harvard University Press.

Langer, S. K. (1953). Feeling and form: A theory of art. London: Routledge \& Kegan Paul.

Langer, S. K. (1960). Philosophy in a new key: A study in the symbolism of reason, rite, and art. Cambridge, Massachusetts: Harvard University Press.

Langer, S. K. (1962). Philosophical sketches. Baltimore: The Johns Hopkins University Press.

Lauer, Q. (1965). Introduction (Q. Lauer, Trans.). In E. Husserl (Ed.), Phenomenology and the crisis of philosophy (pp. 1-68). New York: Harper \& Row.

Lees, H. (2004). All that, and a Janet Jackson moment, too. New Zealand Listener, 192(3331), 64.

Lehman, E. V. (1995). Symphony orchestra organizations: Development of the literature since 1960. Harmony: Forum of the Symphony Orchestra Institute, 1, 37-54.

Lindseth, A., \& Norberg, A. (2004). A phenomenological hermeneutical method for researching lived experience. Scandinavian Journal of Caring Sciences, 18(2), 145-153. 
Linstead, S. (1999a). Ashes and madness: The play of negativity and the poetics of organization. In S. Linstead \& H. Höpfl (Eds.), The aesthetics of organization (pp. 61-92). London: Sage.

Linstead, S. (1999b). An introduction to the textuality of organizations. Studies in Cultures, Organizations \& Societies, 5(1), 1-10.

Linstead, S., \& Höpfl, H. J. (Eds.). (1999). The aesthetics of organization. London: Sage.

Lofland, J., \& Lofland, L. H. (1995). Analyzing social settings: A guide to qualitative observation and analysis. Belmont, California: Wadsworth.

Lucas, G. (2001). Why can't I understand this? [Blog]. Human-Computer Techno-Lit Space. Retrieved March 10, 2003, from the World Wide Web: http://litmuse.maconstate.edu/ glucas/archives/000052.shtml

Makkreel, R. A. (1994). The confluence of aesthetics and hermeneutics in Baumgarten, Meier, and Kant. Journal of Aesthetics $\mathcal{E}$ Art Criticism, 54(1), 65-76.

Malpas, S. (2001). Glossary. In S. Malpas (Ed.), Postmodern debates (pp. 174-176). New York: Palgrave.

Manson, R. (1969). The theory of knowledge of Giambattista Vico. Hamden, Connecticut: Archon Books.

Margolis, J. (1987). Schleiermacher among the theorists of language and interpretation. Journal of Aesthetics $\mathcal{E}$ Art Criticism, 45(4), 361-368.

Mariampolski, H. (1999). The power of ethnography. Journal of the Market Research Society, 41(1), 75-86.

Marshall, M. N. (1996). The key informant technique. Family Practice, 13, 92-97.

McCloskey, M. A. (1987). Kant's aesthetic. Basingstoke: MacMillan.

McFee, G. (2005). The artistic and the aesthetic. British Journal of Aesthetics, $45(4), 368-387$.

McPhee, R. D. (2004). Text, agency, and organization in the light of structuration theory. Organization - Interdisciplinary Journal of Organization Theory and Society, 11(3), 355-371. 
Meisiek, S. (2004). Which catharsis do they mean? Aristotle, Moreno, Boal and organization theatre. Organization Studies, 25(5), 797-816.

Mienczakowski, J., Smith, R., \& Sinclair, M. (1996). On the road to catharsis: A theoretical framework for change. Qualitative Inquiry, 2(4), 439-462.

Mintzberg, H. (1979). The structuring of organizations: A synthesis of the research. Englewood Cliffs, New Jersey: Prentice-Hall.

Mintzberg, H. (1987). Crafting strategy. Harvard Business Review, 65(4), 66-75.

Mintzberg, H. (1994). The rise and fall of strategic planning: Reconceiving roles for planning, plans, planners. New York: The Free Press.

Mintzberg, H., \& Westley, F. (1985). Spinning on symbolism: Imagining strategy. Journal of Management, 11(2), 63-64.

Mintzberg, H., \& Westley, F. (2001). Decision making: It's not what you think. MIT Sloan Management Review, 42(3), 89-93.

Mitchell, W. J. T. (1987). Iconology: Image, text, ideology. Chicago: The University of Chicago Press.

Monin, N. (2004). Management theory: A critical and reflexive reading. London: Routledge.

Monin, N., \& Monin, D. J. (2005). Hijacking the fairy tale: Genre blurring and allegorical breaching in management literature. Organization, 12(4), 511-528.

Monotti, R. G. (2002). Against disinterestedness [Website]. London Consortium. Retrieved March 10, 2003, from the World Wide Web: http://www.londonconsortium.com/kantmonotti0102.doc

Montuori, A. (2003). The complexity of improvisation and the improvisation of complexity: Social science, art and creativity. Human Relations, 56(2), 237-255.

Moore, F. C. T. (1996). Bergson: Thinking backwards. Cambridge: Cambridge University Press.

Nace, T. (2003). Gangs of America: The rise of corporate power and the disabling of democracy. San Francisco: Berrett-Koehler. 
Nanay, B. (2005). Is twofoldness necessary for representational seeing? British Journal of Aesthetics, 45(3), 248-257.

Nerlich, B., \& Clarke, D. D. (2001). Mind, meaning and metaphor: The philosophy and psychology of metaphor in 19th-century Germany. History of the Human Sciences, 14(2), 39-61.

Nierenberg, R. (2003). What is the Music Paradigm? [Website]. The Music Paradigm. Retrieved November 17, 2003, from the World Wide Web: http://www.themusicparadigm.com/what is.asp

Nietzsche, F. (1871/1956). The birth of tragedy (F. Golffing, Trans.). New York: Anchor Books.

Nietzsche, F. (1885/1969). Thus spoke Zarathustra. Harmondsworth: Penguin Books.

Nietzsche, F. (1887/1956). The genealogy of morals (F. Golffing, Trans.). New York: Anchor Books.

Nietzsche, F. (1887/1994). On the genealogy of morality (C. Diethe, Trans.). Cambridge: Cambridge University Press.

Nietzsche, F. (1887/2004). The gay science [Website]. Retrieved January 12, 2005, from the World Wide Web: http://www.geocities.com/thenietzschechannel/diefrohl7.htm

Nietzsche, F. (1901/1968). The will to power (W. Kaufmann \& R. J. Hollingdale, Trans.). New York: Vintage Books.

Nissen, J. (2002). Matthew, mission and method. International Review of Mission, 91(360), 73-86.

Okure, T. (2000). 'I will open my mouth in parables' (Matt 13:35): A case for a gospel-based biblical hermeneutics. New Testament Studies, 46(3), 445-463.

Onsman, H. (2003). The uncertain art of management. Sydney: McGraw-Hill.

Orwell, G. (1949/1989). Nineteen eighty-four. London: Penguin Books.

Osborne, H. (1970). Aesthetics and art theory: An historical introduction. New York: E. P. Dutton.

Pappe, H. O. (2003). Enlightenment [Dictionary]. The Dictionary of the History of Ideas. Retrieved July 11, 2005, from the World Wide Web: http://etext.lib.virginia.edu/cgi-local/DHI/ot2www- 
dhi?specfile=/texts/english/dhi/dhi.o2w\&act=text\&offset=5654756\& query=enlightenment\&tag=ENLIGHTENMENT

Peterson, R. A. (1986). From impresario to arts administrator: Formal accountability in nonprofit cultural organizations. In P. J. DiMaggio (Ed.), Nonprofit enterprise in the arts: Studies in mission and constraint (pp. 161-183). Oxford: Oxford University Press.

Phillips, N., Lawrence, T. B., \& Hardy, C. (2004). Discourse and institutions. Academy of Management Review, 29(4), 635-652.

Picart, C. J. S., \& Gergen, K. (2004). Dharma dancing: Ballroom dancing and the relational order. Qualitative Inquiry, 10(6), 836-868.

Pogrebin, R. (2003). Musicians urge board to keep Maazel [Newspaper]. New York Times. Retrieved December 10, 2003, from the World Wide Web: http://www.nytimes.com/2003/12/10/arts/music/10PHIL.html?th

Polanyi, M., \& Prosch, H. (1977). Meaning. Chicago: University of Chicago Press.

Pondy, L. R. (1983). The role of metaphors and myths in organization and the facilitation of change. In L. R. Pondy \& P. J. Frost \& G. Morgan \& T. C. Dandridge (Eds.), Organization symbolism (pp. 157-166). London: Jai Press.

Porter, J. I. (1995). The invention of Dionysus and the Platonic midwife: Nietzsche's 'Birth of Tragedy'. Journal of the History of Philosophy, 33(3), 467-497.

Porter, J. I. (2000). The invention of Dionysus: An essay on The Birth of Tragedy. Stanford CA: Stanford University Press.

Postrel, V. (2003). The substance of style: How the rise of aesthetic value is remaking commerce, culture and consciousness. New York: HarperCollins.

Putnam, L. L., \& Cooren, F. (2004). Alternative perspectives on the role of text and agency in constituting organizations. Organization Interdisciplinary Journal of Organization Theory and Society, 11(3), 323-333.

Read, H. (1967). Art and alienation: The role of the artist in society. London: Thames and Hudson. 
Rehn, A. (2002). Pretty ugly: Notes on the moral economy of method. Ephemera: Critical Dialogues on Organisation, 2(1), 43-52.

Richards, R. A. (2004). A fitness model of evaluation. Journal of Aesthetics and Art Criticism, 62(3), 263-275.

Rieser, M. (1986). Roman Ingarden and his time. In J. G. Harrell (Ed.), The work of music and the problem of its identity (pp. 159-173). London: Macmillan.

Robichaud, D., Giroux, H., \& Taylor, J. R. (2004). The metaconversation: The recursive property of language as a key to organizing. Academy of Management Review, 29(4), 617-634.

Rorty, R. (1989). Contingency, irony, and solidarity. Cambridge: Cambridge University Press.

Rorty, R. (1991). Inquiry as recontextualization: An anti-dualist account of interpretation, Objectivity, relativism, and truth: Philosophical papers volume 1 (pp. 93-110). Cambridge: Cambridge University Press.

Rorty, R., Nystrom, D., \& Puckett, K. (1998). Against bosses, against oligarchies: A conversation with Richard Rorty. Charlottesville, Virginia: Prickly Pear Pamphlets.

Rudd, G. (2000). Organization discourse and the symbolic tensions between artistic and business ideologies. Journal of Applied Communication Research, 28(2), 117-143.

Rudman, B. (2004, December 8). You wouldn't get these architectural monstrosities in Sydney. The New Zealand Herald, p. A2.

Rueger, A., \& Evren, S. (2005). The role of symbolic presentation in Kant's theory of taste. British Journal of Aesthetics, 45(3), 229-247.

Sadler-Smith, E., \& Shefy, E. (2004). The intuitive executive: Understanding and applying 'gut feel' in decision-making. Academy of Management Executive, 18(4), 76-91.

Sartre, J.-P. (1971). Sketch for a theory of the emotions (P. Mairet, Trans.). London: Methuen.

Savile, A. (1982). The test of time: An essay in philosophical aesthetics. Oxford: Clarendon Press. 
Schein, E. (2004). Organizational culture and leadership (3rd ed.). San Francisco: Jossey-Bass.

Schein, E. H. (2006). From brainwashing to organizational therapy: A conceptual and empirical journey in search of 'systemic' health and a general model of change dynamics. A drama in five acts. Organization Studies, 27(2), 287-301.

Schiller, F. (1795/1965). On the aesthetic education of man, in a series of letters (R. Snell, Trans.). New York: F. Ungar.

Schlag, P. (2002). The aesthetics of American law. Harvard Law Review, 115(1047), 1049-1118.

Schoeman, M. (2003). Nietzsche: Perspektivisme, agonistiese pluralisme, en die wil tot mag. South African Journal of Philosophy, 22(4), 347-359.

Schön, D. A. (1983). The reflective practitioner: How professionals think in action. New York: Basic Books.

Schumacher, E. F. (1973/1999). Small is beautiful: Economics as if people mattered. Point Roberts, Washington: Hartley \& Marks.

Schumacher, E. F. (1977). A guide for the perplexed. New York: Harper Row.

Schutz, A., \& Luckmann, T. (1974). The structures of the life-world (R. M. Zaner \& T. H. Engelhardt, Trans.). London: Heinemann.

Schwartz, H. S. (1990). Narcissistic process and corporate decay: The theory of the organizational ideal. New York: New York University Press.

Schwartzman, H. (1993). Ethnography in organizations (Vol. 27). Newbury Park, California: Sage.

SCOS (2006). [Website]. Standing Conference on Organizational Symbolism. Retrieved November 12, 2006, from the World Wide Web: http://www.scos.org/

Scott, L. M. (1994). The bridge from text to mind: Adapting readerresponse theory to consumer research. Journal of Consumer Research, 21(3), 461-480.

Seifter, H., \& Economy, P. (2001). Leadership ensemble: Lessons in collaborative management from the world's only conductorless orchestra. New York: Times Books. 
Sharpe, R. A. (2000). Music and humanism: An essay in the aesthetics of music. Oxford: Oxford University Press.

Singer, A. E. (2003). Aesthetic reason: Artworks and the deliberative ethos. University Park, Pennsylvania: Pennsylvania State University Press.

Small, C. (1996). Music, society, education. Hanover, New Hampshire: University Press of New England.

Smith, D. W. (2002). Deleuze on Bacon: Three conceptual trajectories in The logic of sensation. In G. Deleuze (Ed.), Francis Bacon:

The logic of sensation (pp. vii-xxvii). Minneapolis: University of Minnesota Press.

Solomon, R. C. (2001). Introducing philosophy (7th ed.). Fort Worth: Harcourt College Publishers.

Sorbom, G. (1994). Aristotle on music as representation. Journal of Aesthetics \& Art Criticism, 52(1), 37-46.

Spradley, J. P. (1979). The ethnographic interview. New York: Holt, Rinehart and Winston.

Stanford, W. B. (1983). Greek tragedy and the emotions: An introductory study. London: Routledge \& Kegan Paul.

Starkey, K. (2003). Eleven characters in search of an ethic: Or the spirit of capitalism revisited. In S. Linstead (Ed.), Text/work: Representing organization and organizing representation (pp. 204-218). London: Routledge.

Starkey, K. P., \& Hatchuel, A. (2002). The long detour: Foucault's history of desire and pleasure. Organization, 9(4), 641-657.

Strati, A. (1998). Organizational symbolism as a social construction: A perspective from the sociology of knowledge. Human Relations, 51(11), 1379-1380.

Strati, A. (1999a). The aesthetic approach in organization studies. In S. Linstead \& H. Höpfl (Eds.), The aesthetics of organization (pp. 13-34). London: Sage.

Strati, A. (1999b). Organization and aesthetics. London: Sage. 
Strati, A. (2002, June 14-15). Aesthetics, tacit knowledge and organization as hypertext. Paper presented at the Managing as Designing Conference, Cleveland.

Strati, A., \& Guillet de Monthoux, P. (2002). Introduction: Organizing aesthetics. Human Relations, 55(7), 755-767.

Tamisari, F. (2000). The meaning of the steps is in between: Dancing and the curse of compliments. Australian Journal of Anthropology, 11(3), 274-286.

Tate, J. W. (1998). The hermeneutic circle vs. the Enlightenment. Telos, Winter(110), 9-38.

Taylor, F. W. (1911/1998). The principles of scientific management. Norcross, Georgia: Engineering \& Management Press.

Taylor, S. S. (2002). Overcoming aesthetic muteness: Researching organizational members' aesthetic experience. Human Relations, 55(7), 821-840.

Taylor, S. S. (2003). Ties that bind. Management Communication Quarterly, 17(2), 280-300.

Taylor, S. S. (2004). Presentational form in first person research: Off-line collaborative reflection using art. Action Research, 2(1), 71-88.

Thomas, J. (1993). Doing critical ethnography (Vol. 26). Newbury Park, California: Sage.

Thurén, L. (2001). John Chrysostom as a rhetorical critic: The hermeneutics of an early father. Biblical Interpretation, 9(2), 180-218.

Tindall, B. (2004). The plight of the white-tie worker [Newspaper]. New York Times. Retrieved July 5, 2004, from the World Wide Web: http://www.nytimes.com/2004/07/04/arts/music/04TIND.html?page wanted $=1 \&$ th

Torbert, B., Cook-Greuter, S., Fisher, D., Foldy, E., Gauthier, A., Keeley, J., Rooke, D., Ross, S., Royce, C., Rudolph, J., Taylor, S., \& Tran, M. (2004). Action inquiry: The secret of timely and transforming leadership. San Francisco: Berrett-Koehler. 
Tsoukas, H. (1991). The missing link: A transformational view of metaphors in organizational science. Academy of Management Review, 16(3), 566-585.

Van Delinder, J. (2005). Taylorism, managerial control strategies, and the ballets of Balanchine and Stravinsky. American Behavioral Scientist, 48(11), 1439-1452.

Van Maanen, J. (1987). Tales of the field: On writing ethnography. Chicago: The University of Chicago Press.

Van Maanen, J. (1995). Style as theory. Organization Science, 6(1), 133-143.

Vaughan, F. (1972). The political philosophy of Giambattista Vico. An introduction to La Scienza Nuova. The Hague: Nijhoff.

Verene, D. P. (1976). Vico's philosophy of imagination. In G. Tagliacozzo \& M. Mooney \& D. P. Verene (Eds.), Vico and contemporary thought 1 (pp. 20-43). London: MacMillan.

Vico, G. (1744/1999). New science: Principles of the new science concerning the common nature of nations (D. Marsh, Trans.

3rd ed.). London: Penguin.

Waxman, R. (1996). Apollo and Dionysus: Donald Barthelme's dance of life. Studies in Short Fiction, 33(2), 229-233.

Webster, J. (2001). Sonata form. In S. Sadie \& J. Turrell (Eds.), The new Grove dictionary of music and musicians (pp. 687-701). London: Macmillan.

Weick, K. E. (1979). The social psychology of organizing. Reading, Massachusetts: Addison-Wesley.

Weick, K. E. (1995). Sensemaking in organizations. Thousand Oaks, California: Sage.

Weick, K. E. (1996). Speaking to practice: The scholarship of integration. Journal of Management Inquiry, 5(3), 251-258.

Weick, K. E. (2004). Mundane poetics: Searching for wisdom in organization studies. Organization Studies, 25(4), 653-668.

Welsch, W. (1997). Undoing aesthetics (A. Inkpin, Trans.). London: Sage. 
Wheatley, M. J. (1992). Leadership and the new science. San Francisco:

Berrett-Koehler.

Wichterman, C. (1999). The orchestra forum: A discussion of symphony orchestras in the US [Website]. The Andrew W. Mellon Foundation. Retrieved June 13, 2003, from the World Wide Web: http://www.mellon.org/orchmain.html

Wilkerson, D., Sherrill, J., \& Sherrill, E. (1967). The Cross and the Switchblade. London: Oliphants.

Williams, P., \& Ledbetter, D. (2004). Figured bass [Dictionary]. Grove Music Online. Retrieved July 19, 2004, from the World Wide Web: http://www.grovemusic.com/shared/views/article.html?section=mu $\underline{\text { sic.09623 }}$

Williams, R. (1983). Keywords: A vocabulary of culture and society. New York: Oxford University Press.

Williams, R. (1988). A vocabulary of culture and society. London: Fontana Press.

Willis, P. E. (1990). Moving culture: An enquiry into the cultural activities of young people. London: Calouste Gulbenkian Foundation.

Willis, P. E. (2000). The ethnographic imagination. Malden, Massachusetts: Polity Press.

Wilson, P. (2000). The Athenian institution of the 'khoregia': The chorus, the city and the stage. Cambridge: Cambridge University Press.

Witkin, R. W. (1974). The intelligence of feeling. London: Heinemann.

Wolfe, R. A., Weick, K. E., Usher, J. M., Terborg, J. R., Poppo, L., Murrell, A. J., Dukerich, J. M., Core, D. C., Dickson, K. E., \& Jourdan, J. S. (2005). Sport and organizational studies: Exploring synergy. Journal of Management Inquiry, 14(2), 182-210.

Worden, S. (1998). Representation in ethnography. Administrative Science Quarterly, 43(1), 201-205.

Wright, R. (1993). Stolen continents: The Indian story. London: Pimlico.

Wright, R. (2005). A short history of progress. New York: Carroll \& Graf.

Yakura, E. K. (2002). Charting time: Timelines as temporal boundary objects. Academy of Management Journal, 45(5), 956-971. 
Ziems, D. (2004). The morphological approach for unconscious consumer motivation research. Journal of Advertising Research, 44(2), 210-215. 